\title{
WestVirginiaUniversity
}

THE RESEARCH REPOSITORY @ WVU

Graduate Theses, Dissertations, and Problem Reports

2010

\section{Heavy-duty diesel engine oil aging effects on emissions}

Mrinmoy Dam

West Virginia University

Follow this and additional works at: https://researchrepository.wvu.edu/etd

\section{Recommended Citation}

Dam, Mrinmoy, "Heavy-duty diesel engine oil aging effects on emissions" (2010). Graduate Theses, Dissertations, and Problem Reports. 2095.

https://researchrepository.wvu.edu/etd/2095

This Thesis is protected by copyright and/or related rights. It has been brought to you by the The Research Repository @ WVU with permission from the rights-holder(s). You are free to use this Thesis in any way that is permitted by the copyright and related rights legislation that applies to your use. For other uses you must obtain permission from the rights-holder(s) directly, unless additional rights are indicated by a Creative Commons license in the record and/ or on the work itself. This Thesis has been accepted for inclusion in WVU Graduate Theses, Dissertations, and Problem Reports collection by an authorized administrator of The Research Repository @ WVU. For more information, please contact researchrepository@mail.wvu.edu. 


\title{
HeAvy-duty Diesel Engine OIL AgING EFFeCts on EMissions
}

\author{
Mrinmoy Dam
}

\author{
Thesis submitted to the \\ College of Engineering and Mineral Resources \\ at West Virginia University \\ in partial fulfillment of the requirements \\ for the degree of
}

\author{
Master of Science \\ in \\ Mechanical Engineering \\ Gregory J. Thompson, Ph.D., Chair \\ Mridul Gautam, Ph.D. \\ Nigel N. Clark, Ph.D. \\ Department of Mechanical and Aerospace Engineering \\ Morgantown, West Virginia \\ 2010
}

Keywords: Oil Aging, Diesel, Emissions, Particle Sizing

Copyright 2010 Mrinmoy Dam 


\section{Abstract \\ Heavy-duty Diesel Engine Oil Aging Effects on Emissions \\ Mrinmoy Dam}

Diesel engines are highly reliable, durable and are used for wide range of applications with low fuel usage owing to its higher thermal efficiency compared to other mobile power sources. Heavy-duty diesel engines are used for both on-road and off-road applications and dominate the heavy-duty engine segment of the United States transportation market. However, diesel engine exhaust emissions affect the ambient air quality by producing higher levels of oxides of nitrogen (NOx) and particulate matter (PM) compared to other mobile sources. New diesel engines produce significantly lower levels of PM and NOx emissions to comply with 2010 EPA emission limits compared to just a decade ago. But, the reliability of an on-road diesel engine (over 1 million miles) results in a significant portion of the heavyduty engine truck fleet containing many legacy diesel engines in operation and these engines are relatively high NOx and PM emitters. Various programs to introduce fuels, additives, and retrofit devices to reduce NOx and PM emissions from these legacy engines have been carried out in states such as California and Texas. In these programs, emissions are compared between a baseline condition and the candidate technology configuration using a representative legacy engine. However, a small variation in the emissions levels can lead to either pass or failure of the candidate technology. The motivation for this research study was to investigate how engine oil aging history in a legacy engine affects the emission levels which may cause these decisive small variations.

A research study was undertaken to determine engine oil aging effects on gaseous and particulate matter emissions from a 12.7L 1992 Detroit Diesel Series 60 legacy heavy-duty diesel engine. Commercially available Shell Rotella ${ }^{\circledR}$ SAE $15 \mathrm{~W}-40$ engine oil was used to evaluate exhaust emission constituents up to 40 hours of oil aging, in two different test campaigns. The engine was exercised over transient and steady state test cycles. Apart from measurement of regulated gaseous and gravimetric PM emissions from the engine, PM number concentration levels were also measured. Oil samples were analyzed to study changes in its physical properties along with ash content, soot contamination, and metal content. Additionally, the oil samples were analyzed for determination of particle size distribution of suspended particles in the samples.

From the research, no significant changes in regulated gaseous and PM emission were observed during either test campaigns that could be attributed to the lubricant oil. Analysis of the oil samples showed no significant change in viscosity and density within the aging time period, but showed increase in total acid number (TAN) by $21 \%$, soot content and metal content, whereas decrease in total base number (TBN) by $14.5 \%$. Investigation into particle sizing of suspended particles in the oil samples suggests contamination of the oil by larger diameter particles during the initial 15 hours of its use compared to particles found from the oil samples from later part of the aging time period. 


\section{ACKNOWLEDGEMENT}

My belief that I can always do more than what I think and better than what I am doing, brought me to this stage of my life where I got an opportunity to explore the avenues of 'research' and to successfully finish my graduate education. I felt overwhelmed by the

glimpse of the unfathomable ocean of scientific knowledge available but still I feel the urge to plunge deep inside it.

First of all, I would like to thank my research advisor Dr. Gregory Thompson for introducing me into this interesting field of engines and emissions, and guiding me throughout the entire research study and in preparation of this thesis. His hands-on learning approach, organizing skills and cultivating the virtues of professionalism as an engineer in me, are few of the learning outcomes I acquired as his Graduate Research Assistant. Secondly, I am thankful to my committee member Dr. Nigel Clark for providing me with useful inputs and insight in this research endeavor and in reviewing this work. My gratitude goes to my other committee member, Dr. Mridul Gautam for his encouragement in pursuing quality work by setting himself as an example.

I would also like to acknowledge my sincere gratitude to Bradley Ralston from the CAFEE lab for practically teaching me everything I know about running engine emission tests. Thanks to Geoff Newlin, Byron Rapp and Oscar Delgado for helping me in the lab during engine testing. My sincere thanks to my other lab-mates Marc Besch, Arvind Thiruvengadam, Hemanth Kappanna and Manoharan Thiagarajan for making all those long hours in the office enjoyable and sharing many interesting stories.

Lastly, I will always cherish the company of my friends in Morgantown who filled my life in the graduate school with fun and made it memorable. But above all, I want to convey my earnest gratitude to my parents for having faith in my dreams and to my brother who was always there to take care of them during my long absences from the family. 


\section{TABLE OF CONTENTS}

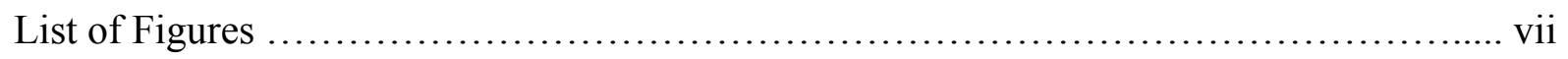

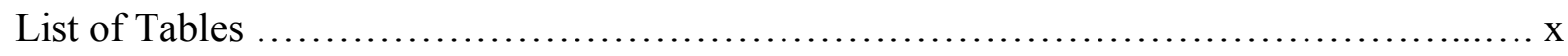

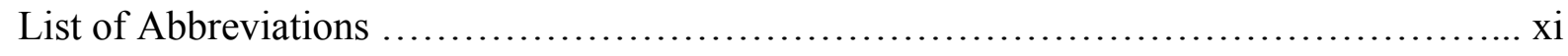

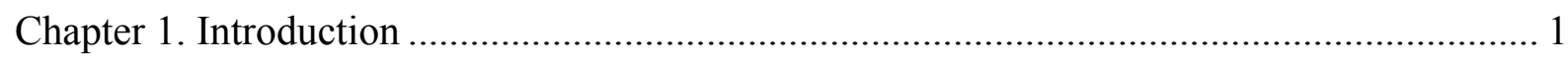

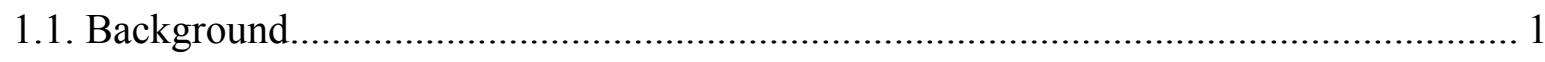

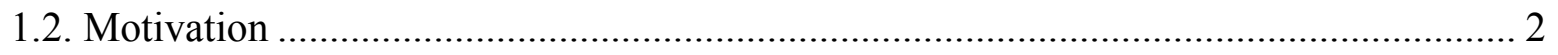

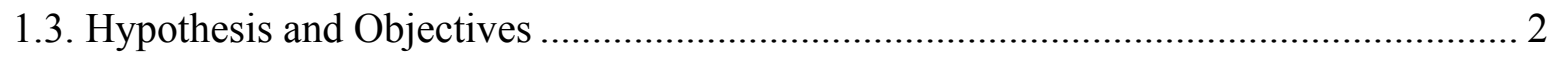

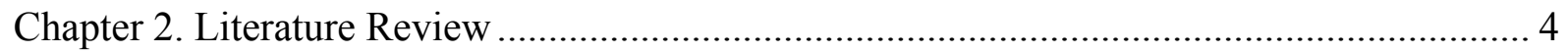

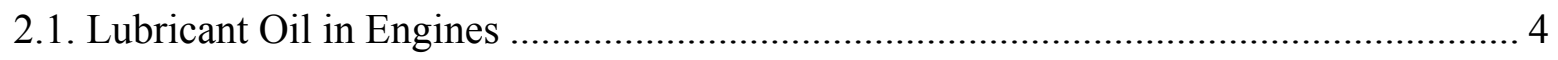

2.1.1. Composition of Lubricant Oil........................................................................... 5

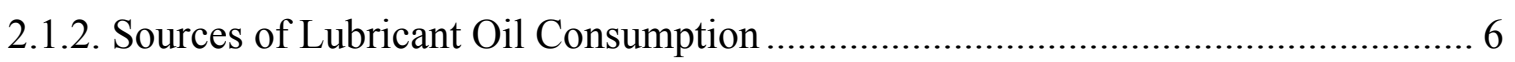

2.1.3. Contribution of Lubricant Oil in Engine Exhaust Emissions .................................... 6

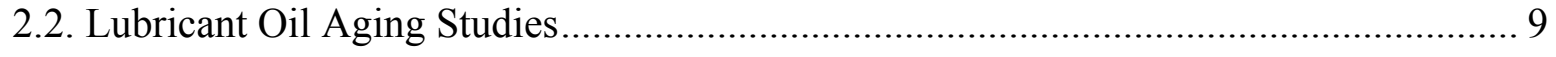

2.3. Diesel Particulate Matter ...................................................................................... 12

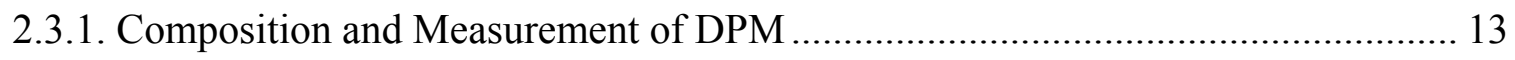

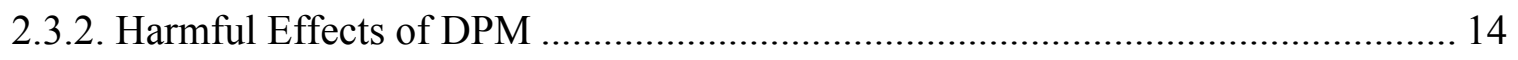

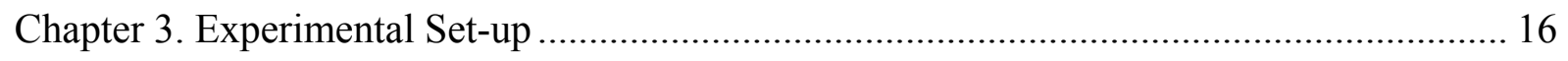

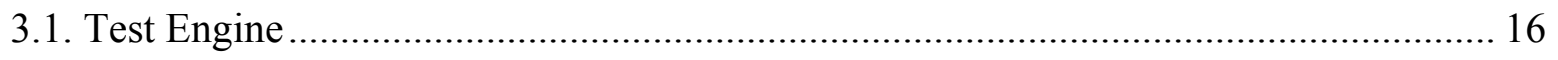

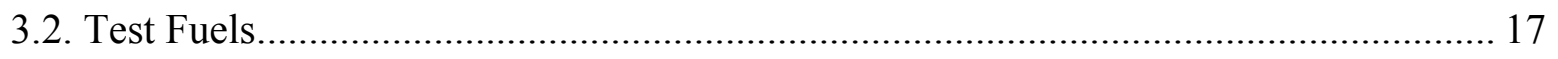

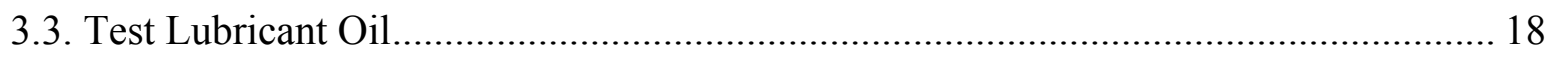

3.4. Engine and Emissions Research Laboratory, WVU................................................. 18

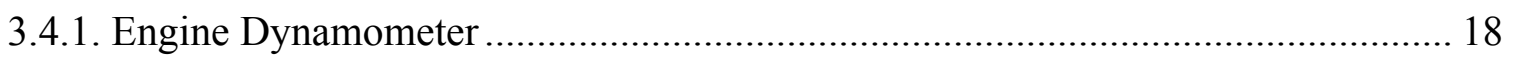

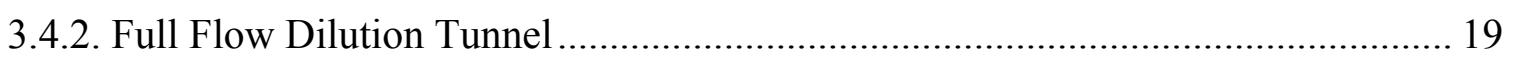

3.4.3. Gaseous Sampling System........................................................................... 22

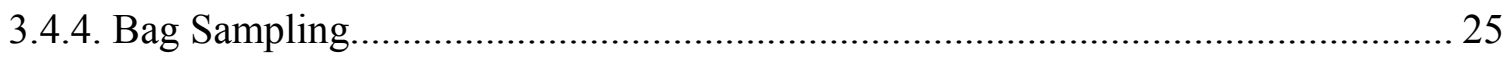

3.4.5. Fuel Measurement System.............................................................................. 26

3.4.6. Operator Control and Data Acquisition (DAQ) System........................................ 26

3.4.7. Barometric Pressure and Humidity Measurement................................................... 27

3.4.8. Particulate Matter Sampling System ………………..................................... 28 


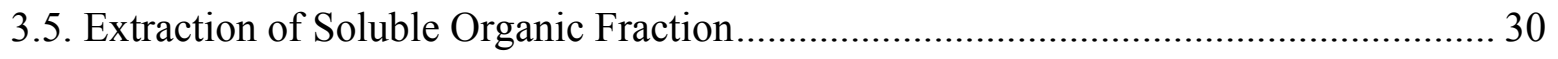

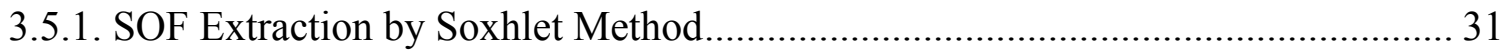

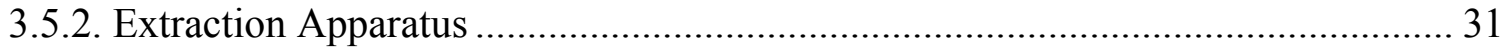

3.5.3. Filter Preparation ..................................................................................... 32

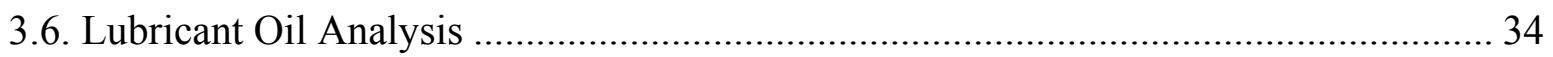

3.6.1. Physical Property Analysis of Oil Samples ......................................................... 34

3.6.2. Particle Sizing of Oil Samples ............................................................................... 36

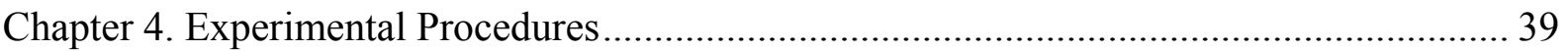

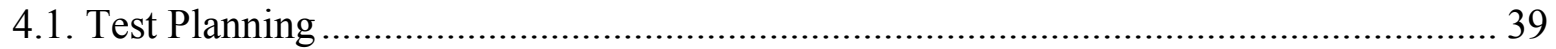

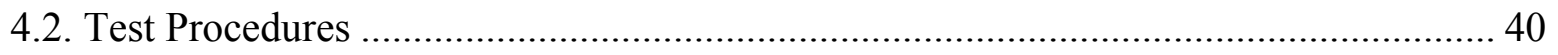

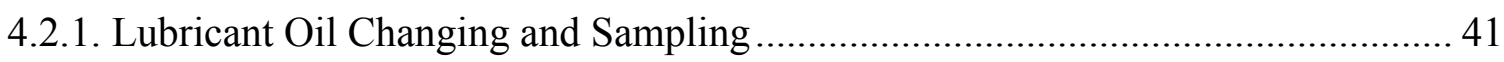

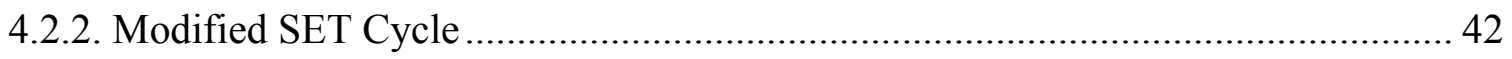

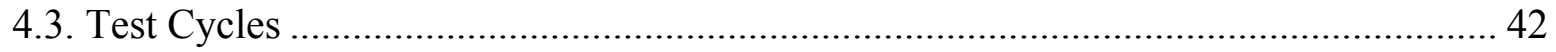

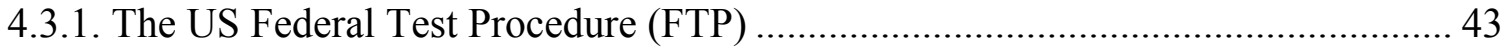

4.3.2. Supplemental Emissions Test (SET) ............................................................... 45

4.4. Overview of Statistical Tools Used for Data Analysis.................................................... 46

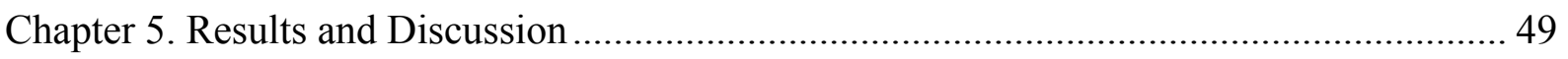

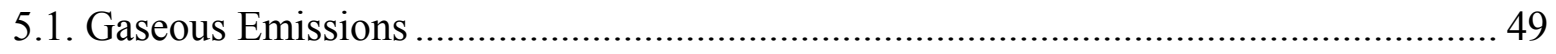

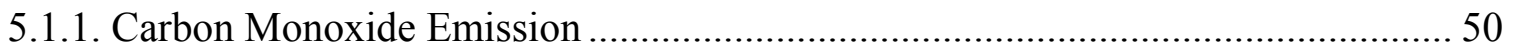

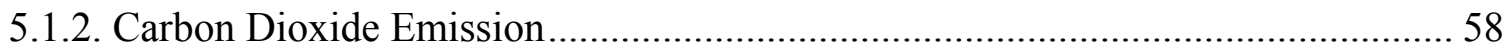

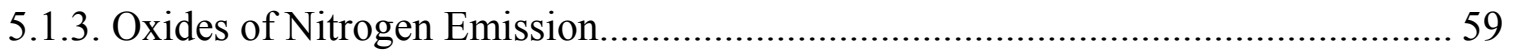

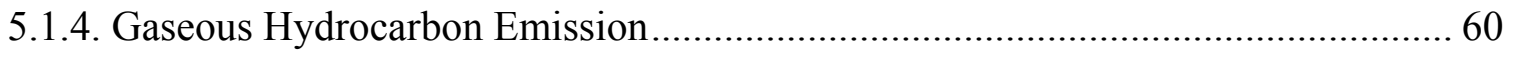

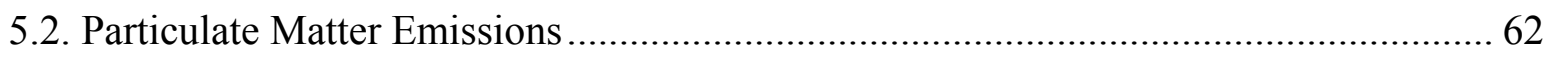

5.2.1. Gravimetric Particulate Matter Emission ............................................................. 62

5.2.2. Number-Based Particulate Matter Emission ............................................................. 67

5.2.3. Gravimetric PM Emission Using Cyclone Separator .............................................. 77

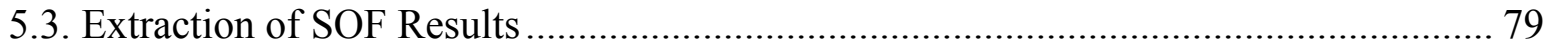

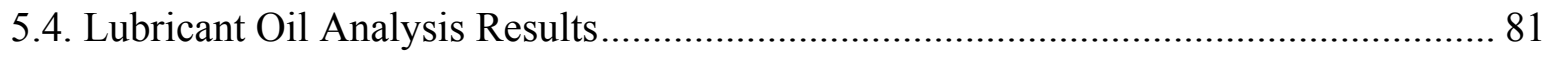

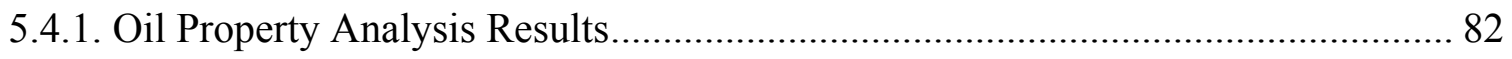

5.4.2. Particle Sizing of Oil Sample Results.................................................................. 90

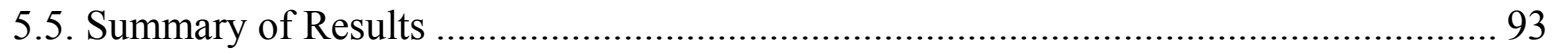

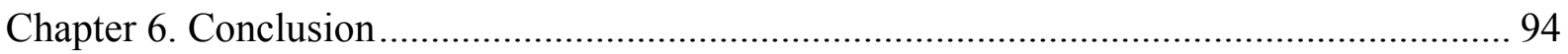




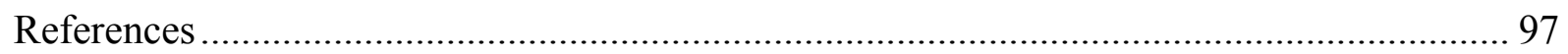

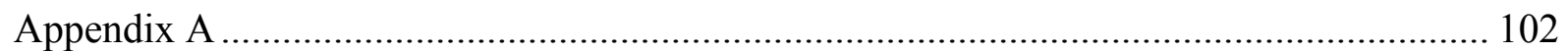

A.1. The U.S. EPA Heavy-Duty Diesel Engine Exhaust Emission Standards ................ 102

A.2. Emission from FTP Test Sequences ................................................................. 103

A.3. Emission from Steady State Test Sequences ...................................................... 105

A.4. Humidity and Barometric Pressure from FTP Test Groups ................................... 107

A.5. Biodiesel Mixing Information ...................................................................... 108

A.6. SOF Filter Preparation Technique ....................................................................... 109

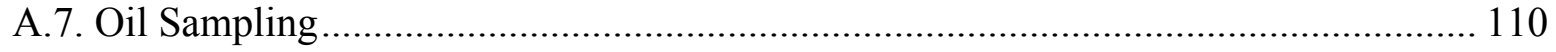

A.8. Zetasizer ${ }^{\circledR}$ Sample Preparation - Oil/Decane Mixing ............................................ 110

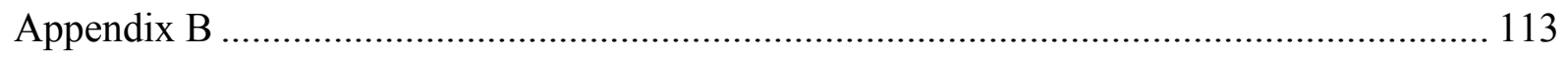

B.1. Emissions versus Barometric Pressure .......................................................... 113

B.2. Emissions versus Dilution Air Humidity ............................................................ 116

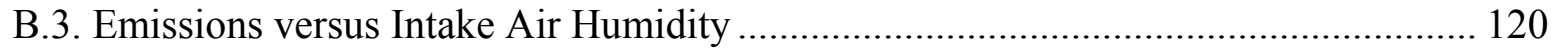

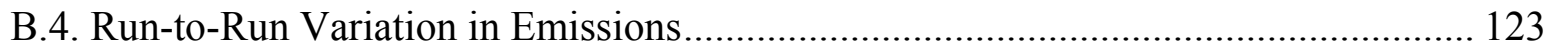

B.5. Steady State Continuous Emissions.................................................................. 126

B.6. Statistical Analysis of Emission - Box Plots ...................................................... 127

B.7. Statistical Analysis of Emission - Multiple-Comparison Plots............................... 132

B.8. Statistical Analysis of Emission - ANOVA Results ......................................... 136

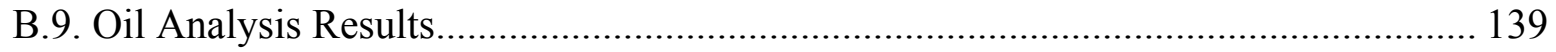

B.10. Metal Concentration in Oil Samples............................................................. 140

B.11. Normalized Particle Size Distribution Plots ..................................................... 142 


\section{LIST OF FIGURES}

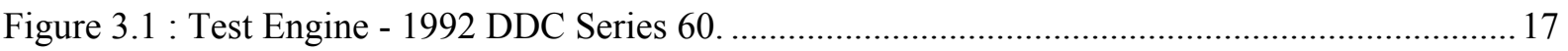

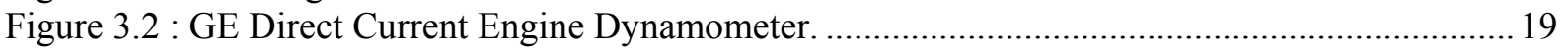

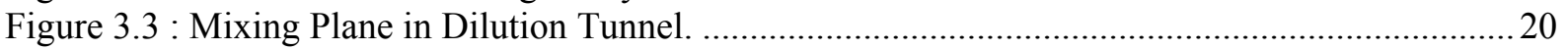

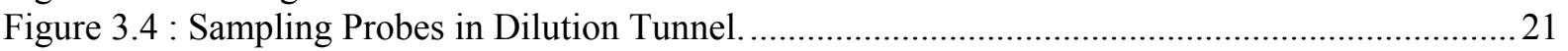

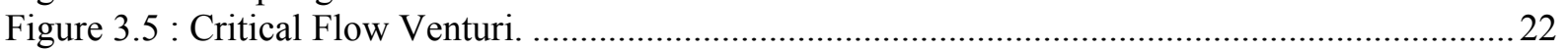

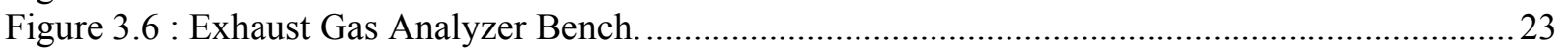

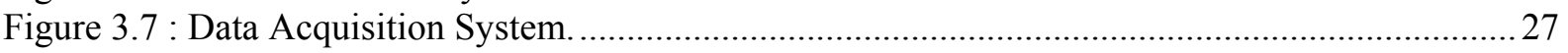

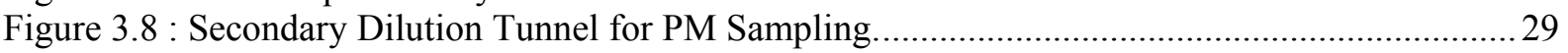

Figure 3.9 : DMS500- Classifier Rings and Charged Rod [36] ...................................................... 30

Figure 3.10 : Arrangement of Soxhlet Apparatus for SOF Extraction. ............................................ 32

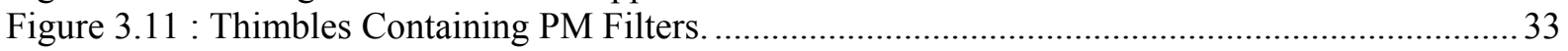

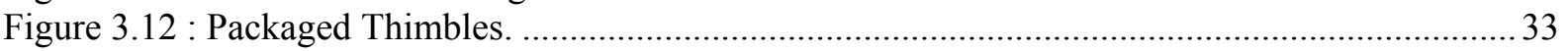

Figure 3.13 : Zetasizer ${ }^{\circledR}$ Nano Particle Sizing Instrument.............................................................. 37

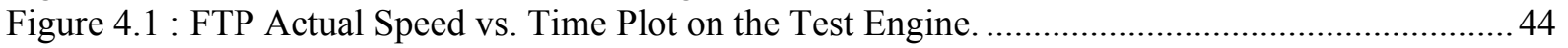

Figure 4.2 : FTP Actual Torque vs. Time Plot on the Test Engine. ................................................... 44

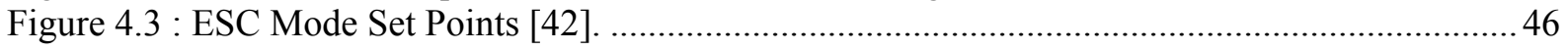

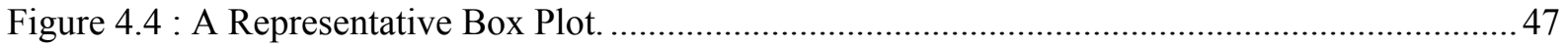

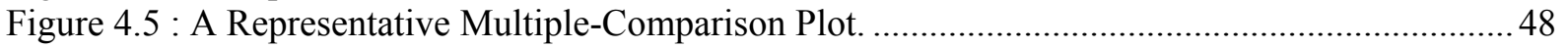

Figure 5.1 : Run-to-Run Variation in BsCO Emission from FTPs.................................................. 51

Figure 5.2 : Box Plot of CO Emission from First Set FTP Test Groups. ........................................... 52

Figure 5.3 : Multiple-Comparison Plot of CO Emission from First Set FTP Test Groups. .................. 53

Figure 5.4 : Box Plot of CO Emission from Second Set FTP Test Groups........................................ 54

Figure 5.5 : Multiple-Comparison Plot of CO Emission from Second Set FTP Test Groups................55

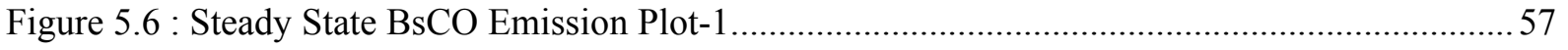

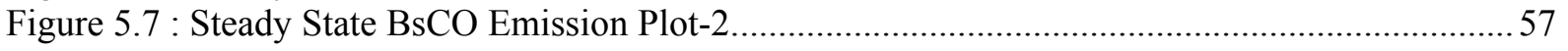

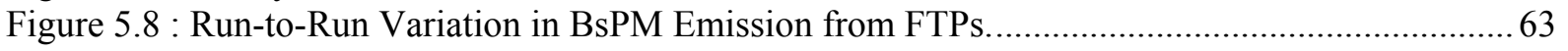

Figure 5.9 : Box Plot of PM Emission from First Set FTP Test Groups. .............................................. 64

Figure 5.10 : Box Plot of PM Emission from Second Set FTP Test Groups........................................ 64

Figure 5.11 : Multiple-Comparison Plot of TPM Emission from First Set FTP Test Groups................ 65

Figure 5.12 : Multiple-Comparison Plot of TPM Emission from Second Set FTP Test Groups. .......... 65

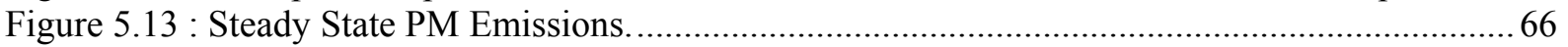

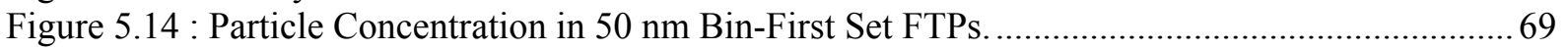

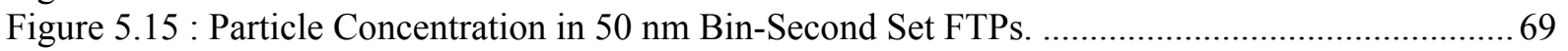

Figure 5.16 : Particle Concentration in 100 nm Bin-First Set FTPs................................................... 70

Figure 5.17 : Particle Concentration in 100 nm Bin-Second Set FTPs............................................... 71

Figure 5.18 : Particle Concentration in 1000 nm Bin-First Set FTPs................................................... 72

Figure 5.19: Particle Concentration in 1000nm Bin-Second Set FTPs. ............................................ 72

Figure 5.20 : Particle Concentration in 50 nm Bin-Steady State Tests. ............................................. 73

Figure 5.21 : Particle Concentration in $100 \mathrm{~nm}$ Bin-Steady State Tests............................................. 74

Figure 5.22 : Particle Concentration in $1000 \mathrm{~nm}$ Bin-Steady State Tests............................................ 74

Figure 5.23 : Particle Concentration from the Three Bins-First Set FTPs........................................ 75

Figure 5.24 : Particle Concentration from the Three Bins-Second Set FTPs. ..................................... 76

Figure 5.25: Change in Total Particle Concentration over Aging Time........................................... 77

Figure 5.26 : BsPM Emission from PM1, PM2.5, PM10 Cyclones. ................................................... 78

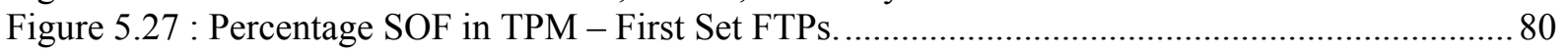

Figure 5.28 : Percentage SOF in TPM - Second Set FTPs. ............................................................ 80 
Figure 5.29 : Percent Difference in Percentage SOF w.r.t. Baseline FTPs. ....................................... 81

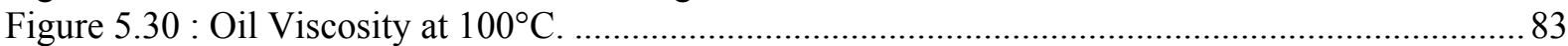

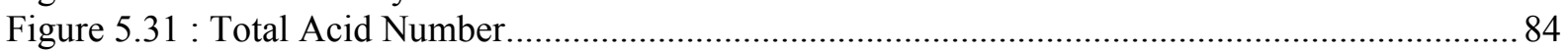

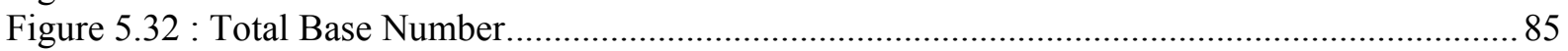

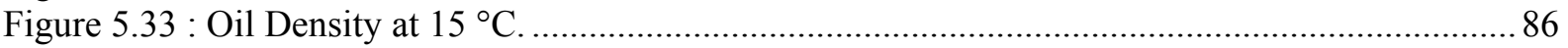

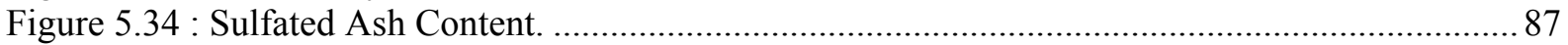

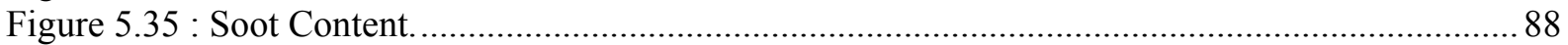

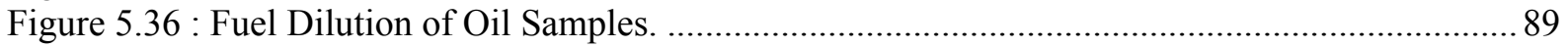

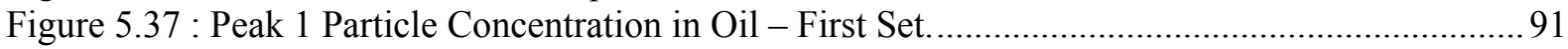

Figure 5.38 : Peak 1 Particle Concentration in Oil - Second Set. .................................................... 91

Figure 5.39 : Variation in Peak Particle Concentrations in the Standard (DP 5820).......................... 92

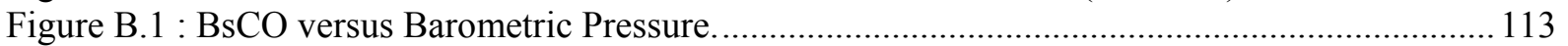

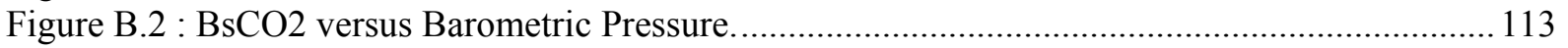

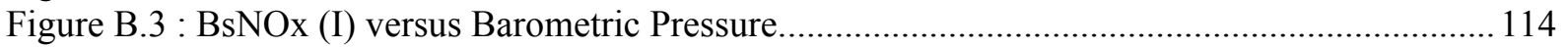

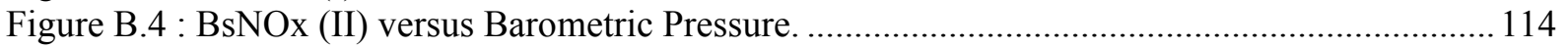

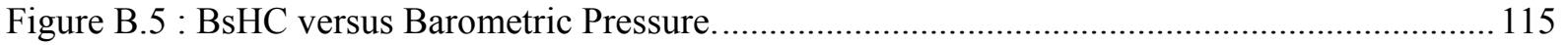

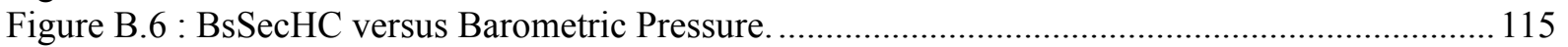

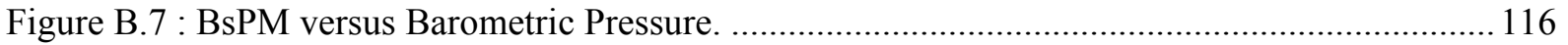

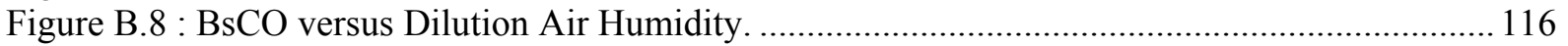

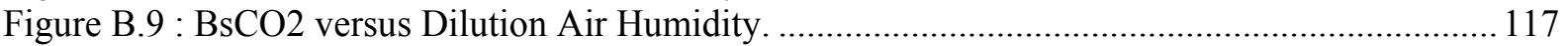

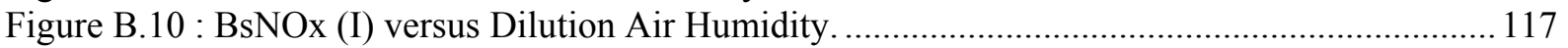

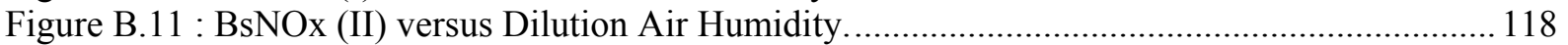

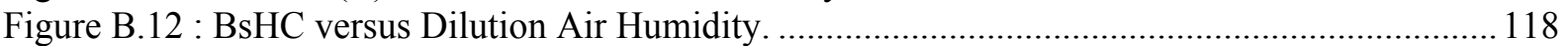

Figure B.13 : BsSecHC versus Dilution Air Humidity................................................................... 119

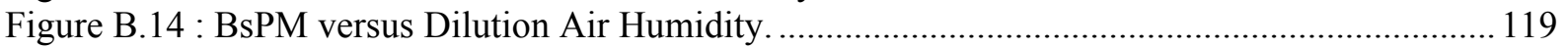

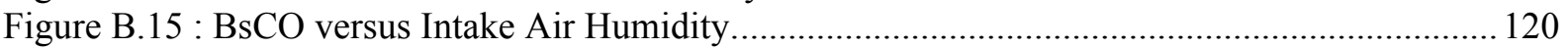

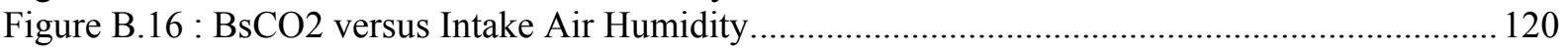

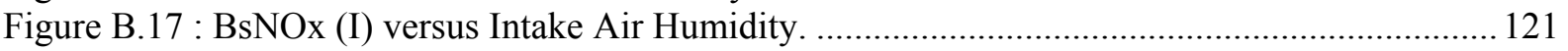

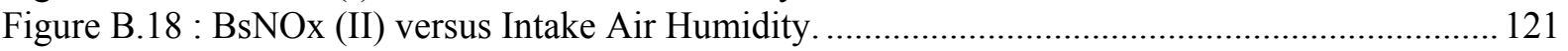

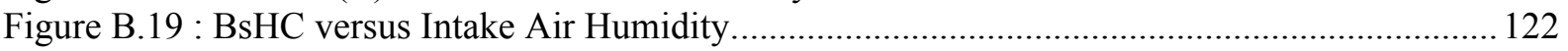

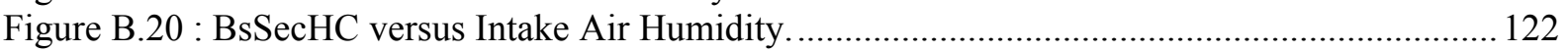

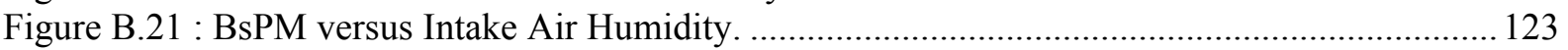

Figure B.22 : Run-to-Run Variation in BsCO2 Emission from FTPs. .............................................. 123

Figure B.23 : Run-to-Run Variation in BsNOx (I) Emission from FTPs......................................... 124

Figure B.24 : Run-to-Run Variation in BsNOx (II) Emission from FTPs......................................... 124

Figure B.25 : Run-to-Run Variation in BsHC Emission from FTPs. ............................................ 125

Figure B.26 : Run-to-Run Variation in BsSecHC Emission from FTPs. ......................................... 125

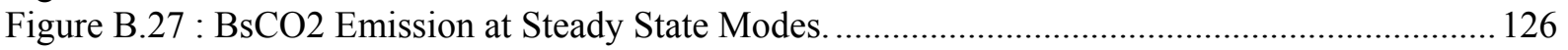

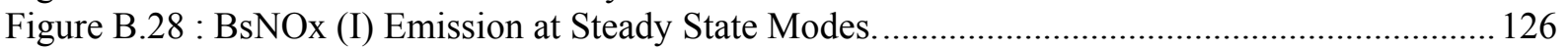

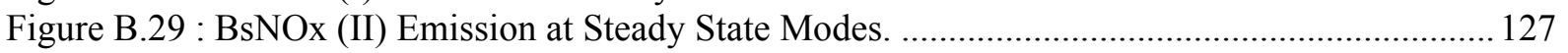

Figure B.30 : Box Plot of CO2 Emission from First Set FTP Test Groups....................................... 127

Figure B.31 : Box Plot of CO2 Emission from Second Set FTP Test Groups. ................................... 128

Figure B.32 : Box Plot of NOx (I) Emission from First Set FTP Test Groups................................... 128

Figure B.33 : Box Plot of NOx (I) Emission from Second Set FTP Test Groups.............................. 129

Figure B.34 : Box Plot of NOx (II) Emission from First Set FTP Test Groups. ................................. 129

Figure B.35 : Box Plot of NOx (II) Emission from Second Set FTP Test Groups.............................. 130

Figure B.36 : Box Plot of HC Emission from Second Set FTP Test Groups. ..................................... 130

Figure B.37 : Box Plot of SecHC Emission from First Set FTP Test Groups................................... 131

Figure B.38 : Box Plot of SecHC Emission from Second Set FTP Test Groups................................ 131

Figure B.39 : Multiple-Comparison Plot of CO2 Emission from First Set FTP Test Groups.............. 132

Figure B.40 : Multiple-Comparison Plot of CO2 Emission from Second Set FTP Test Groups. ........ 132 
Figure B.41 : Multiple-Comparison Plot of NOx (I) Emission from First Set FTP Test Groups........ 133

Figure B.42 : Multiple-Comparison Plot of NOx (I) Emission from Second Set FTP Test Groups... 133

Figure B.43 : Multiple-Comparison Plot of NOx (II) Emission from First Set FTP Test Groups. ..... 134

Figure B.44 : Multiple-Comparison Plot of NOx (II) Emission from Second Set FTP Test Groups.. 134

Figure B.45 : Multiple-Comparison Plot of HC Emission from Second Set FTP Test Groups. ......... 135

Figure B.46 : Multiple-Comparison Plot of SecHC Emission from First Set FTP Test Groups......... 135

Figure B.47 : Multiple-Comparison Plot of SecHC Emission from Second Set FTP Test Groups.... 136

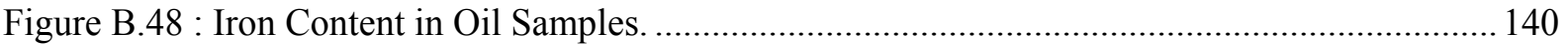

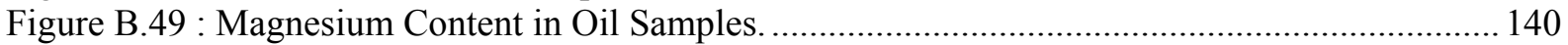

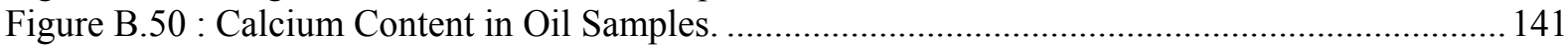

Figure B.51 : Phosphorus and Zinc Content in Oil Samples. ....................................................... 141

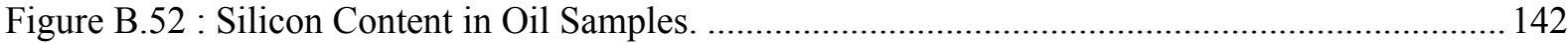

Figure B.53 : Normalized Particle Size Distribution in WVOil0343 Oil Sample............................. 142

Figure B.54 : Normalized Particle Size Distribution in WVOil0344 Oil Sample............................... 143

Figure B.55 : Normalized Particle Size Distribution in WVOil0345 Oil Sample............................... 143

Figure B.56 : Normalized Particle Size Distribution in WVOil0346 Oil Sample............................. 144

Figure B.57 : Normalized Particle Size Distribution in WVOil0347 Oil Sample............................... 144

Figure B.58 : Normalized Particle Size Distribution in WVOil0348 Oil Sample............................... 145

Figure B.59 : Normalized Particle Size Distribution in WVOil0349 Oil Sample.............................. 145

Figure B.60 : Normalized Particle Size Distribution in WVOil0350 Oil Sample............................... 146

Figure B.61 : Normalized Particle Size Distribution in WVOil0401 Oil Sample............................... 146

Figure B.62 : Normalized Particle Size Distribution in WVOil0402 Oil Sample.............................. 147

Figure B.63 : Normalized Particle Size Distribution in WVOil0403 Oil Sample............................... 147

Figure B.64 : Normalized Particle Size Distribution in WVOil0404 Oil Sample............................... 148

Figure B.65 : Normalized Particle Size Distribution in WVOil0405 Oil Sample............................... 148

Figure B.66 : Normalized Particle Size Distribution in WVOil0406 Oil Sample.............................. 149

Figure B.67 : Normalized Particle Size Distribution in WVOil0407 Oil Sample............................... 149

Figure B.68 : Normalized Particle Size Distribution in WVOil0408 Oil Sample.............................. 150 


\section{LIST OF TABLES}

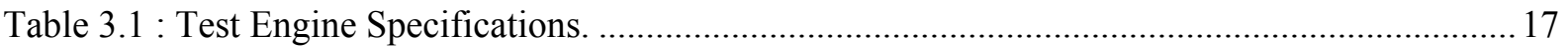

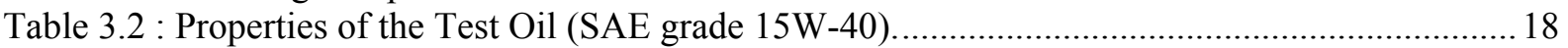

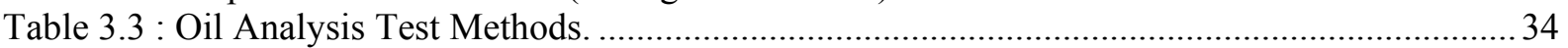

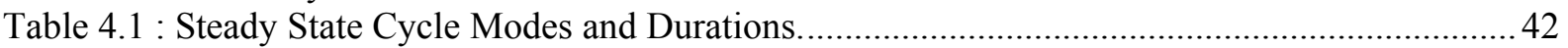

Table 5.1 : ANOVA Analysis Results of CO Emission from First Set FTP Test Groups....................52

Table 5.2 : ANOVA Analysis Results of CO Emission from Second Set FTP Test Groups. ...............54

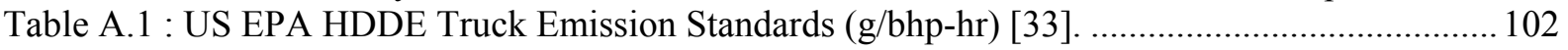

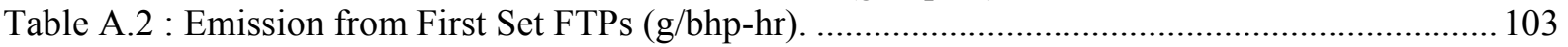

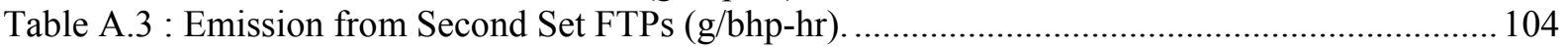

Table A.4 : Emission from Steady State Test Sequences (g/bhp-hr), Contd.................................. 105

Table A.5 : Emission from Steady State Test Sequences (g/bhp-hr).......................................... 106

Table A.6 : Averaged Humidity and Barometric Pressure from First Set FTPs................................. 107

Table A.7 : Averaged Humidity and Barometric Pressure from Second Set FTPs........................... 107

Table A.8 : Biodiesel Mixing Log Sheet - First Set Tests. .............................................................. 108

Table A.9 : Biodiesel Mixing Log Sheet - Second Set Tests.......................................................... 108

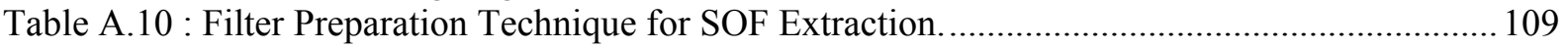

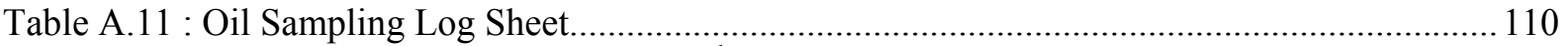

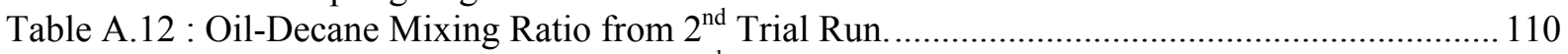

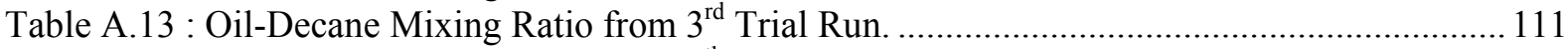

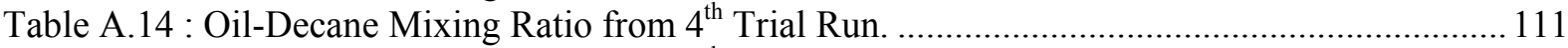

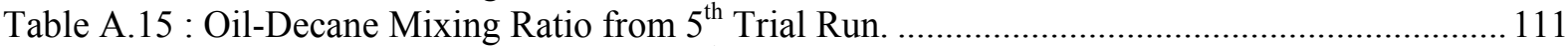

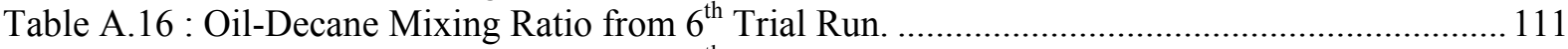

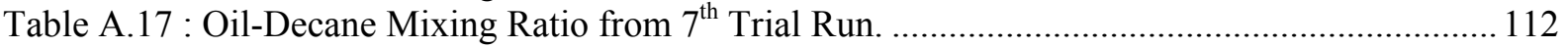

Table A.18 : DP5820-Distilled Water Mixing Ratio for the Standard. ............................................ 112

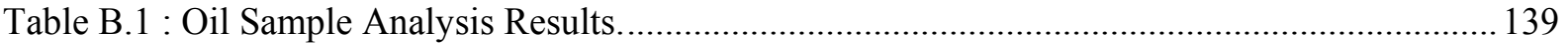




\section{List OF ABbREVIATIONS}

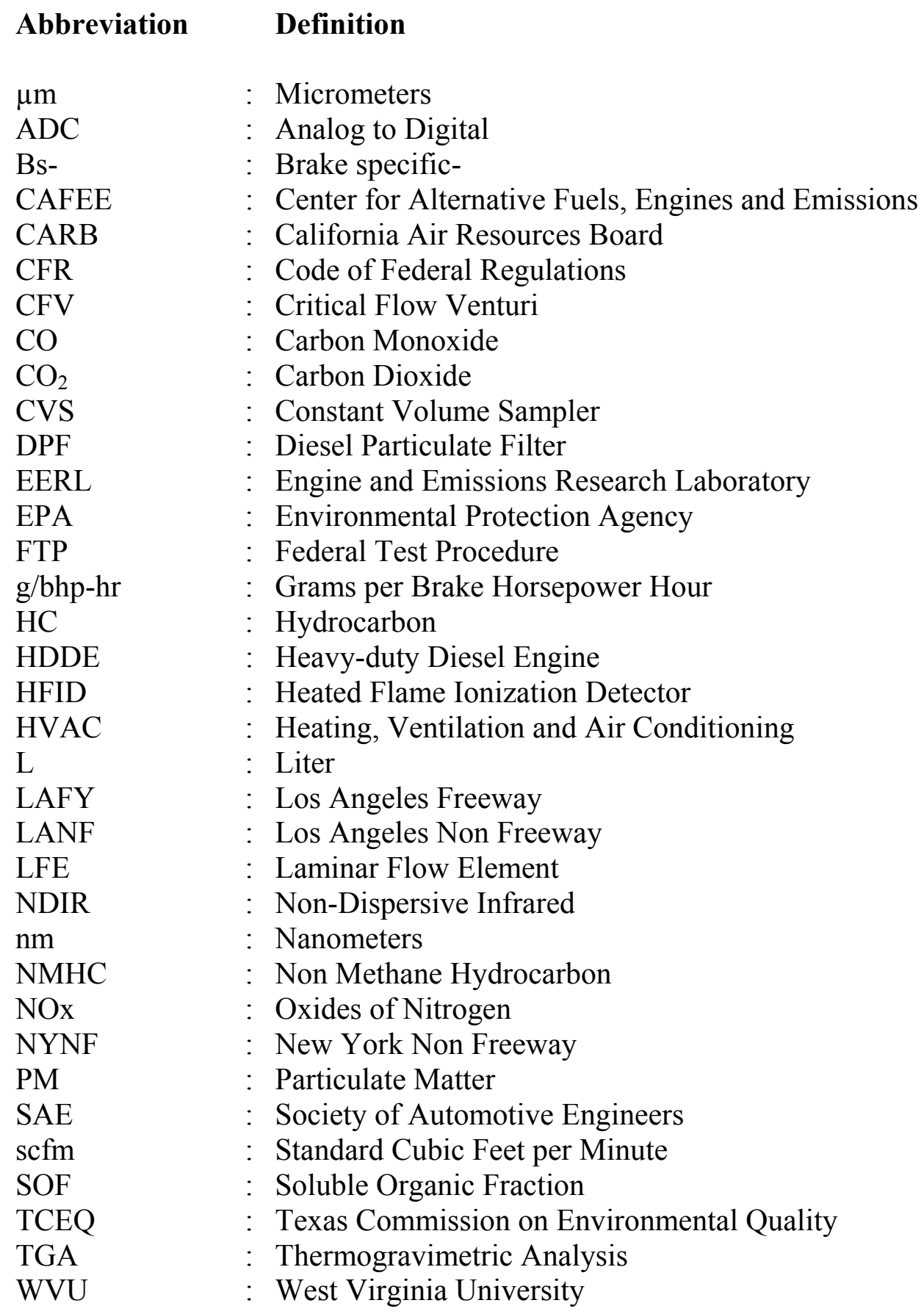




\section{Chapter 1. INTRODUCTION}

\subsection{Background}

The consequences of air pollution on human health and to the environment are well known. Today, it is a general consensus among major economies of the world to collectively address this issue of pollution caused by burning of petroleum-based fuels. The recently held United Nations summit on climate change at Copenhagen, Denmark from $7^{\text {th }}$ to $18^{\text {th }}$ December 2009, where 193 countries around the world participated to reach a accord to address the issue, emphasized on this concern [1]. In the United States, emissions from onroad and off-road mobile sources contribute a considerable share of the regulated emissions emitted into the atmosphere.

From the incipient of the Clean Air Act of 1970 in the U.S., the emissions regulatory bodies such as the United States Environmental Protection Agency (U.S. EPA), California Air Resources Board (CARB), Texas Commission on Environmental Quality (TCEQ), and others have tightened the emission limits for all mobile sources of air pollution. The U.S. EPA has defined over 150 species as toxic pollutants to the environment, of which hydrocarbons (HC), particulate matter (PM), carbon monoxide (CO), non-methane hydrocarbons (NMHC) and oxides of nitrogen (NOx), are the regulated emissions from mobile sources.

Heavy-duty diesel engines (HDDE), considering its high reliability, durability and higher thermal efficiency compared to other mobile power sources, are used in wide range of applications with high power requirements. Owing to these qualities, HDDEs continues to dominate the heavy-duty engine segment in the United States transportation market. But higher NOx emission and PM emission, relative to other combustion systems, from diesel engines is a concern. Through the last decade, EPA has gradually lowered the emission limits for these two species to $0.2 \mathrm{~g} / \mathrm{bhp}-\mathrm{hr}$ and $0.01 \mathrm{~g} / \mathrm{bhp}-\mathrm{hr}$, respectively. Appendix A.1 provides a list of exhaust emission limits applicable to on-road HDDE trucks from the last two decades. 


\subsection{Motivation}

Modern HDDEs, equipped with after-treatment devices like particulate filters, catalytic reducers and with inclusion of fuel additives, have achieved the regulated NOx and PM emission limits. However, given to the longevity of HDDEs, a large number of high NOx and PM emitting legacy diesel engine fleets are still in operation. Changes in exhaust emission standards do not enforce phasing out of these legacy HDDEs, which may prove to be uneconomical for small fleet owners. But to meet the overall emission limits from all sources as mandated by State Implementation Plans, the emissions from these legacy engines may have to be reduced. In the states like California and Texas, there are fuel certification programs to reduce emissions from these legacy HDDEs.

In many cases, the success or failure of a new technology applied to a legacy engine for fuel certification or verification emissions test programs depends on small variations in the measurement of emissions from the tests. These decisively small variations in emission measurements can be caused by many factors that can contribute to the engine exhaust emissions. It has been reported in literature that lubricant oils contribute to exhaust emissions from internal combustion engines, discussed later in Section 2.1.3 in the next chapter. Hence, lubricant oil can be one of the many factors which can cause this small difference in emissions measurements. The motivation behind this research study was to investigate whether lubricant oil is an influencing factor that can cause these small variations during a fuel certification or verification emission tests on legacy HDDEs.

\subsection{Hypothesis and Objectives}

To guide this research study, the following hypothesis was assumed and the research objectives were framed to validate or invalidate the hypothesis:

Lubricant oil aging has an effect on engine exhaust emissions after an oil change, thus affecting emissions measurements for a HDDE.

Hence, the global objective of this research study was to investigate how lubricant oil aging history in legacy HDDEs affects regulated gaseous and PM emissions. Following research questions were listed to guide the investigation in this study: 
1. Are there any influences on engine exhaust emissions from a legacy HDDE that can be attributed to the lubricant oil during its usage?

2. If lubricant oil does affect exhaust emissions, how does it change the regulated gaseous and particulate matter emissions over time after an oil change?

3. Can a typical stabilization time period for physical properties of lubricant oil used in the HDDE be predicted?

This research study will try to answer these questions in the concluding chapter of this document and discuss further research possibilities in the subject area. 


\section{Chapter 2. LiTERATURE REVIEW}

Mechanical friction in internal combustion (IC) engines cause considerable amount of losses in terms of loss in fuel economy, performance and longevity of engine parts. This fact has drawn substantial interest in research and development of newer lubrication technologies and improvements in lubricant oil formulations. In fact, a study [2] has observed that an engine friction reduction of $10 \%$, if applied to all US passenger cars, would result in a fuel savings of 3.4 billion gallons in 2007. Besides minimizing friction, studies have shown that lubricant oil also significantly contributes to engine exhaust emissions. This chapter discusses usage, consumption of oil in diesel engines and its contribution to exhaust emission.

\subsection{Lubricant Oil in Engines}

In a diesel IC engine, a piston assembly creates the boundary between the combustion chamber and the crank case while providing the means to transfer energy from the high pressure gas to useful mechanical shaft work. To prevent transport of high pressure combustion gases from the combustion chamber to crank case, it is essential that the piston assembly should provide the necessary seal along the inner wall liner of the cylinders, while in motion. Piston rings mounted on the ring grooves in the piston provides this necessary seal. A lubricant oil, apart from minimizing friction between the piston rings and the inside wall liner, facilitates the sealing of the gap between the rings and the wall liner [5].

Additionally, lubricant oil performs other necessary functions for efficient operation of diesel engines. Following are some important functions lubricant oil performs [4]:

a) Reducing wear in components like bearings, pistons, piston rings, cylinder liners and the valve trains.

b) Preventing corrosion in the components caused due to acids and moisture.

c) Cleaning pistons and preventing sludge build-up on the internal surfaces.

d) Lubricating seals and controlling swelling to prevent leakage due to seal failure.

e) Piston cooling. 
A proper lubricant oil formulation to carry out these functions under high temperature and pressure conditions inside the combustion chamber is vital. However, new emissions standards for diesel engines have raised the expectations from oil formulation.

\subsubsection{Composition of Lubricant Oil}

Typically, lubricant oils consist of a base oil (approximately $75-83 \%$, w/w), a viscosity modifier $(5-8 \%, \mathrm{w} / \mathrm{w})$ and an additive package $(12-18 \%, \mathrm{w} / \mathrm{w})$ [3]. The additive package is added in the formulation of oils for modern diesel engines, to enhance its capability to perform some of the above mentioned functions effectively.

The base oil is composed of a base stock or a blend of number of base stocks. Base stocks are manufactured using variety of processes such as distillation, solvent refining, hydrogen processing, oligomerization, esterification and refining. The base stocks are classified into several different groups based on the concentration of saturates and sulfates and by the viscosity indices of the base stocks [4].

The additive packages typically consist of number of different additives which are added to impart or enhance properties that protect engine surfaces, modify oil properties or protect the base oil. Some of the commonly available additive package types that can be found in modern diesel engine oils are [4]:

a) Engine surface protection additives:

i) Detergents and detergents/inhibitors to keep engine surfaces clean e.g. sulfonates, phenates, and salicilates.

ii) Anti-wear additives (ZDTP).

iii) Rust and corrosion inhibitors (detergents, ZDTP, triazoles, and thiodiazoles).

iv) Friction modifiers.

b) Oil property modification additives:

i) Antifoam agents (silicone oils).

ii) Viscosity improvers and pour point depressants (hydrogen and oxygen based).

c) Base oil protection: 
i) Antioxidants and metal deactivators (ZDTP, phenates, phosphonates, phenolics, amines).

Viscosity modifiers are chain-like polymers which are added to improve the viscosity index of the base oil. The viscosity of the oil and the viscosity index increases depending on the molecular mass and the concentration of the viscosity modifier [4].

\subsubsection{Sources of Lubricant Oil Consumption}

Lubricant oil is known to be consumed during normal operations of engines in small but not insignificant quantities. There are many possible sources of oil consumption in an internal combustion engine. Throw-off of oil from the top land of the piston rings into the combustion chamber as a result of inertia force on the oil during varying engine operating conditions, transport of oil in liquid and mist form into the chamber due to reverse gas flow, entrainment of oil mist into the chamber by blowby gases through the intake air system, oil evaporation from the piston-ring-liner system, and leakage of oil from valve guide system in the intake port are some possible sources of oil consumption [5] [6]. In the case of turbocharged engines, oil leakage past the turbocharger seal also contributes to the total oil consumption. However, the piston-ring-liner system makes the largest contribution to the total oil consumption in the engines [7].

Another study [8] investigated transport of oil into the combustion chamber under different steady state and transient operating conditions of a spark-ignited engine. The study suggested that at low load condition, more oil deposition were found on the pistons than high load condition at same speed due to increase gas flow at high load. However, in transient operating condition, oil transport to and from the piston showed dependency on the throttle position.

\subsubsection{Contribution of Lubricant Oil in Engine Exhaust Emissions}

Researchers have found that interaction of oil with the combustion gases inside the combustion chamber and its consumption during normal engine operations has substantial contribution in diesel engine emissions, particularly PM emission. Hilden and Mayer [9] conducted a study to determine the contribution of engine oil to total and extractable PM emissions during transient engine operation in light-duty diesel powered vehicles. It was 
found that oil contribution to total PM emission was in the range of 7-14\% but oil contributed a significant portion in extractable PM emission in the range of 30-55\%. Oil contribution to PM emission also showed dependency on type of oil used. This was attributed to viscosity and volatility changes which might have affected the PM emission.

From the study conducted by Dowling [10], it was shown that lubricant oil can have significant impact on type and level of emissions from diesel engines. The objective of the study was to develop prototype low emission oil (LEO) for diesel engines and to evaluate effects of different lubricant oil formulations on diesel engine exhaust emissions. For evaluation of emissions, a Volkswagen Passat passenger car with 1.6L turbocharged IDI diesel engine was tested over ECE 15 and EUDC test cycles for a total of 5,000 km, on a chassis dynamometer. It was observed the emissions varied from the same engine running on the same oil, as the oil aged. Initial decreases in HC and PM emissions were observed for the first 2,000 km and both emissions showed similar trends. NOx emission showed a gradual decrease in the first $2,000 \mathrm{~km}$ and then no change in the emission was observed for rest of the aging period. However, $\mathrm{CO}$ emission showed a gradual initial increase and then maintained a constant value at around 3,000 km. Additionally, the study suggested that formulation of oil solely to meet the contemporary emission limits might fail to meet the lubricant oil evaluation tests in case of its usage with high sulfur diesel and leaded gasoline fuels. Besides contribution of oil on on-road diesel engine emissions, a research study by Miller [11] on marine engines was aimed to determine the relationship between lubricant oil derived particulate matter emission rate and the engine oil consumption. The study found that oil derived SOF in PM had approximately linear relationship with engine oil consumption. Emission of insoluble fraction of PM showed dependency on load conditions and consequently on intake air pressure.

A study was conducted by Andersson et al. [12] on a European heavy-duty diesel engine, 7.8L, 6 cylinders, Iveco Cursor 8, equipped with diesel particulate filter. The engine was tested on ESC and ETC cycles to investigate the impacts of different oil formulations on engine exhaust emissions, using Swedish Class 1 Diesel fuel. The results showed no significant effect on regulated gaseous emissions from the different oil formulations but nucleation mode particle number emissions showed dependency on both oil formulation and drive cycle. PM mass emission was low because of high filtration efficiency of the DPF, and 
hence high variability in mass measurement of PM was observed, which led to no conclusion on contribution of oil on gravimetric PM emission. A similar study [13] conducted on a smaller engine (2.2 L Mercedes-Benz 611 CIDI engine) also showed significant effects of oil properties like viscosity, volatility on PM and NOx emissions under the given conditions.

Recently, some concerns about deterioration in performance of after-treatment devices such as diesel particulate filters (DPF) by emission of additive-metals as a result of consumption of oil have been reported. A DPF is very sensitive to organo-metallic ash derived from calcium and magnesium containing additives found in lubricant oils. This had led to filter plugging and affected engine operations. Therefore characterization of oil-derived exhaust emission species is very important. In a study conducted by Froelund and Yilmaz [14] to determine impacts of oil consumption on particulate matter emission from three UScertified HDDEs from the 1990's, showed significant contribution of oil in total PM emission from the engines in the range of 20-30\%. Oil design characteristics like viscosity showed inverse proportionality relationship with amount of oil derived PM emission, whereas volatility showed direct proportionality relationship with amount of oil derived PM emission. Oil consumption studies showed that at high-speed full-load operating condition of the engines, piston-ring-liner system was the major contributor of oil consumption. A similar observation was also reported by Laurence et al. [15] where particulate matter emission rate increased with decreased viscosity of oil. The study also concluded that increased ring gap width facilitated reverse flow of oil into the combustion chamber which in turn encouraged PM emission.

Additionally, a study was conducted by Andersson et al. [16] to investigate contribution of oil in nucleation mode particle emissions. The study investigated the effect of sulfur and phosphorus levels in the oil which was believed to contribute in formation of nucleation mode particles. The results showed oil sulfur and phosphorus levels positively affected emission of nucleation mode particles where effect of phosphorus was larger than that of sulfur on mass basis nucleation mode particle emission.

The above discussion leads to the conclusion that oil significantly contributes to diesel engine exhaust emissions, particularly PM emission. Hence in this research study, measurement and quantification of PM emission, mass-based and number-based, during oil 
aging was one of the primary focus areas. A brief review of diesel PM and its harmful effects to human health and environment is discussed later in Section 2.3 for the reader to understand the magnitude of ill-effects of diesel particulate matter.

\subsection{Lubricant Oil Aging Studies}

It is important to investigate the effects of oil aging on emissions from diesel engines. Engines are subjected to periodical oil change but how long fresh oil typically takes to stabilize its properties and how it affects gaseous and particulate emission during this period of stabilization, is not completely understood in case of HDDEs. Studies have shown that fresh oil takes some initial time of engine operation for its properties to stabilize, which is dependent on type of oil used and the engine.

Cooke [17] conducted an extensive investigative study to evaluate the nature of interaction between engine operating conditions, fuel and contemporary lubricant oil formulation for a low particulate emission engine. The primary goal of this study was to identify formulation changes in existing oil, and suggest a fuel-oil combination to comply with 1990 EPA emissions standards for heavy-duty diesel engines. A 12.7L 1987 Detroit Diesel Series 60 diesel engine, very similar to the test engine used in this research study, was used to age SAE grade $15 \mathrm{~W}-40$ oil up to 250 hours based with the anticipation that significant lubricant oil and engine deterioration could be achieved within the time period. The engine was mostly operated at idle, peak power, and peak torque steady state conditions. Apart from quantification of engine deterioration events, like piston wristpin bearing wear, piston/liner scuffing, 'heavy ring-belt carbon deposition' and ring sticking tendencies, the study also determined effects on gaseous and particulate matter exhaust emissions, oil consumption and oil deterioration during the aging time. The results showed no significant increase in regulated gaseous emissions under the given conditions. However, a strong direct relationship between oil consumption rates and particulate matter emission rates was observed. Contribution of oil to PM emission was observed in the order of $5 \%$ of the total PM mass under high load conditions but considerably higher under part load conditions.

A similar study conducted by Andrews et al. [18] using a smaller 0.22L Petter IDI single cylinder engine to investigate the influence of oil aging on exhaust emissions. The 
study incurred 120 hours of oil aging using A2 diesel and SAE grade 15W-50 lubricant oil. The results showed initial decrease in PM emission till 50 hours then it increased with variation of $30-40 \%$, which was attributed to carbon emission variations during the aging period. Thermogravimetric Analysis (TGA) of oil samples showed fuel dilution of oil up to $10 \%$ and increase contribution of oil fraction in particulate SOF during the 120 hours. No significant change in $\mathrm{CO}$ and NOx emission was observed. Total HC and unburned HC emissions were high initially but fell as the oil aged and again increased after 50 hours, the phenomenon was attributed to oil volatility effects.

Moreover, an extensive research program [19] was conducted by a consortium of the U.S. Department of Energy, the American Chemistry Council (ACC), the American Petroleum Institute (API), the Engine Manufacturers Association (EMA), the Manufacturers of Emission Controls Association, the CARB and the South Coast Air Quality Management District (SCAQMD) called as APBF-DEC program. The objective of the program was to seek the optimal combination of low-sulfur diesel fuels, lubricants, diesel engines, and emission control systems to meet the projected emissions standards for the 2004 to 2010 time period and to enhance the collective knowledge base in the subject area. The program covered engines ranging from light-duty passenger car diesel engines to heavy-duty diesel engines from different engine manufacturers and collectively included 2000 hours of aging approximately representing 100,000 miles of on-road use. In the lubricant oil technology evaluation part of the program, a medium-duty International T444E diesel engine was used to determine the effects of oil aging on engine out emissions, consequently to suggest changes in oil formulation for better performance and longevity of after-treatment devices to be used for modern diesel engines. The study suggested that oil formulation had statistically significant effects on regulated gaseous and particulate matter emissions. Also, these emissions showed dramatic dependency on oil consumption method. Accelerated oil consumption showed increase in $\mathrm{HC}, \mathrm{CO}$ and $\mathrm{PM}$ emissions from the engine.

More recently, similar studies were performed by Sappok et al. [20] and Sinha et al. [21] using biodiesel. Sappok used a medium-duty 5.9L, six cylinder Cummins ISB 300 diesel engine, fitted with rapid lubricant aging system, and used conventional CI-4 diesel engine lubricant oil as well as CJ-4 oil in the study. The objective of the study was to understand the manner in which specific lubricant oil and fuel properties affect the engine and after-treatment 
system performance, and long-term service life. The oil was aged up to 80 hours using ULSD and soy-derived B100 biodiesel as fuel in different test campaigns. Chemical and physical analysis of oil properties at increasing aging time showed oil degradation in terms of increase in pentane insolubles (sludge), viscosity (up to 50 centistrokes), total acid number (TAN) (up to $4 \mathrm{mg} \mathrm{KOH} / \mathrm{g}$ ) within first 20 hours in case of conventional diesel fuel. Soy-derived B100 showed comparatively lower PM emission, higher ash emission and higher oxidation level of lubricant oil through fuel dilution of oil which was solely attributed to interference of ester present in the biodiesel. No significant deterioration of engine hardware was observed within the aging time period.

In the study conducted by Sinha [21], a 2.5L, four-cylinder direct-injection Mahindra MDI 3000 diesel engine was used. Similar to the previous study, mineral diesel and biodiesel, B20 in this case, were used as fuels and SAE grade 20W-40 oil was used as lubricant oil. The oil was aged up to 100 hours on each fuel to investigate relative changes in tribological properties of the oil on usage of biodiesel, compared to conventional diesel. The results showed gradual increase in ash content, density, moisture content, viscosity, pentane and benzene insolubles but decrease in total base number (TBN) over 100 hours of aging for both the types of fuels. Additionally, biodiesel showed lower deterioration of oil and wear of engine components during the aging period.

However, no general consensus on a typical stabilization period for oil properties can be drawn from these studies. The results from testing of smaller bore diesel engines may vary significantly from testing of comparatively larger bore engines. Smaller bore engines generally have smaller oil sumps, which may cause an apparent faster deterioration of oil properties. Additionally, it can be said that oil samples collected from small bore sumps may provide a sufficiently homogenized sample than samples taken from oil sumps in larger bore heavy-duty engines. Note that none of the previous studies discussed above had explored the impact on particulate matter number emission during the oil aging periods. However, in this research study, PM particle number concentration data in different particle size bins were collected to determine effect on number-based PM emission during oil aging. 


\subsection{Diesel Particulate Matter}

Particulate matter is perhaps the most characteristic emission from diesel engines which can be responsible for the black smoke one sees coming out from diesel engine exhaust. In literature it is referred as diesel particulate matter (DPM) or particulate matter (PM). The U.S. EPA mandate to continually restrict the limits on PM emission during the last decade has resulted in a limit of $0.01 \mathrm{~g} / \mathrm{bhp}$-hr for PM for on-road heavy-duty diesel engine trucks to comply with 2007 emissions standard, which is approximately $98 \%$ reduction from 1998 emissions standard [Appendix A.1]. Although a considerable amount of basic research has been conducted to understand the chemistry behind formation of diesel particulates during various engine operating conditions and its effects on human health, and to the environment, no general consensus on the subject matter has been achieved. It was mentioned earlier that diesel particulate matter emissions are subjected to diesel emissions regulation by emission regulatory bodies and new technologies to pursue the enforced limits have drawn attention from researchers around the world. One of the first particle sizing studies was conducted by Vuk et al. [22] where they conducted experiments to understand the distribution of particle sizes in PM and to determine a method to quantify it. Multiple metal plates, each with hundreds of small holes ranging from $6.05 \mu \mathrm{m}$ to $0.53 \mu \mathrm{m}$ diameters, were used and placed in the engine exhaust steam to capture particles of different sizes from the exhaust. The particle

size and concentration in the exhaust was estimated by counting the number of blocked holes in the metal plates of corresponding hole diameters. But, today there are many commercially available instruments for measurement and quantification of PM.

From the regulatory point of view, diesel particulate matter is not a specifically defined substance but is only defined through specific sampling methods used for collection of PM, because quantification of PM significantly depends on sampling methodologies. However, different researchers have defined PM based on their observations. For example, Burtscher [23] describes PM as "a complex mixture characterized by widely changing chemical composition and physical properties." This complex mixture of solid particles and liquid droplets is generated by many factors including fuel used, engine technology, engine operating conditions, exhaust after-treatment and the atmospheric exposure time. It was also reported [24] that diesel particulates are composed of elemental carbon particles that 
agglomerate and adsorb other species to form structures having complex physical and chemical properties. It was observed that diesel particulates have bimodal size distribution, comprising of smaller nuclei mode and larger accumulation mode particles.

\subsubsection{Composition and Measurement of DPM}

Traditionally, PM is divided into three main fractions, based on combination of its physical and chemical analysis, solid fraction (SOL) which constitutes elemental carbon and ash; SOF, consisting of fuel derived SOF and oil derived SOF; and sulfate particulates $\left(\mathrm{SO}_{4}\right)$, which constitute sulfuric acid and water. These different fractions of particles are formed at different stages of escapement of exhaust gases through the exhaust system. Depending on temperature in the exhaust system, smaller particles undergo limited oxidation and further agglomeration to form larger particles [25].

Measurement and quantification of PM emission is as complex as its definition. As mentioned before, quantification of PM emissions largely depends on sampling method used. Most of the sampling method tries to mimic real-world conditions of PM formation by diluting engine exhaust with ambient air but unlike gaseous emissions measurement, no single absolute method for PM emission measurement exists. However, a standardized mass based PM emission sampling and measurement system suggested by the U.S. EPA is available, which is commonly used to quantify total PM emissions in the US and Europe. The method quantifies PM emission based on gravimetric analysis of PM deposits on a filter media collected from diluted engine exhaust. Additionally, concerns over increased number-based particulate matter emission from modern low emission diesel engines fitted with aftertreatment devices have recently gained momentum. A study [26] indicated the concern of the adverse health effects that can be caused by ultrafine particles than larger diameter PM particles. Particle sizing measurement of diesel particulates is often called as art. There are many particle sizing instrument based on different principles are available for determination of particle size distribution of PM emissions at different engine operating conditions. But again, the quantification depends on sampling methodology used. A recent study conducted by Swanson et al. [27] mentioned various particle sizing instruments like scanning mobility particle sizer (SMPS), engine exhaust particle sizer (EEPS), DMS500, electrical low pressure 
impactor (ELPI) and Dekati mass monitor (DMM) in quantification PM emissions to comply with 2007 HDDE emission limits.

\subsubsection{Harmful Effects of DPM}

Diesel particulate matter is known to contribute significantly to deterioration ambient air quality and cause adverse impact on human health. The predominant emission from diesel engines, NOx and PM in form of volatile organic compounds (VOCs) are reported to be a precursor to ozone and other greenhouse gases, and are considered as air pollutants [28]. Additionally, it was observed that diesel exhaust is also responsible for a substantial percentage of the rising amount of atmospheric particles which may reduce cloud cover and rainfall [29].

Apart from its harmful impact on the environment, diesel particulate matter is attributed to many carcinogenic diseases in human beings. Due to increased use of light-duty diesel engine in passenger cars and vans, many studies on the health effects caused by inhaling diesel exhaust was initiated. The main focus of harmful effects of diesel emissions was centered on the primary concern of long term exposure to the emissions which can cause cancer, particularly lung cancer. The Health Effects Institute (HEI) reported that, a number of epidemiologic and experimental studies have suggested that the effects of short term exposure to diesel exhaust particles on the respiratory and immune system, particularly in individuals with asthma and other allergic diseases, may also be a concern [28]. A review by McClellan [30] on an epidemiologic study performed on the London Transit Authority workers during 1950 to 1974, who were exposed to diesel exhaust, found that the overall annual lung cancer rate in these workers was 159 per $10^{5}$ workers. Diesel exhaust particle are submicron in size and can be readily inhaled. Approximately one-fourth of the particle mass inhaled by people is deposited in the pulmonary region, some of which is retained with a half life of several hundred days. Silverman et al. [31] noted an increased risk of lower urinary tract cancer in truck drivers, with risk increasing with the duration of employment. He found that the relative risk for operators of diesel trucks was 11.9 times that of people who did not drive trucks. However, in all these studies on impact on health of the human subjects exposed to diesel particulate emissions did not consider other social variables like life style, smoking and drinking habits, and professional obligations which might have biased the research outcome. 
It is also noted that modern diesel engines may not cause some of the above problems and hence may pose lesser serious concerns in this regard, compared to diesel engines of yesteryears.

Polycyclic aromatic hydrocarbons (PAHs) are present within the SOF of PM. Many PAHs are considered to have human carcinogenic potential with propensity to penetrate deep into lung tissue [30]. A number of national and international agencies have designated diesel exhaust, more specifically diesel PM, as a "probable" human carcinogen [31]. The state of California identified diesel particulates, both the solid and organic phase as a toxic air contaminant in California [32]. More recently, diesel PM was included to a list of substances which are thought to be human carcinogens during the $9^{\text {th }}$ National Toxicology Report on Carcinogens by the U.S. National Institute for Environmental Health Sciences (NIEHS) [29].

The discussion and studies mentioned above on diesel particulate matter and it harmful effects was not an attempt to provide a comprehensive understanding of diesel PM but a brief review on the subject matter. There are scores of research observations and finding are available in literature which can be referred for further understanding of diesel particulate matters. 


\section{Chapter 3. EXPERIMENTAL SET-UP}

This chapter discusses various systems, devices, instruments and procedures used in this research study. The engine tests were conducted in the Engine and Emissions Research Laboratory (EERL) of the Center for Alternative Fuels, Engines and Emissions (CAFEE) at West Virginia University which followed procedures as described in 40 CFR Part 86, Subpart $\mathrm{N}$ and 40 CFR Part 1065 [33]. In the following discussion, corresponding sections of the CFR are mentioned in square brackets wherever applicable.

\subsection{Test Engine}

The engine used for this study was a 1992 Detroit Diesel Corporation Series 60 legacy on-road heavy-duty diesel engine which was modified to suit the laboratory testing environment. The air-to-air intercooler found in a typical on-road vehicle was replaced with a liquid-to-air intercooler, and the radiator was replaced with a liquid-to-liquid heat exchanger. Other accessories like fan and air conditioning unit were removed. The EERL heating, ventilation and air conditioning system supplied the intake air and a laboratory filter was used in the place of the intake air filter and a valve simulated the inlet depression. Exhaust mufflers were replaced by an exhaust backpressure valve in the exhaust pipe.

The test engine was a turbocharged, direct injection, $12.7 \mathrm{~L}$, in-line six cylinder engine from Detroit Diesel Corporation. The engine met the EPA emissions standard for 1991 as mentioned in Appendix A.1. The engine was procured as a salvaged engine from an over-theroad truck by CAFEE with no known history but periodical engine maintenance has been performed since its procurement. The engine specifications are provided in Table 3.1, a photograph of the engine can be seen in Figure 3.1. 
Table 3.1 : Test Engine Specifications.

\begin{tabular}{|l|l|}
\hline Engine Manufacturer & Detroit Diesel Corporation \\
\hline Engine Model, Year & DDC Series 60, 1992 \\
\hline Configuration & In-line 6 cylinder \\
\hline Displacement (L) & 12.7 \\
\hline Power Rating (hp) & $360 @ 1810 \mathrm{rpm}$ \\
\hline Torque Rating (ft-lbs) & $1450 @ 1200 \mathrm{rpm}$ \\
\hline Compression Ratio & $15: 1$ \\
\hline Bore x Stroke (mm x mm) & 130 x 160 \\
\hline Air Handling & Turbocharged, Intercooled \\
\hline
\end{tabular}

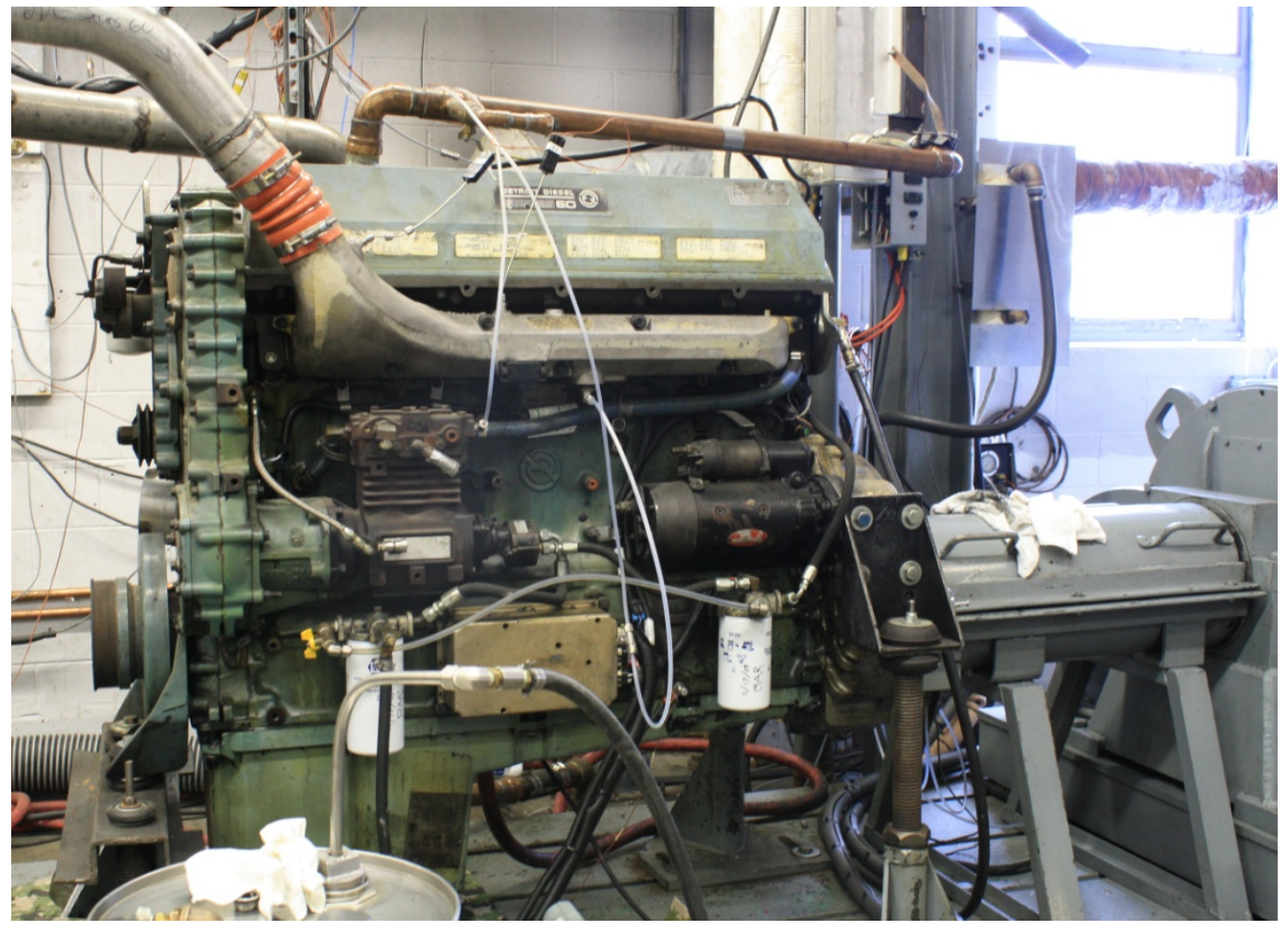

Figure 3.1 : Test Engine - 1992 DDC Series 60.

\subsection{Test Fuels}

The objective of this research study was to determine the effects of oil aging on engine exhaust emissions. To achieve this purpose only one type of fuel from the EERL 500 gallon day tank was used for running the engine to eliminate any variability in the exhaust emissions that could be caused by using different types or batches of fuels. But, as a part of the study biodiesel (B-20) was also used in some test sequences to determine fuel dilution of oil. For the 
major part of engine testing, locally-available in the Morgantown, West Virginia area Guttmann number 2 diesel was used. The biodiesel (B-20) was prepared in-house and the fuel mixing information can be found in Appendix A.5.

\subsection{Test Lubricant Oil}

The baseline test oil chosen for this study was commercially available SAE grade 15W-40 lubricant oil for heavy-duty diesel engine marketed by Shell Oil Company as Shell Rotella ${ }^{\circledR}$ T. The oil meets the recommendations specified for DDC Series 60 Engines [34]. Table 3.2 provides information about basic properties of the oil from the Shell Rotella® brochure and from the results obtained from the analysis of fresh oil by Analysts Inc. The oil analysis test methods used by the external laboratory are discussed in Section 3.6.

Table 3.2 : Properties of the Test Oil (SAE grade 15W-40).

\begin{tabular}{|l|l|l|l|}
\hline Property & Test Method & $\begin{array}{l}\text { Rottella }{ }^{\circledR} \\
\text { Brochure }\end{array}$ & $\begin{array}{l}\text { Analysts } \\
\text { Inc. }\end{array}$ \\
\hline Kinematic Viscosity @ 40 $4{ }^{\circ} \mathrm{C}, \mathrm{cSt}$ & ASTM D 445 & 118 & - \\
\hline Kinematic Viscosity @ $100^{\circ} \mathrm{C}, \mathrm{cSt}$ & ASTM D 445 & 15.7 & 15.4 \\
\hline Viscosity Index & ASTM D 2270 & 141 & - \\
\hline Pour Point, ${ }^{\circ} \mathrm{C}\left({ }^{\circ} \mathrm{F}\right)$ & ASTM D 97 & $-36(-33)$ & - \\
\hline Flash Point, ${ }^{\circ} \mathrm{C}\left({ }^{\circ} \mathrm{F}\right)$ & ASTM D 92 & $213(415)$ & - \\
\hline Neutralization No., TBN-E & ASTM D 2896 & 11.5 & - \\
\hline Sulfate Ash, \% w/w & ASTM D 874 & 1.47 & 0.94 \\
\hline
\end{tabular}

\subsection{Engine and Emissions Research Laboratory, WVU}

The following sections discuss different systems and components in the EERL used for this research study. This section provides information about the laboratory systems but should not be treated as a comprehensive documentation on the subject matter.

\subsubsection{Engine Dynamometer}

In laboratory testing environments, dynamometers serve the purpose of loading the engine to simulate real-world load conditions as prescribed by different test cycles for engine dynamometer testing. The CFR requires the engine to be run within a sufficiently close range to the prescribed speed and load set points over the entire test cycle and meet the regression limits laid out by it [40 CFR $\$ 86.1308-84]$. This was achieved by controlling the 
dynamometer speed and the engine throttle position. The engine speed was controlled by the dynamometer and a proportional-integral-derivative (PID) controller was used to specify and adjust the throttle position. These parameters were tuned before testing the engine to meet the regression requirement for FTPs.

The dynamometer used for engine testing was a General Electric direct current, model GE 42G263AK, type DYC243, air cooled, capable of absorbing $550 \mathrm{hp}$ and motoring $500 \mathrm{hp}$ with a maximum speed of $3000 \mathrm{rpm}$. The engine was coupled to the dynamometer by a drive shaft with universal joints at each ends and a Vulkan coupling. A load cell was used to measure the torque on the dynamometer and the engine speed was measured through a digital encoder mounted on the dynamometer. Figure 3.2 shows the dynamometer used for engine testing.

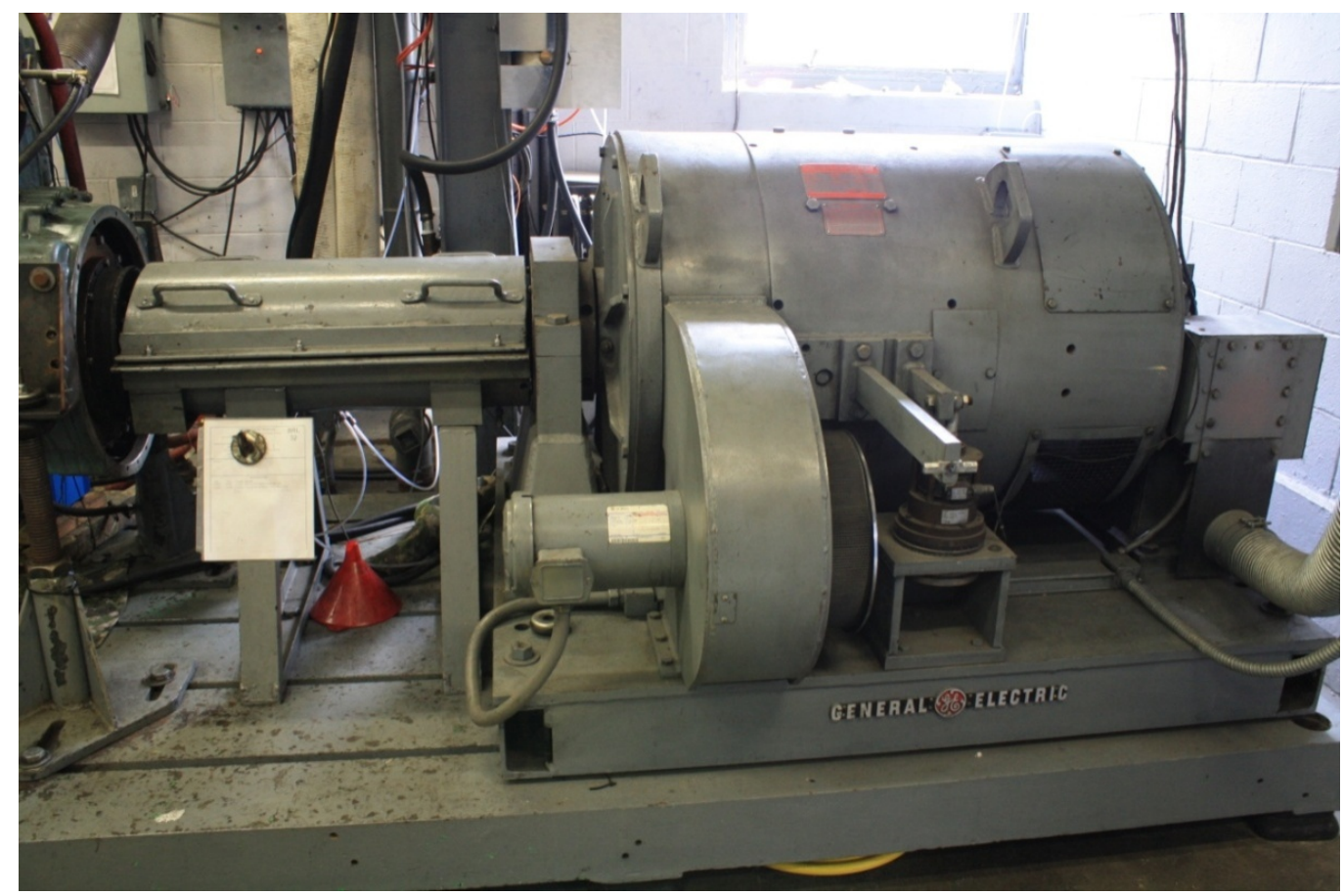

Figure 3.2 : GE Direct Current Engine Dynamometer.

\subsubsection{Full Flow Dilution Tunnel}

Dilution tunnels are controlled volume spaces used in emission testing to mix the raw engine exhaust with ambient air to mimic real-world mixing of engine exhaust with ambient air. The dilution of engine exhaust inside the tunnel allows chemical and physical reactions to occur and lowers the raw exhaust temperature, hence preventing condensation of the gaseous 
mix by lowering its dew point. Formation of water droplets inside the tunnel is not preferred as it can negatively affect emissions measurement. The primary purpose of the tunnel is to encourage formation of particulate matter, diesel particulate matter in this case, which was discussed in Section 2.3, and also to facilitate measurement of gaseous emissions.

The dilution tunnel in the EERL which was used for this research was an 18 inches diameter stainless steel duct of approximately 40 feet in length. Critical flow venture, constant volume sampler (CFV-CVS) method of emission mass measurement, as prescribed in $40 \mathrm{CFR}$ $\$ 86.1309-90$, was used for this dilution tunnel. A $75 \mathrm{hp}$ blower installed to pull the diluted exhaust through a set of four CFVs, three $1000 \mathrm{scfm}$ and one $400 \mathrm{scfm}$ venturi, was used to obtain the desirable mass flow rate of the diluted exhaust. A mixing orifice was placed at the end of insulated raw exhaust pipe in order to facilitate proper mixing with the ambient air. At 10 diameters of the dilution tunnel, approximately 180 inches, downstream of the tunnel from the mixing orifice, sampling probes were installed in a radial arrangement to the tunnel in one plane called as sampling plane. The diluted exhaust samples were collected from these probes to the analyzers bench through heated lines to prevent condensation. A photograph of the dilution tunnel along with mixing plane is shown in Figure 3.3 and the sampling plane is shown in Figure 3.4.

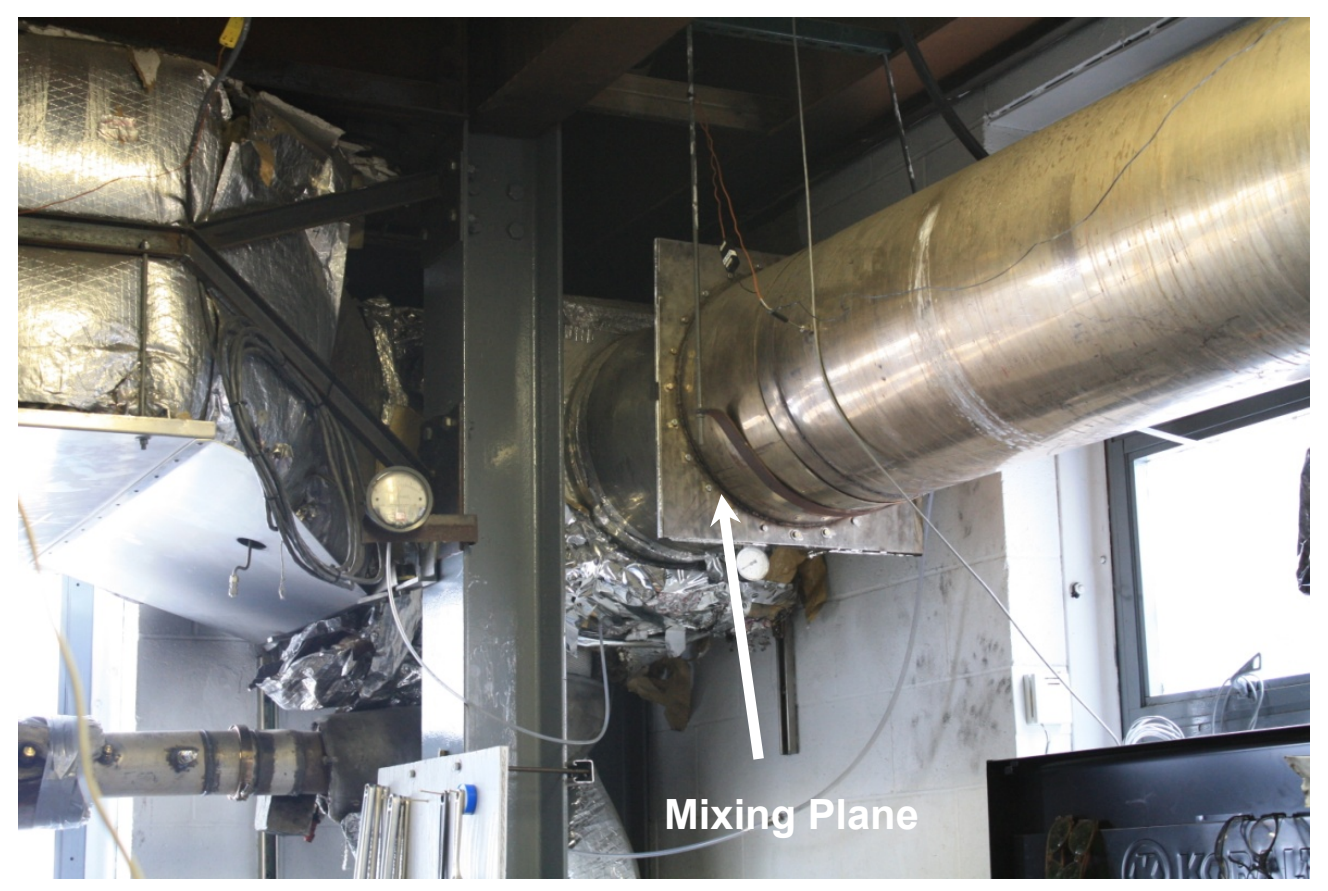

Figure 3.3 : Mixing Plane in Dilution Tunnel. 


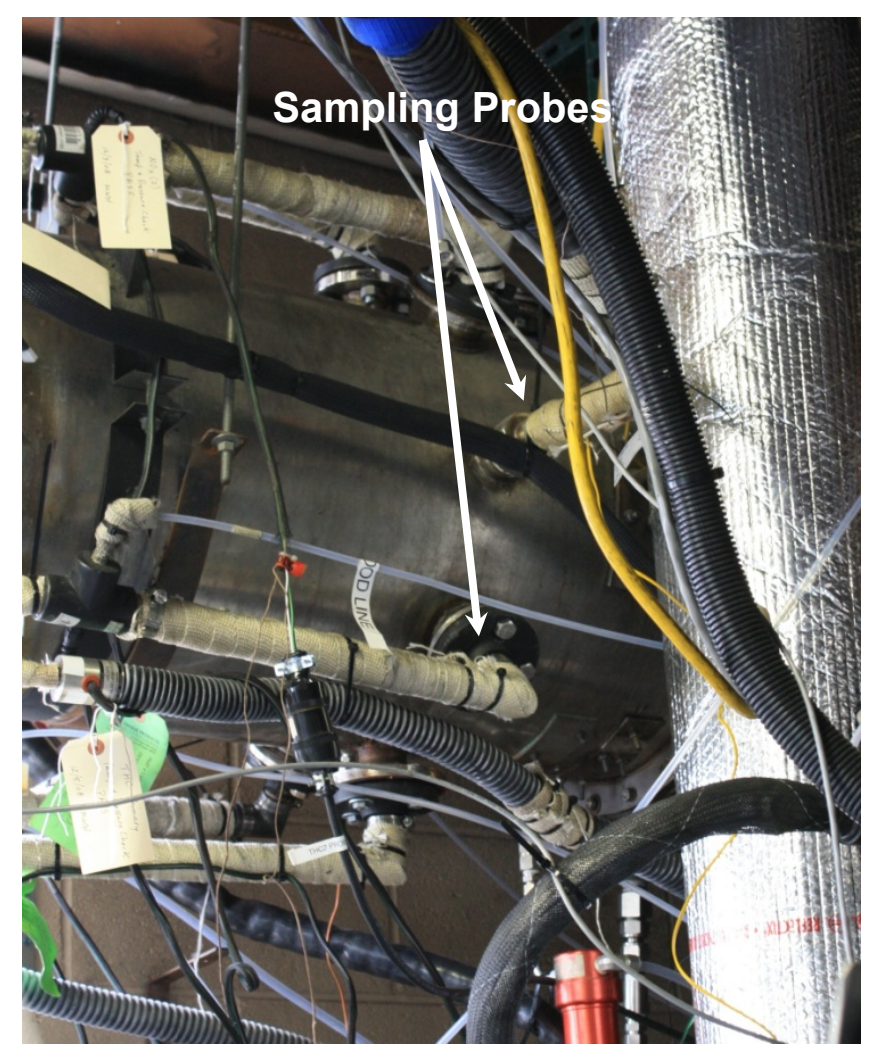

Figure 3.4 : Sampling Probes in Dilution Tunnel.

The CFV-CVS method of emission mass measurement system for the tunnel in the EERL had four CFVs, out of which one $400 \mathrm{scfm}$ and two $1000 \mathrm{scfm}$ venturi were used to obtain a nominal flow rate of $2400 \mathrm{scfm}$. A photograph of the CFVs is shown in Figure 3.5. Mass flow rate though venturi was proportional to pressure and temperature of the diluted mix before entering the throat. The actual mass flow rate through the venturi was calculated using the following expression.

$$
Q_{\text {(corrected) }}=K_{V} \frac{P_{a b s}}{\sqrt{T_{a b s}}}
$$

Where;

$\mathrm{Q}=$ Corrected flow rate through the venturi, scfm.

$\mathrm{K}_{\mathrm{v}}=$ Calibration constant for the venturi.

$\mathrm{P}_{\mathrm{abs}}=$ Absolute pressure of the diluted mix before the venture throat.

$\mathrm{T}_{\mathrm{abs}}=$ Absolute pressure of the diluted mix before the venture throat. 


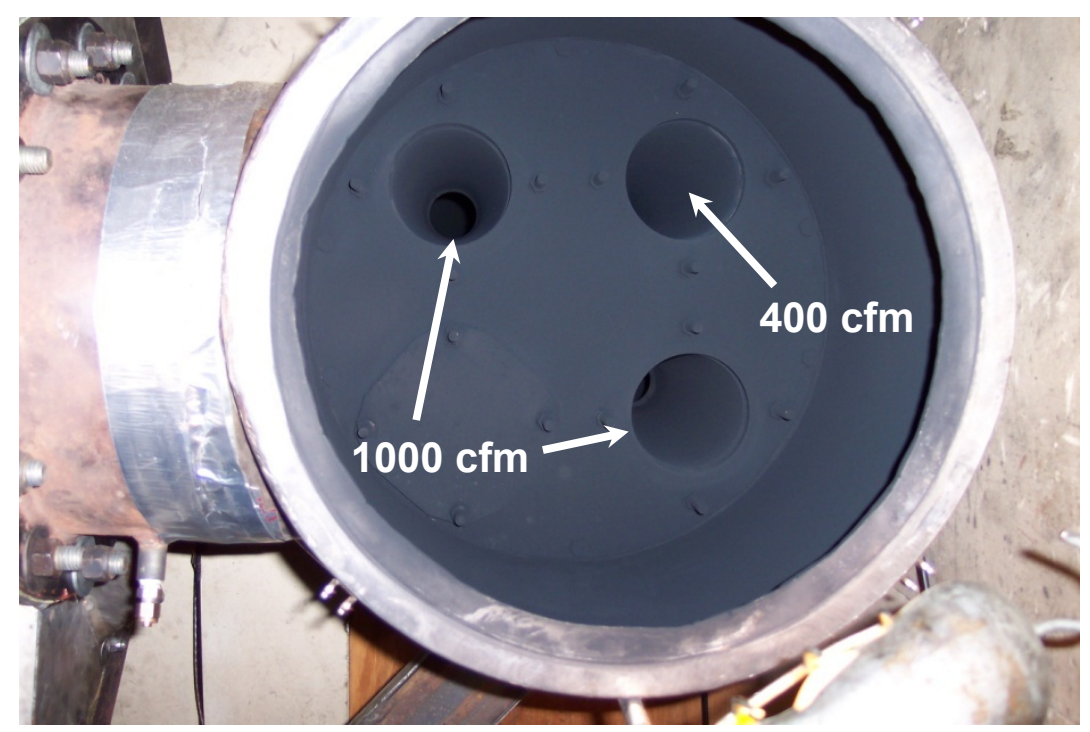

Figure 3.5 : Critical Flow Venturi.

\subsubsection{Gaseous Sampling System}

The gaseous sampling system in the EERL incorporates heated sampling probes, heated sampling lines, heated pumps, heated filters, a chiller unit and gas analyzers. Diluted exhaust samples from the sampling probes installed in the dilution tunnel were transferred by heated pumps and sent to the gas analyzers. All lines and equipments were maintained at a temperature above the dew point of the diluted mix to prevent condensation. Five probes, two for HC; two for NOx, the first NOx analyzer, represented as NOx (I); the second NOx analyzer, represented as NOx (II); and combined $\mathrm{CO}$ and $\mathrm{CO}_{2}$ were used for sampling. The $\mathrm{HC}$ lines, pumps, and filters were maintained at $375 \pm 20^{\circ} \mathrm{F}$ and the lines, pumps, and filters for $\mathrm{NOx}$, and $\mathrm{CO} / \mathrm{CO}_{2}$ were maintained at $235 \pm 20^{\circ} \mathrm{F}$. The $\mathrm{HC}$ sample line was maintained at a higher temperature to ensure that heavy hydrocarbons were not condensed in the sampling system. The $\mathrm{CO} / \mathrm{CO}_{2}$ sample was pumped through a Dominic Hunter compressed air dryer to remove moisture from the sample. The exhaust sample was filtered before passing it to the analyzer using heated micro-fiber filters maintained at $235^{\circ} \mathrm{F}$ for the $\mathrm{NOx}$ and $\mathrm{CO} / \mathrm{CO}_{2}$ systems. In the case of $\mathrm{HC}$ system, the analyzers had its own internal filter to prevent intrusion of particulate matter in it. Note that the $\mathrm{CO} / \mathrm{CO}_{2}$ system sample was maintained above room temperature $\left(\sim 70^{\circ} \mathrm{F}\right)$ after the compressed air dryer. 


\subsubsection{Exhaust Gas Analyzer Bench}

The exhaust gas analyzer bench used in this research incorporates gas analyzers from Rosemount Analytical, Horiba, California Analytical Instruments and Eco Physics. A photograph of the analyzer bench can be seen in Figure 3.6. Details of these gas analyzers are summarized in the following sections.

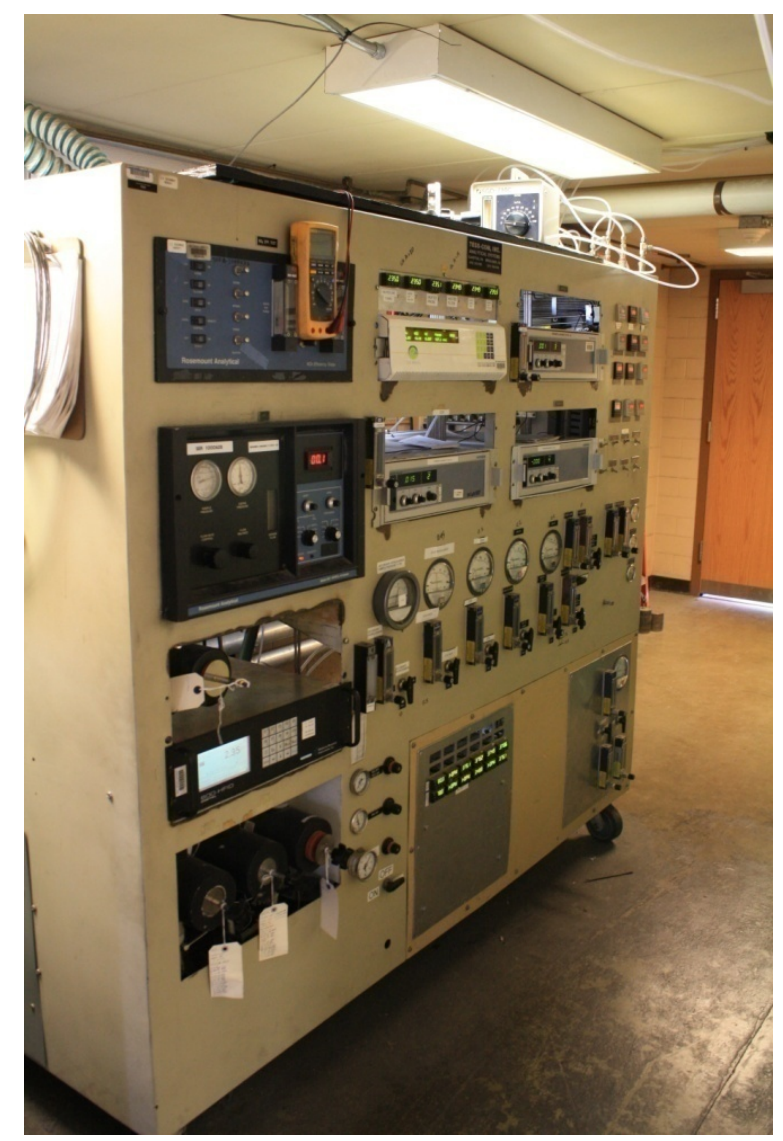

Figure 3.6 : Exhaust Gas Analyzer Bench.

\subsubsection{Hydrocarbon Analyzer}

The analyzer used for measurement of gaseous HC was a Horiba FIA-236 HFID analyzer. The heated flame ionization detector (HFID) worked on the principle of detecting the current generated by mobilization of ions which in turn estimated a measure of hydrocarbon concentration in the diluted sample. HFID had a heated oven which contained a flame fueled by regulated flow of a gaseous mix of $40 \%$ hydrogen and $60 \%$ helium. When the diluted sample was passed through the flame, hydrocarbons initiated an ionization process to produce electrons and positive ions. These charged particles tend to get attracted to oppositely 
charged electrode, electrons towards anode and positive ions towards cathode. This mobilization of charged particles generated a small ionization current which was proportional to the concentration of hydrocarbon atoms in the sample. Consequently, this current was converted to a voltage signal which had a linear response curve. The analyzer was capable of measuring concentration ranging from 1 to $5,000 \mathrm{ppm}$.

A California Analytical Instruments (model 600M-HFID) was also used in parallel to the Horiba analyzer to ensure precision of recorded data and was used as a QA/QC device. This instrument was also operated on the same HFID principle as the Horiba FIA-236 analyzer and used a separate probe, heated line, and pump system from the Horiba HFID system.

\subsubsection{Oxides of Nitrogen Analyzer}

Oxides of nitrogen (NOx) include nitric oxide $(\mathrm{NO})$ and nitrogen dioxide $\left(\mathrm{NO}_{2}\right)$. A chemiluminescent analyzer by Rosemount (model 955) was used for measurement of NOx in the diluted exhaust. Chemiluminescence is a phenomenon of photon emission during chemical reaction which occurs when $\mathrm{NO}$ reacts with ozone to form $\mathrm{NO}_{2}$. Ozone in the analyzer was produced by ultraviolet irradiation of oxygen in a quartz tube. Approximately $10 \%$ of $\mathrm{NO}_{2}$ formed in the reaction was in an excited state, which immediately released photons to reach a stable state. A photon detector in the analyzer detected this emitted photon and converted the photon emissions into a voltage proportional to the number of NO molecules in the diluted exhaust stream. In diesel engine exhaust some $\mathrm{NOx}$ are $\mathrm{NO}_{2}$, therefore, the analyzer converted incoming $\mathrm{NO}_{2}$ to $\mathrm{NO}$ separately, prior to the ozone chamber, and combined with the diluted NO from the sampling probe in the dilution tunnel. This estimated a total measurement of NOx in the diluted exhaust sample. The Rosemount model 955 can measure NOx concentrations ranging from $10 \mathrm{ppm}$ to $10000 \mathrm{ppm}$.

Another NOx analyzer, Eco Physics (model CLD $822 \mathrm{CM}$ h) was used as a QA/QC device which also works on the same principle as the Rosemount analyzer. But, a separate probe, heated line, and pump system was used for this analyzer.

\subsubsection{Carbon Monoxide (CO) and Carbon Dioxide $\left(\mathrm{CO}_{2}\right)$ Analyzer}

The $\mathrm{CO}$ and $\mathrm{CO}_{2}$ analyzers used in this research were Horiba model AIA-210 and Horiba model AIA-210 LE, respectively. The analyzers were non-dispersive infrared (NDIR) 
devices which were based on the principle of absorption of a particular frequency of infrared radiation by a gas where the frequency of the radiation was characteristic to the gas. The analyzer passed infrared radiation through cells containing the reference gas and the sampling gas. At a particular frequency in the infrared spectrum, the sampling gas absorbed the radiation. The device measured this absorption energy, which in turn estimated the concentration of the gas in the sample. A low CO analyzer was used for a range up to 1000 ppm and a high CO analyzer was used for a range up to $5000 \mathrm{ppm}$, to facilitate precise measurement of wide ranges of $\mathrm{CO}$ emissions produced during transient and steady state engine operations.

\subsubsection{Bag Sampling}

Samples of ambient or background air and diluted exhaust emission from the primary dilution tunnel were collected over the entire test cycle in two separate 80 liter Tedlar bags for integrated emission analysis. The sample for the background bag was collected from the conditioned dilution air, upstream of the mixing plane, before introduction of raw engine out emissions, through a Teflon tube. Dilute bag sample was drawn by a probe located at the sampling plane through a separate Teflon tube. After the test, the sample from each bag was pumped to the gaseous analyzers. In the case of HC and NOx samples, the bag samples was directed to the heated probes (flooded probe) located in the primary dilution tunnel, from there it followed the same sample line to the analyzers as for continuous emission sampling. In the case of $\mathrm{CO}_{2}$ and $\mathrm{CO}$, the bag samples were directly sent to the analyzers through a chiller unit. At the completion of the bag sample analysis, the bags were evacuated using a vacuum pump to a vacuum of 26 inches of $\mathrm{Hg}$ for the next test.

The samples from the bags were analyzed using the same above mentioned exhaust gas analyzers, which were used from continuous emission measurement during the test cycle. The background emission measurement values were considered in calculation of exhaust emission levels from the engine to account for exhaust constituents present in the ambient dilution air. The averaged emission measurement values from the dilute bag were used as a QA/QC procedure to check with integrated continuous emission measurement values from the primary dilution tunnel. 


\subsubsection{Fuel Measurement System}

Precise measurement of fuel consumption during a test cycle is a vital part of engine testing procedure. There are three different methods which were generally used in the EERL to determine fuel consumption during a test cycle. The first method was the carbon balance method, in which the amount of carbon recovered from the diluted exhaust was proportional to the amount of fuel consumed. In this fuel consumption equation, specific gravity of the test fuel, hydrogen-to-carbon, oxygen-to-carbon ratios of the test fuel, and the mass of $\mathrm{HC}, \mathrm{CO}$ and $\mathrm{CO}_{2}$ were taken in account.

The second method used incorporated measuring the fuel consumption from a Max Machinery (Model 710) fuel flow meter, fuel conditioning system. The fuel system consisted of a fuel tank, fuel supply and return lines, fuel meter, fuel pump and a heat exchanger. The purpose of the heat exchanger was to maintain the fuel temperature at approximately $95^{\circ} \mathrm{F}$, which was below the permissible temperature of $110^{\circ} \mathrm{F}$ [40 CFR $\left.\S 86.1330-90\right]$. The fuel metering system generated a digital output signal, which was recorded in the data acquisition system to quantify the mass flow rate of fuel consumed by the engine.

The third method used was a method of using a scale to record weight of fuel before and after a test cycle to calculate the total fuel consumption per test cycle. A 30 gallon barrel, on the scale, was used to feed fuel to the engine through the Max Machinery model 710 fuel meter system. The total weight of the barrel was recorded before and after the test cycle in the laboratory test QA sheet. The scale was accurate to approximately $0.5 \%$ of a typical FTP fuel consumption.

\subsubsection{Operator Control and Data Acquisition (DAQ) System}

The laboratory test data were recorded using a computer-controlled data acquisition system (DAQ) as shown in Figure 3.7. Various transducers used for measurement of parameters like pressure, temperature transmitted a current or a voltage signal which was proportional to the magnitude of the physical quantity measured. The DAQ system stored data in form of voltages, in case of a current signal, the signal is suitably converted to a voltage signal.

The DAQ system collected data using a signal conditioning backplane with Analog 3B system modules and RTI-815 ADC data acquisition boards housed inside the computer. 
Various engine test cell operation like engine mapping, test run, continuous emission measurement, test report generation were controlled by a in-house MS BASIC 7.1 program, details of which are documented elsewhere [35]. The data were recorded in ADC codes which were later reduced to engineering units using an in-house Visual Basic 6 based reduction program.

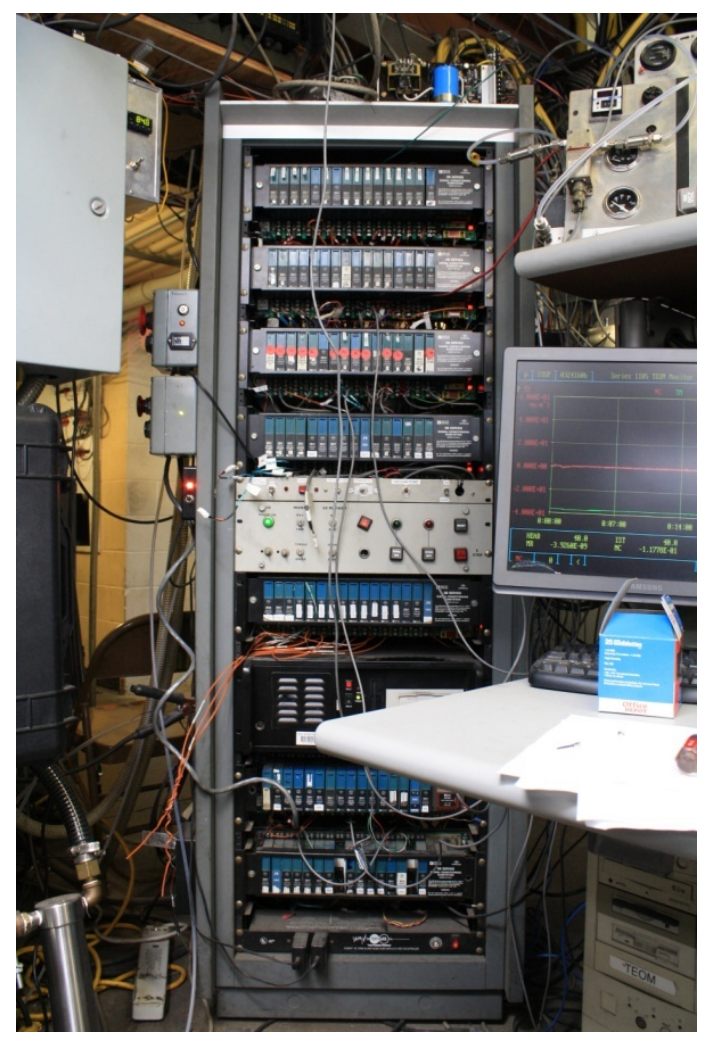

Figure 3.7 : Data Acquisition System.

\subsubsection{Barometric Pressure and Humidity Measurement}

To understand the effect of environmental factors like barometric pressure, dilution air humidity, and intake air humidity on exhaust emissions, these factors were taken into account in this study, which is discussed later in Chapter 5. Barometric pressure was measured using a Heise ${ }^{\circledR}$ handheld pressure calibrator at the being of each FTP test cycle and reported in inches of $\mathrm{Hg}$ (mercury) in this document. 'Dilution air humidity' here means humidity of the air used for dilution of the raw exhaust from the engine inside the dilution tunnel, which mixed with raw exhaust at the mixing plane. It was measured using wet bulb/dry bulb method of humidity measurement at a point approximately 2 meter before the mixing plane. Humidity of the 
intake air to the engine, called as 'intake air humidity' here, was measured using a GE dew point sensor and an EdgeTech hygrometer as a secondary QA/QC device. These instruments were installed in the intake air duct of the laboratory before the air was introduced to the engine intake. Dilution air and intake air humidity is reported in grains per pound of dry air.

\subsubsection{Particulate Matter Sampling System}

Quantification of particulate matter (PM) emission from the engine was one of the focus areas of this research. A number of PM sampling devices were used to quantify PM mass emission and PM number emission in different particle size bins along with total PM mass emission. At the EERL, there was a provision for collecting a portion of the diluted sample from the primary dilution tunnel at the sampling plane, into a secondary dilution tunnel (shown in Figure 3.8) where the PM was collected over filters mounted in a housing unit. As per the prescribed regulation [40 CFR \$86.1310-90], the diluted sample in the secondary tunnel was maintained at or below $125^{\circ} \mathrm{F}\left(51.7^{\circ} \mathrm{C}\right)$ during the entire test periods and the volumetric flow rate of the sample through the filters was maintained by a mass flow controller. The PM filters used in the secondary dilution tunnel for total PM mass emission measurement were $70 \mathrm{~mm}$ T60A20 Pallflex membrane filters. These filters were preconditioned, pre-weighed in the EERL clean room facility prior to its usage for the tests. The same room facility was used to post-weigh the filters using the same conditioning procedure as the pre-weight measurement procedure. 


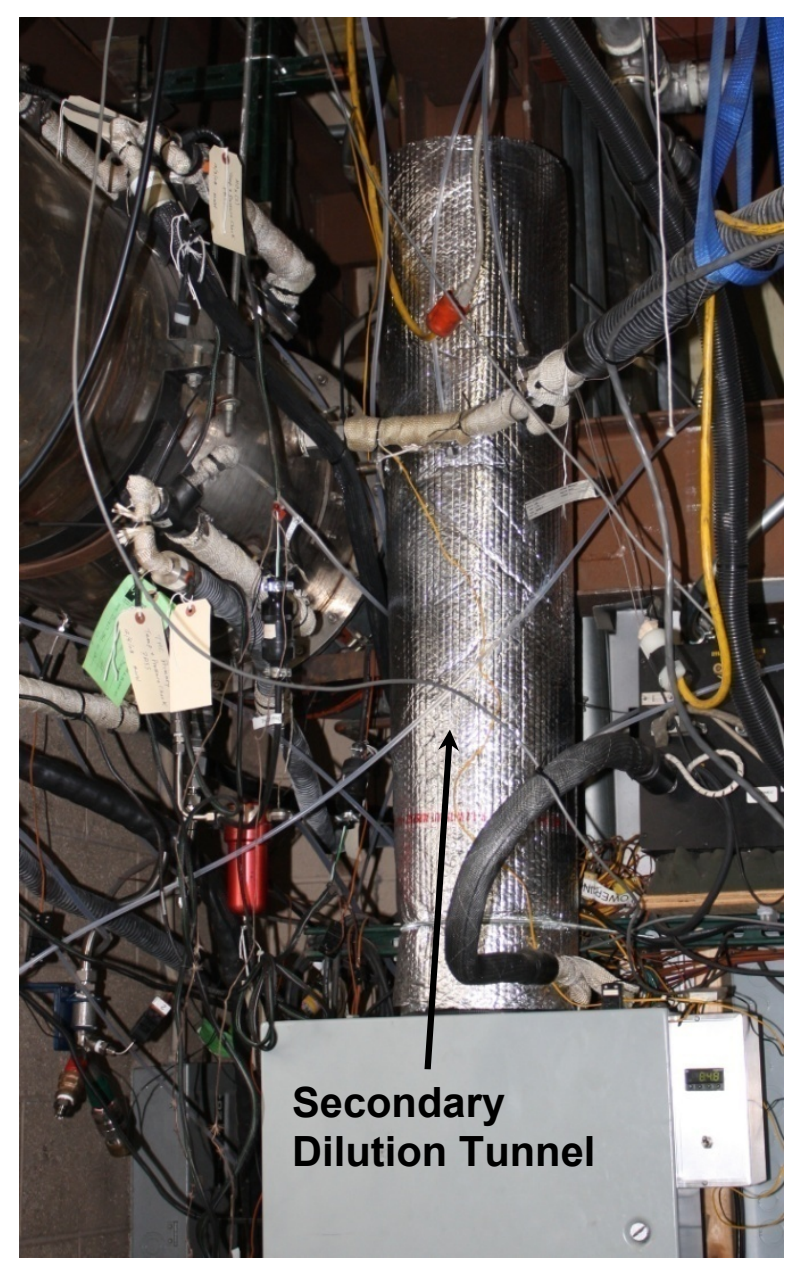

Figure 3.8 : Secondary Dilution Tunnel for PM Sampling.

\subsubsection{DMS500}

There are many particle-sizing instruments available for determination of particle size distribution in diesel exhaust emissions. In this research, a differential mobility spectrometer called DMS500 from Cambustion Ltd., Cambridge, U.K. was used. The instrument was meant for detection of fast changing particle size distribution pattern and was suitable for particle size measurement during transient engine operations. The instrument detected particles of sizes ranging from $5 \mathrm{~nm}$ to $1000 \mathrm{~nm}$. The device was based on the principle of deflection of charged towards grounded electrometer rings called classifier rings, by their repulsion from a central high voltage rod. The landing of particles on different classifier rings is a function of the amount of charge and aerodynamic drag on the particle [36]. Figure 3.9 shows a schematic diagram of the classifier rings and the charger in the DMS500. The diluted exhaust sample for the DMS500 was taken from the main dilution tunnel at approximate three 
meter downstream of the sampling plane. This diluted sample was further diluted using a secondary heated ejector dilutor system. The construction, working of the secondary dilution system and a comprehensive study other available particle sizing instruments are discussed elsewhere [37].

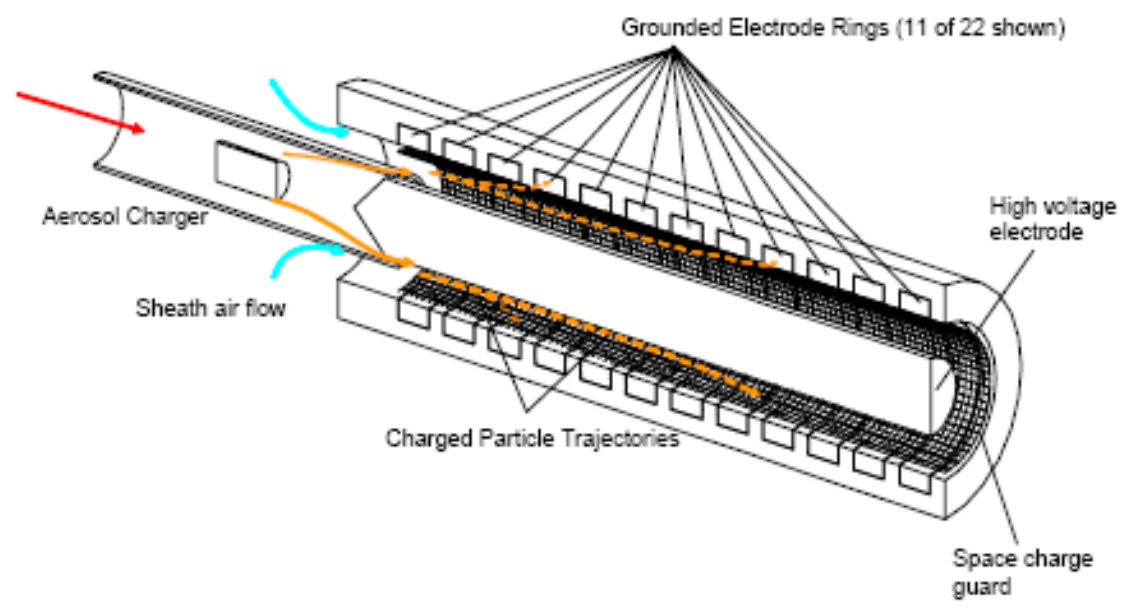

Figure 3.9 : DMS500- Classifier Rings and Charged Rod [36].

\subsubsection{PM Cyclone Separators}

For determination of gravimetric PM emissions in particle size ranges of $1 \mu \mathrm{m}, 2.5 \mu \mathrm{m}$ and $10 \mu \mathrm{m}$, cyclone separators of these particle size bins were used. A portion of diluted sample from the primary dilution tunnel was collected at the sampling plane using sampling pumps connected to the arrangement of PM cyclone system. The flow through each of the PM cyclones was maintained at 16.7 liter per minute using critical flow orifices. PM deposition was collected on $47 \mathrm{~mm}$ T60A20 Pallflex membrane filters. Software was used to monitor the flow rate during test cycles and a controller interfaced with the main data acquisition system was used to synchronize pump operations with start and end of the test cycles. The PM cyclones were supplied by BGI Inc. U.S.A.

\subsection{Extraction of Soluble Organic Fraction}

Apart from gravimetric analysis of PM filters, PM deposits on these filters can be subjected to certain physical and chemical analysis to determine several unregulated emissions, such as the SOF, PAH, and sulfates. To separate the SOF of diesel PM from the total PM, a method of extracting SOF from PM by using a solvent in a Soxhlet extractor is 
widely used [38]. The most commonly employed solvent is dichloromethane (DCM), as recommended by the EPA. Some other solvents used are toluene, benzene-ethanol and benzene-methanol mixtures [25]. The solvent used in this research project was a mixture of $68 \%$ toluene and $32 \%$ ethanol by weight. Usages of toluene sometimes favor the extraction of heavy PAH when compared with usage of DCM. But, addition of alcohol to the solvent mixture may lead to extraction of some sulfates [39].

An alternative method of extracting SOF from diesel particulates is vacuum evaporation and the fraction so obtained is called volatile organic fraction. A drawback of this method is water and sulfate from PM also evaporates [25]. This method was not used in this research.

\subsubsection{SOF Extraction by Soxhlet Method}

As discussed above, the Soxhlet method of extraction of SOF from the total PM deposits on the PM filters is based on using Soxhlet extraction apparatus to dissolve the fraction by passing the solvent mixture through it repeatedly over a period of time. The construction and working of the apparatus, the procedure to prepare the PM filters for extraction are explained in the following sections. The EERL did not have the extraction facility in its laboratory so the PM filters were prepared for extraction inside the clean room facility in the EERL and then transported to another laboratory facility in the university.

\subsubsection{Extraction Apparatus}

Figure 3.10 shows the arrangement of twelve units of extraction apparatus used for extraction of SOF from the PM filters. The glass thimbles containing folded PM filters were placed inside the main chamber of the Soxhlet extractors, which were placed onto the glass flasks containing measured amount of the solvent mixture. The Soxhlet extractors were then equipped with condensers, carrying continuously running water, to condense the evaporating solvent back to the flask through the extractor. Each setup was placed on a heater to reflux the solvent again through the extractor. The contact surfaces between the glass apparatus were firmly saturated by the solvent before mounting on each other to ensure no lose of solvent vapors to ambient. 
The extraction process started with evaporation of the solvent from the flask to the extractor through the distillation arm of the extractor, where it was condensed back to the extractor till the level in the extractor reaches the peak of the siphon arm. Once the extractor was filled to the level, the siphon arm automatically siphoned back the solvent into the flask. Then again it was heated to evaporate to the extractor. Boileezers ${ }^{\circledR}$ were added to the solvent in the flask to aid rapid evaporation of the solvent. The siphoned solvent dissolved the soluble organic fraction from the PM deposits on the filter paper. It was observed that each cycle of extraction approximately took 15-20 minutes. This process was continued for approximately 11 hours for each set of 12 extractor units for all the PM filters subjected to SOF extraction.

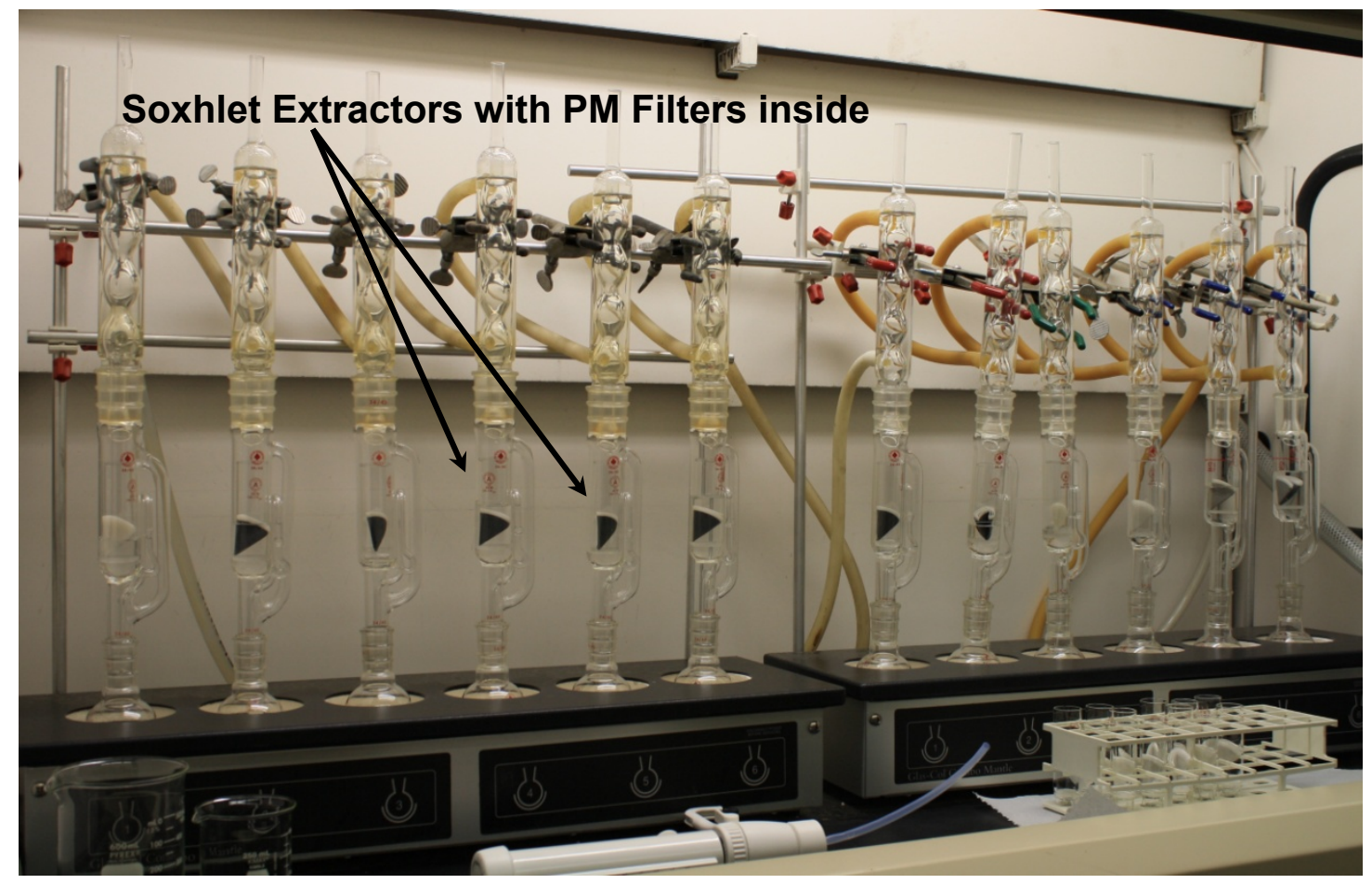

Figure 3.10 : Arrangement of Soxhlet Apparatus for SOF Extraction.

\subsubsection{Filter Preparation}

PM filter preparation for SOF extraction was a delicate and precision process. The filers were carefully prepared to minimize any variability that can be caused by improper handling and transportation of the filters. The process started with precise folding of the filters in the way as demonstrated in Appendix A.6, inside the clean room facility. The folded filters were inserted inside the numbered glass thimbles, Figure 3.11, with maximum care to prevent rupturing of the filter material. Each PM filter pair was assigned to a particular thimble 
number and a log sheet was maintained to track the filters during the entire process of its transportation to another facility and back to the clean room. The thimbles were packed in the plastic containers, as shown in Figure 3.12, for transportation to the extraction facility.

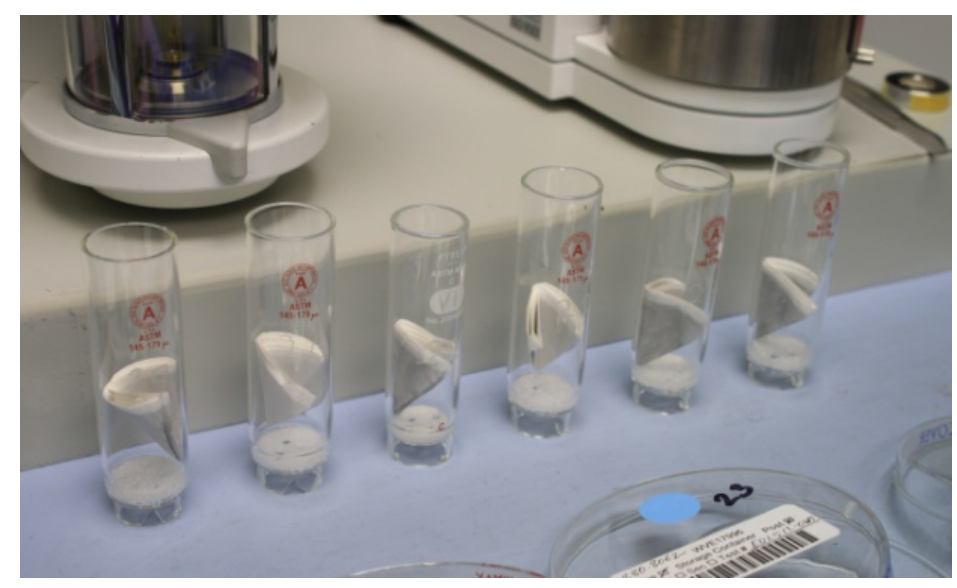

Figure 3.11 : Thimbles Containing PM Filters.

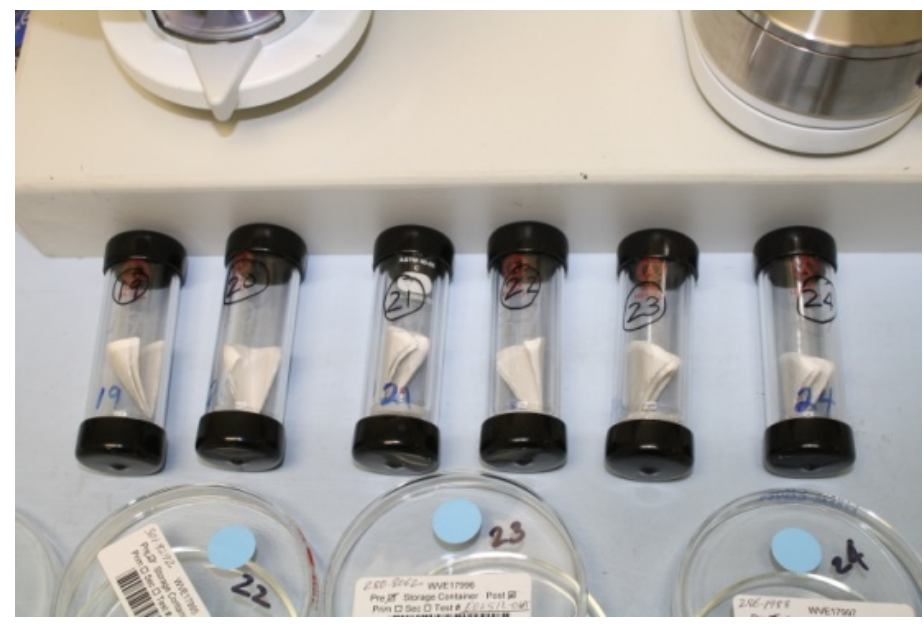

Figure 3.12 : Packaged Thimbles.

At the extraction facility, the thimbles were carefully placed inside the extractors which were also numbered to facilitate filter tracking. After completion of each session of extraction, the extractor were loaded with next set of thimbles and the wet thimbles from the last session were kept inside the fume hood for approximately 11 hours. Once dried these filters were transported back to the EERL using the same packaging method and then weighed again, after the proper conditioning in the clean room, to determine percentage SOF extracted. 


\subsection{Lubricant Oil Analysis}

Oil samples were collected at specified interval of time from the engine oil sump in clean plastic containers for further analysis of physical properties of the oil samples. The procedure of oil sampling is described in Section 4.2.1 in the next chapter. One of the interests of this research was to study changes in properties such as viscosity, acid content, base content, density, ash content, soot contamination along with other properties of oil as it ages. Apart from determination of these properties, it was also intended to determine sizing of suspended particles in the oil samples.

\subsubsection{Physical Property Analysis of Oil Samples}

The oil samples were analyzed for determination of viscosity, total acid number (TAN), total base number (TBN), density, ash content, soot contamination, fuel dilution and metal content. The analytical test methods used for determination of these properties are listed in Table 3.3 and described in this section. Similar analytical test methods were also used in other studies, [7], [20] and [21]. These tests were conducted by an external laboratory, Analysts, Inc. at their Chicago, IL facility.

Table 3.3 : Oil Analysis Test Methods.

\begin{tabular}{|l|l|}
\hline \multicolumn{1}{|c|}{ Property } & \multicolumn{1}{c|}{ Test Method } \\
\hline Viscosity @ 100 ${ }^{\circ} \mathrm{C}$ & ASTM D445 \\
\hline Total Acid Number & ASTM D664 \\
\hline Total Base Number & ASTM D664 \\
\hline Density & ASTM D1298 \\
\hline \multirow{2}{*}{ Ash Content } & ASTM D482 for Used Oil \\
\cline { 2 - 2 } & ASTM D874 for Fresh Oil \\
\hline Metal Content & ASTM D5185 \\
\hline Fuel Dilution & OEM method \\
\hline Soot content & OEM method (by LEM) \\
\hline
\end{tabular}

The descriptions of ASTM test methods are sourced from ASTM website of standards, more information on these methods can be obtained from ASTM booklet of standards.

Viscosity (ASTM D445): The test method is used for determination of kinematic viscosity of liquid petroleum products. The method is based on measurement of time taken by the liquid sample to flow through a calibrated glass capillary viscometer under gravity. The 
range of kinematic viscosities covered by this test method is from 0.2 to $300 \mathrm{~mm}^{2} / \mathrm{s}$ at specified temperature ranges. The values are reported in SI units, $\mathrm{mm}^{2} / \mathrm{s}$ or centistrokes.

Total Acid and Base Number (ASTM D664): The acid or base number is the measure of amount of acidic or basic substance in the oil, under the test conditions. In this method, the relative amount of acidic and basic substances in the oil is determined by titration with bases and acids, respectively. The values are reported in SI units, $\mathrm{mg} / \mathrm{g} \mathrm{KOH}$ for acid number and $\mathrm{mg} \mathrm{KOH} / \mathrm{g}$ for base number of samples.

Density (ASTM D1298): The method is used for determination of density, relative density (specific gravity), or API gravity for low viscosity transparent liquids by using a glass hydrometer. The values can be reported in any convenient units at a specified temperature. In this document, the values are reported as $\mathrm{Kg} / \mathrm{L}$ at $15^{\circ} \mathrm{C}$.

Ash Content (ASTM D482, D874): Ash in lubricant oils, crude oils, fuels are normally considered as undesirable contaminants that can result from oil or waters-soluble metallic compounds or from extraneous solids like dirt and rust. The method D482 can be used for determination of ash content in used lubricant oil and method D874 is used for determination of sulfated ash in unused lubricant oil containing additives. The values are reported in $\% \mathrm{w} / \mathrm{w}$ in this document.

Metal Content (ASTM D5185): This method is used for rapid determination of 22 elements in used lubricant oil samples by inductively coupled plasma atomic emission spectrometry (ICP-AES). The method can also be used for determination of baseline concentration levels of metal additives in unused oil samples. The concentration levels of elements are reported as a volume concentration in ppm in this document.

Fuel Dilution (OEM method): A method developed by Analysts Inc. for determination of fuel dilution in used lubrication oils was used for this research. The method is proprietary to the company, no further detail was provided. Fuel dilution levels are reported in $\% \mathrm{w} / \mathrm{w}$ of oil in this document.

Soot Content (OEM method): A method called Light Extinction Measurement $(\mathrm{LEM} \AA)$ developed by Analysts, Inc. was used for determination of soot levels in used oil samples. The method claims to be rapid, cost effective and incurs an accuracy equivalent to 
TGA method of determination of soot content. Soot content levels are reported in $\% \mathrm{w} / \mathrm{w}$ of oil in this document.

\subsubsection{Particle Sizing of Oil Samples}

Another part of oil analysis was to study particle size distribution of suspended particles in the lubricant oil samples. The purpose was to investigate any inclusion or contamination of suspended solid particles in the bulk of oil samples that might occur as the oil aged in the engine. For determination of particle size distribution in the oil samples, Zetasizer ${ }^{\circledR}$ Nano ZS (model ZEN3600) from Malvern Instruments Ltd., Worcestershire, U.K., was used. The following sections describe the principle, construction, working of the instrument and preparation of the samples for measurement.

\subsubsection{Zetasizer ${ }^{\circledR}$ Nano}

Zetasizer ${ }^{\circledR}$ Nano Series was used for determination of particle size distribution in liquid media. Measurement of particle sizes by the instrument was based on a process called Dynamic Light Scattering (DLS). DLS measures Brownian motion of particles in the liquid media and relates this to size of the particles in it.

In the instrument, a laser beam was fired into the sample under measurement, this beam of light, when traveling through the liquid media, was scattered by the particles inside the liquid. The scattered light was detected by a screen or a detector, as called in this case, positioned at an angle to the direction of the laser beam and it recorded the pattern of scattered light falling on the screen. Larger particles caused larger scattering of light and exhibited slower Brownian movement whereas smaller particles moved faster and scattered less light. The fluctuation in the pattern of light scattering was recorded by the detector repeatedly after every small unit of time (generally in the order of nanoseconds or microseconds) and a correlation was drawn with its previous observations. Slow moving larger particles exhibited lesser fluctuation in the scattering pattern as compared to fast moving smaller particles. The higher the fluctuation the faster the correlation decay from 1 to 0 . The instrument measured this correlation decay with respect to time to estimate size or mean diameter of the particles in the liquid media [40]. The instrument is generally used for measurement particle sizes of colloidal solutions of silica gels but this was the first known attempt to use it for analysis of diesel engine oil samples. 
Figure 3.13 shows a photograph of the instrument. It consisted of a measurement cell area on the top of the instrument with a lid to cover while measurements were conducted. The rectangular transparent plastic cells, also called as 'cuvettes', as shown in Figure 3.13, containing the diluted oil samples, were inserted inside the chamber in the cell area and the lid was closed before starting the measurement process through an interface software in the computer. After measurement the software generated normalized particle size distribution plots for the respective samples. Numbered cuvettes from different test trials can be seen in a palate in the foreground of the photograph.

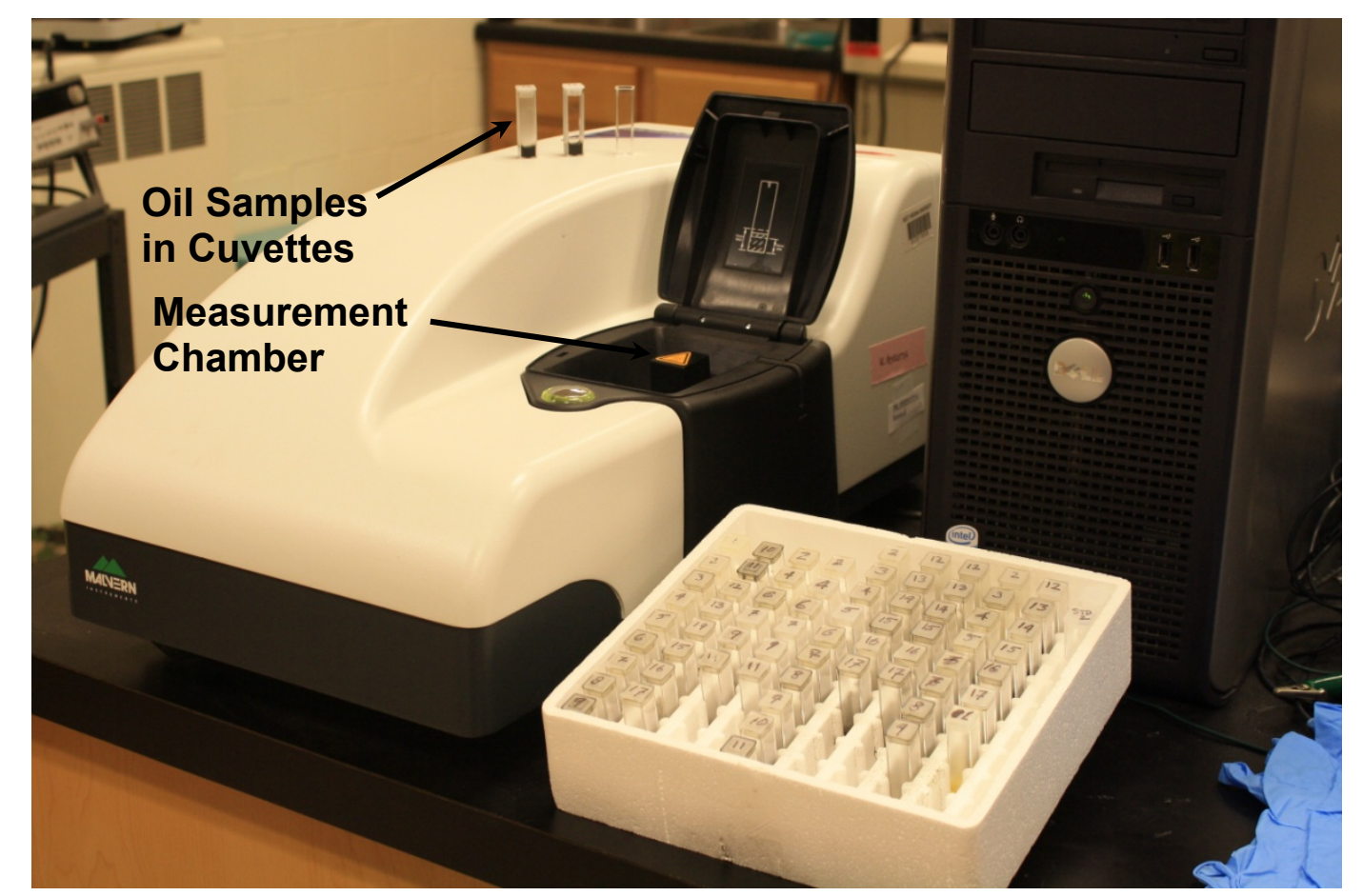

Figure 3.13 : Zetasizer® Nano Particle Sizing Instrument.

\subsubsection{Sample Preparation for Measurement}

The oil samples from the engine oil sump were too viscous, concentrated and partially opaque to be measured by Zetasizer ${ }^{\circledR}$ Nano for particle sizing. A solvent was needed to dilute the oil and to obtain a better transparency of the bulk fluid. Petroleum based hydrocarbons like toluene, $\mathrm{n}$-decane and diesel fuel were tried as a solvent. Toluene showed a reaction with the plastic cuvettes in which sample for measurement were prepared. Oil showed good solubility in diesel fuel but diesel was not used as the solvent. The n-decane showed good solvency to oil and at the same time showed chemical passivity towards the material of the 
cuvettes. Hence, n-decane was selected as solvent for oil in this research. The n-decane was obtained from standard industrial chemical bottle from Sigma-Aldrich®.

The samples for measurement were prepared by taking approximate $1 \mathrm{ml}$ of decane in the cuvettes and then dripping two to three drops of oil from the oil sample containers using a dropper. Necessary care was taken to prevent contamination of original oil samples in this process. These samples were then inserted into the chamber in the cell area for measurement. The cuvettes were weighed using a microbalance before pouring decane in it, after pouring decane and again after adding drops of oil sample into the solution. A log sheet was maintained to record the oil/decane weight ratios of the samples in cuvettes to quantify the contents of the solution. The log sheet is provided in Appendix A.8. It was important to monitor the shift in zero of the instrument between measurements of the samples to eliminate any offset in reading of particle sizes that might be incurred while using the instrument for long period of time for all of the oil samples. The n-decane; Nexsil 8, a colloidal silica sol; and DP5820, colloidal silica in ethylene glycol were tried as standards for this purpose. The ndecane and Nexsil 8 solutions showed poor repeatability in measurement of mean particle diameter using the instrument whereas DP5820 showed better repeatability than the other two. A solution of DP5820 in distilled water was used as a standard for the instrument, the mixing ratio of DP5820/water is provided in Appendix A.8. The standard was subjected to particle size measurement using the instrument after measurement of every five diluted oil samples. The results from particle size measurement of the diluted oil samples are presented in Section 5.4.2 in Chapter 5. 


\section{Chapter 4. EXPERIMENTAL Procedures}

This chapter discusses the procedures and methodologies followed to execute the research objectives. Oil sampling procedure, emission test cycles used in the study and statistical tools used for data analysis are discussed herein.

\subsection{Test Planning}

To achieve stabilization of oil properties and to determine the effects of oil aging on exhaust emissions, an approximate aging time for each set of oil change had to be assumed which would be feasible within the given project budget. Based on similar prior studies [20] [21] on lubricant oil aging, it was reported that after 25 to 30 hours of aging time, the lubricant oil properties showed a tendency of stabilization. This research aimed to limit the number of aging hours to focus particularly during the initial 20 to 30 hours of oil aging. Furthermore, it was decided that it would be more economical to run the engine for fewer or equal number of hours in the second test set, based on the observations from the first set of oil aging tests.

The on-road heavy-duty engine FTP transient test cycle and steady state test cycle were chosen for engine dynamometer testing. These test cycles are discussed later in this chapter. The FTP cycle was chosen to simulate transient engine operating conditions during the oil aging period. The purpose of exercising the engine over steady state cycles was to determine effects on emissions during specific speed and load conditions. Additionally, steady state cycles were used for accumulation of engine running hours between transient cycles, hence to optimize laboratory usage time. The FTP cycle was also of interest since this cycle is used during the verification or certification of devices, fuels, and additives for on-road HDDEs in the California and Texas programs.

In the first phase of the study, engine testing phase, gaseous emissions data for $\mathrm{CO}$, $\mathrm{CO}_{2}$, NOx, and $\mathrm{HC}$ emissions were collected using the exhaust gas analyzers discussed in Chapter 3. As mentioned before, the determination of PM emission was one of the focus areas in this research, a number of PM measurement instruments were decided to be used for capturing PM data. Apart from collecting total mass-based PM emission from the dilution 
tunnel, a DMS500 was used to capture particle number concentration levels, and a PM cyclone separator was used to classify mass-based PM emissions in three different particle size bins.

In the second phase of the study, all post engine test experiments were conducted. The experiments included SOF extraction from PM filters for determination percentage SOF in total PM, physical property analysis of oil samples and measurement of particle size distribution of suspended particles in the oil samples collected during engine testing phase.

The test plan was broken down into the following specific tasks to be performed during and after engine testing phase to meet the test objectives.

1. Measurement of continuous gaseous and particulate emissions data during the transient and steady state test cycles.

2. Collection of mass-based PM emission on PM filters for gravimetric analysis, and subsequently capturing PM particle number concentration levels using the DMS500. PM cyclones were used only in the second set of tests for collecting mass-based PM emission in three particle size categories of $1 \mu \mathrm{m}, 2.5 \mu \mathrm{m}$ and $10 \mu \mathrm{m}$ particle diameters.

3. Collection of oil samples from the engine oil sump at specified time intervals over the aging period for analysis of physical properties of the oil samples.

4. Extraction of SOF from PM-laden filters.

5. Analysis of oil samples to determine changes in physical properties of oil during aging.

6. Determination of size distribution of suspended particles in the oil samples.

\subsection{Test Procedures}

This section discusses the procedure followed for oil sampling from engine oil sump, oil changing after completion of each test sets, and designing of the modified SET steady state cycle used in this study. 


\subsubsection{Lubricant Oil Changing and Sampling}

The task of changing oil after completion of each test set was a vital part for maintaining data quality from the tests by preventing contamination of fresh oil by residual oil in the engine from the previous test set. The oil changing procedure was conducted in the following sequence.

1. The engine was allowed to cool down for at least an hour before the oil was drained out from the oil sump, to allow sufficient time for the oil to flow back to the sump.

2. The used oil filters were replaced with new oil filters (pre-filled with test oil before mounting on the engine).

3. The engine was filled with fresh test oil up to the recommended oil level.

4. The engine was idled for 5 minutes, and then was gradually ramped from idle speed-zero load point to maximum speed-full load point to warm up the engine and to allow the oil to circulate inside the engine.

5. The engine was run for approximately 5-6 minutes till the oil temperature reached around $180^{\circ} \mathrm{F}$.

6. The engine was stopped and allowed to cool down typically for 4-5 minutes before the first engine map was generated.

The above procedure might have minimized contamination of fresh oil by residual oil from previous test set but it was not practically possible to drain every drop of residual oil from the engine before it was filled with fresh oil. Additionally, the above procedure mimicked the general procedure used for oil changes in the laboratory. For oil sampling, at the specified time interval, approximately $250 \mathrm{ml}$ of sample was drained out from the sump into a cleaned, numbered plastic container, 30 minutes after the engine has stopped. Before the sample was collected in the container, approximately a gallon of oil was drained out in a cleaned plastic jar and pour back to the engine. This process was repeated three times to circulate sufficient quantity of oil through the engine sump oil collection location, to ensure proper mixing of the oil in the sump before the sample was collected. 


\subsubsection{Modified SET Cycle}

In the engine testing phase, the engine was exercised over transient and steady state cycles. The transient cycle used was as recommended for HDDE FTP transient cycle but the steady state cycle was modified based on ESC or SET test cycle. Details of these cycles are discussed in Section 4.3.

The six mode steady state cycle used in this study was basically designed by taking the idle mode, corner mode points of the ESC rectangle and one mode point inside the rectangle. The purpose was to cover the speed and load points in the ESC rectangle along with minimizing total fuel consumption per steady state cycle. The mode durations were assigned based on two objectives to meet. First, the total work done by the engine during the entire cycle should be close to the total work done by the engine during a typical FTP cycle. Secondly, mode durations should be long enough to capture significant amount of PM on the PM filter from the dilution tunnel. For calculation purposes in this study, a weight of $1.3 \mathrm{mg}$ of PM on the $70 \mathrm{~mm}$ filter was considered as a significant amount. The gaseous emissions data collection duration was assigned longer than PM data collection duration. The total duration of the steady state cycle was designed for 50 minutes along with 10 seconds of stabilization time in between each mode. Table 4.1 shows the steady state cycle modes points used in this study. The modes are represented in the sequence as it was executed in the cycle.

Table 4.1 : Steady State Cycle Modes and Durations.

\begin{tabular}{|r|r|r|r|r|r|r|r|}
\hline $\begin{array}{c}\text { Cycle } \\
\text { Modes }\end{array}$ & $\begin{array}{c}\text { Reference } \\
\text { ESC } \\
\text { Modes }\end{array}$ & $\begin{array}{c}\text { Speed } \\
\text { (rpm) }\end{array}$ & $\begin{array}{c}\text { Torque } \\
\text { (ft-lb) }\end{array}$ & $\begin{array}{c}\text { Mode } \\
\text { Duration } \\
\text { (sec) }\end{array}$ & $\begin{array}{c}\text { Gas Data } \\
\text { Collection } \\
\text { Duration } \\
\text { (sec) }\end{array}$ & $\begin{array}{c}\text { PM Data } \\
\text { Collection } \\
\text { Duration } \\
\text { (sec) }\end{array}$ & $\begin{array}{c}\text { Stabilization } \\
\text { Time } \\
\text { (sec) }\end{array}$ \\
\hline 1 & idle & 601 & 0 & 1320 & 660 & 650 & 10 \\
\hline 2 & 3 & 1421 & 633 & 300 & 180 & 170 & 10 \\
\hline 3 & 2 & 1199 & 1333 & 240 & 130 & 120 & 10 \\
\hline 4 & 7 & 1199 & 333 & 480 & 360 & 350 & 10 \\
\hline 5 & 10 & 1642 & 1175 & 240 & 130 & 120 & 10 \\
\hline 6 & 11 & 1642 & 294 & 420 & 300 & 290 & 10 \\
\hline
\end{tabular}

\subsection{Test Cycles}

For emission testing on engine dynamometer and chassis dynamometer different test cycles are used, which tries to simulates different near real-world driving conditions. Some of 
the commonly used test cycles for diesel engines on engine dynamometer in the US are Federal Test Procedure (FTP), Supplemental Emissions Test (SET), and Non-road Transient Cycle (NRTC).

For emission certification of on-road heavy-duty diesel engine trucks in the US, the engines are tested on the US FTP transient cycle. Additionally, engine manufacturers, research laboratories also use SET or ESC steady state cycle as a part of certification testing procedure. For this study, the engine was exercised over these two cycles. These cycles are discussed in the following sections.

\subsubsection{The US Federal Test Procedure (FTP)}

The heavy-duty on-road Federal Test Procedure transient cycle was developed to simulate a unified test cycle for variety of buses and trucks running on heavy-duty diesel engines in cities in the US, taking into account of on-road traffic in and around the cities and also expressways. The cycle is based on the EPA Urban Dynamometer Driving Schedule (UDDS) chassis dynamometer driving cycle data.

The FTP cycle is a combination of three different driving cycles, which are repeated one after the other followed by the first cycle again to form a 1200 seconds (or 20 minutes) test cycle. These cycles are New York Non Freeway (NYNF), Los Angeles Non Freeway (LANF) and Los Angeles Freeway (LAFY). The NYNF represents light urban traffic with frequent starts and stops in New York City, LANF is a crowded urban traffic with few stops and LAFY simulates crowded freeway traffic in Los Angeles. The FTP cycle is run in the sequence of NYNF, LANF, LAFY and NYNF. Speed and torque curves in a typical FTP test cycle are shown in Figure 4.1 and Figure 4.2, respectively. The speed and torque data points in the plots are obtained from an actual FTP test, the test number is E02510-02.

In this study, the FTP cycle set points were generated from the percentages of engine speed and torque from the engine mapping data. For emissions testing purposes, the engine was started with the first FTP cycle, which was called 'warm-start,' followed by two or three more FTP cycles, which were called 'hot-starts.' The data from the FTP tests presented in Chapter 5 include only hot-start emissions data. After a FTP test a soak time of 20 minutes was allowed before the next hot-start FTP test. 


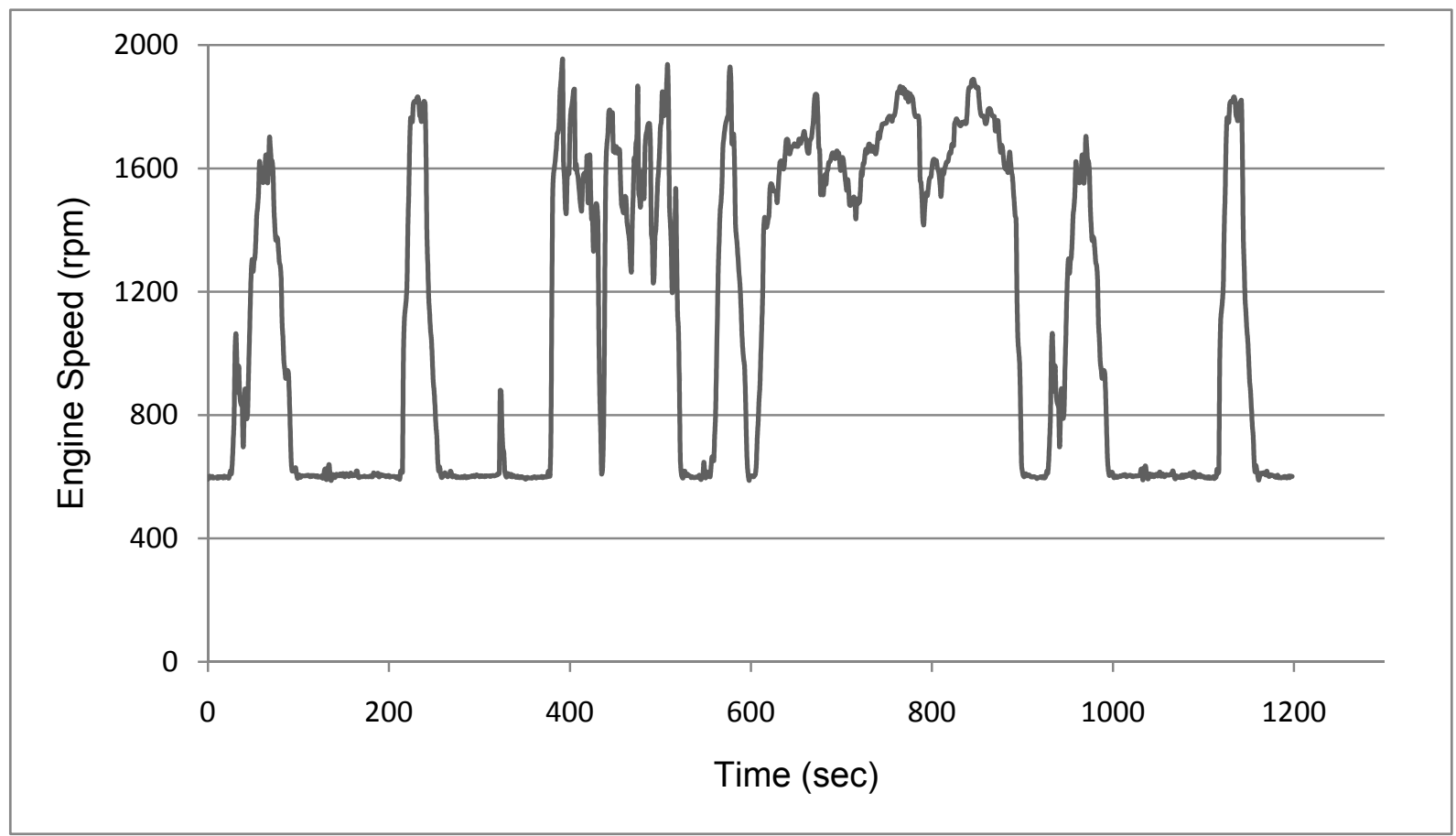

Figure 4.1 : FTP Actual Speed vs. Time Plot on the Test Engine.

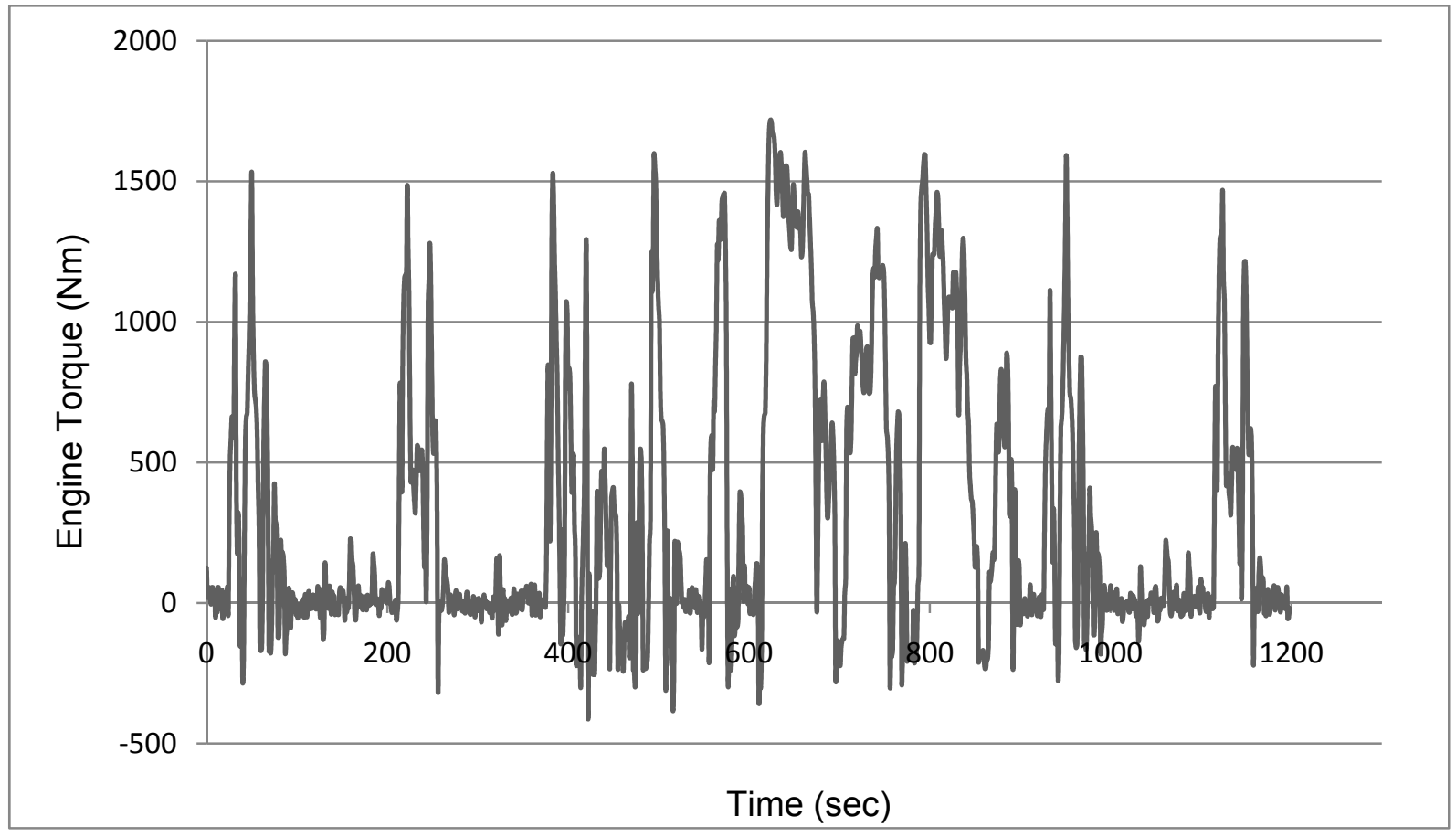

Figure 4.2 : FTP Actual Torque vs. Time Plot on the Test Engine. 


\subsubsection{Supplemental Emissions Test (SET)}

Apart from FTP testing, consent decree engines subjected US EPA 2004 emission standards and model year of 2007 and later are required to show compliance with 13-mode Supplemental Emissions Test (SET). The SET has two versions: a ramped mode cycle (RMC) and a discrete mode cycle (DMC). The discrete mode cycle of SET is US equivalent of European Stationary Cycle (ESC).

The ESC test cycle is a 13 mode cycle, where the modes lie on intersections of three different speed ratings and four percentages of load rating. The modes are pictorially represented in Figure 4.3. Each mode has an assigned weighting factor. The speed points in the figure, $\mathrm{n}_{\mathrm{A}}, \mathrm{n}_{\mathrm{B}}$ and $\mathrm{n}_{\mathrm{C}}$ are calculated by using the following formula.

$$
\begin{aligned}
& n_{A}=n_{l o}+0.25\left(n_{h i}-n_{l o}\right) \\
& n_{B}=n_{l o}+0.50\left(n_{h i}-n_{l o}\right) \\
& n_{C}=n_{l o}+0.75\left(n_{h i}-n_{l o}\right)
\end{aligned}
$$

Where,

$\mathrm{n}_{\mathrm{lo}}=$ the lowest speed that occur when the power is $50 \%$ of the declared maximum net power in the power curve.

$\mathrm{n}_{\mathrm{hi}}=$ The highest speed that occur when the power is $70 \%$ of the declared maximum net power in the power curve. 


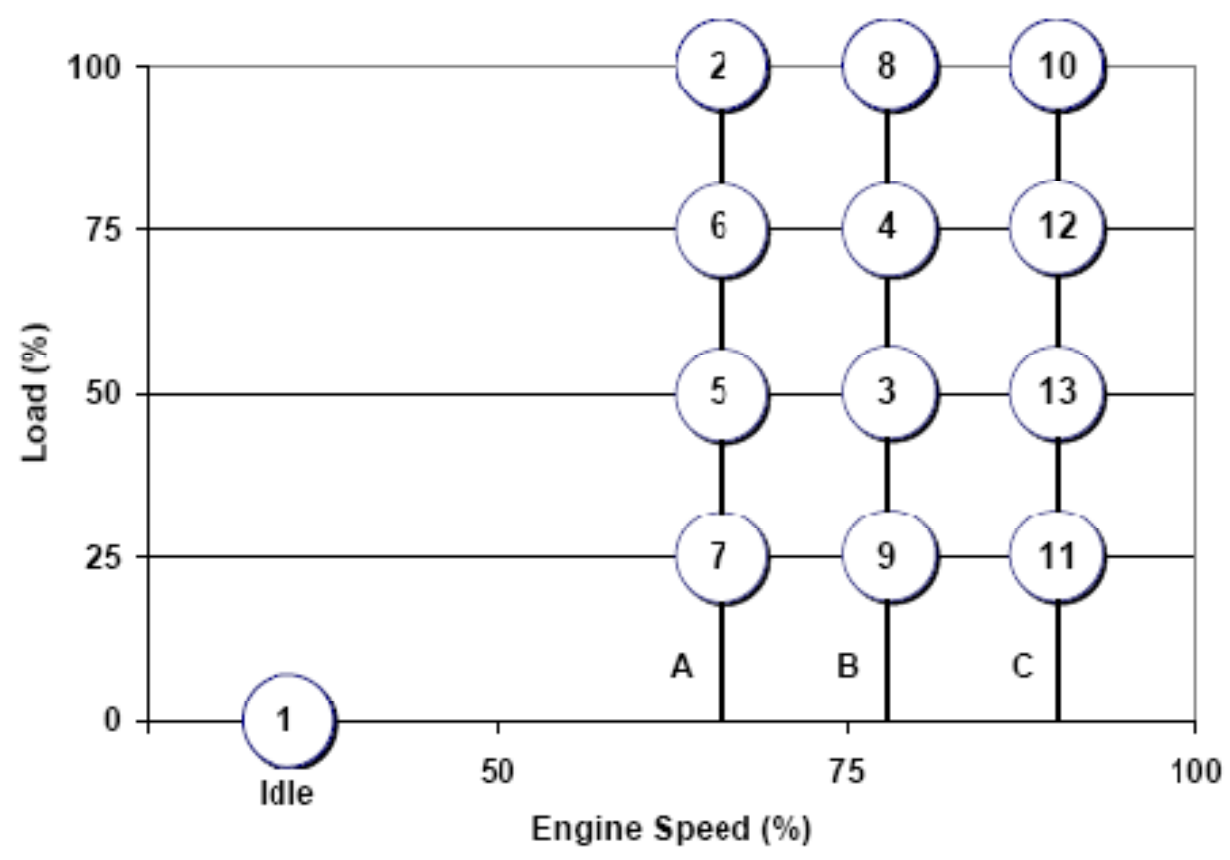

Figure 4.3 : ESC Mode Set Points [42].

The cycle can be run on an engine dynamometer, not necessarily in the sequence as the modes are numbered. As recommended by CFR, the engine should run at the specified speed point within $\pm 50 \mathrm{rpm}$ and the torque point should be held within $\pm 2 \%$ of the maximum torque at that speed. The gaseous emissions data and particulate emissions data are collected towards the end of each mode typically for 60 to 120 seconds, to allow the engine to stabilize speed and torque changes before the data are collected for the mode.

\subsection{Overview of Statistical Tools Used for Data Analysis}

This section provides a brief review on the statistical tools and terms used for interpretation of data and presentation of results in the next chapter.

Coefficient of Variation (COV): COV is a measure of variability in a given data set. It is defined as the ratio of standard deviation of a data set to the mean of the data set. High COV values indicate high variation in the data set.

$$
\operatorname{COV}=\frac{\sigma}{\mu}
$$

Where, $\sigma=$ Standard deviation of the given data set 
and, $\mu=$ Mean of the given data set.

Analysis of Variance (ANOVA): It is a statistical method of comparing means of several data sets to evaluate the null hypothesis $\left(\mathrm{H}_{\mathrm{o}}\right)$, where the null hypothesis is that the means of several data sets are equal. The ANOVA analysis only tests the hypothesis and tells whether the means of the several data sets are different. One-way ANOVA method was used for comparison test data sets in this research study.

Box Plots: Box plots are pictorial representation of five quantities from a given data set. Figure 4.4 represents a sample box plot of brake-specific HC emissions from the second test set. The bottommost line of the box represents first quartile $\mathrm{Q}_{1}$ (median of the data set to the left of the median of the entire data set) of the emission data set and the uppermost line of the box represents the third quartile $\mathrm{Q}_{3}$ (median of the data set to the right of the median of the entire data set). The middle red line in the box represents the median of the whole data set. The extended vertical lines from the top and the bottom of the boxes represent the range of the data sets [43].

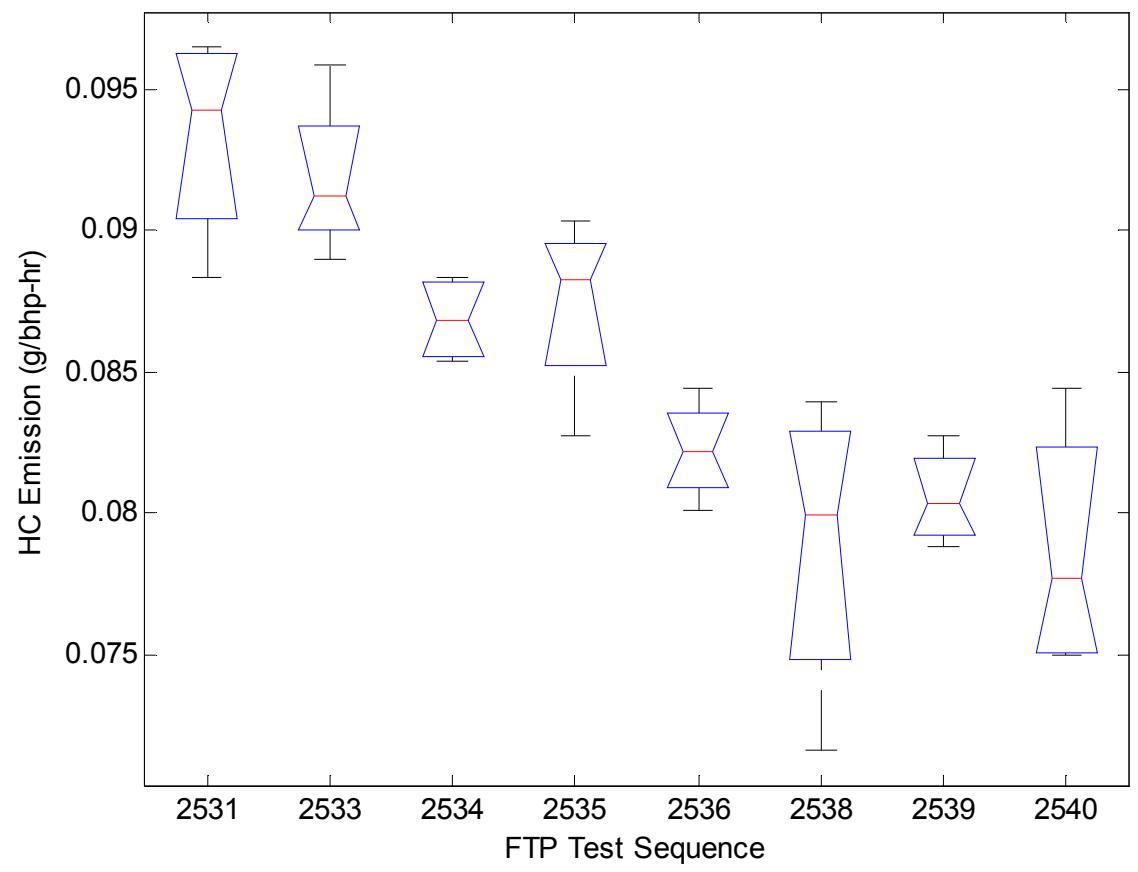

Figure 4.4 : A Representative Box Plot. 
Multiple Comparison Plots: In one-way ANOVA analysis, the means of several data sets are compared to test the null hypothesis that the means are all same against the general alternative that the means are different. However, sometimes the alternative is too general to infer further information from the given data set. One-way ANOVA only test the null hypothesis but does not predict which pair of means from the given data sets is significantly different. To estimate significant change in emissions during oil aging, emissions data from each FTP test groups were compared with baseline test group. A statistical function 'multcompare ( )' available in MATLAB ${ }^{\circledR}$ Statistical Toolbox for multiple comparisons of means from several data sets was used for this purpose. An alpha value of 0.05 , which is a confidence interval of $95 \%$, was used to determine the significance levels. Figure 4.5 shows a representative multiple-comparison plot of brake-specific PM emissions from the first test set. The lines represent mean PM emissions from each test groups. The blue line on the top represents mean PM emission from the baseline test group of the set. The test groups which have significantly different mean than the baseline test group are marked in red, test groups 2522 and 2523 in this example. Other test groups whose means are not significantly different from the baseline test group are marked in gray.

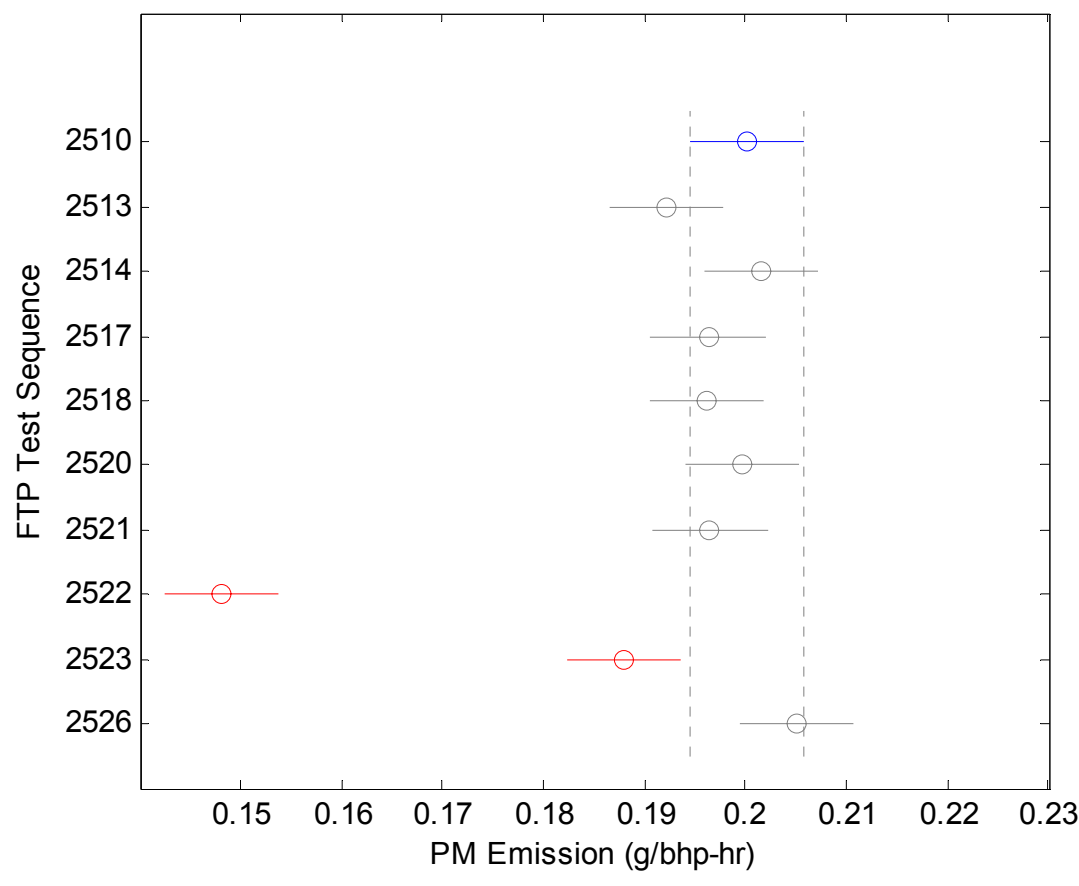

Figure 4.5 : A Representative Multiple-Comparison Plot. 


\section{Chapter 5. RESUlTS AND DISCUSSION}

The observations and results from the research study are discussed in this chapter. The test results are presented in the following order: regulated gaseous emissions results from the transient and steady state tests; particulate matter emission results from transient and steady state tests; results from extraction of soluble organic fractions; and results obtained from analysis of lubricant oil for its physical properties and, particle sizing measurements of the oil samples.

All the related results are presented together in this chapter as far as possible, but the descriptive data, redundant charts and plots are provided in the appendices of this document. In the discussion that follows, FTP and steady state test numbers are called as either test sequences or test groups depending on the context of the discussion, but both effectively means the same. For example, E02510 is a test sequence whereas the same can be called as 2510 test group.

\subsection{Gaseous Emissions}

The four gaseous species collected from the dilution tunnel during the engine testing phase were $\mathrm{CO}, \mathrm{CO}_{2}, \mathrm{NOx}$ and gaseous $\mathrm{HC}$. Emission results of these gaseous species are discussed here. In the case of NOx and HC emissions, the emission measurements were taken using two separate analyzers for each of the species and the analyzers were from different manufacturers, as described in Section 3.4.3. The data from the analyzers were not averaged to obtain a consolidated number for data analysis, to prevent any biases that may occur due differences in make and model of the analyzers. Hence, the data from the Rosemount and Eco

Physics NOx analyzer are referred as NOx (I) and NOx (II), and Horiba and California Analytical Instruments $\mathrm{HC}$ analyzers are referred as HC and Secondary HC abbreviated as 'SecHC,' respectively.

It is important to mention here that each FTP test sequence in both campaign sets generally consisted of three to four hot starts. It is noted that more back-to-back hot starts tends to lower the run-to-run variations in emission measurements by narrowing the spread of normal distribution of the data sets and hence provide a tight standard deviation. However, 
conducting more hot starts FTPs increases cost and time of projects. The three or four hot starts were a trade-off between cost and precision. Moreover, one of the limitations of using statistical tool like ANOVA is that the analysis assumes normally distributed data set. Hence, it is also noted that in this research study, there wasn't significant number of data points in each data sets to claim a normally distributed data set.

Also, the first set of tests (40 hours oil aging time period) included both FTP and steady state tests, so the FTP test sequences weren't run back-to-back; the influence of interspacing transient tests with steady state tests on emissions need to be understood. Additionally, this work assumes 'proper' engine operating conditions with no mechanical malfunctioning, tampering with engine control unit or execution of incorrect test cycles.

The test-to-test data for gaseous and particulate matter emissions obtained from FTP transient tests are provided in Appendix A.2 and the data obtained from steady state tests are provided in Appendix A.3. The FTP and steady state test sequence numbers are tabulated from top to bottom of the tables in the increasing order of cumulative oil aging time. Each FTP test sequence incurred 20 minutes of oil aging and each steady state test sequence accumulated 200 minutes of oil aging time. In the first test set where steady state tests were run in between FTP tests, the test sequence numbers were given according to their order of occurrence. For example, E02511 and E02512 were steady state tests which were conducted after FTP test E02510 but before FTP test E02513.

\subsubsection{Carbon Monoxide Emission}

Figure 5.1 shows run-to-run variations in $\mathrm{CO}$ emission from the FTP test sequences from both the test sets of oil aging. The mean percentage COV was observed approximately around $1 \%$ for both test sets with a maximum of $2.4 \%$ for the first set. These values were within the normal range of 2-3\% run-to-run variations in $\mathrm{CO}$ emission that are typically observed in the laboratory for similar FTP tests. 


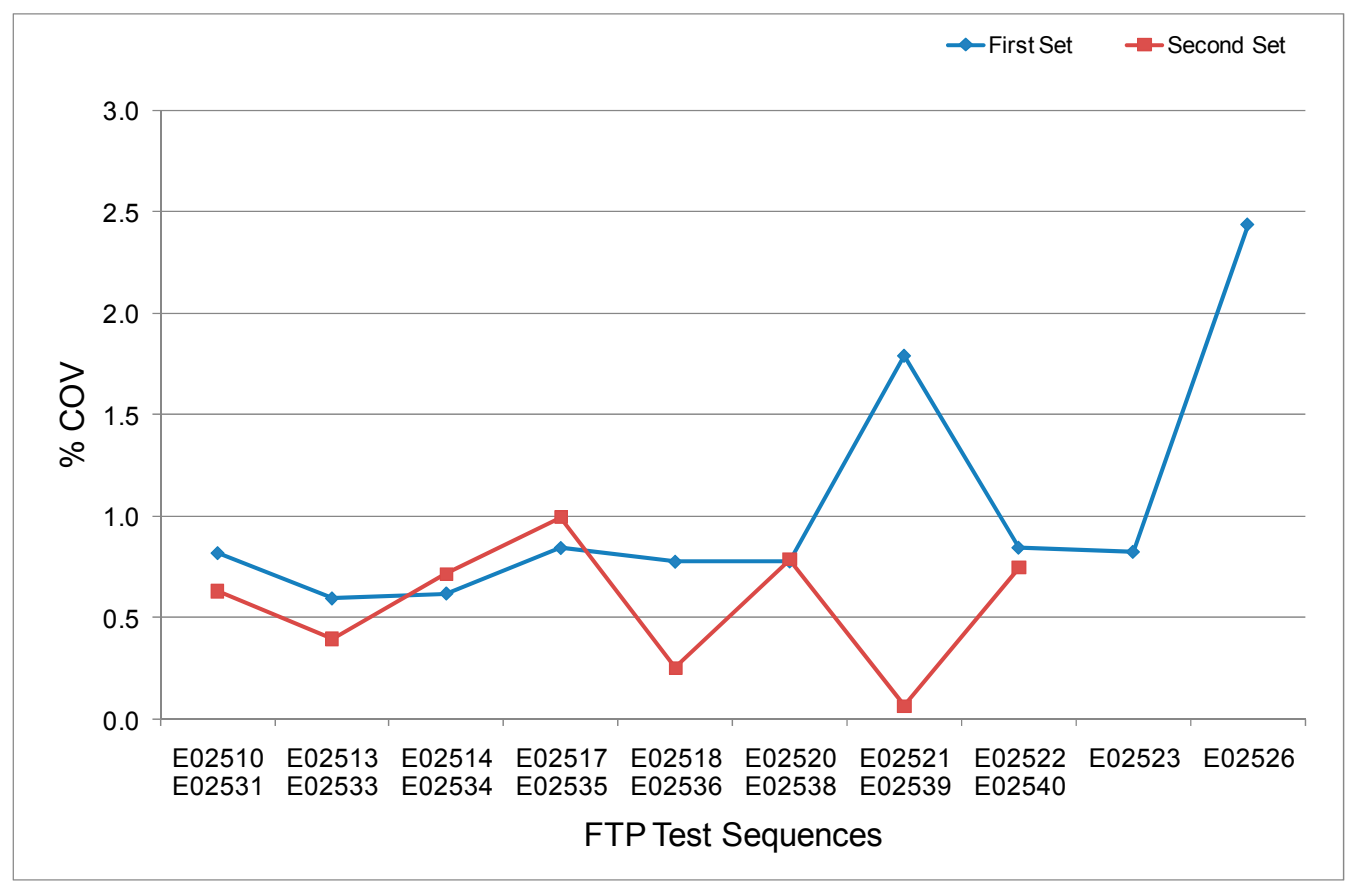

Figure 5.1 : Run-to-Run Variation in BsCO Emission from FTPs.

A box plot of brake-specific CO emissions from the FTP test sequences of the first set is shown in Figure 5.2. The abscissa label indicates the FTP test group numbers from the first set and ordinate shows the brake-specific $\mathrm{CO}$ emission. The meanings of the lines in the box plot and in the multiple-comparison plot are explained in Section 4.4. An ANOVA analysis was conducted between the test groups to find if the test groups were significantly different from the baseline test group 2510. A multiple-comparison analysis between the groups was also performed to find the groups whose means were significantly different from the mean of the baseline group. The ANOVA analysis results are shown in Table 5.1 and the multiplecomparison plot is shown in Figure 5.3. From the plot, it is can be observed that the mean brake-specific $\mathrm{CO}$ emission from test group 2522 was significantly lower than that of baseline test group, whereas test group 2526 showed significantly higher emission compared to the baseline test group. 


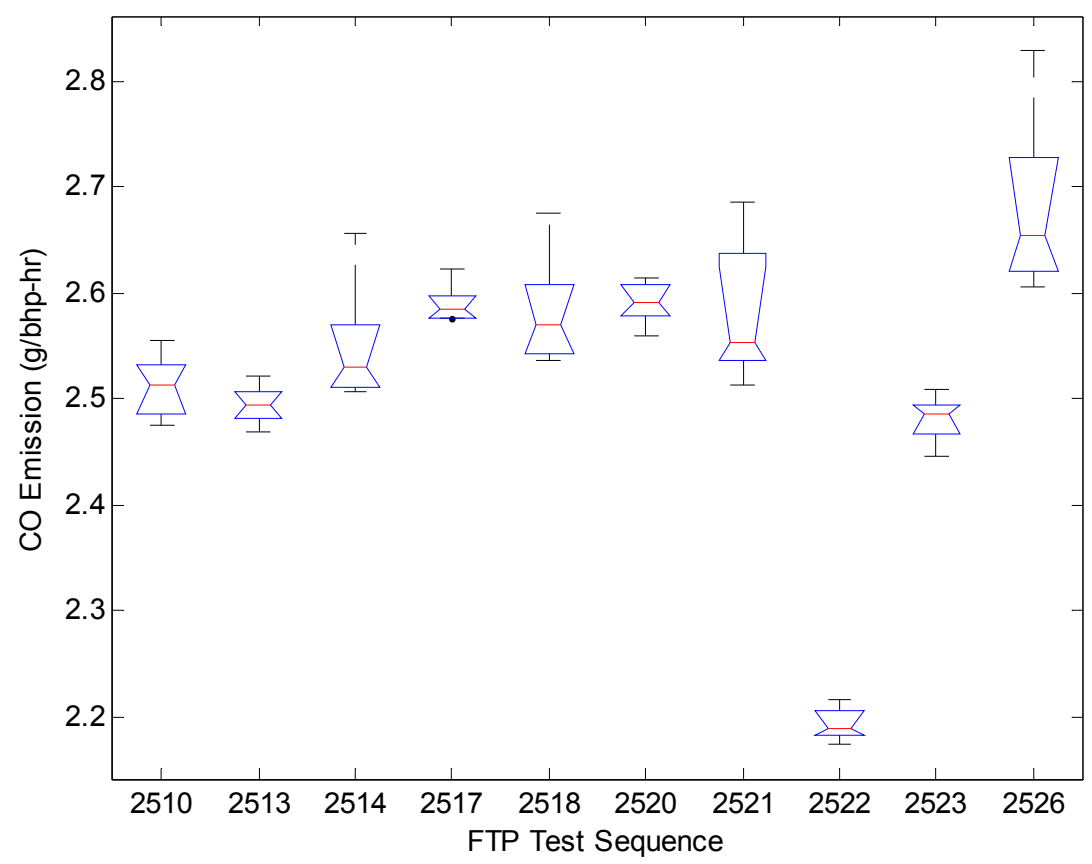

Figure 5.2 : Box Plot of CO Emission from First Set FTP Test Groups.

Table 5.1 : ANOVA Analysis Results of CO Emission from First Set FTP Test Groups.

CO Emission-First Set

Analysis of Variance

Source Sum of Squares df Mean Square

$\mathbf{F}$

Prob $>$ F

Columns

\begin{tabular}{r|r|r}
0.76780898 & 9 & 0.085312109
\end{tabular}

37.7377

1.11E-16

Error

\begin{tabular}{l|l|l|}
0.0904264 & 40 & 0.00226066
\end{tabular}

Total

0.8582353849 


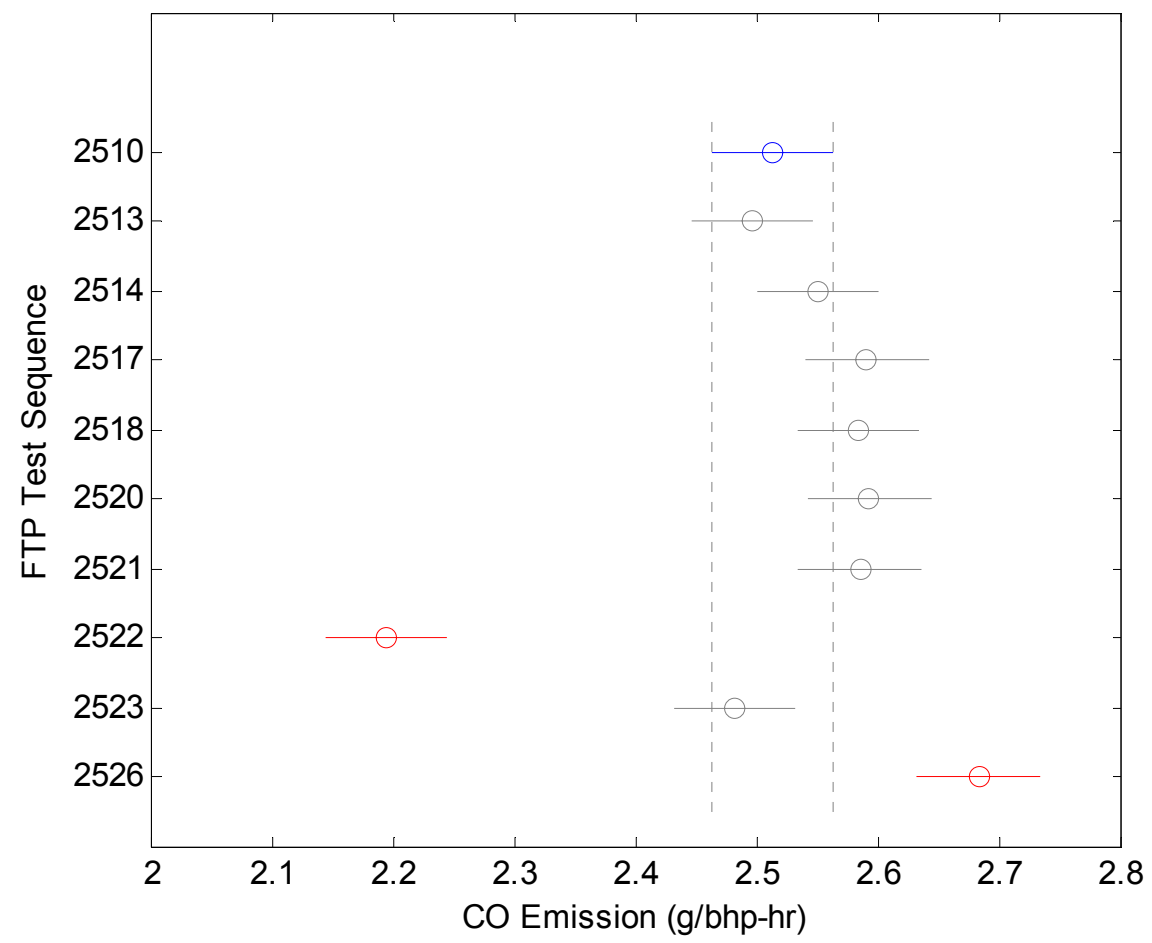

Figure 5.3 : Multiple-Comparison Plot of CO Emission from First Set FTP Test Groups.

In test group 2522, B-20 biodiesel was used as the fuel. The low $\mathrm{CO}$ emission from this test group can be attributed to the usage of biodiesel. This might be because biodiesel had lesser carbon content and more oxygen content than Guttmann test fuel on percentage weightto-weight basis, hence less $\mathrm{CO}$ molecules was produced during combustion. The test group 2526 was run on Guttmann test fuel which was preceded by FTP test sequence E02523, E02524 and E02525, all were run on the test fuel. Test sequences E02524 and E02525 were not part of this research study but the engine run time was included in calculation of cumulative oil aging time. At this point, the cause of high CO emission in test group 2626 cannot be inferred.

Figure 5.4 shows the box plot of $\mathrm{CO}$ emissions from the second set test sequences and Figure 5.5 shows the multiple-comparison between the test groups. The ANOVA analysis results are shown in Table 5.2. It can be observed from the second figure that the emissions from the test groups 2536, 2538, 2539, 2540 had significantly lower means compared to the baseline test group of the second set, 2531. Again, it should be noted here that test group 2536 was run on the test fuel after purging the engine fuel lines entirely with $100 \%$ biodiesel (B- 
100) then again purging with the test fuel, without running the engine, and test group 2538 was run on B-20 biodiesel. Again, it is noted here that the biodiesel contributed to the lower $\mathrm{CO}$ emission. Test group 2539 and 2540 were run on the Guttmann test fuel but the emissions were significantly lower than the baseline test group.

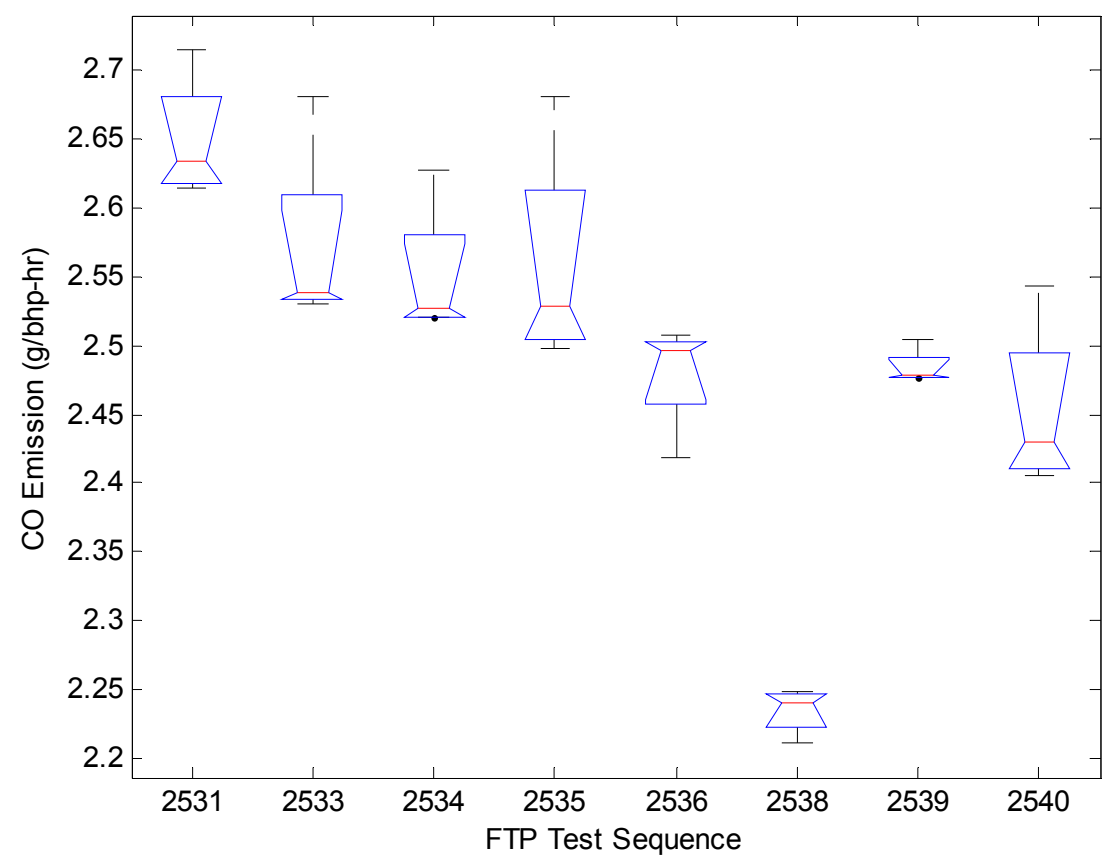

Figure 5.4 : Box Plot of CO Emission from Second Set FTP Test Groups.

Table 5.2 : ANOVA Analysis Results of CO Emission from Second Set FTP Test Groups.

\begin{tabular}{|c|c|c|c|c|c|}
\hline \multicolumn{6}{|c|}{ CO Emission-Second Set } \\
\hline \multicolumn{6}{|c|}{ Analysis of Variance } \\
\hline Source & Sum of Squares & df & Mean Square & $\mathbf{F}$ & Prob $>F$ \\
\hline Columns & 0.426544219 & 7 & 0.060934888 & 20.9281 & 8.99E-09 \\
\hline Error & 0.06987925 & 24 & 0.002911635 & & \\
\hline Total & 0.496423469 & 31 & & & \\
\hline
\end{tabular}




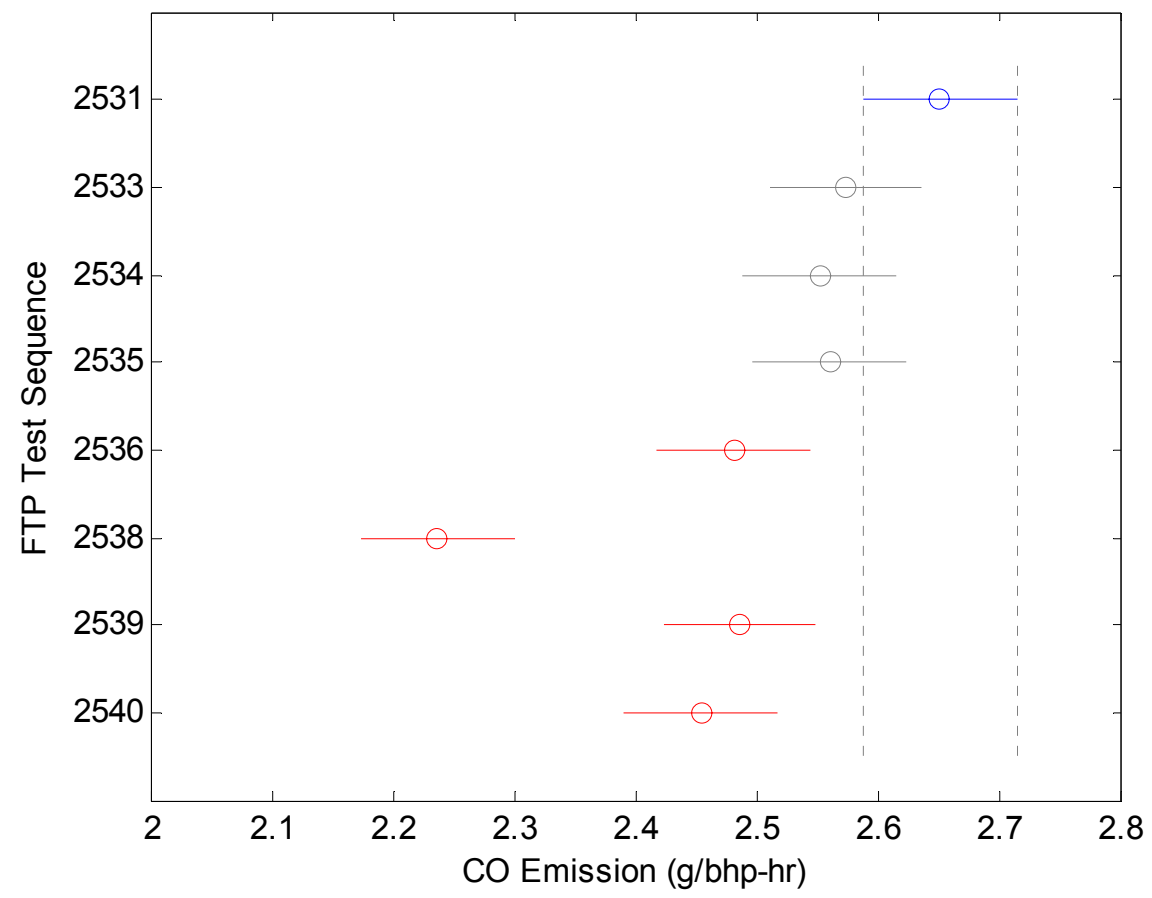

Figure 5.5 : Multiple-Comparison Plot of CO Emission from Second Set FTP Test Groups.

Measurement of emission levels from diesel engines by using a full-flow dilution tunnel method can be affected significantly by various environmental factors like barometric pressure, dilution air humidity, and intake air humidity. These environmental factors were taken into account to study the effect on exhaust emissions based on the results obtained in this work [37]. Section 3.4.7 discusses the measurement methodologies of these quantities.

Appendix B.1 shows the relationship of barometric pressure with exhaust gas emissions and, Appendix B.2 and Appendix B.3 presents the relationship with dilution air humidity and intake air humidity, respectively; these values are averaged data from the test runs in each FTP test sequence. A strong relationship between $\mathrm{CO}$ emission and barometric pressure with coefficient of correlation $\mathrm{r}^{2}=0.7$, was observed, where $\mathrm{CO}$ emission showed inverse linear proportionality with barometric pressure. Whereas, it can be seen that CO emission tended to increase with increase in dilution air humidity but had weak relationship $\left(\mathrm{r}^{2}=0.3\right)$. No definitive relationship can be drawn between $\mathrm{CO}$ emission and intake air humidity. 
Referring to the information in Appendix A.4, for the first set, average dilution air humidity for test sequence E02522 and E02526 were 16.26\% lower and 8.37\% higher than the baseline test sequence, respectively. This partly explains lower CO emission in E02522 test sequence and higher emission in E02526 compared to the baseline. However, average barometric pressure recorded during these test sequences varied $\pm 0.5 \%$ with respect to the baseline. It can be inferred here that dilution air humidity did affect $\mathrm{CO}$ emissions from the FTP tests. This may be due to water interactions with the CO NDIR analyzer and the fact that the 40 CFR Part 86, Subpart N tunnel sampling system does not account for the dilution air humidity. It should be noted that the 2007 and newer engine model year emission regulations, 40 CFR Part 1065, does account for the dilution air humidity.

$\mathrm{CO}$ emissions data from the steady state tests are shown in Figure 5.6 and Figure 5.7. The data are from steady state test sequences E02511, E02512, E02515, E02516 and E02519 from the first set of oil aging tests. The emission data plotted in the figures are averages of the continuous emission data from each mode in the test sequences, averaged over mode time. No attempt was made to average four repetitions of each mode over the 200 minutes of continuous engine run which could cause failure to capture changes in emission within this time bracket. The first steady state test was run after 240 minutes of transient engine operation. Also, test sequence E02515 is preceded by two FTP test sequences and E02519 is preceded by one FTP test sequence, but the aging time, as shown in the abscissa, includes cumulative engine run time. Note that only Modes 2, 3, 7, 10 and 11 are shown, emissions data from the idle mode runs were not taken into account here, because at idle modes the engine did not produce work hence emissions in terms of brake-specific emissions could not be obtained. 


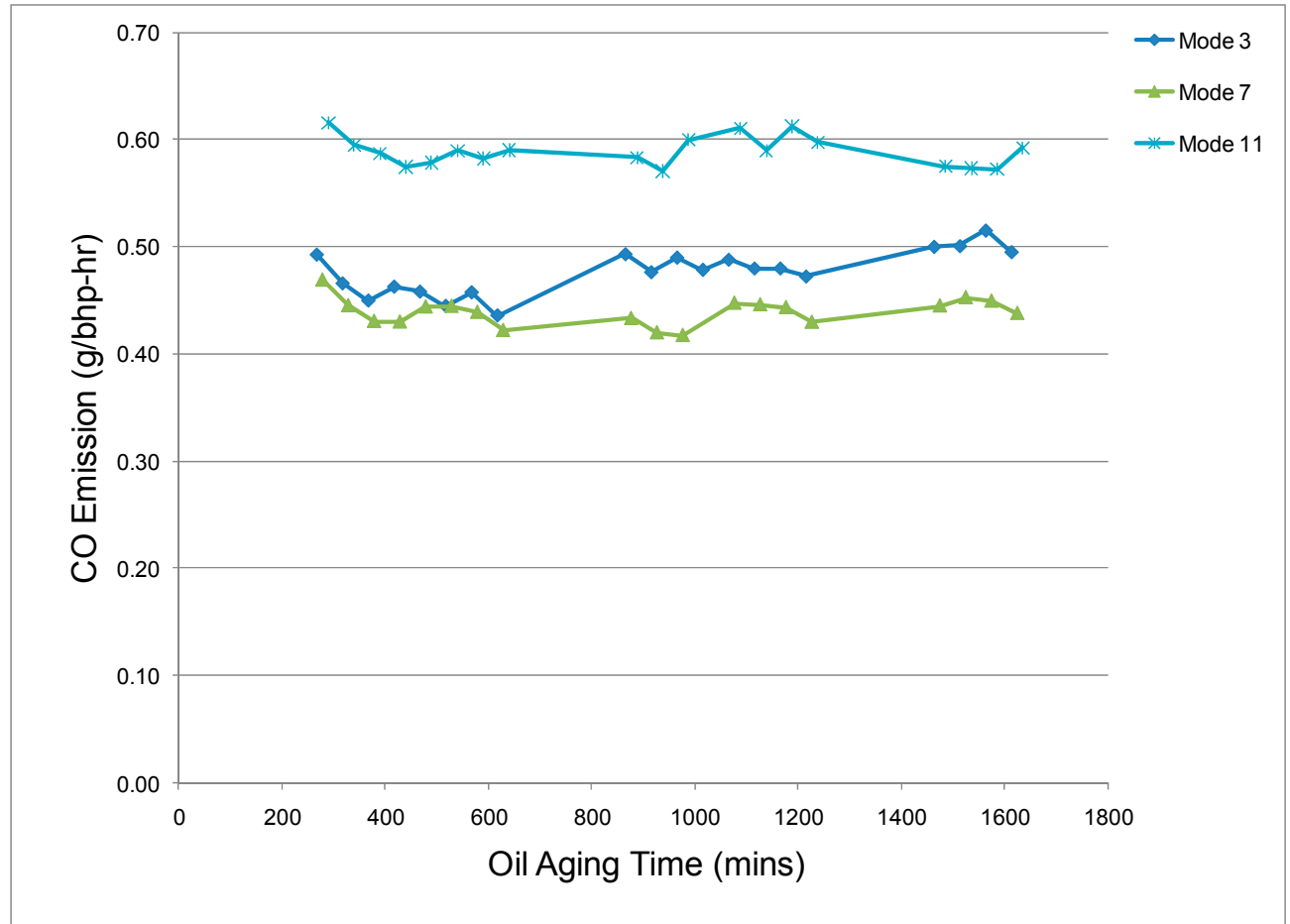

Figure 5.6 : Steady State BsCO Emission Plot-1.

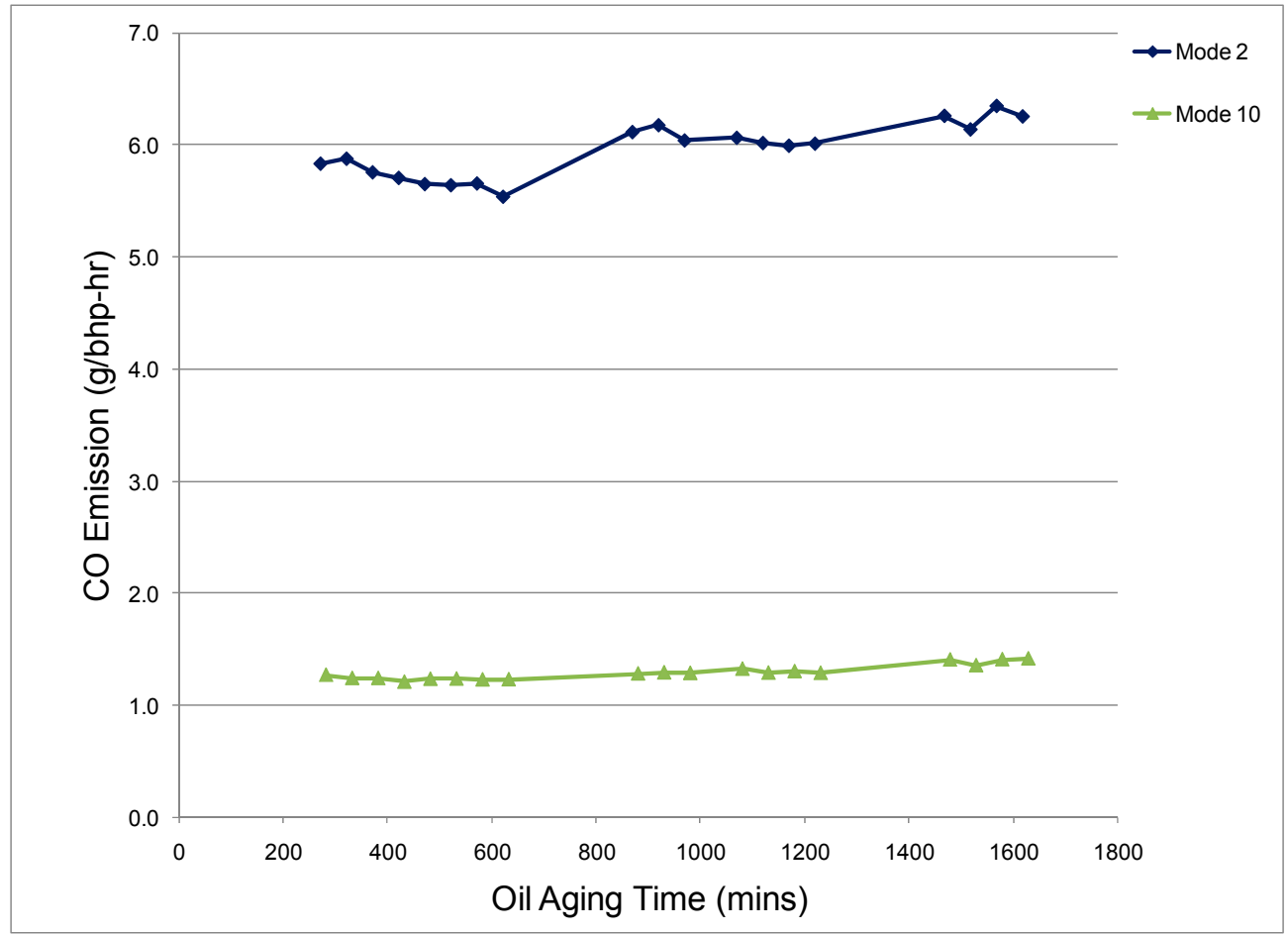

Figure 5.7 : Steady State BsCO Emission Plot-2. 
From the above figures, it can be seen that Mode 2, 100\% load-low speed, showed highest brake-specific $\mathrm{CO}$ emission in the order of $6 \mathrm{~g} / \mathrm{bhp}$-hr as compared to all other modes. Mode 10,100\% load-high speed, resulted in 1 to $1.5 \mathrm{~g} / \mathrm{bhp}-\mathrm{hr} \mathrm{CO}$ emission whereas Mode 3, 7 and 11 showed lower emission in the order of 0.45 to $0.60 \mathrm{~g} / \mathrm{bhp}-\mathrm{hr}$. By examining the steady state test CO emission data in Appendix A.3, it was observed that only in Mode 10 the emission increased up to $12 \%$ with respect to the Mode 10 of the baseline steady state test, in the last test sequence. This can be partly contributed to the rapid aging of oil at this full loadhigh speed engine operating condition. Other modes did not show significant change in CO emission during the oil aging time bracket.

From the above discussion, it can be inferred that no statistically significant change in $\mathrm{CO}$ emission was observed during the given time period that can be attributed to aging of the engine oil.

\subsubsection{Carbon Dioxide Emission}

Run-to-run variations in $\mathrm{CO}_{2}$ emissions from the FTP tests can be seen in Figure B.22 in Appendix B.4. The mean percentage COV was observed around $0.15 \%$ for both the test sets which was within the range of $0.1-0.2 \%$ variation normally observed in the laboratory for similar tests. Figure B.30 and Figure B.31 displays the box plots of $\mathrm{CO}_{2}$ emission data from both the sets and the ANOVA analysis results are presented in Appendix B.8. From the multiple-comparison of $\mathrm{CO}_{2}$ emission data, Figure B.39 and Figure B.40, most of the test groups from both test sets did not show any statistically significant difference in their mean with respect to the baseline FTP. But, test group 2520 in the first set had significantly lower mean than the baseline test group. The reason for this suspected outlier (speaking in reference to the multiple-comparison plot) cannot be determined at this point.

Usage of biodiesel in the test group 2522 in the first set and in the test group 2538 in the second set caused no significant change in $\mathrm{CO}_{2}$ emission. Figure B.2, Figure B.9 and Figure B.16 in Appendix B shows the relationship with barometric pressure, dilution air humidity and intake air humidity, respectively. No relationships can be drawn from the available data on effects of these factors on $\mathrm{CO}_{2}$ emissions.

$\mathrm{CO}_{2}$ emissions data from steady state tests is shown in Figure B.27. Mode 11, high speed-25\% load, showed highest $\mathrm{CO}_{2}$ emission followed by Mode 7, low speed-25\% load. It 
is interesting to note here that Mode 2 and Mode 10, both full load modes showed 16-17\% lower $\mathrm{CO}_{2}$ emissions with respect to the $25 \%$ load modes (owing to higher thermal efficiencies) but showed higher $\mathrm{CO}$ emissions. This may explain a tendency of incomplete combustion of fuel charge at full load modes and complete combustion at lower load modes. Also, no significant change in $\mathrm{CO}_{2}$ emission was observed in all the modes with respect to the baseline modes during the given oil aging time bracket. The highest percentage decrease in $\mathrm{CO}_{2}$ emission was observed in Mode 11 which was little lower than $0.5 \%$. This value may not be significant as $0.1-0.2 \%$ run-to-run variation was incurred in the data. It can be inferred here that there was no statistically significant change observed in $\mathrm{CO}_{2}$ emission during the oil aging time period.

\subsubsection{Oxides of Nitrogen Emission}

NOx emission was also measured during the engine testing phase. The run-to-run variations in NOx emission from FTP tests from both test sets by NOx (I) and NOx (II) analyzers can be seen in Figure B.23 and Figure B.24, respectively. Both analyzers showed a mean variation of $0.5 \%$, with an exception in NOx (II) for the last test sequences in the first test set. From the test QA records it was found that NOx (II) analyzer went out of range in the last test sequence. The run-to-run variation values were close to the normal laboratory variation of $0.5-0.6 \%$. Figure B.32 to Figure B.35 show box plots of NOx emission measured by the two NOx analyzers from both test sets and Figure B.41 to Figure B.44 shows multiplecomparison of the same test sets. The ANOVA analysis results for NOx emission data can be seen in Appendix B.8.

From the multiple-comparison plots for the first set, NOx (I) did not show any test groups which had significantly different mean from the mean of the baseline test group whereas NOx (II) analyzer data showed four test groups with significantly higher means. Additionally, no definitive relationships were observed between NOx emission with barometric pressure and dilution air humidity from the available data. It is understood that intake air humidity does affect NOx emission as higher intake air humidity tends to lower the combustion temperature which in turn results in lower NOx emissions [44]. However, a correction factor was applied to the reported NOx values as specified in the 40 CFR Part 86 . NOx (II) emission showed a trend of inverse linearity with intake air humidity, Figure B.18, 
but NOx (I) emission showed relatively weak relationship $\left(r^{2}=0.07\right)$, Figure B.17. This observation was limited by the data points obtained from a limited number of FTP tests which otherwise could have furnished a strong relationship with intake air humidity for both the analyzers.

The results from the steady state tests are shown in Figure B.28 and Figure B.29. The 25\% load modes, Modes 7 and 11, showed almost double the NOx emissions as compared to 100\% load modes, Mode 2 and 10. Mode 3, 50\% load-medium speed, showed approximately $20 \%$ lower NOx emission compared to $25 \%$ load modes. From the steady state test emissions data in Appendix A.3, it was calculated that Mode 7 and Mode 11 showed 0.8-1\% increase in NOx emission whereas Mode 2 and Mode 10 showed up to $1 \%$ decrease in $\mathrm{NO}_{\mathrm{X}}$ emission in the steady state test sequences. It is noted here that the increase in NOx between the FTP and steady state tests was due to a change in ignition strategy implementation in the engine control unit. However, no statistically significant change in NOx emission was observed during the given oil aging time period.

\subsubsection{Gaseous Hydrocarbon Emission}

Emission data from the Horiba $\mathrm{HC}$ analyzers, represented as $\mathrm{HC}$ emission, was not included in the first test set emission results as the analyzer read considerably higher emission values as compared to California Analytical Instruments analyzer, SecHC, due to unknown reasons. The mean run-to-run variation in hydrocarbon emissions was observed to be approximately 4-5\%, Figure B.25 and Figure B.26, for both the test sets, which is within the normal laboratory variation for similar FTP tests.

The box plots of $\mathrm{HC}$ and SecHC emissions from both test sets are shown in Figure B.36 to Figure B.38, and the ANOVA analysis results are provided in Appendix B.8. Figure B.45 to Figure B.47 shows the multiple-comparison analysis between the test groups in both the test sets. Test group 2522 had only significantly lower mean than the baseline test group in the first set, which can be attributed to lower gaseous $\mathrm{HC}$ emission due to usage of biodiesel in the test group. Whereas in the second set, $\mathrm{HC}$ emissions showed that the last four test groups 2536, 2528, 2539 and 2540 had significantly lower mean than the baseline test group and the SecHC emissions also showed test group 2535 with significantly lower mean along with these four test groups. It was mentioned earlier, test sequence E02536 was ran on the test 
fuel after B-100 purging and E02538 was ran on B-20 biodiesel. Lower gaseous HC emission in these two test groups may be contributed by interaction and usage of biodiesel at this point.

Gaseous $\mathrm{HC}$ emission showed a strong correlation, $\left(\mathrm{r}^{2}=0.94\right)$ for $\mathrm{HC}$ analyzer and $\left(r^{2}=0.54\right)$ for SecHC analyzer, with barometric pressure, Figure B.5 and Figure B.6. There was a tendency of decrease in gaseous $\mathrm{HC}$ emission with increase in barometric pressure. From the SecHC data, it can be calculated that approximately $2 \%$ increase in barometric pressure showed approximately 19\% decrease in gaseous $\mathrm{HC}$ emission. But, gaseous $\mathrm{HC}$ emission showed direct linear proportionality with dilution air humidity, though a strong correlation coefficient could not be obtained from the test data, Figure B.12 and Figure B.13. From the averaged humidity and barometric pressure information for the FTP tests in Appendix A.4, in test sequence E02535 in the second set, no significant change in barometric pressure was observed but considerable drop in dilution air humidity was observed. For test sequences E02535, E02536, E02538, E02539 and E02540, a drop in dilution air humidity was observed in the range of $20 \%, 15 \%, 25 \%, 32 \%$ and $33 \%$ respectively. Drop in dilution air humidity in these test sequences might have caused a drop in gaseous $\mathrm{HC}$ emissions. It cannot be inferred in this scenario whether the significant decrease in gaseous HC emission was because of biodiesel interaction, drop in dilution air humidity, or due to aging of oil.

It is important to note here that the second test set of oil aging tests were run during the month of December 2008 when the day-to-day change in weather conditions in Morgantown, WV were considerably large. No outside laboratory ambient variables like temperature, relative humidity, snow or rain fall data were recorded during the tests. Though the environmental conditions inside the laboratory was controlled by a HVAC system, effects of drastic changes in outside environmental conditions on the laboratory ambient conditions was not accounted in this research study. The exact causes of drop in dilution air humidity in the second set cannot be explained at this point but changes in outside laboratory ambient conditions might be suspected. Also note that a relatively simple wet-bulb/dry-bulb device was used to record the dilution air humidity level and any problems with the wet bulb wick (wick becomes crusted with elements or becomes dirt) would influence this measurement; however, no known problems existed and the problems listed above generally results in an apparent high relative humidity reading instead of a low reading. 
Steady state test emission data for gaseous HC emission is not discussed here, as the data from the Horiba HC analyzer, the only analyzer used for steady state tests was suspected to be erroneous because of unknown reasons.

\subsection{Particulate Matter Emissions}

Measurement of particulate matter emission during engine testing was one of the focus areas of this research study. Apart from measurement of total gravimetric particulate matter emissions from FTP transient and steady state tests; a DMS500 for determination of PM number emissions or number concentration levels; and three cyclone separators for PM sizes $\mathrm{PM}_{1}, \mathrm{PM}_{2.5}, \mathrm{PM}_{10}$ were also used. The discussion in this section begins with the results of mass-based or gravimetric PM emissions, followed by results from the DMS500 on numberbased PM emission, and then the results from the PM cyclone separators are discussed.

\subsubsection{Gravimetric Particulate Matter Emission}

The results discussed here are based on the data from gravimetric analysis of the filter media used for collection of particulate matter emission. Mass-based particulate matter emission is referred as TPM or PM emission.

The mean run-to-run variation in TPM emissions was observed around $1.5 \%$ for both test sets, Figure 5.8, which was within the normal laboratory variation of 3-5\% for similar type of tests. Box plots of TPM emission data are shown in Figure 5.9 and Figure 5.10. Lower emissions can be seen for biodiesel run test group 2522 and 2538. The PM emissions in these test groups were $20-25 \%$ lower than the emission from the baseline test group which was ran on Guttmann number 2 diesel. Other test groups showed a mean decrease of 5\% in PM emissions with respect to the baseline group.

The ANOVA analysis results on TPM emission are presented in Appendix B.8. Multiple-comparison between different test group emissions in the first set, Figure 5.11, showed test groups 2522 and 2523 had significantly lower mean emission than that of the baseline test group. In the second set, Figure 5.12, test group 2538 showed significantly lower mean emission from baseline test group of the set. Lower TPM emission in test groups 2522 and 2538 is attributed to the usage of biodiesel. Relationships of TPM emission with barometric pressure, dilution air humidity and intake air humidity can be seen in Figure B.7, 
Figure B.14 and Figure B.21 in Appendix B, respectively. An inverse linear proportionality was observed between TPM emission and barometric pressure whereas intake air humidity showed direct linear proportionality with TPM emission. No definitive relationship could be drawn with dilution air humidity. From the available data, the impact of barometric pressure and intake air humidity on test group 2523 could not be determined. Hence the cause of significantly lower emission in this test group is not known.

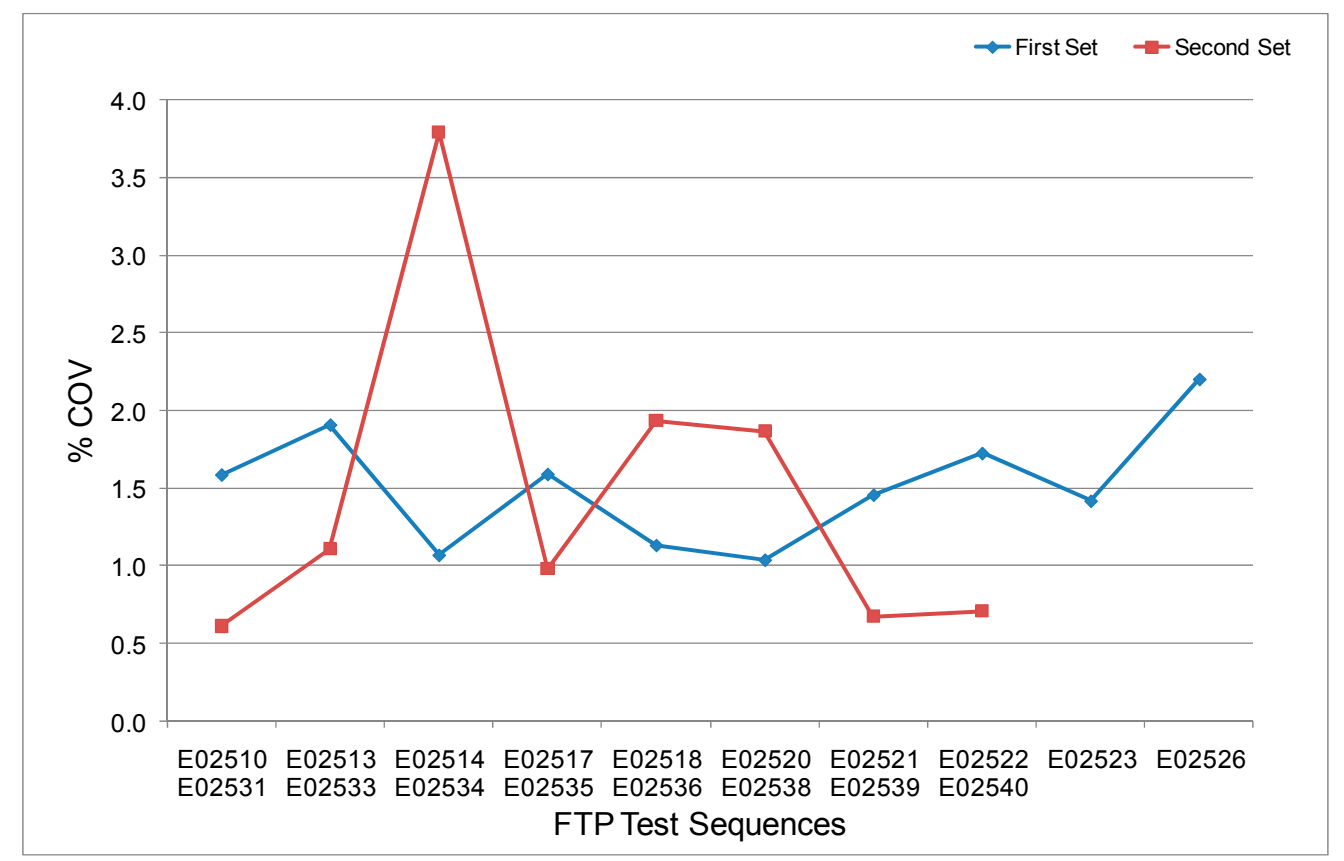

Figure 5.8 : Run-to-Run Variation in BsPM Emission from FTPs. 


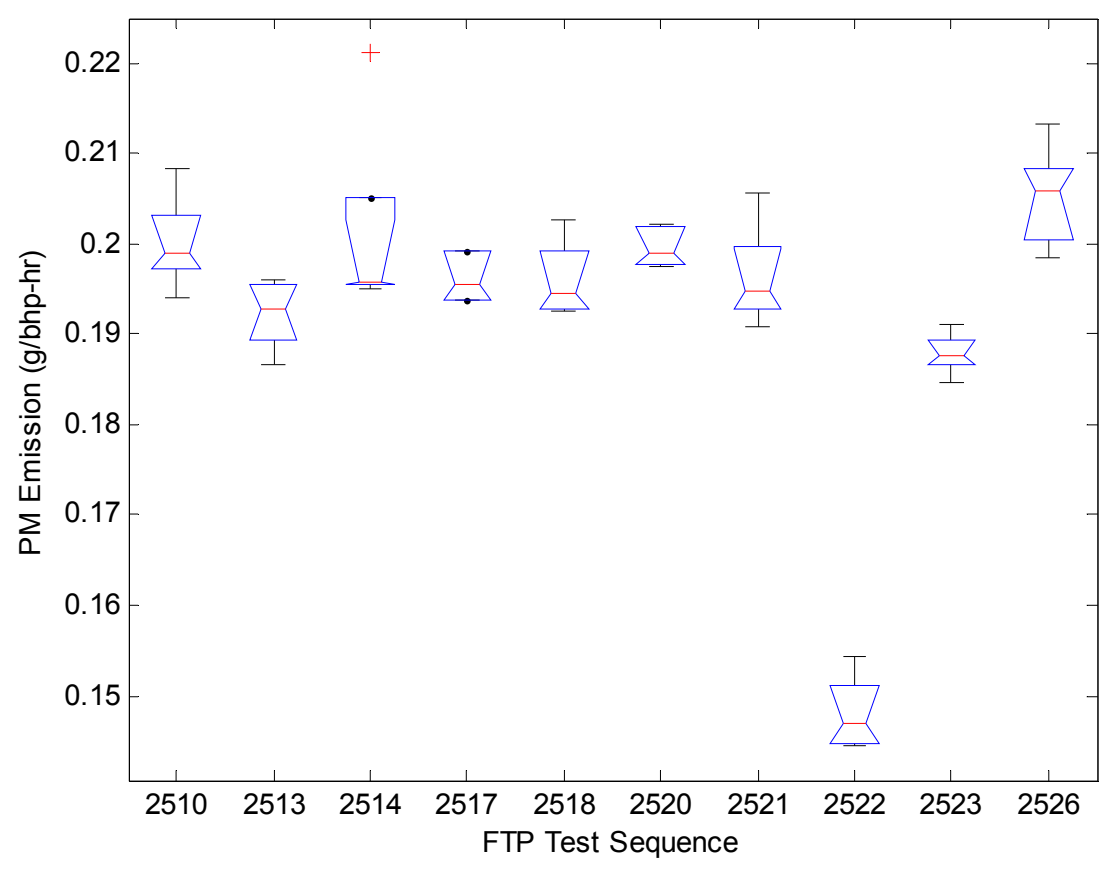

Figure 5.9 : Box Plot of PM Emission from First Set FTP Test Groups.

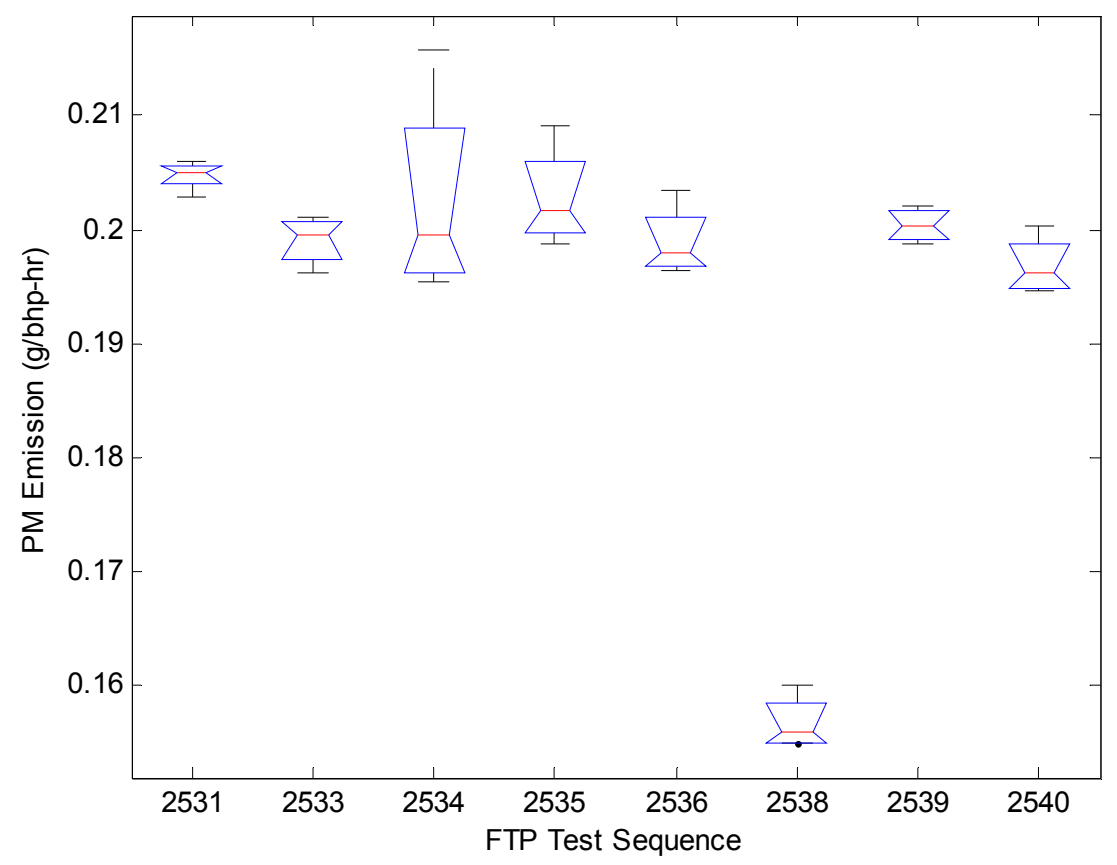

Figure 5.10 : Box Plot of PM Emission from Second Set FTP Test Groups. 


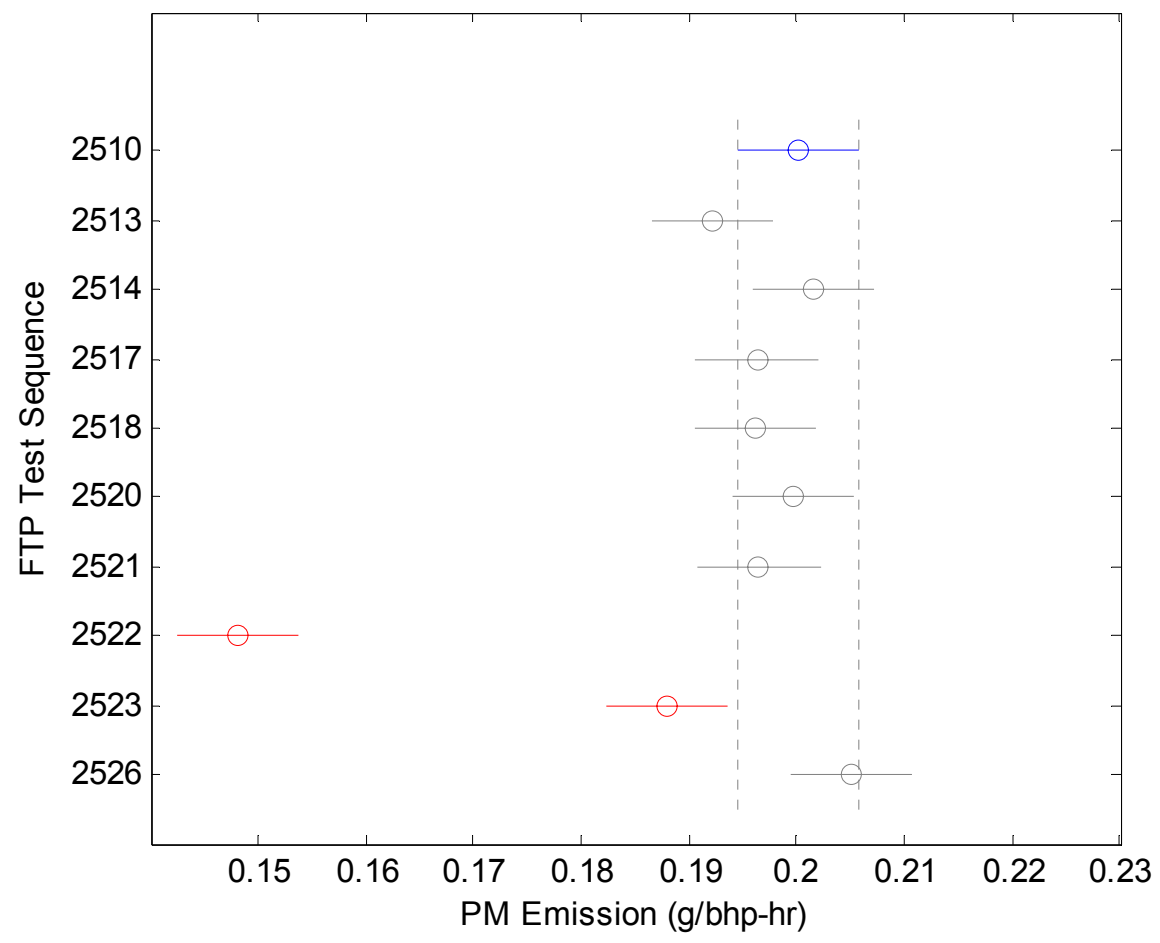

Figure 5.11 : Multiple-Comparison Plot of TPM Emission from First Set FTP Test Groups.

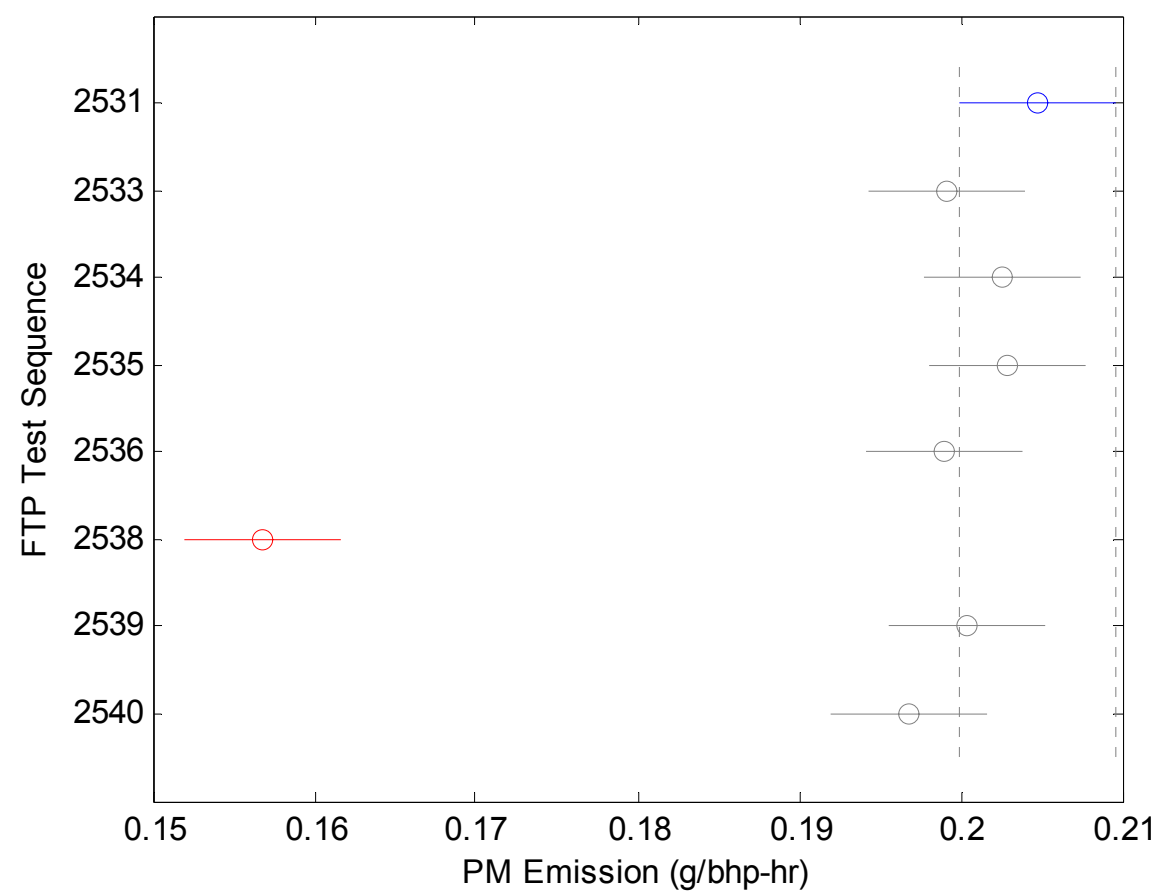

Figure 5.12 : Multiple-Comparison Plot of TPM Emission from Second Set FTP Test Groups. 
Figure 5.13 shows brake-specific TPM emission observed at different steady state modes. Mode 2, low speed-100\% load, showed the highest PM emissions in the order of 0.20 to $0.25 \mathrm{~g} / \mathrm{bhp}-\mathrm{hr}$ which was approximately four times higher than PM emission from the $25 \%$ load modes. Mode 10, high speed-100\% load, showed lower PM emission than Mode 2 but approximately two times higher than the $25 \%$ load modes emissions. It was discussed earlier that the $100 \%$ load modes produced higher CO emission than $25 \%$ load modes. This clearly explains occurrence of incomplete combustion of the charge inside the combustion chambers at $100 \%$ load modes. Examining the steady state test data in Appendix A.3, it was observed that Mode 10 showed gradual decreases in PM emission in the order of 20 to $25 \%$ with respect to the baseline steady state test group, 2511, over the aging time bracket.

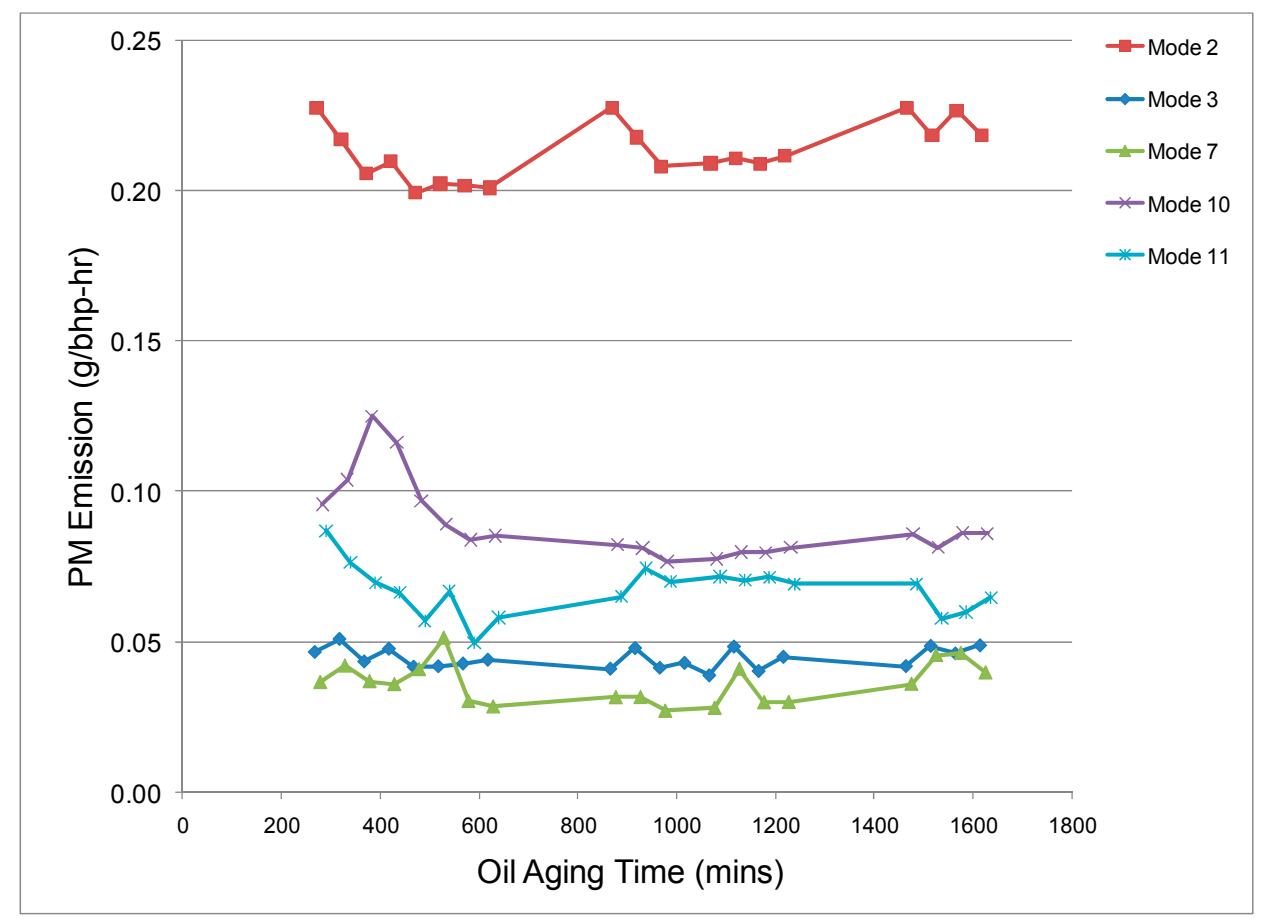

Figure 5.13 : Steady State PM Emissions.

From the above discussion, it can be inferred that no statistically significant change in gravimetric total PM emission was observed during 2500 minutes time period of oil aging. An average of 5\% decrease was observed in FTP tests during the given engine run time, but this value may not be significant as 1.5 to $2 \%$ run-to-run variation was incurred in measurement of the PM emissions. 


\subsubsection{Number-Based Particulate Matter Emission}

The number concentration level of particulate matter emission was collected by the DMS500 for both FTP and steady state tests. It was mentioned in the discussion of DMS500 in Chapter 3, proper cleaning the instrument after every FTP tests was vital for collecting quality data from the next test and the process was to be carried out carefully without damaging the fine precision components inside the instrument. Hence, in case of FTP tests, the data presented here were collected from every alternate hot start FTP tests. Each steady state tests were 50 minutes long and a test sequences consisted of four 50 minutes run, hence, were 200 minutes long. To ensure measurement of quality data during this long time period, data were collected for every alternate 50 minutes steady state engine run. Additionally, particle number concentration data were collected for half the mode time at each mode, towards the end of the modes, to prevent excessive deposition of particles on the classifier rings during each 50 minutes steady state test. So, the data presented here for steady state tests includes only particle number concentration levels from half the mode time. No attempt was made to double the particle concentration value for each mode to reflect total concentration values over the entire mode time.

For the purpose of maintaining quality in data analysis, the particle number concentration data from the DMS500 for all FTP tests, were time aligned with reference to the peak speed of each FTP test cycles. This was done by taking the time at which the peak speed occur in the first baseline FTP test (Test Sequence E02510-02 for the first test set and E02531-02 for the second test set) as the reference time. Then the data from other FTP tests were arranged in such a way that the time at which the peak speeds of these FTP test cycles occur get aligned with the reference time of their respective test sets. The end result of this alignment would produce a particle number concentration data set where each tests of the data set would have super-imposable speed versus time plots with some extraneous data outside the 20 minutes time bracket of a FTP test. These extraneous data were not considered for analysis here. This was done to prevent incurring residual PM particle concentration levels in the sample line, immediately before beginning of a FTP test cycle and immediately after completion of the test cycle, in data analysis. Secondly, all number concentration data were filtered to eliminate background noise. Particle number concentration levels below or equal to the order of magnitude $10^{04}$ particles per cubic centimeter of the sample was considered as 
noise. It should be noted here that noise level was observed higher at the smaller particle diameter ranges than larger particle diameter ranges, particularly in the nanoparticle ranges.

To capture the changes in different sizes of PM particles, the particle number concentration data obtained from the DMS500 was classified into three separate size bins; particles with particle diameter less the $50 \mathrm{~nm}$ (represented as $50 \mathrm{~nm}$ Bin), particles with particle diameter greater than or equal to $50 \mathrm{~nm}$ but less than or equal to $100 \mathrm{~nm}$ (represented as $100 \mathrm{~nm} \mathrm{Bin),} \mathrm{and} \mathrm{particles} \mathrm{with} \mathrm{particle} \mathrm{diameter} \mathrm{greater} \mathrm{than} 100 \mathrm{~nm}$ but less than or equal to $1000 \mathrm{~nm}$ (represented as $1000 \mathrm{~nm}$ Bin). This classification of particles was done based on general classification of diesel particulate matter available in literature [41], into nanoparticles, ultrafine particles, and fine particles corresponding to the respective particle size bins mentioned before.

For analysis of number-based particulate matter emission data from the FTP tests, the test cycle was further broken into its four unit phases; New York Non Freeway (NYNF), Los Angeles Non Freeway (LANF), Los Angeles Freeway (LAFY) routes. These routes are discussed earlier in Section 4.3.1. This facilitated observation of number based particulate matter emission during the different types of test routes.

Figure 5.14 and Figure 5.15 shows averaged number concentration of the $50 \mathrm{~nm}$ Bin particles from both test sets. In the first set, LAFY and LANF routes produced higher number concentration of particles compared to the first and second NYNF routes throughout the entire 2500 minutes of engine run. No significant change in the order of magnitude of number concentration levels was observed in the first set. In the second set, LAFY and LANF routes again showed high concentration levels in the $50 \mathrm{~nm}$ Bin particles. Second set data showed increase in the concentration level by an order of magnitude only in LANF route. This observation could not be verified using the data obtained from the first test set because of unavailability of FTP test data points during the 120 to 800 minutes time bracket. It should be recalled here that steady state test were run during this time bracket in the first test set. 


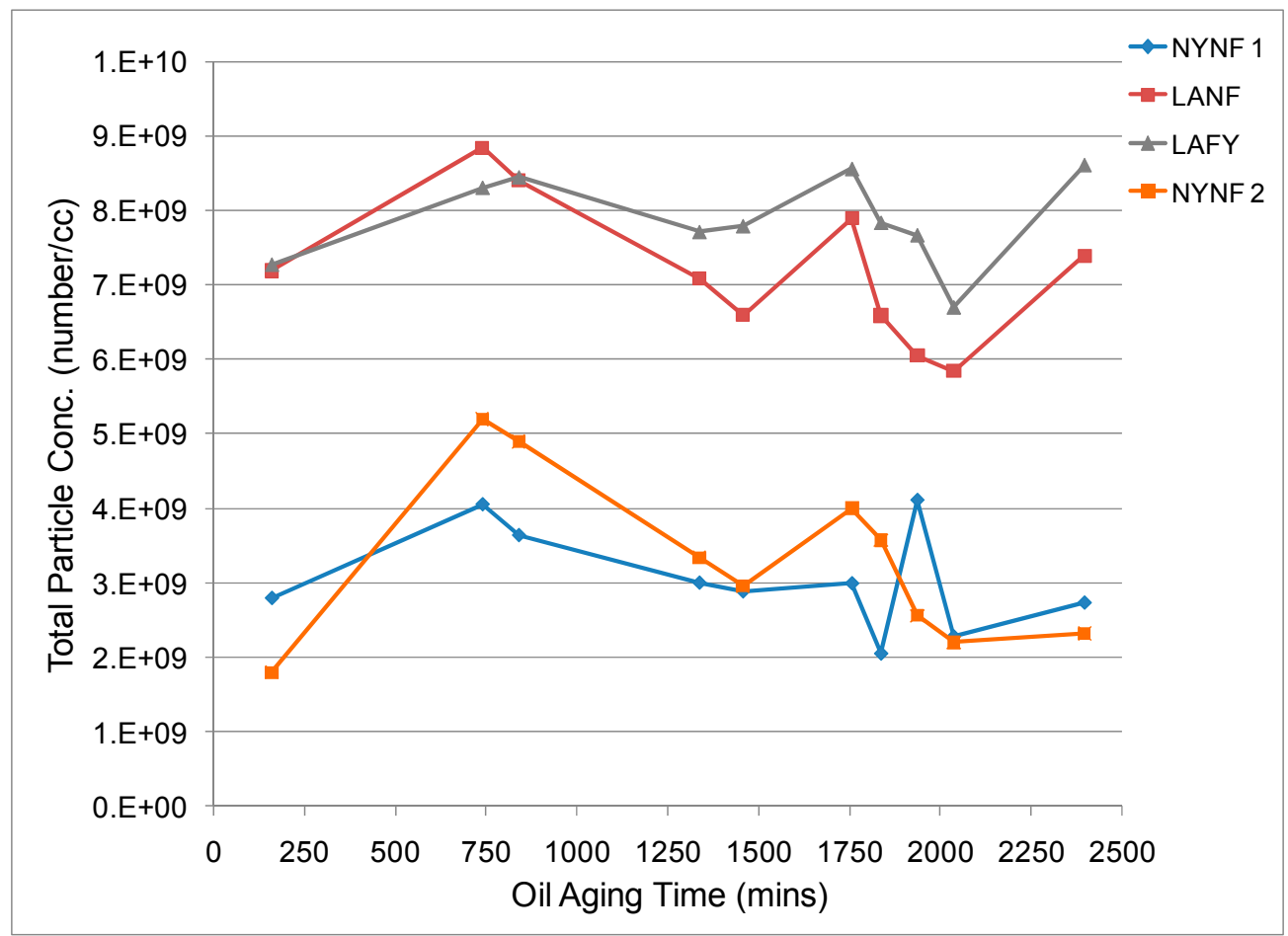

Figure 5.14 : Particle Concentration in $50 \mathrm{~nm}$ Bin-First Set FTPs.

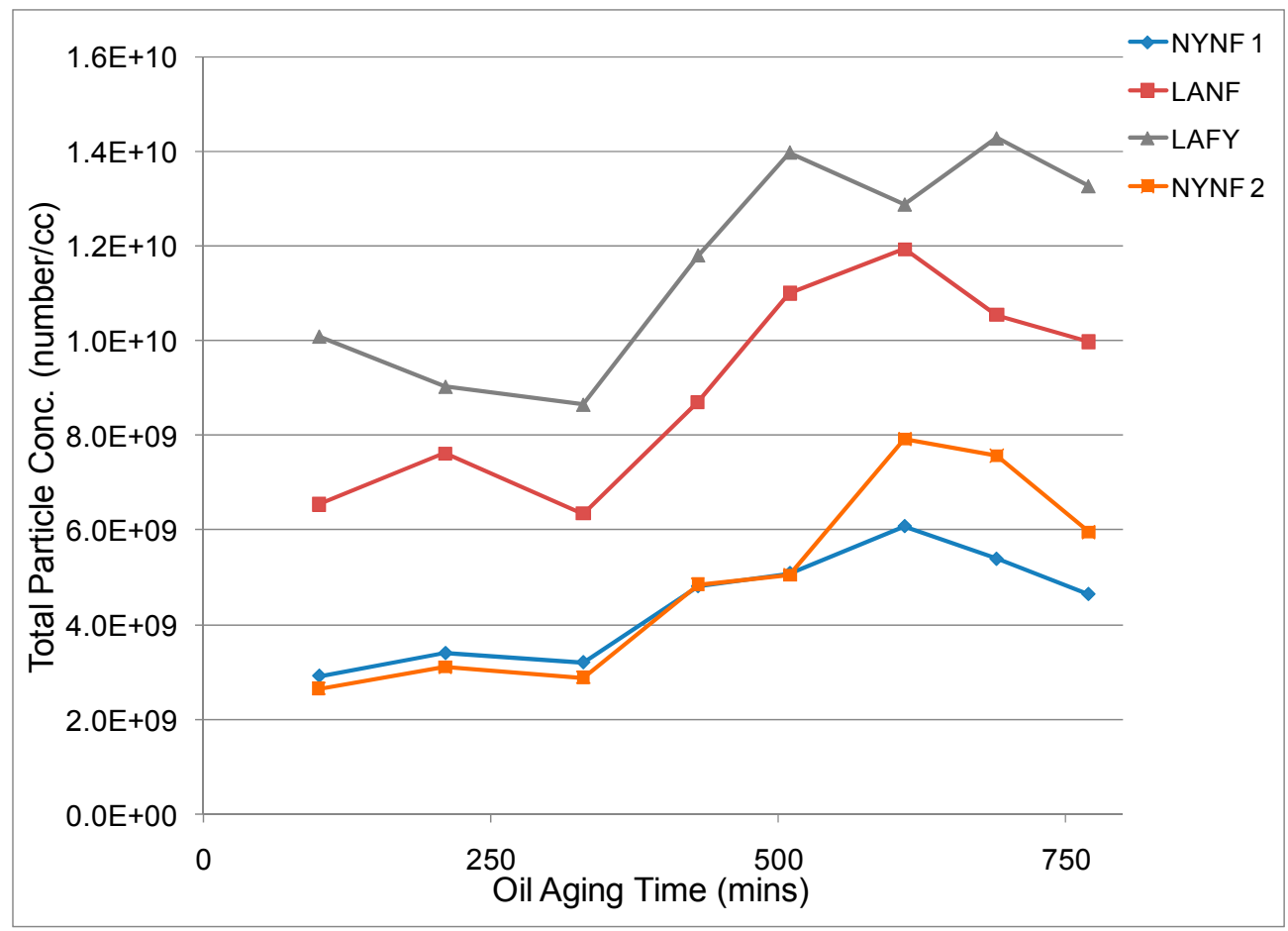

Figure 5.15 : Particle Concentration in $50 \mathrm{~nm}$ Bin-Second Set FTPs. 
Figure 5.16 and Figure 5.17 shows averaged particle number concentration levels in the $100 \mathrm{~nm}$ Bin from the first and the second test sets, respectively. Again, in this particle size bin, both the test sets showed higher concentration levels from LAFY and LANF routes compared to NYNF routes. Also, from Figure 5.16, it can be seen that particle number concentration levels from the two NYNF routes were super-imposable. The sudden decrease (10-12\% drop) in particle concentration level in LAFY route, around 2000 minutes in the first set was attributed to FTP test sequence E02522, where the fuel used was B-20 biodiesel. No significant change in order of magnitude in particle number concentration levels were observed during the oil aging time period from both the test sets.

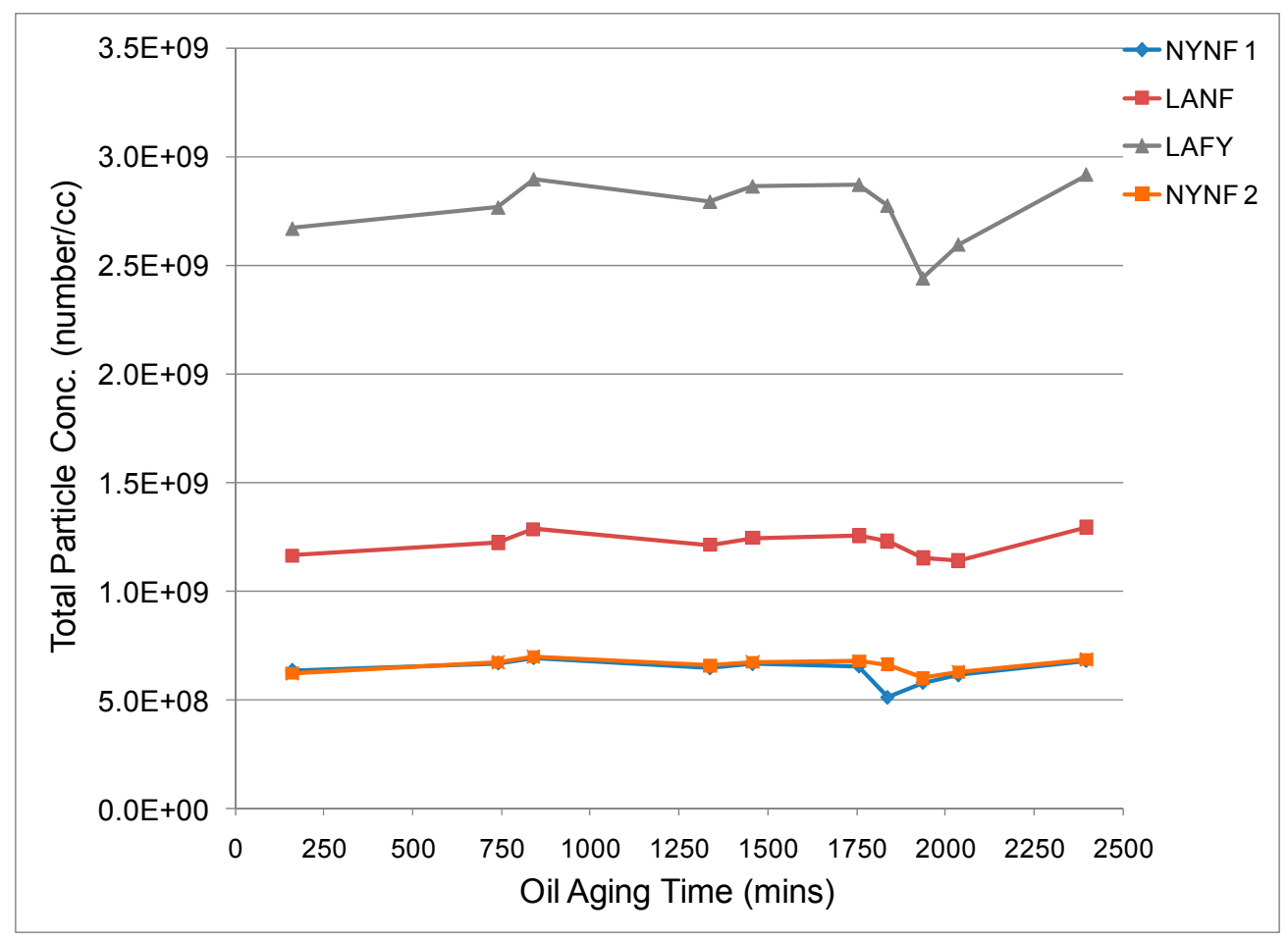

Figure 5.16 : Particle Concentration in $100 \mathrm{~nm}$ Bin-First Set FTPs. 


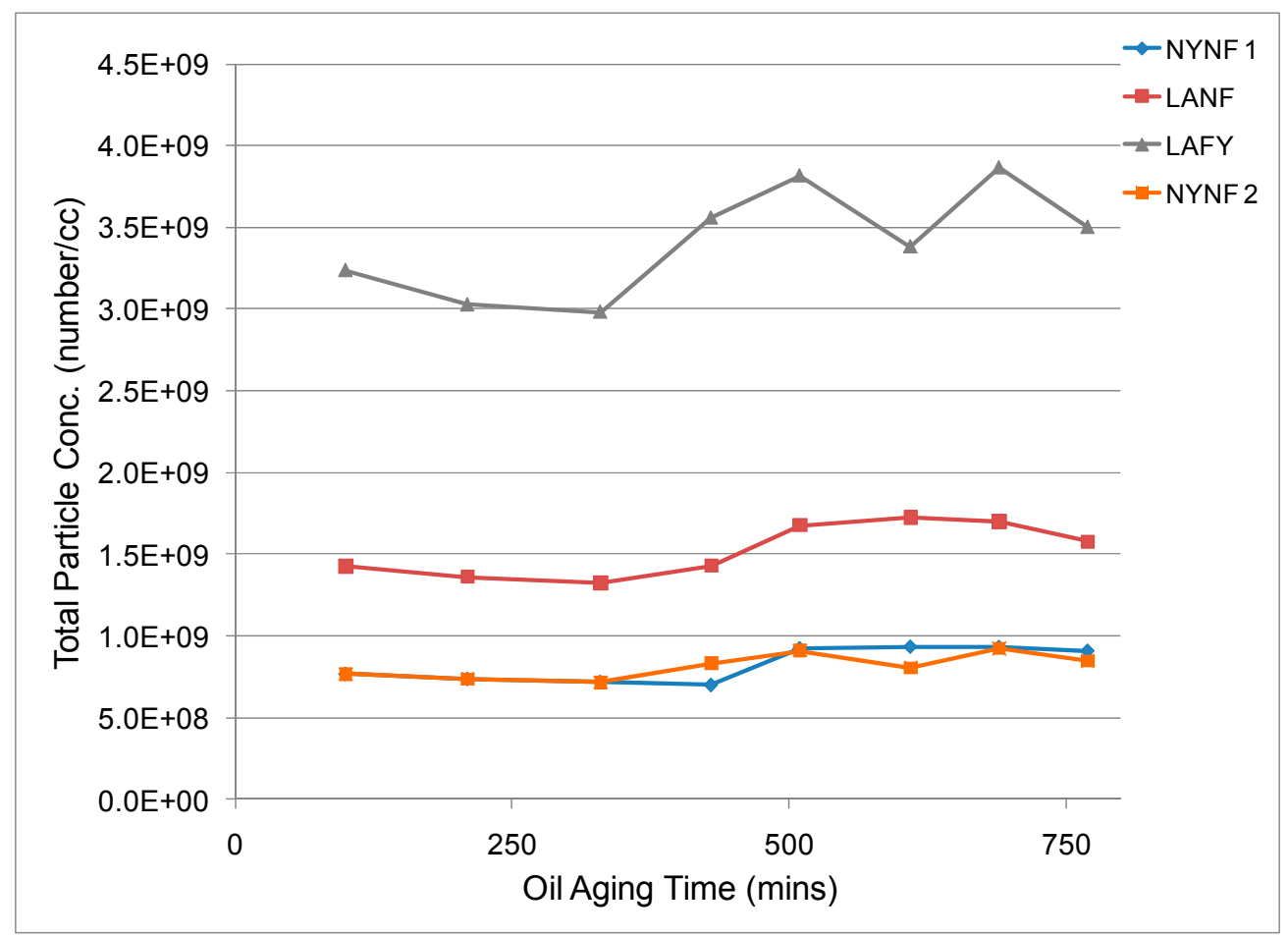

Figure 5.17 : Particle Concentration in $100 \mathrm{~nm}$ Bin-Second Set FTPs.

Figure 5.18 and Figure 5.19 shows averaged particle number concentration levels in the $1000 \mathrm{~nm}$ Bin. Similar to the other two bin particle number concentration levels, LAFY route exhibited the highest concentration level, followed by LANF route. Also, the data from the first and the second NYNF routes did not show any significant differences. The sudden drop in particle number concentration level around 2000 minutes in the first set and around 600 minutes in the second set corresponds to FTP test sequence E02522 and E02538, which were ran on B-20 biodiesel. Again in this particle size bin, no significant change in particle number concentration was observed in first and second FTP test sets. 


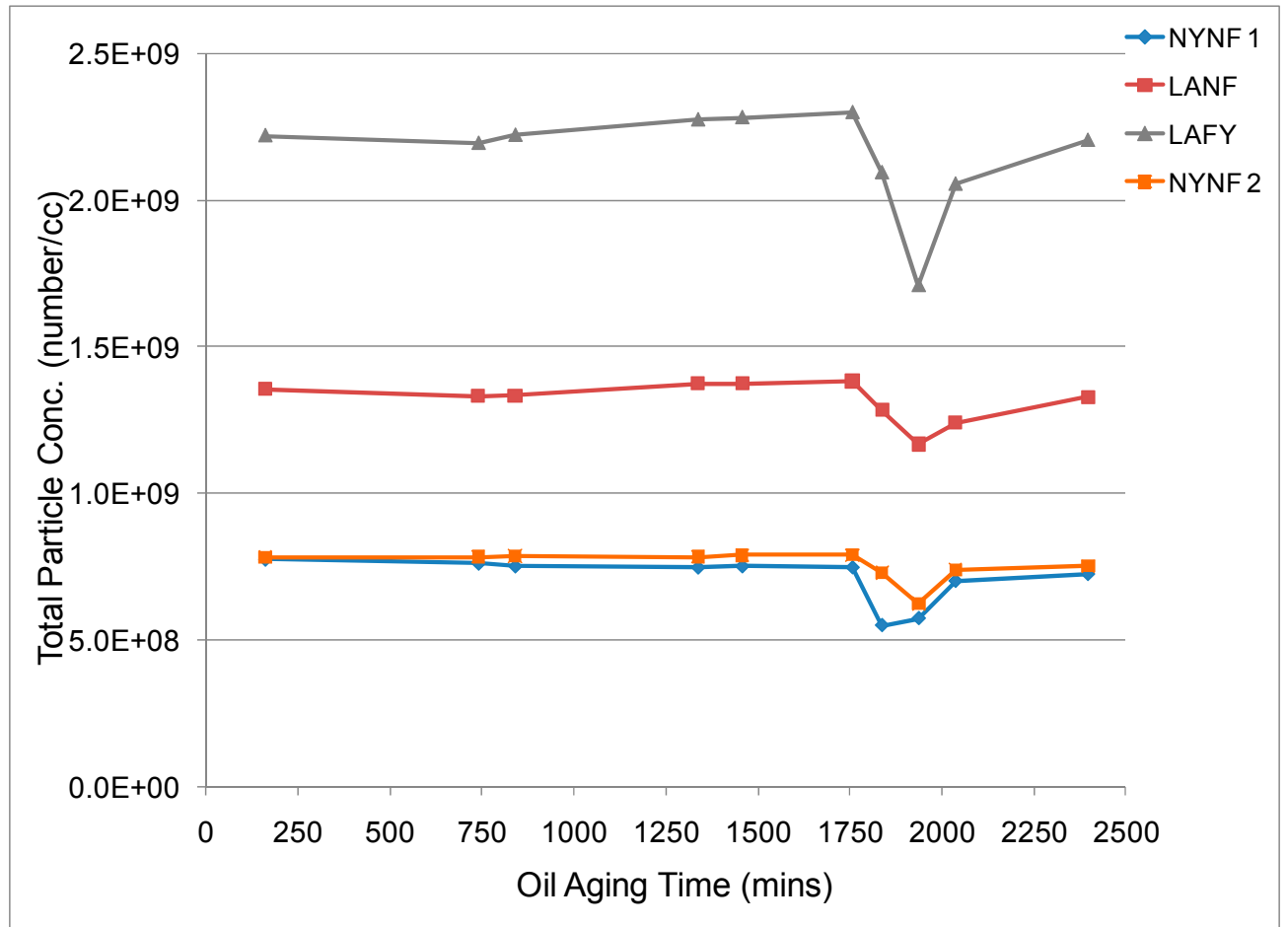

Figure 5.18 : Particle Concentration in $1000 \mathrm{~nm}$ Bin-First Set FTPs.

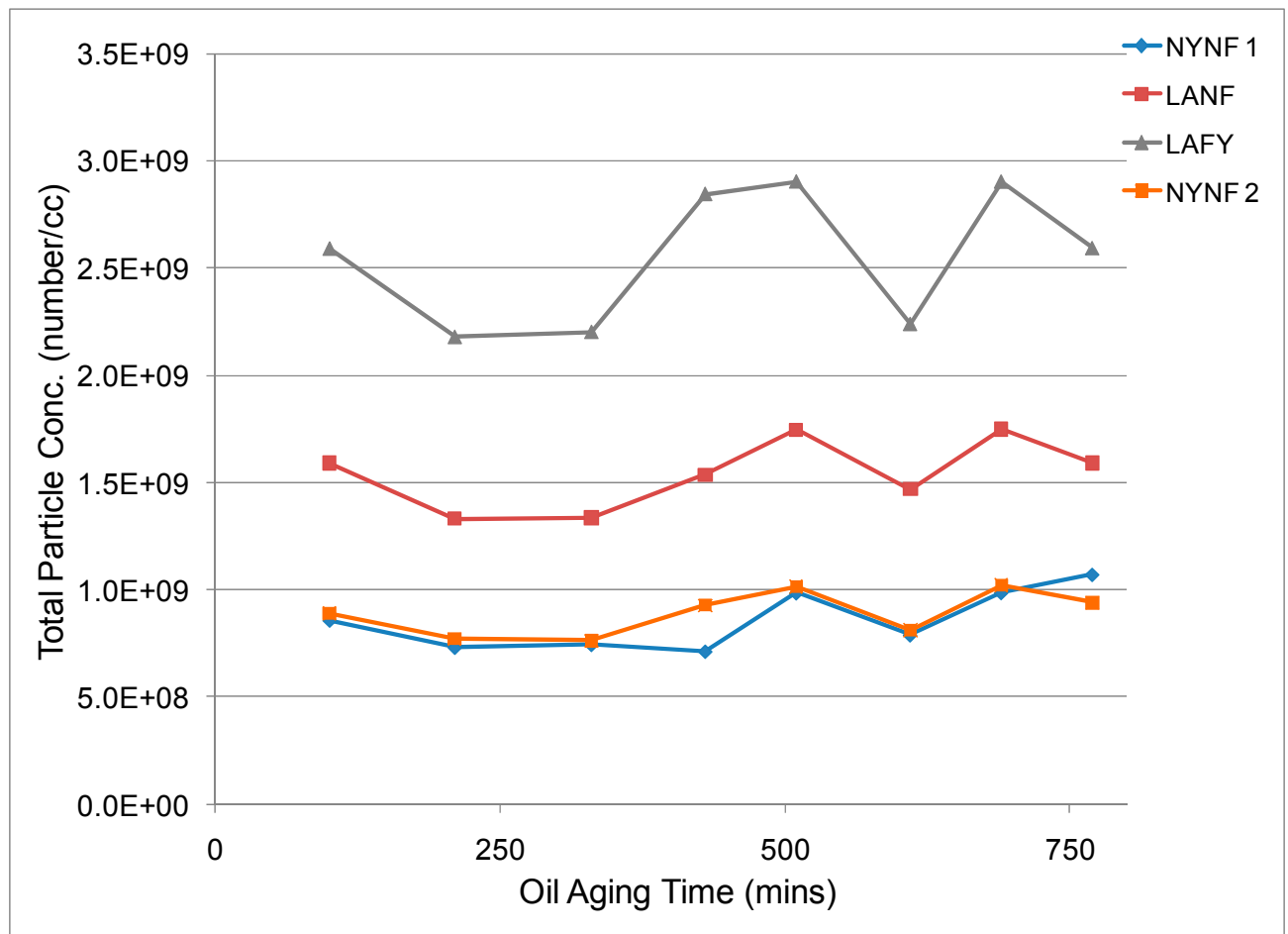

Figure 5.19: Particle Concentration in 1000nm Bin-Second Set FTPs. 
The results from steady state tests on averaged particle number concentration levels in the three bins are shown in Figure 5.20, Figure 5.21, and Figure 5.22. In the $50 \mathrm{~nm}$ Bin, Mode 10 , high speed-100\% load, showed highest particle number concentration level in the order of $10^{10}$ particles per cubic centimeter compared to the other five modes which produced concentration levels in the order of $10^{09}$ particles per cubic centimeter. In the $100 \mathrm{~nm}$ Bin and the $1000 \mathrm{~nm}$ Bin, 25\% load modes, Mode 7 and Mode 11, showed higher particle number concentration levels compared to $100 \%$ load modes. No significant change in order of magnitude of number concentration levels was observed in the steady state test data during the aging time bracket.

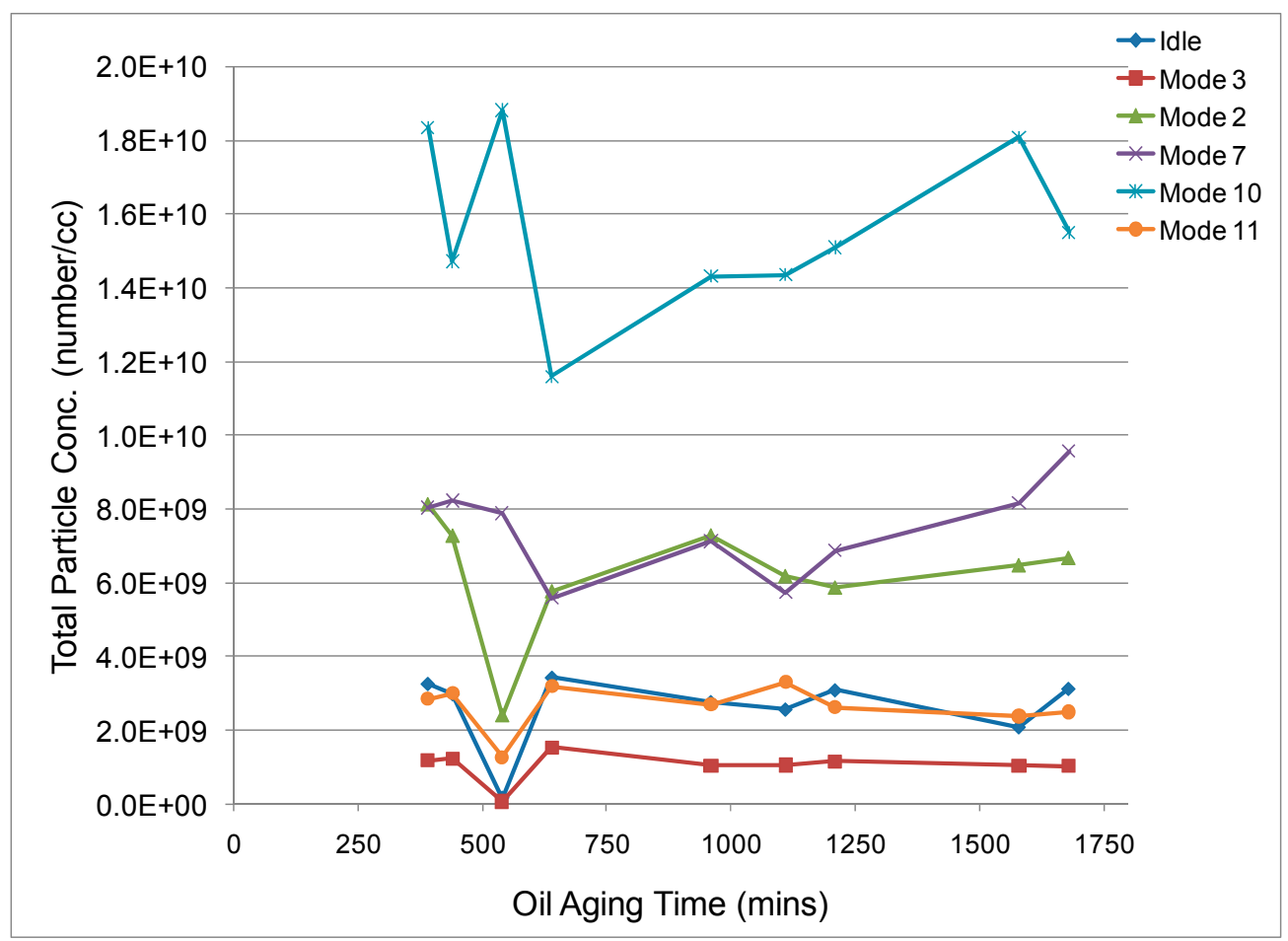

Figure 5.20 : Particle Concentration in $50 \mathrm{~nm}$ Bin-Steady State Tests. 


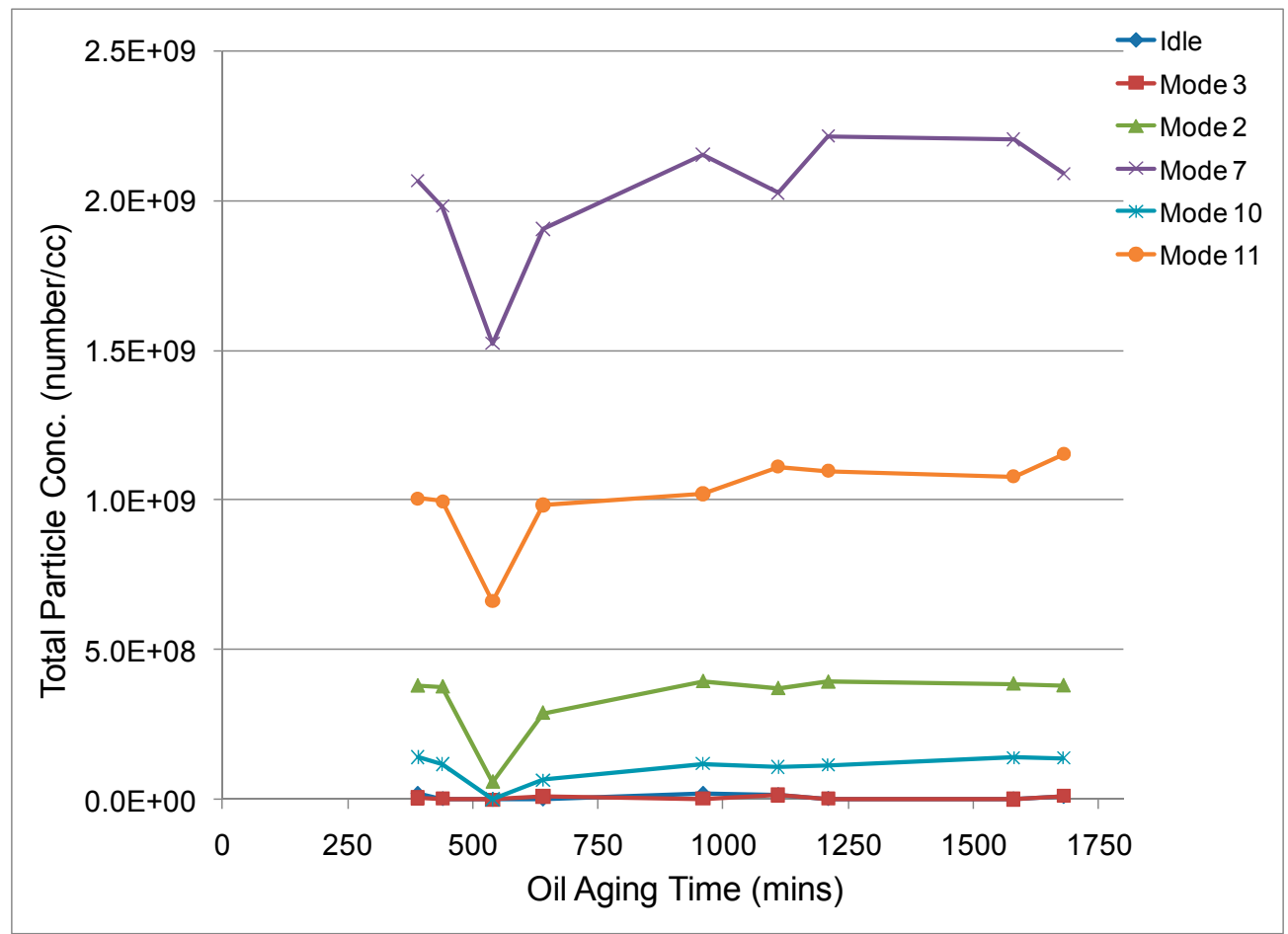

Figure 5.21 : Particle Concentration in $100 \mathrm{~nm}$ Bin-Steady State Tests.

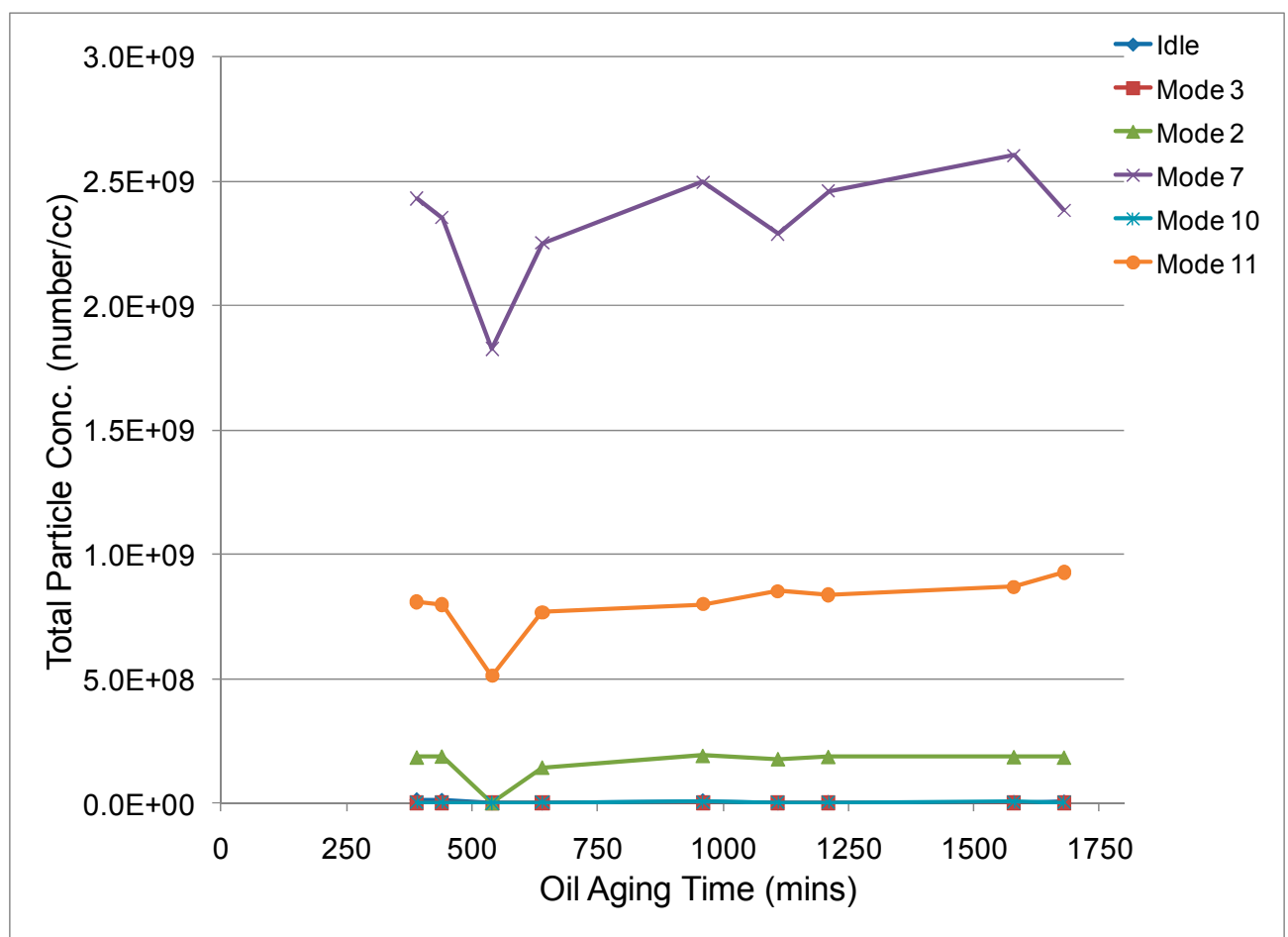

Figure 5.22 : Particle Concentration in $1000 \mathrm{~nm}$ Bin-Steady State Tests. 
Figure 5.23 and Figure 5.24 shows total particle number concentration levels observed in the three particle size bins during FTP tests from both test sets. Clearly, number concentration levels in the $50 \mathrm{~nm}$ Bin were the highest, in the order of $10^{10}$ particles per cubic centimeter of the sample, whereas the $100 \mathrm{~nm}$ and the $1000 \mathrm{~nm}$ Bin particles showed concentration level in the order of $10^{09}$ particles per cubic centimeters of the sample. It can be observed from this research that there was higher PM particle number concentration levels in nanoparticle size range than ultrafine and fine particle size ranges when the engine was exercised on FTP transient test cycles.

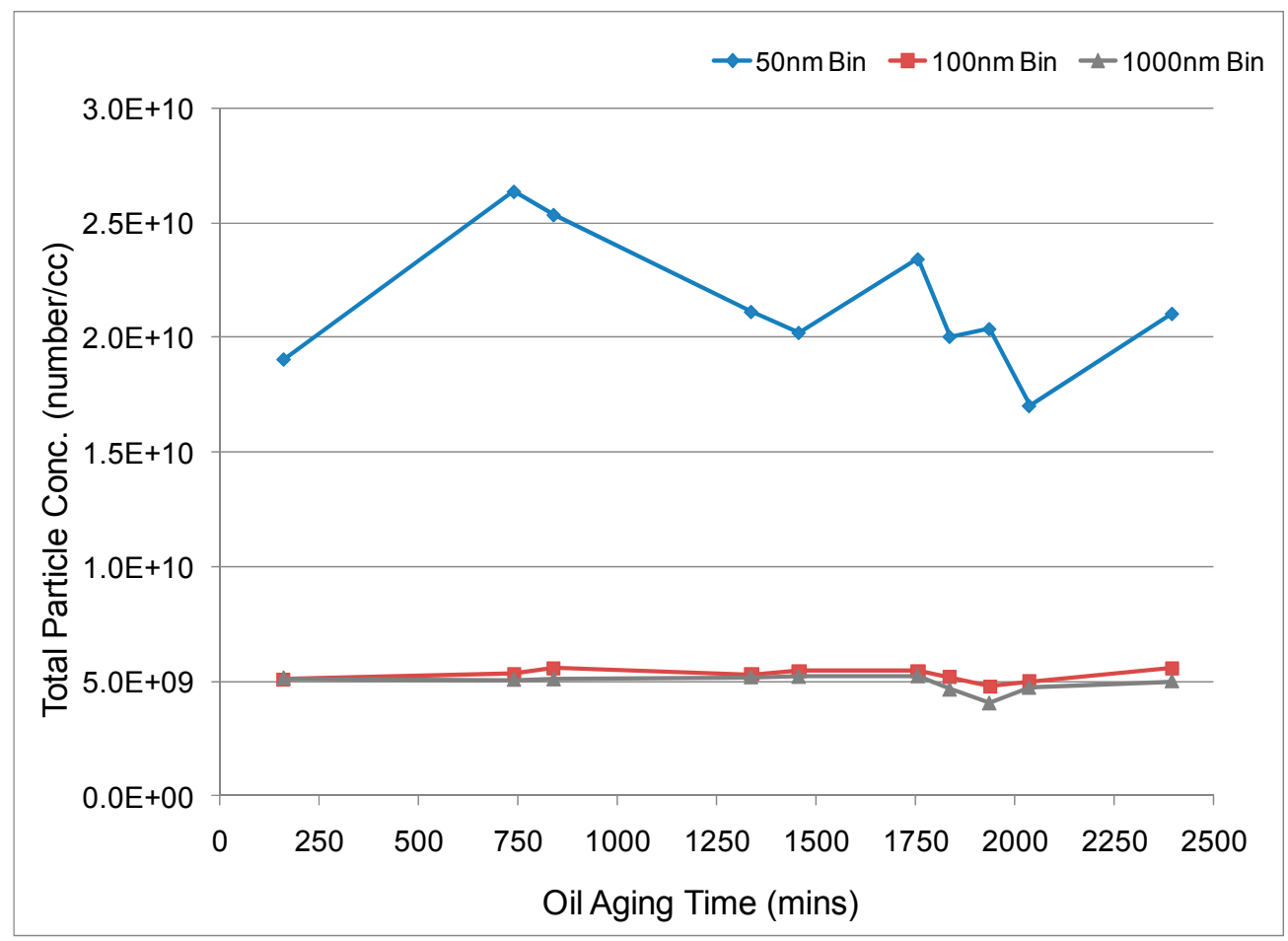

Figure 5.23 : Particle Concentration from the Three Bins-First Set FTPs. 


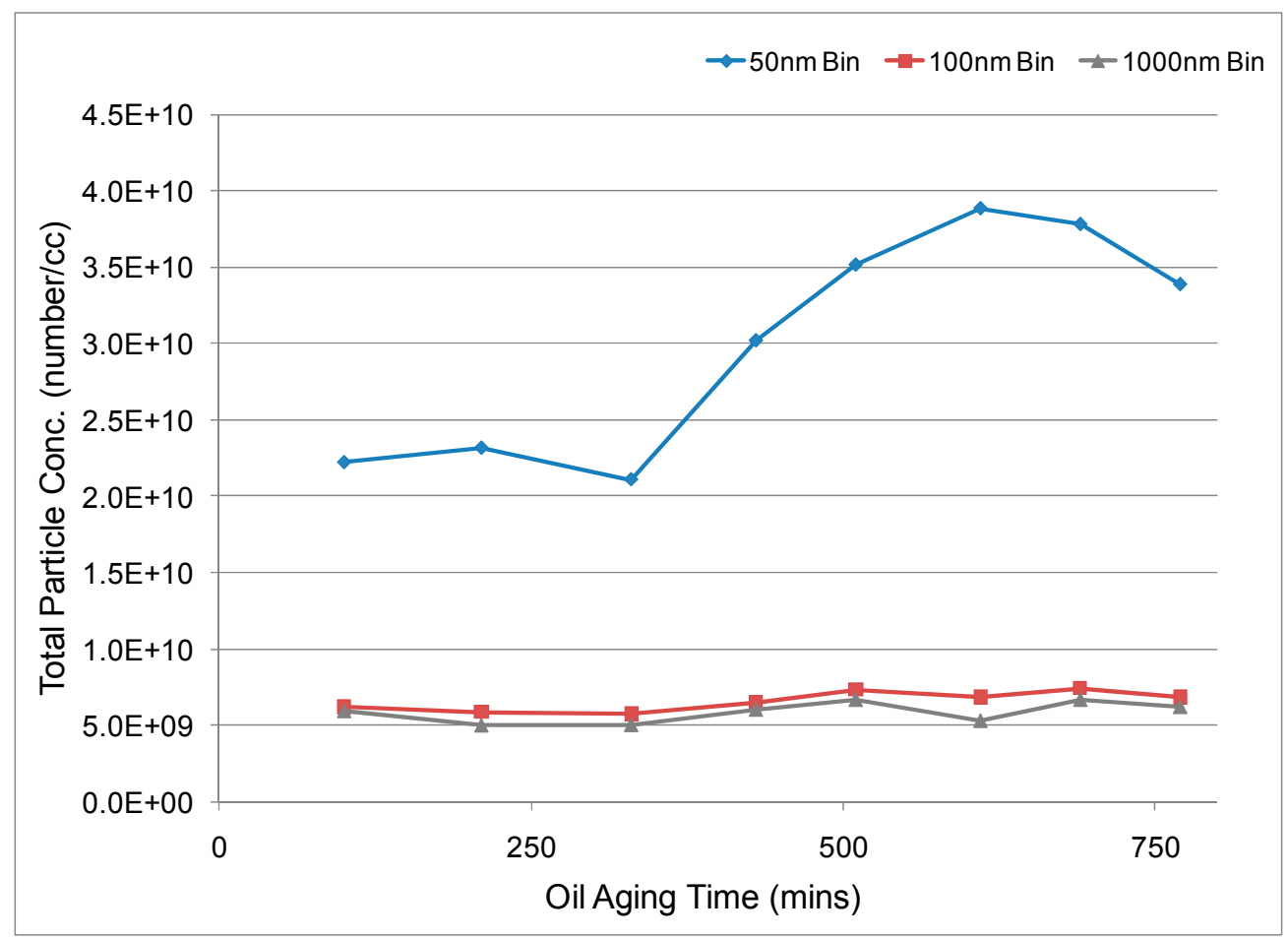

Figure 5.24 : Particle Concentration from the Three Bins-Second Set FTPS.

Total particle number concentration emissions, including all the particle size bins, from both the test sets can be seen in Figure 5.25. An increase of only one order of magnitude in the concentration levels was observed during the 100 to 800 minutes of time bracket in the second set. No change in particle number concentration levels was observed in the first test set. 


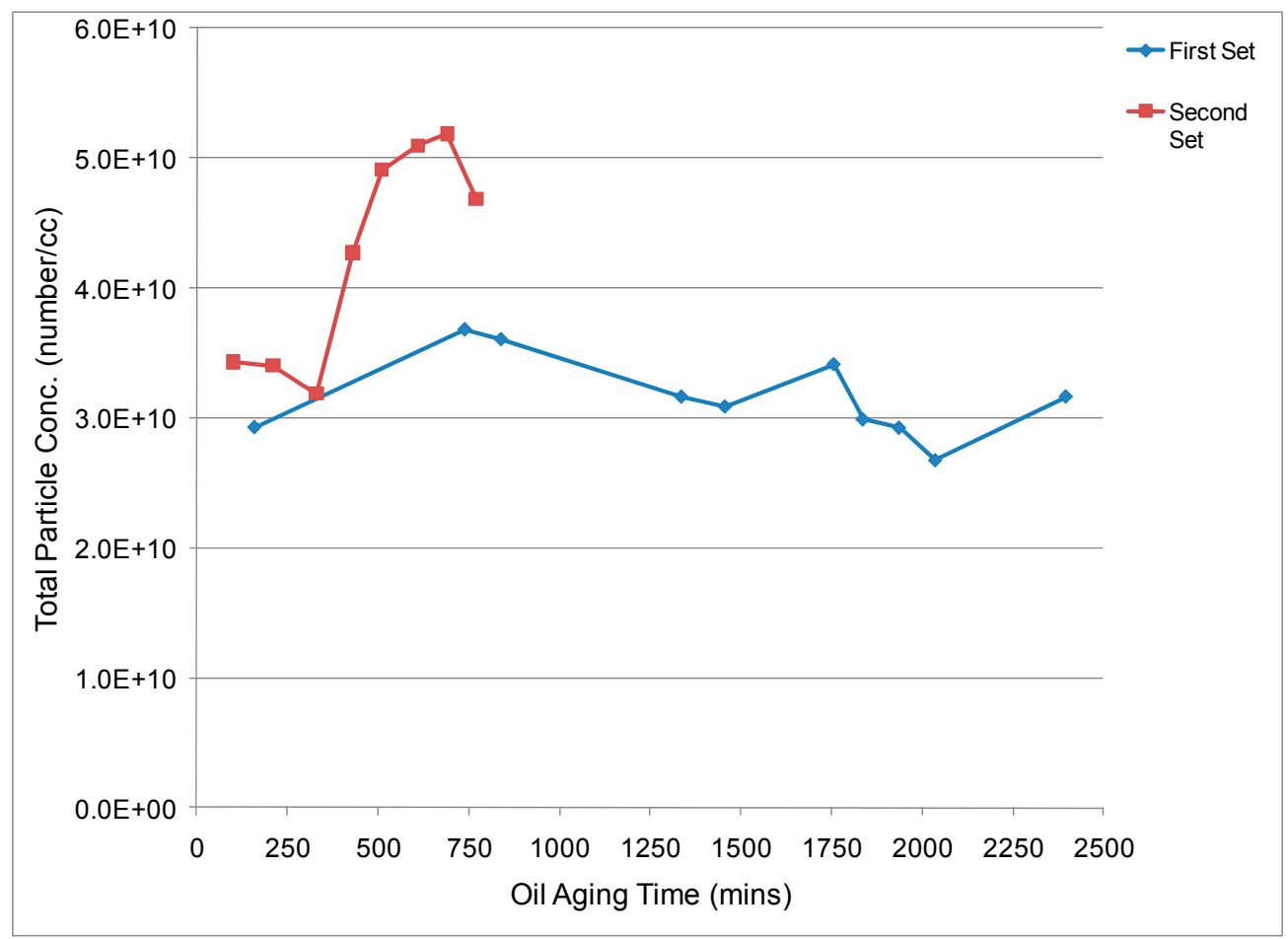

Figure 5.25 : Change in Total Particle Concentration over Aging Time.

From the above discussion, it can be summarized that no significant change in total PM particle number concentration levels was observed during both test sets. Additionally, all particle size bins showed no change in particle number concentration levels except the $50 \mathrm{~nm}$ Bin from the second test set. From the steady state tests, 100\% load modes showed high concentration levels of nanoparticles whereas $25 \%$ load modes produced high concentration levels of ultrafine and fine particles. Usage of biodiesel showed a definitive drop in particle number concentration levels in the $100 \mathrm{~nm}$ and the $1000 \mathrm{~nm}$ Bin particles.

\subsubsection{Gravimetric PM Emission Using Cyclone Separator}

To further classify mass-based PM emissions into separate particle size bins for particles larger than $1000 \mathrm{~nm}$, three size bins for PM particle sizes of $1 \mu \mathrm{m}, 2.5 \mu \mathrm{m}$ and 10 $\mu \mathrm{m}$ were used. These size bins particles were collected using three PM cyclone separators of sizes $\mathrm{PM}_{1}, \mathrm{PM}_{2.5}$ and $\mathrm{PM}_{10}$. However, in this case, $\mathrm{PM}_{1}$ included all $\mathrm{PM}$ particles whose mean diameters were less than or equal to $1 \mu \mathrm{m} ; \mathrm{PM}_{2.5}$ included particles with mean diameter less than or equal to $2.5 \mu \mathrm{m}$; and $\mathrm{PM}_{10}$ included all particles with mean diameter less than or equal to $10 \mu \mathrm{m}$. 
The PM sample was collected from the primary dilution tunnel from the same sampling plane where the other sampling probes were located. The cyclones were fitted with critical flow orifice of theoretical flow rate of 16.7 liter per minute. The data presented here were obtained from gravimetric analysis of particulate matter emissions collected on $47 \mathrm{~mm}$ PM filter media. Figure 5.26 shows brake-specific PM emissions in the three particle size bins from the FTP test sequences in the second set. A decrease of 20-22\% in PM emission was observed in the test sequence E02538, which was run on B-20 biodiesel. No significant change in overall PM emission was observed during the entire set.

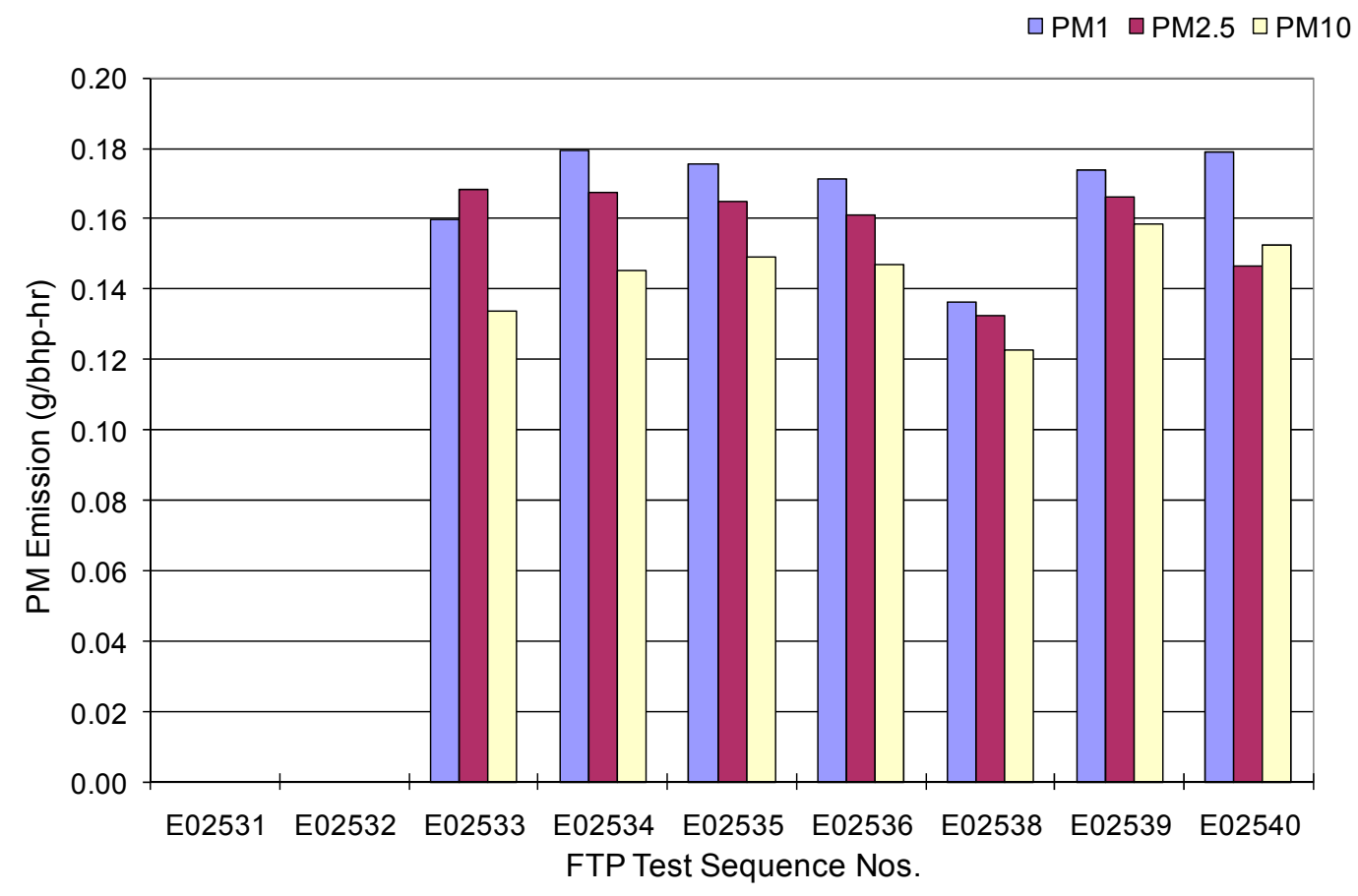

Figure 5.26 : BsPM Emission from $P M_{1}, P M_{2.5}, P M_{10}$ Cyclones.

It is interesting to note here that brake specific mass of $\mathrm{PM}_{10}$ particles was observed lower than $\mathrm{PM}_{1}$ and $\mathrm{PM}_{2.5}$, which is logically not realistic. After careful inspection of the $\mathrm{PM}$ cyclone sampling system, leaks in $\mathrm{PM}_{2.5}$ and $\mathrm{PM}_{10}$ sampling lines were found. Hence the data presented for these particle size bins stands invalid. However, the data are still presented to show that the same trends were observed with all three sampling systems, assuming a constant leak, and hence a consistent bias, in the $\mathrm{PM}_{2.5}$ and $\mathrm{PM}_{10}$ sample systems. It would be 
interesting to conduct further oil aging tests with corrected cyclone sampling system to see the effects in these three particle size bins.

\subsection{Extraction of SOF Results}

The PM filter media from the FTP and steady state tests were subjected to extraction of soluble organic fractions (SOF) by the Soxhlet extraction process. The data presented here are only from the FTP tests. No detectable SOF was found from the steady state tests filters. This may be because of significantly low deposition of PM on the filters during idle and 25\% load modes. For extraction of SOF by Soxhlet method, it was observed that lower the deposition of PM on the filters, higher is the variability in SOF measurement [45].

The filters were weighed before and after the extraction process to determine the decrease in filter weight using the same scale and procedure as the TPM weighing procedure. The amount of decrease in weight was equal to the amount of SOF extracted from the filter. This SOF values were then corrected with field blank SOF values of cleaned and normal PM filter media to account for mass loss that might be have occurred in a new unused filter media subjected to the SOF extraction procedure.

Figure 5.27 and Figure 5.28 shows averaged percentage of SOF found in the PM filters of the FTP test sequences from the first and the second test sets, respectively. The error bars represents one standard deviation, on positive and negative side, of the respective test groups. The test groups from the first set showed an average of 13-15\% SOF. Similarly, in the second test set showed around 15\% SOF in total PM. In both the sets, one group, E02522 in the first set and E02538 in the second set, showed comparatively high percentage SOF, 18$19 \%$. It should be recalled here that these test groups were biodiesel run tests; although these tests showed high SOF fractions, the TPM from these tests were lower than the Guttmann test fuel TPM values. Figure 5.29 shows percentage difference in percentage SOF with respect to the baseline FTP test groups in each set. From the first set results, a decrease in percentage SOF, in the range of $17-19 \%$, was observed during the first 700-800 minutes. The second test set also showed initial decrease in percentage SOF, $13-14 \%$, and then gradually increased up to $15 \%$ around 600 minutes. This increase may be attributed to the usage of biodiesel at that 
time interval. Similar results were also observed in the first test set around 2000 minutes, which corresponds to biodiesel run test group in the first test set.

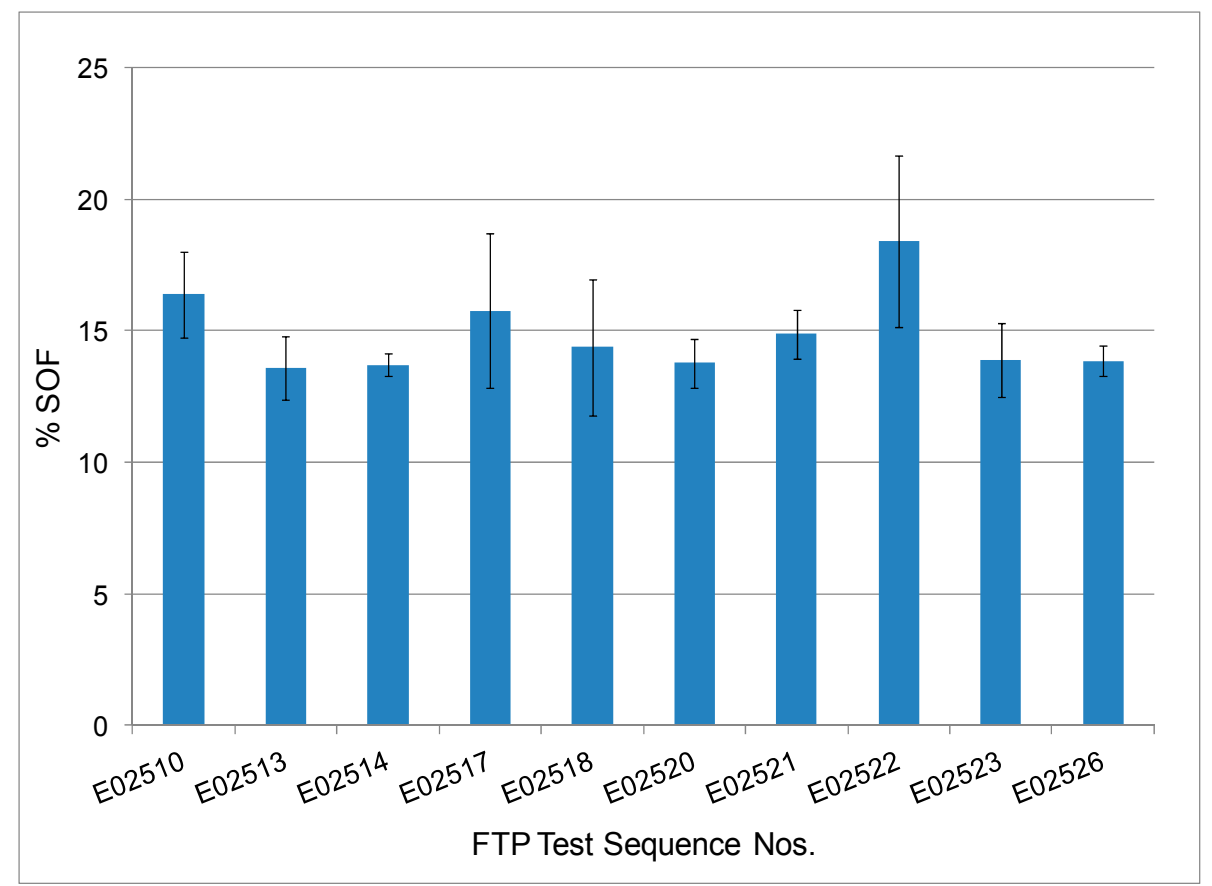

Figure 5.27 : Percentage SOF in TPM-First Set FTPs.

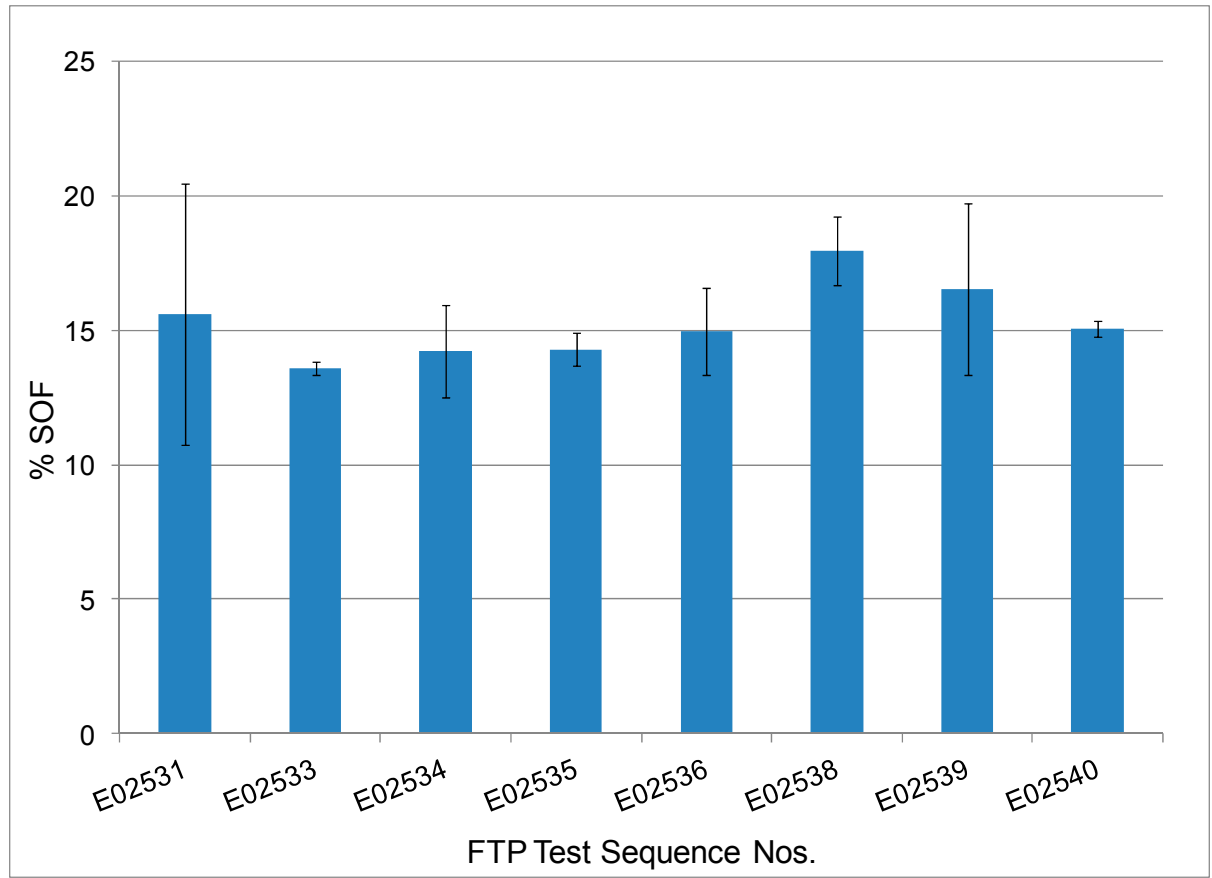

Figure 5.28 : Percentage SOF in TPM-Second Set FTPs. 


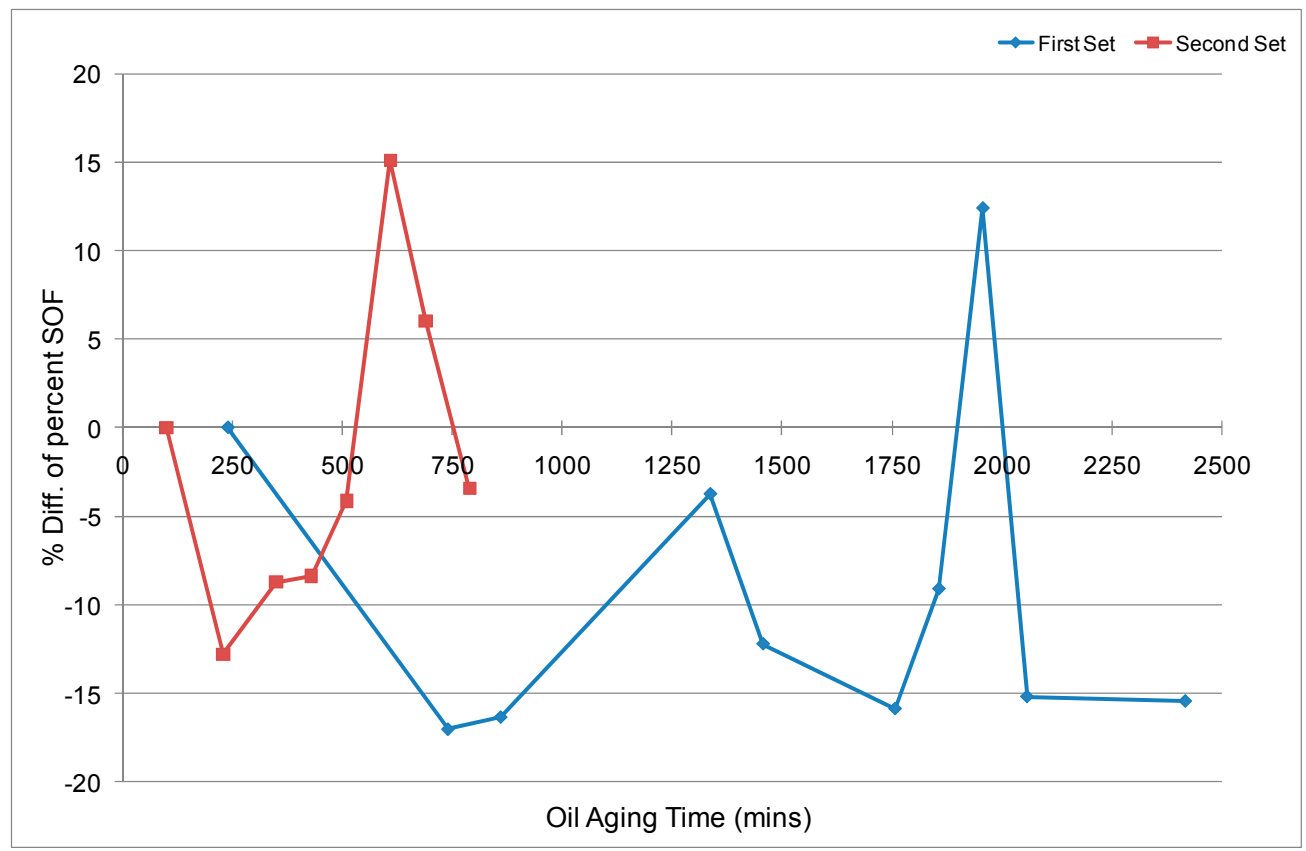

Figure 5.29 : Percent Difference in Percentage SOF w.r.t. Baseline FTPs.

It can be suspected here that there was a decrease in percentage SOF during first 600800 minutes of oil aging but no definitive claim can be made based on the data available. But, it can be inferred here that usage of biodiesel increased the percentage SOF in total PM emission up to $4 \%$ higher than the number 2 diesel (test fuel in this case). It would be interesting to conduct further analysis to determine oil derived SOF contribution to the total SOF by using C-14 radiotracer technique as conducted in this study [17], but this was beyond the scope of this research.

\subsection{Lubricant Oil Analysis Results}

During the course of engine tests lubricant oil samples were collected from the oil sump at specified interval time in both the sets of tests. The time intervals at which the oil samples were collected are provided in Appendix A.7. Analysis of physical properties was conducted for the oil samples to observe any changes. Additionally, an investigative work was done on the collected oil samples to observe particle size concentration distribution of suspended particles in the samples. This section discusses the results obtained from the physical property analysis of the oil samples followed by particle sizing observations in the 
samples. The results from the analysis of the oil samples for different properties are tabulated in Appendix B.9.

It is noted here that the oil was aged up to approximately 40 hours, which represented around 2000 miles of a typical on-road truck operation assuming that the truck was operated at an average speed of 50 miles per hour. For a typical heavy-duty diesel engine truck, DDC Series 60 in this case, recommended oil drain interval is 15,000 miles [34]. Therefore, considering its real-world application scenario, the oil was aged up to $10 \%$ of its projected life and was comparatively new.

\subsubsection{Oil Property Analysis Results}

The results presented here include analysis of nine oil samples from the first test set and four oil samples from the second test set. Due to limitation in the project budget, only selected samples were analyzed from both test sets. The physical properties and the respective test methods used for analysis of the oil samples as conducted by Analysts Inc. was mentioned in Table 3.3 in Chapter 3. It should be noted here that only four oil samples from the second set were analyzed which corresponds to a small time bracket of 430 to 790 minutes of oil aging. The data shown at zero minutes of aging time corresponds to data obtained from analysis of a fresh oil sample.

\subsubsection{Viscosity}

Figure 5.30 shows the change in kinematic viscosity (at $100{ }^{\circ} \mathrm{C}$ ) of the used oil samples with respect to oil aging time. It can be inferred from the figure that no significant change in viscosity of oil samples was observed over the aging time of 2500 minutes. The kinematic viscosity values for fresh oil sample and the used oil samples were obtained around 15 centiStrokes. The data obtained for the second set was for a small time bracket, it is presented in the figure but no inference could be drawn from the data. 


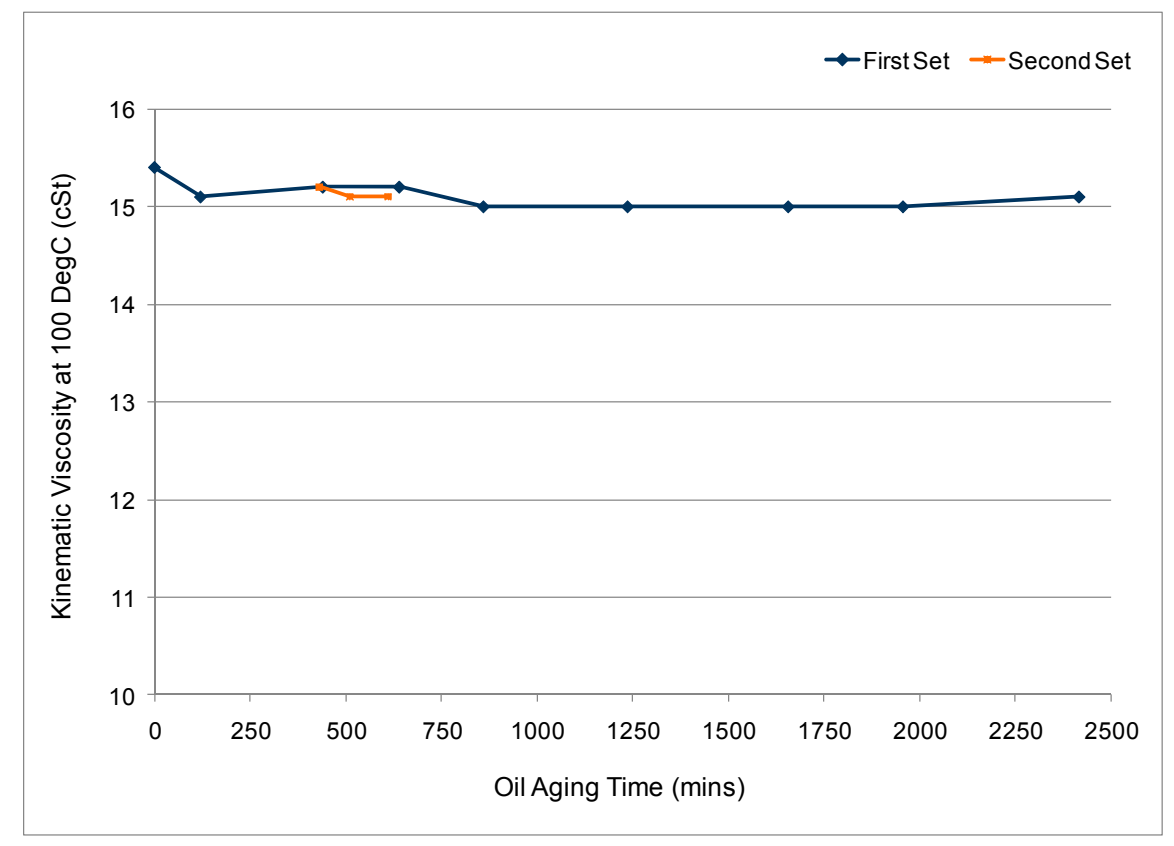

Figure 5.30 : Oil Viscosity at $100^{\circ} \mathrm{C}$.

\subsubsection{Total Acid Number}

Figure 5.31 shows the change in total acid number (TAN) of the used lubricant oil sample from both test sets. It can be observed that TAN of the oil sample increased with the aging time for the first set. TAN of fresh oil was obtained as $1.34 \mathrm{mg} / \mathrm{g} \mathrm{KOH}$ whereas used oil sample read up to $1.62 \mathrm{mg} / \mathrm{g} \mathrm{KOH}$ of sample, which is clearly an increase of $21 \%$ over the entire aging time of 2500 minutes. 


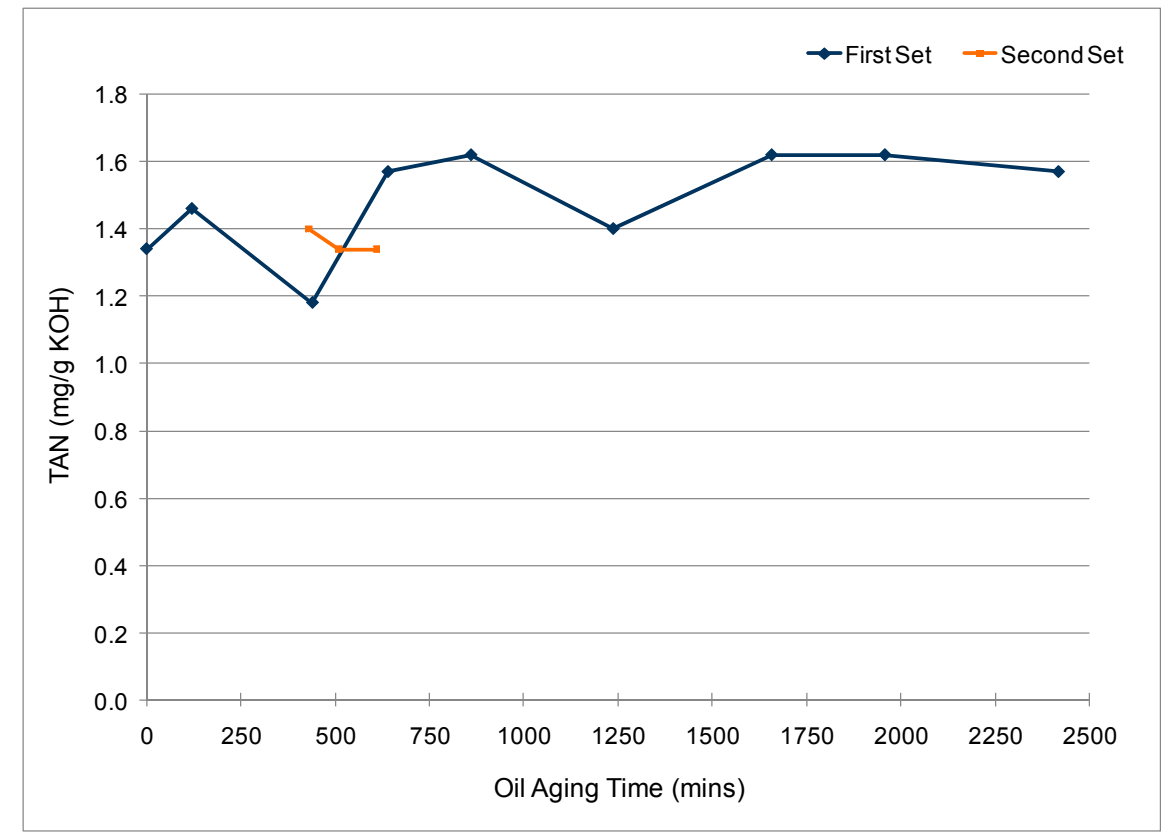

Figure 5.31 : Total Acid Number.

\subsubsection{Total Base Number}

Figure 5.32 shows change in total base number (TBN) of the oil samples. The results showed decrease in TBN over the 2500 minutes of aging time of the first set. The sample of fresh oil showed a TBN of $8.51 \mathrm{mg} \mathrm{KOH} / \mathrm{g}$ whereas TBN for used oil was as low as $6.5 \mathrm{mg}$ $\mathrm{KOH} / \mathrm{g}$ of sample. A decrease of $14.5 \%$ with respect to fresh oil was observed for the last oil sample of the set. It was reported that higher TBN values, which means absence of free strong acids, gives more stability to oil. The decrease in TBN value results from interaction of basic additives in the oil with acidic combustion products and from decomposition of basic additives under high temperature conditions experienced inside the combustion chamber [21]. 


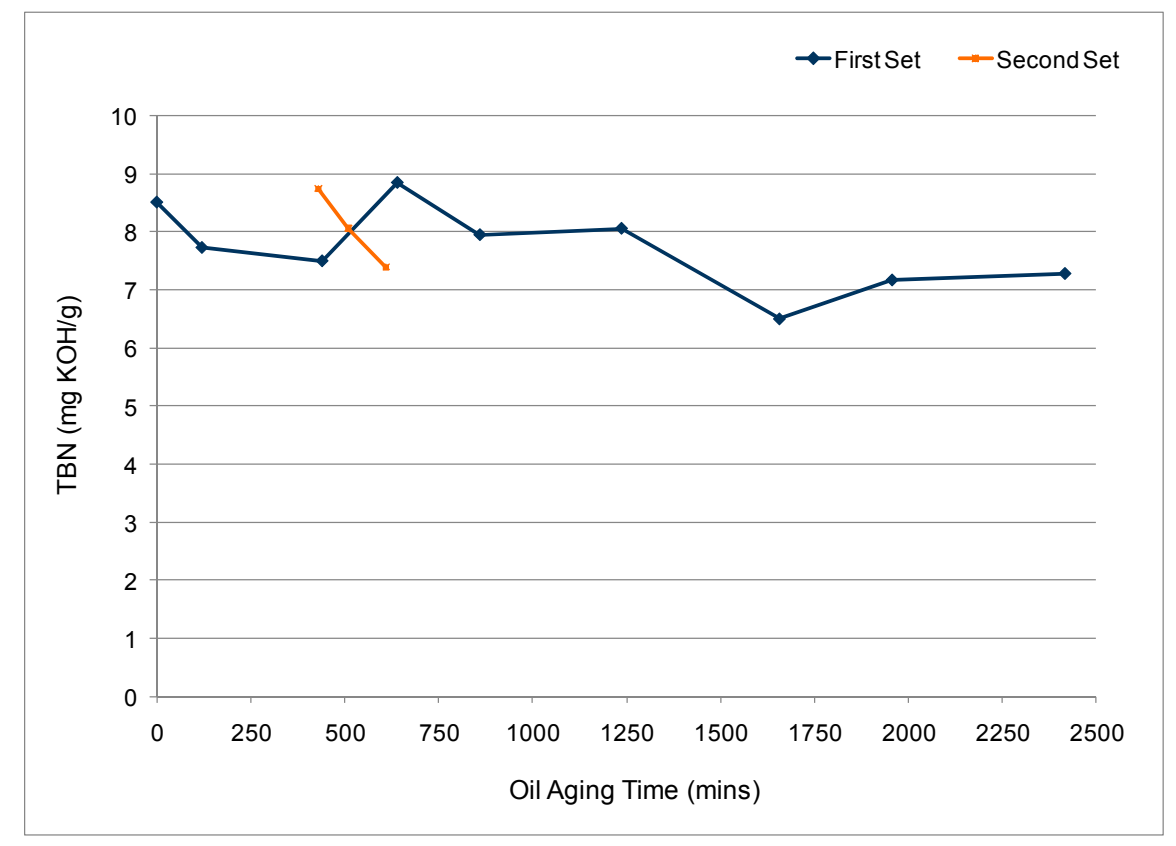

Figure 5.32 : Total Base Number.

\subsubsection{Density}

The change in density of the oil samples over the oil aging time in shown in Figure 5.33. No change in oil density was observed during the aging period. It should be noted here that for determination of oil density by ASTM D1298 test method, typically $125 \mathrm{ml}$ of oil sample is required for accuracy of the test results. But, a limited quantity of oil samples were collected during the engine testing phase, hence not enough quantity of oil samples could be provided to the laboratory. This might had partly affected the accuracy of the measurements and therefore no change in density of oil was observed. 


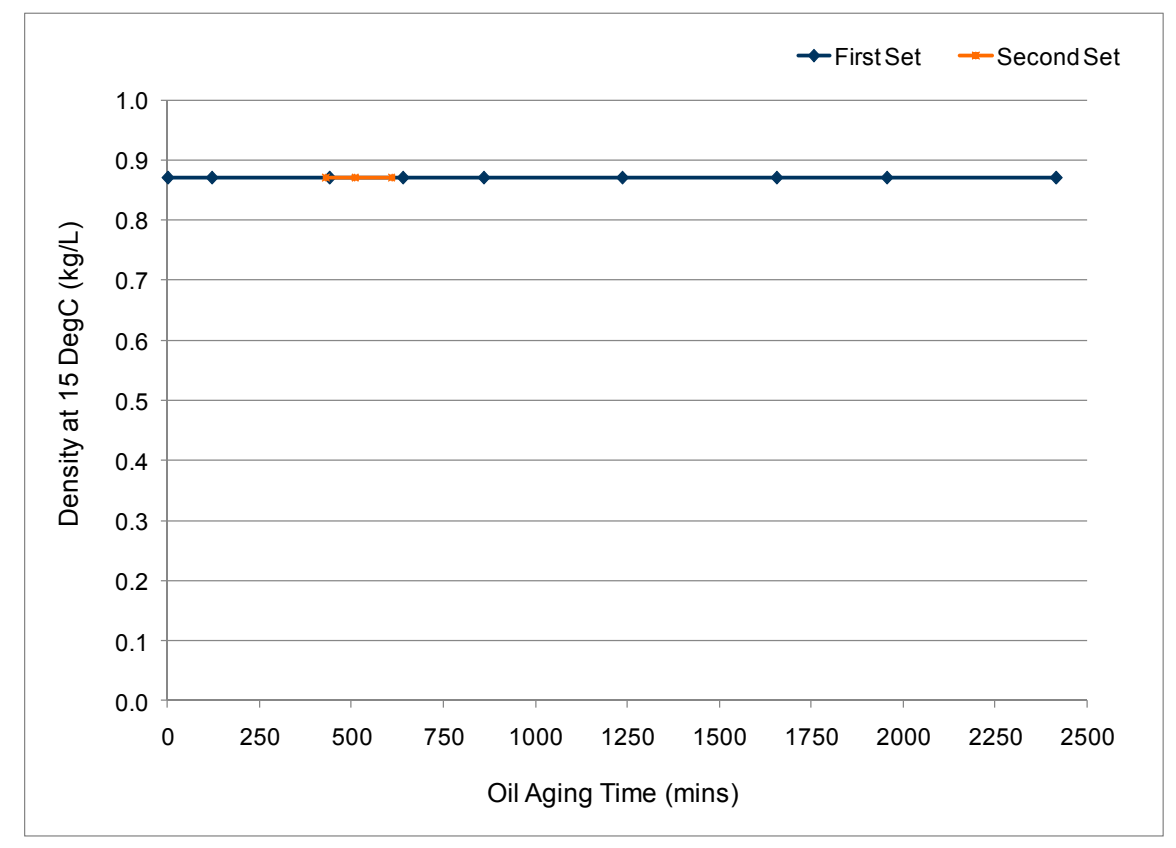

Figure 5.33 : Oil Density at $15^{\circ} \mathrm{C}$.

\subsubsection{Ash Content}

The oil samples were analyzed to determine levels of sulfated ash in the samples. Figure 5.34 shows the results of ash content levels found in the oil samples. It is interesting to note here that ash content level in fresh oil sample, $0.94 \%(\mathrm{w} / \mathrm{w})$, was observed higher than the used oil samples. The ash content levels in the used oil samples were observed around 0.8 $\%(\mathrm{w} / \mathrm{w})$ of the sample. The reason for higher ash content in the fresh oil is not known at this point. The limitation of the ASTM methods, D482 and D874, may be taken into account here. Overall a decrease of $15 \%(\mathrm{w} / \mathrm{w})$ in ash content levels was observed during the aging time. 


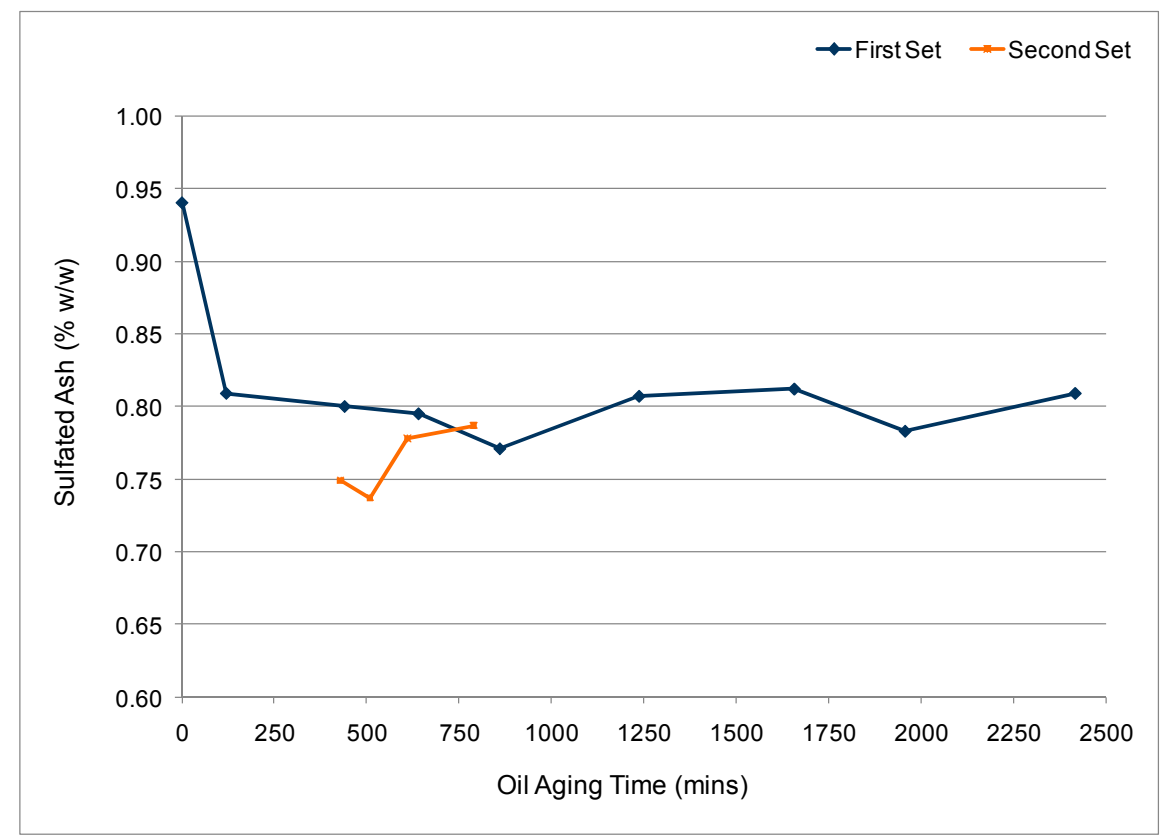

Figure 5.34 : Sulfated Ash Content.

\subsubsection{Soot Contamination}

Figure 5.35 shows levels of soot content in the oil samples. Clearly, the soot content level in the oil sample increased over the aging time period. The unused oil sample showed a soot content level of $0.01 \%(\mathrm{w} / \mathrm{w})$ which in case of used oil sample increased up to $0.25 \%$ (w/w) within first 2000 minutes of engine operation. The last data point from first test set in the figure was considerably low and may be suspected as an outlier. 


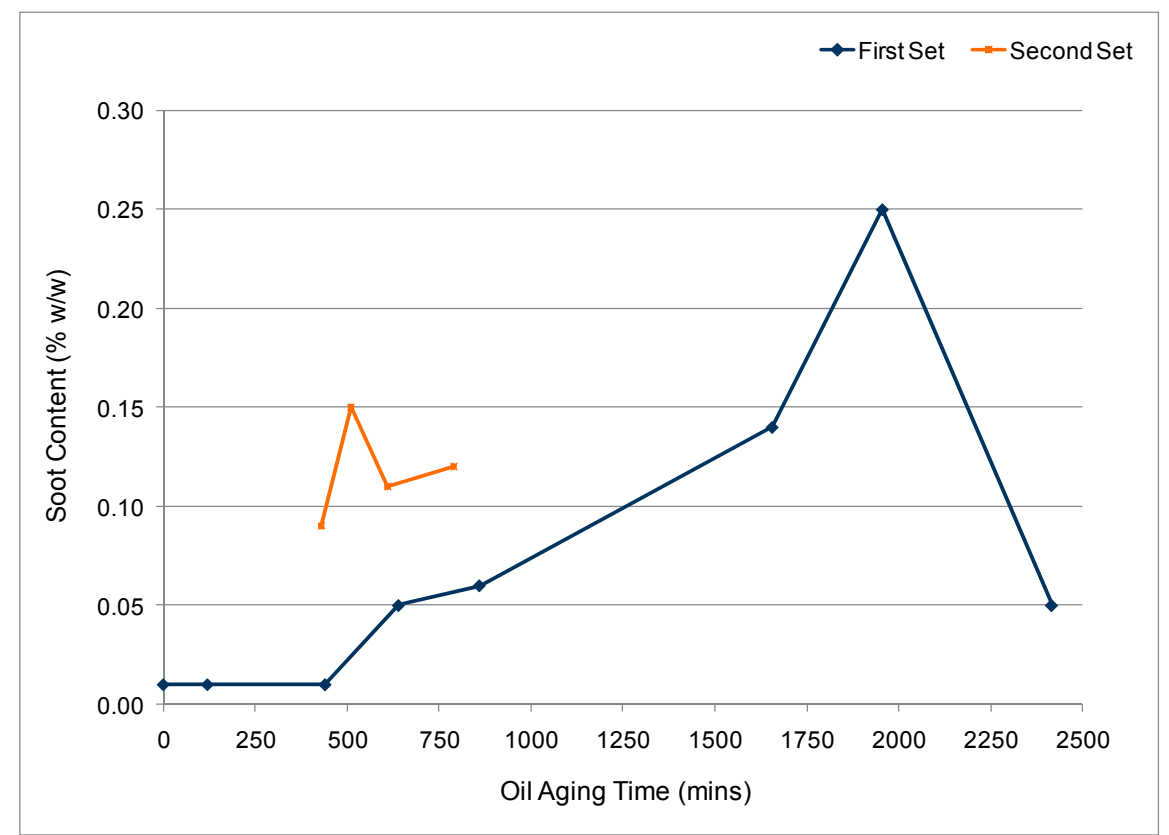

Figure 5.35 : Soot Content.

\subsubsection{Fuel Dilution}

Figure 5.36 shows the change in fuel dilution of oil over the oil aging time period. It is interesting to observe here that fuel dilution of fresh unused oil showed a value of $1.9 \%, \mathrm{w} / \mathrm{W}$ of oil, whereas the used oil samples showed comparatively lower values. A trend of increasing fuel dilution in oil can be observed in the oil samples. It is not known whether the OEM method used by the laboratory for determination of fuel dilution in oil had same level accuracy of analysis for unused oil samples as it had for used oil samples. It cannot be inferred here if the fuel dilution of oil increased during aging time period. 


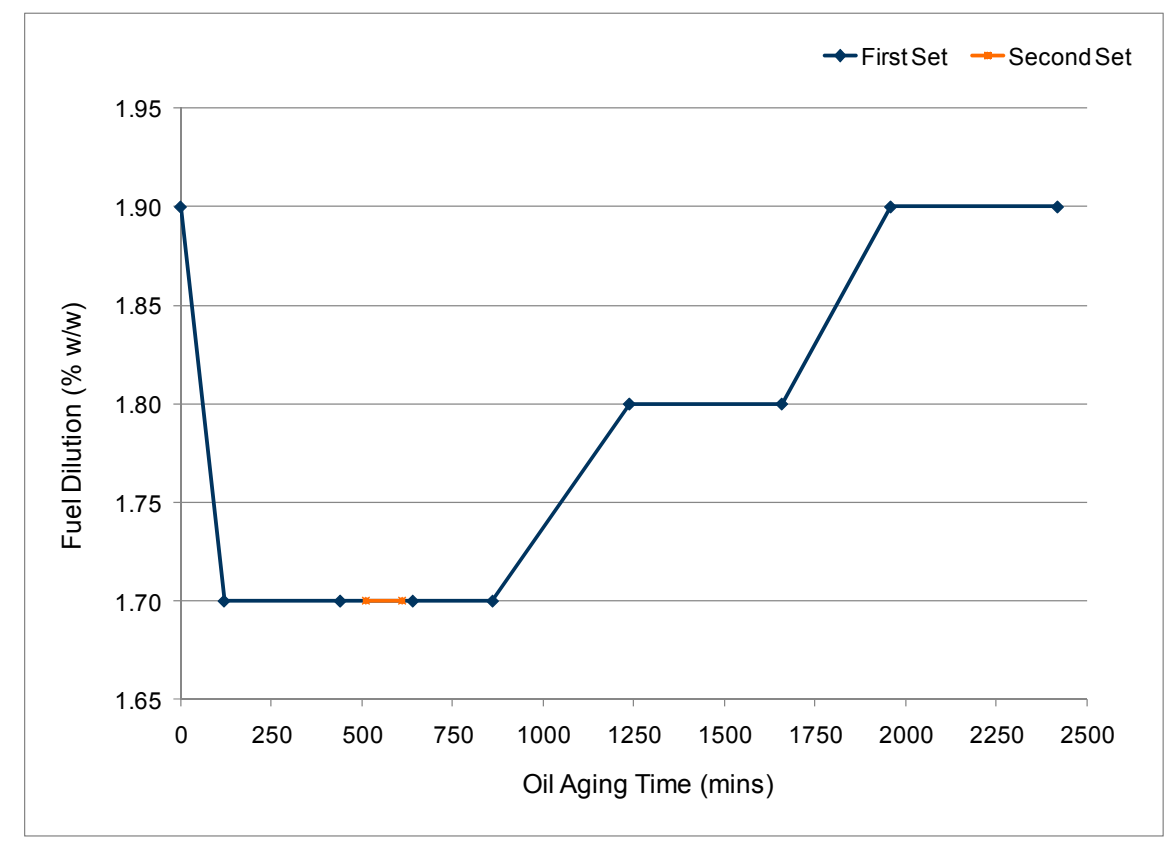

Figure 5.36 : Fuel Dilution of Oil Samples.

\subsubsection{Metal Content}

Metals like iron, magnesium, calcium, phosphorus, zinc, and silicon showed change in concentration levels in the oil samples. The results obtained from the analysis of these metals are discussed here, tabulated concentration levels of these metals and other metals are provided in Table B.1. Figure B.48 to Figure B.52 in the Appendix B.10 shows the change in concentration levels of the above metals in the oil samples. From the Figure B.48, iron showed a $100 \%$ increase in concentration level from $2 \mathrm{ppm}$ in fresh oil sample up to $4 \mathrm{ppm}$ in the last used oil sample. No definite conclusion can be drawn for magnesium content, Figure B.49. Calcium showed initial increase in concentration level up to 650 minutes from 2094 ppm in fresh oil sample to $2390 \mathrm{ppm}$ in used oil, Figure B.50, and then no significant change in concentration level was observed during the rest of aging time period. In the case of phosphorus and zinc, an initial increase of $12-14 \%$ in concentration level was observed up to 650 minutes of aging time, but no significant change was observed in the samples from the later part of the aging time, Figure B.51. It is interesting to observe here that silicon concentration level in the oil samples gradually increased from $2 \mathrm{ppm}$ to $9 \mathrm{ppm}$ over the entire aging time period, Figure B.52. 
From the above discussions, it can be summarized that 2500 minutes, or approximately 40 hours, of oil aging had no impact on oil viscosity, whereas TAN showed an overall increase of $21 \%$ and TBN showed a decrease of $14.5 \%$. No significant effect of switching between Guttmann diesel and biodiesel on TAN and TBN values was observed from the oil analysis data. Soot contamination of oil gradually increased over the aging time period and metal concentration levels such as iron had almost doubled during the aging time period. This can be attributed to inclusion and contamination of oil by wear debris from various metallic components of the piston-cylinder assembly. In diesel engines, the components which are normally subjected to wear are piston rings, piston, cylinder liner, bearing and crankshaft [21].

\subsubsection{Particle Sizing of Oil Sample Results}

Oil samples were subjected to measurement of mean diameter of the population of suspended particles in it by using the Malvern's Zetasizer ${ }^{\circledR}$ Nano particle measurement instrument meant for particle sizing in liquid media. This part of the study was purely investigative in nature; validity of the results obtained from the instrument for particle sizing in oil samples can be debatable. This instrument showed erroneous results in case of fresh oil and hence could not be used for analysis of fresh oil samples. The data obtained from the instrument for each samples and at each time was averaged data over 15 measurement repetition done by the instrument internally, which was set as an input to the interface software of the instrument before starting each measurement process. Each sample was analyzed for four or five times on different days to prevent any biasing in data that may occur by improper handling or contamination of oil samples. The following section discusses the change in Peak 1 diameter values (the normalized peak representing 95\% of suspended particle population in the oil samples) observed in the oil samples. The normalized plots of mean particle diameter values for the oil samples are provided in Appendix B.11.

Figure 5.37 shows change in mean diameter of particles in peak 1 in the oil samples from the first test set. The time on abscissa corresponds to the oil aging time for each oil samples. A trend of gradual decrease in mean particle diameter over the entire aging time can be observed in the figure. The mean particle diameter values from peak 1 in the oil samples 
from the second set can be seen in Figure 5.38. No definitive trend can be inferred from the second set during the aging time period.

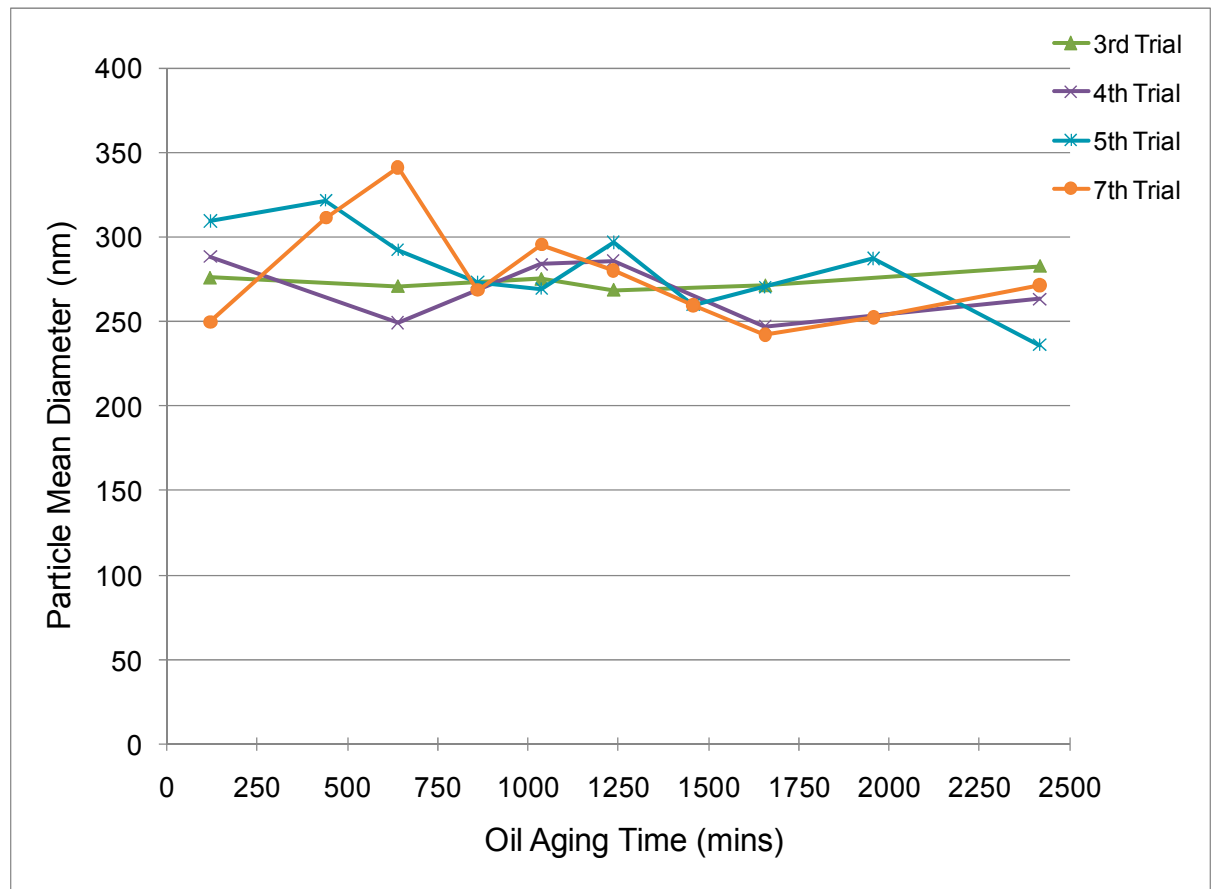

Figure 5.37 : Peak 1 Particle Concentration in Oil - First Set.

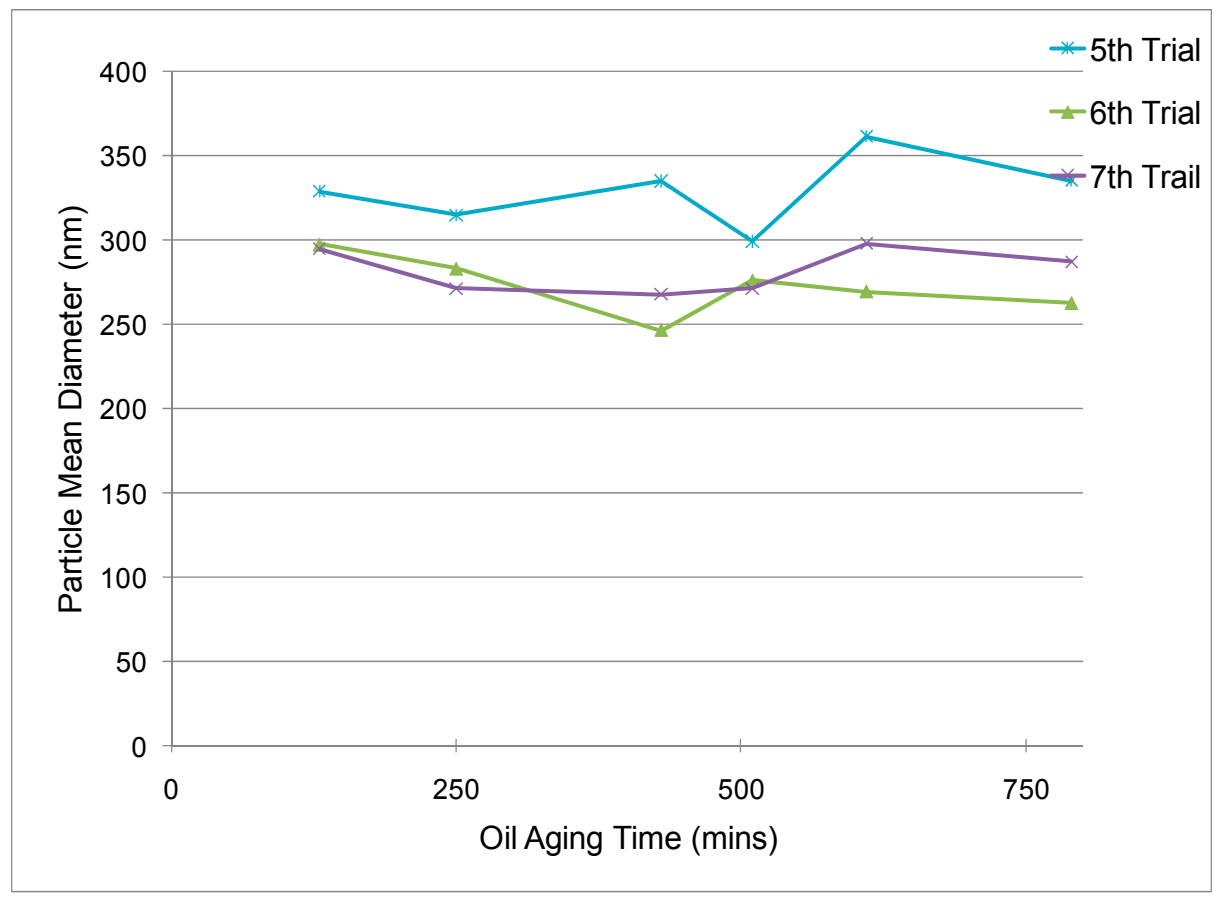

Figure 5.38: Peak 1 Particle Concentration in Oil - Second Set. 
Figure 5.39 shows variation in the mean particle diameter of the standard (DP5820) used to monitor zero shift of the instrument in between the measurements. The numbers on the abscissa show attempt numbers when the standard was used. Mean particle diameter from all three peaks are shown in the figure, where Peak 1 represented $95 \%$ of the particle population in the standard. No significant change in mean diameter values Peak 1 particles was observed, this illustrates the repeatability of the instrument.

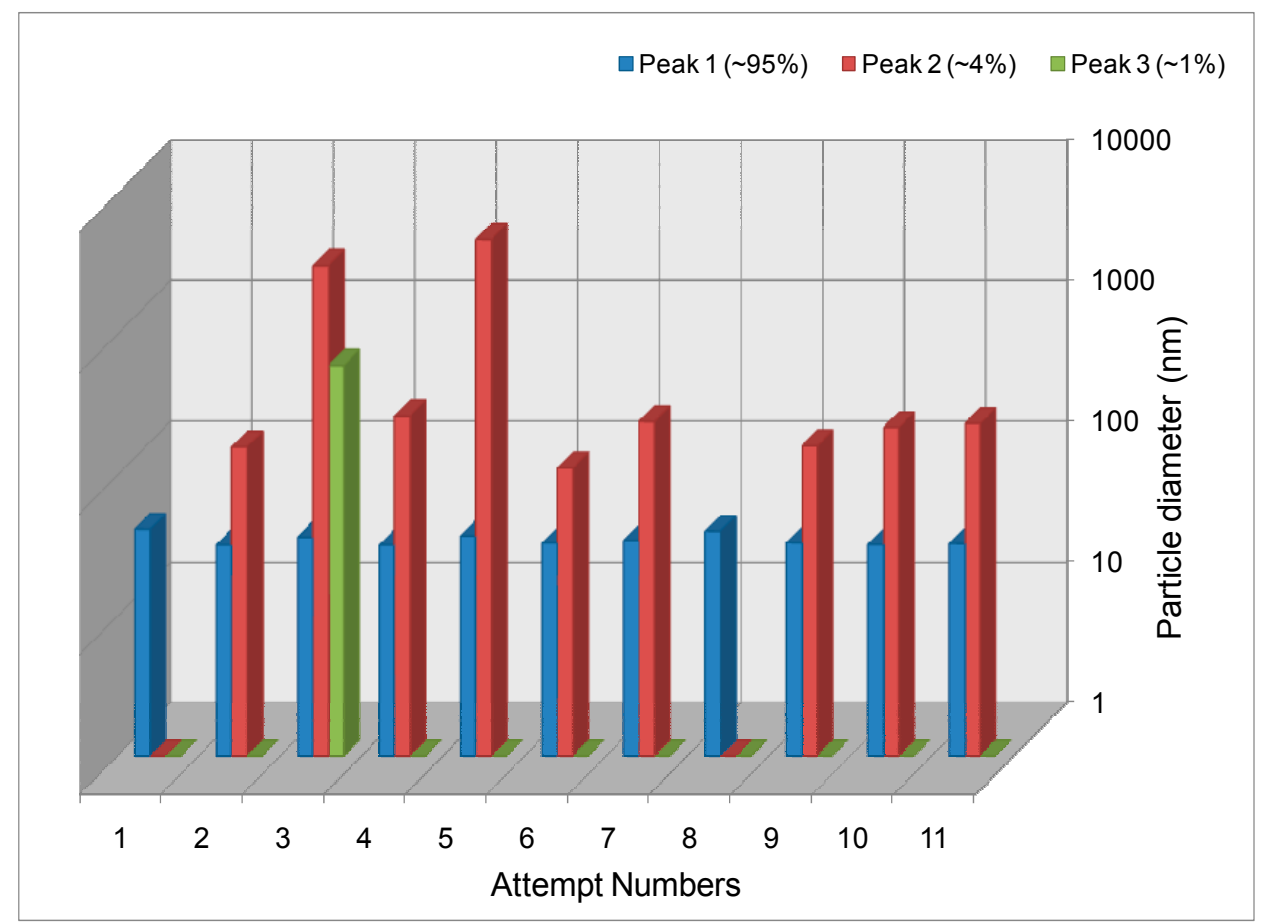

Figure 5.39 : Variation in Peak Particle Concentrations in the Standard (DP 5820).

From the above results obtained from the measurement of mean particle diameters of suspended particles in the oil samples, it can be inferred that larger diameter particles, 300$400 \mathrm{~nm}$, contaminated the oil during the initial 13-15 hours of use. The contaminants can be induced soot or some additive in the oil which showed change in physical properties over the period of oil aging, but no definitive substance can be classified at this point. Further research on the composition of particles found in the oil samples may be able answer this question. 


\subsection{Summary of Results}

From the above discussions on results obtained from this research study to determine the effects of lubricant oil aging on engine-out emissions, no significant change in regulated gaseous emissions of $\mathrm{CO}, \mathrm{CO}_{2}, \mathrm{NOx}$ and $\mathrm{HC}$ was observed during the aging period. However, some changes in emissions during different steady state engine operating modes was observed but no conclusion on contribution of oil aging on the phenomena can be drawn from the data. It is interesting to note here that similar studies [12] [46] on oil aging and formulation effects on exhaust emissions also reported insignificant change in the regulated gaseous emissions.

Total mass-based PM emission did not show significant change during the oil aging time period with exceptions to the cases of biodiesel usage where TPM emissions were 2025\% lower than the Guttmann fuel TPM emissions. Number-based PM emissions results showed increase in nanoparticles (50 nm Bin particles) number concentration levels only by an order of magnitude in the second test set during initial 800 minutes of oil aging, but the claim could not be verified with the first test set. Larger particles in the size bins of $100 \mathrm{~nm}$ Bin and $1000 \mathrm{~nm}$ Bin did not show significant change in number concentration levels over the aging time period. However, a study [47] found that dosing of oil in diesel fuel showed increased PM particle number emission in solid nuclei mode particles of mean diameter less than $30 \mathrm{~nm}$.

Change in percentage SOF in TPM emissions during the oil aging time period was not significant. Usage of biodiesel showed $4 \%$ higher SOF in the TPM emissions compared to Guttmann diesel.

Physical property analysis of the oil samples showed no change in viscosity, but, increase in TAN, decrease in TBN and increased soot contamination. Concentration levels of wear metal such as iron in oil approximately doubled as the oil aged.

Measurement and particle sizing of suspended particles in the oil samples showed contamination of oil by larger particles during initial 13-15 hours of its use. 


\section{Chapter 6. CONCLUSION}

Through the last decade, the emission standards for heavy-duty diesel engine trucks in the United States have seen NOx and PM limits reduced, the predominant emissions from diesel engines. Cutting down on vehicular emission limits, diesel engines in this case, is an effort to address the larger cause of minimizing air pollution by mobile sources and to gradually reduce the concentration levels of harmful regulated emission gases in the atmosphere. Addition of new technologies and modifications in engine design in modern heavy-duty diesel engines, have been capable of achieving the emissions limits. But high level of emissions from legacy heavy-duty diesel engines which are still in operation is a concern. However, modifications in fuel formulation, retrofitting with after-treatment devices in these legacy engines partly address this concern. But to make a new technology viable to the market it has to meet emission regulations. This research study investigated how one of the factors, lubricant oil, may affect a certification or verification program during emission tests that may cause failure to meet the emission limits.

It was observed from this research study conducted on a legacy heavy-duty diesel engine, that there was no significant impact on regulated gaseous and particulate matter emissions during first 40 hours after an oil change that can be attributed to the lubricant oil. However, physical properties of the oil such as total acid number, total base number, soot content, metal content showed change over the aging time.

Total base number decreased which it indicates decrease in stability of basic additives in the oil. Also, usage of oil over the aging time period caused increased soot contamination levels in the oil and inclusion of metal wear debris. This observation was supported by particle sizing measurement of suspended particles in the oil samples, which showed inclusion of larger diameter particles during initial 13-15 hours of oil usage compared to the diameter of particles observed in the oil samples from later part of aging time. However, it should be recalled here that, the oil was aged only up to $10 \%$ of its projected life of real-world application in a typical HDDE.

Referring to the research questions and the hypothesis assumed for this study mentioned in Chapter 1 of this document, following answers can be provided to the questions. 
1. No influence on regulated gaseous and particulate matter emissions from the legacy HDDE can be attributed to the lubricant oil usage in the engine during first 40 hours of its use.

2. The changes in regulated gaseous and particulate matter emissions could not be attributed to the lubricant oil within the aging time. Hence, this question is not applicable for this research scenario.

3. A typical stabilization time period for physical properties of the lubricant oil could not be predict from this research. Further oil aging hour accumulation beyond 40 hours may show a stabilization point.

This research brings us to the conclusion that oil aging history in the legacy HDDEs does not significantly contribute to the emissions of regulated gaseous and particulate matter, at least to the limitations studied in this program. Hence the assumed hypothesis for this study that lubricant oil aging does have an effect on engine exhaust emissions and affects emission measurements for a HDDE is proved invalid. The small variations in emission measurements during a fuel certification or verification emission test programs may not be affected by the factor, lubricant oil, but other environmental factors such as barometric pressure, dilution air humidity and intake air humidity may cause significant variations in emission measurements. Therefore, these quantities need to be monitored closely during emission tests for success of a fuel certification or verification program.

However, the conclusion may not be generalized for all legacy heavy-duty diesel engines from the same make year, as engine design and emission control strategies significantly differ from one manufacturer to other. The scope of the observations from this research study is limited by usage of only one HDDE as a test engine.

\subsection{Recommendations}

The results obtained from this research were very specific to the test conditions used in the study. To obtain a more generalized conclusion, testing of more than one legacy HDDEs from the same make year but different manufacturer is recommended. Also, following recommendations are made to further expand the scope of the research and to gain a better understanding on the subject matter: 
1. For better data precision, it is recommended to conduct more than two similar oil aging test sets on one engine and then same test sets on the other engines while maintaining same test configurations as was on the first engine.

2. The first set of oil aging tests in this study included both FTP transient and steady state tests, which were ran in between each other. But the effects of interspacing transient tests with steady state tests on oil aging are not known. It is recommended to run separate test sets of only transient tests and only steady state tests to understand the impact of oil aging on emissions under these engine operating conditions.

3. It would be interesting to identify the contribution of oil derived PM on total massbased PM emission and consequently oil derived contribution of SOF on total PM by using the techniques as described in the literature [7] [17].

4. Measurement of oil consumption rate can provide useful information about contribution of oil on particulate matter emissions.

5. Other methods of determination of particle size distribution of suspended particle in oil are recommended to validate the accuracy of the data obtained in this research study. 


\section{REFERENCES}

[1] "Copenhagen deal: Key Points," BBC News, BBC, London, England, 19 December 2009, retrieved from http://www.news.bbc.co.uk/2/hi/science/nature/8422307.stm.

[2] Skjoedt, M., Butts, R., Assanis, D.N., and Bohac, S.V., "Effects of Oil Properties on Spark-ignition Gasoline Engine Friction,” Tribology International, Vol. 41, 556-563, 2008.

[3] Boschert, T., "The Lubricant Contribution to Future Low Emission Engine Design," Diesel Particulate and NOx Emissions Course, University of Michigan, Ann Arbor, MI, October 2002.

[4] Jaaskelainen, H. and Majewski, W.A., "Diesel Engine Lubricants," DieselNet, Brampton, ON, Canada, retrieved from http://www.dieselnet.com/tech/lube.html, December 2009.

[5] Yilmaz, E., "Sources and Characteristics of Oil Consumption in a Spark-ignition Engine," Ph.D. Dissertation, Department of Mechanical Engineering, Massachusetts Institute of Technology, Cambridge, MA, 2003.

[6] Stetter, J., Forster, N., Ghandhi, J., and Foster, D., "The Impact of Oil Consumption Mechanisms on Diesel Exhaust Particle Size Distributions and Detailed Exhaust Chemical Composition,” DEER Conference, Newport, RI, August 2003.

[7] George, S., "Investigation of Lubricant Oil Consumption and its Contribution to Particulate Matter Emissions," Ph.D. Dissertation, Department of Mechanical and Aerospace Engineering, West Virginia University, Morgantown, WV, 2008.

[8] Przesmitzki, S. and Tian, T., "Oil Transport Inside the Power Cylinder during Transient Load Changes," SAE Paper No. 2007-01-1054, SAE International, Warrendale, PA, 2007.

[9] Hilden, D.L. and Mayer, W.J., "The Contribution of Engine Oil to Particulate Exhaust Emissions from Light-duty, Diesel-Powered Vehicles," SAE Paper No. 841395, SAE International, Warrendale, PA, 1984. 
[10] Dowling, M., "The Impact of Oil Formulation on Emissions from Diesel Engines," SAE Paper No. 922198, SAE International, Warrendale, PA, 1992.

[11] Miller, T.C., "Characterization of Lube Oil Derived Engine Particulate Emission Rate vs. Lube Oil Consumption," M.S. Thesis, Department of Ocean Engineering and Mechanical Engineering, Massachusetts Institute of Technology, Cambridge, MA, 1996.

[12] Andersson, J.D., Preston, H., Warrens, C., Brett, P., and Payne, M., "Lubricant Composition Impact on the Emissions from a European Heavy Duty Diesel Engine Equipped with a Diesel Particulate Filter," SAE Paper No. 2004-01-3012, SAE International, Warrendale, PA, 2004.

[13] Froelund, K., Owens, E.C., Frame, E., Buckingham, J.P., Garbak, J., Tseregounis, S., and Jackson, A., "Impact of Lubricant Oil on Regulated Emissions of a Light-duty Mercedes-Benz OM611 CIDI-Engine," SAE Paper No. 2001-01-1901, SAE International, Warrendale, PA, 2001.

[14] Froelund, K. and Yilmaz, E., "Impact of Engine Oil Consumption on Particulate Emissions," International Conference on Automotive Technology, Istanbul, Turkey, November 2004.

[15] Laurence, R.B., Wong, V.W., and Brown, A.J., "Effects of Lubrication System Parameters on Diesel Particulate Emission Characteristics," SAE Paper No. 960318, SAE International, Warrendale, PA, 1996.

[16] Andersson, J., Preston, H., Warrens, C., and Brett, P., "Fuel and Lubricant Effects on Nucleation Mode Particle Emissions from a Euro III Light Duty Diesel Vehicle," SAE Paper No. 2004-01-1989, SAE International, Warrendale, PA, 2004.

[17] Cooke, V. B., "Lubrication of Low Emission Diesel Engines - Part 1 and Part 2," SAE Paper No. 900814, SAE International, Warrendale, PA, 1990.

[18] Andrews, G.E., Abdelhalim, S., and Williams, P.T., "The Influence of Lubricating Oil Age on Emissions from an IDI Diesel," SAE Paper No. 931003, SAE International, Warrendale, PA, 1993. 
[19] "Advanced Petroleum-Based Fuels - Diesel Emissions Control (APBF - DEC)," Lubricants Project Phase 1, Final Report, produced for the U.S. Department of Energy by the National Renewable Energy Laboratory (NREL), Golden, CO, August 2004, retrieved from www.nrel.gov/vehiclesandfuels/apbf/pdfs/dec_lub_ph1_report.pdf.

[20] Sappok, A. G. and Wong, V. W., "Impact of Biodiesel on Ash Emissions and Lubricant Properties Fuel Economy and Engine Wear: Comparison with Conventional Diesel Fuel," SAE Paper No. 2008-01-1395, SAE International, Warrendale, PA, 2008.

[21] Sinha, S. and Agarwal, A.K., "Experimental of the Tribological Properties of Lubricating Oil from Biodiesel Fuelled Medium Duty Transportation CIDI Engine," SAE Paper No. 2008-01-1385, SAE International, Warrendale, PA, 2008.

[22] Vuk, C.T., Jones, M.A., and Johnson, J.H., "The Measurement and Analysis of the Physical Character of Diesel Particulate Emissions," SAE Technical Paper No. 760131, SAE International, Warrendale, PA, 1976.

[23] Burtscher, H. and Majewski, W.A., "Particulate Matter Measurements," DieselNet, Brampton, ON, Canada, 2004, see also www.dieselnet.com/tech/measure_dpm.html.

[24] Kittleson, D.B., Watts. W.F., and Johnson, J., "Diesel Aerosol Sampling Methodology-CRC E 43: Final Report," University of Minnesota, Report from the Coordinating Research Council, August 19, 2002.

[25] Majewski, W.A., and Khair, M.K., Diesel Emissions and their Control, SAE International, 2006.

[26] Burtscher, H., "Literature Study on Tailpipe Particulate Emission Measurement for Diesel Engines," Report for Particle Measurement Programme, BUWAL/GRPE, March 2001, retrieved from http://www.akpf.org/pub/burtscher_bericht.pdf.

[27] Swanson, J. and Kittleson, D., "Factors Influencing Mass Collected During 2007 Diesel PM Filter Sampling," SAE Paper No. 2009-01-1517, SAE International, Warrendale, PA, 2009.

[28] HEI Program Summary, "Research on Diesel Exhaust and Other Particles," Health Effects Institute, Charlestown Navy Yard, Boston, MA, 2003. 
[29] Walsh, M.P., "Global Trends in Diesel Emissions Regulation - A 2001 Update," SAE Paper No. 2001-01-0183, SAE International, Warrendale, PA, 2001.

[30] McClellan, Roger O., "Health Effects of Exposure to Diesel Exhaust Particles," Annual Review of Pharmacology and Toxicology, Vol. 27, 279-300, 1987, retrieved from www.arjournals.annualreviews.org/doi/pdf/10.1146/annurev.pa.27.040187.001431.

[31] Silverman, D. T., Hoover, R. N., Albert. S., and Graft, K. M., "Occupation and Cancer of the Lower Urinary Tract in Detroit," Journal of National Cancer Institute, Vol. 70, 237-45, 1983.

[32] "Proposed Identification of Diesel Exhaust as a Toxic Air Contaminant," Report by the Staff of the California Air Resources Board and the Office of Environmental Health Hazard Assessment, Sacramento, California, April 22, 1998.

[33] Code of Federal Regulations, CFR Title 40 Part 86 and 1065, Office of Federal Register, National Archives and Records Administration, Washington, D.C, 2005.

[34] Detroit Diesel Corporation, "Engine Requirements-Lubricating Oil, Fuels and Filters," Bulletin 7SE270 0401, January 2004.

[35] Pei, Y., "Development of Software for the Heavy-Duty Engine Testing at Engine Research Center, West Virginia University,” M.S. Thesis, Department of Mechanical and Aerospace Engineering, West Virginia University, Morgantown, WV, 1993.

[36] DMS500 Fast Particulate Spectrometer User Manual-version 1.8, Cambustion Ltd., Cambridge, U.K., 2003.

[37] Flaim, K.A.C., "Study of the Variations in Continuous Diesel Particulate Matter Size Measurements and Effect of Fuel Properties on DPM Size," M.S. Thesis, Department of Mechanical and Aerospace Engineering, West Virginia University, Morgantown, WV, 2008.

[38] Perez, J.M., Lipari, F., and Seizinger, D.E., "Cooperative Development of Analytical Methods for Diesel Emissions and Particulates - Solvent Extractable, Aldehydes and Sulfate Methods,” SAE Paper No. 840413, SAE International, Warrendale, PA, 1984. 
[39] Perez, J.M., Hills, F.J., Schuetzle, D., and Williams, R.L., "Informational Report on the Measurement and Characterization of Diesel Exhaust Emissions," CRC-APRAC Project No. CAPI-1-64, Coordinating Research Council, December, 1980.

[40] Zetasizer Nano User Manual, Mano 317, Issue 3.0, Malvern Instruments Ltd., Worcestershire, U.K., January 2007.

[41] Kittleson, D.B., "Measurement of Engine Exhaust Particle Size," Center for Diesel Research, University of Minnesota, presented at University of California, Davis, February 2000.

[42] Nuszkowski, J.P., "The Effects of Fuel Additives on Diesel Engine Emissions During Steady State and Transient Operation," Ph.D. Dissertation, Department of Mechanical and Aerospace Engineering, West Virginia University, Morgantown, WV, 2008.

[43] Moore, D.S. and McCabe, G.P., Introduction to the Practice of Statistics, W.H. Freeman and Company, New York, $4^{\text {th }}$ Edition, 2003.

[44] Heywood, J.B., Internal Combustion Engine Fundamentals, McGraw-Hill Book Company, New York, 1988.

[45] Hardin, J.W., "Quantification of Soluble Organic Fraction Measurement Variation in Diesel Particulate Matter Emissions," M.S. Thesis, Department of Mechanical and Aerospace Engineering, West Virginia University, Morgantown, WV, 2008.

[46] Lechner, G., Knafl, A., Assanis, D., Tseregounis, S.I., McMillan, M.L., Tung, S.C., Mulawa, P.A., Bardasz, E., and Cowling, S., "Engine Oil Effects on the Friction and Emissions of a Light-Duty, 2.2L Direct-Injection-Diesel Engine, Part 1-Engine Test Results," SAE Paper No. 2002-01-2681, SAE International, Warrendale, PA, 2002.

[47] Jung, H., Kittleson, D.B., and Zachariah, M.R., "The influence of Engine Lubricating Oil on Diesel Nanoparticle Emissions and Kinetics of Oxidation," SAE Paper No. 2003-01-3179, SAE International, Warrendale, PA, 2003. 


\section{APPENDIX A}

\section{A.1. The U.S. EPA Heavy-Duty Diesel Engine Exhaust Emission Standards}

Table A.1 : US EPA HDDE Truck Emission Standards (g/bhp-hr) [33].

\begin{tabular}{|l|c|c|c|c|c|c|}
\hline Year & $\mathrm{HC}$ & $\mathrm{CO}$ & $\mathrm{NOx}$ & $\mathrm{PM}$ & $\mathrm{NMHC}+\mathrm{NOx}$ & $\mathrm{NMHC}$ \\
\hline 1988 & 1.3 & 15.5 & 10.7 & 0.6 & $\mathrm{~N} / \mathrm{A}$ & $\mathrm{N} / \mathrm{A}$ \\
\hline 1990 & 1.3 & 15.5 & 6 & 0.6 & $\mathrm{~N} / \mathrm{A}$ & $\mathrm{N} / \mathrm{A}$ \\
\hline 1991 & 1.3 & 15.5 & 5 & 0.25 & $\mathrm{~N} / \mathrm{A}$ & $\mathrm{N} / \mathrm{A}$ \\
\hline 1994 & 1.3 & 15.5 & 5 & 0.1 & $\mathrm{~N} / \mathrm{A}$ & $\mathrm{N} / \mathrm{A}$ \\
\hline 1998 & 1.3 & 15.5 & 4 & 0.1 & $\mathrm{~N} / \mathrm{A}$ & $\mathrm{N} / \mathrm{A}$ \\
\hline $2004^{*}$ Option (1) & 1.3 & 15.5 & $\mathrm{~N} / \mathrm{A}$ & 0.1 & 2.4 & $\mathrm{~N} / \mathrm{A}$ \\
\hline $2004^{*}$ Option (2) & 1.3 & 15.5 & $\mathrm{~N} / \mathrm{A}$ & 0.1 & 2.5 & 0.5 \\
\hline $2007-2010$ & 1.3 & 15.5 & 0.2 & 0.01 & $\mathrm{~N} / \mathrm{A}$ & 0.14 \\
\hline
\end{tabular}

* 2004 standards were in effect from October 2002 


\section{A.2. Emission from FTP Test Sequences}

Table A.2 : Emission from First Set FTPs (g/bhp-hr).

\begin{tabular}{|c|c|c|c|c|c|c|c|}
\hline $\begin{array}{l}\text { Test } \\
\text { Sequence }\end{array}$ & $\mathrm{CO}$ & $\mathrm{CO} 2$ & $\mathrm{NOx}(\mathrm{I})$ & $\mathrm{NOx}(\mathrm{II})$ & $\mathrm{HC}$ & $\mathrm{SecHC}$ & PM \\
\hline E 02510-01 & 2.555 & 546.6 & 5.007 & 5.024 & 1.7639 & 0.0950 & 0.20828 \\
\hline \begin{tabular}{|l|l}
$E 02510-02$ \\
\end{tabular} & 2.513 & 542.3 & 4.928 & 4.954 & 1.6724 & 0.0971 & 0.19897 \\
\hline E 02510-03 & 2.525 & 541.2 & 4.914 & 4.938 & 1.6727 & 0.0982 & 0.20149 \\
\hline E 02510-04 & 2.490 & 540.5 & 4.910 & 4.928 & 1.6439 & 0.0960 & 0.19414 \\
\hline E02510-05 & 2.476 & 542.3 & 4.967 & 4.961 & 1.6253 & 0.0945 & 0.19816 \\
\hline E 02510-06 & 2.517 & 540.1 & 4.888 & 4.974 & 1.5586 & 0.0919 & 0.19442 \\
\hline E 02513-01 & 2.521 & 533.1 & 4.866 & 4.957 & 1.3930 & 0.0788 & 0.19612 \\
\hline E 02513-02 & 2.495 & 540.7 & 4.881 & 4.993 & 1.5600 & 0.0911 & 0.19272 \\
\hline E 02513-03 & 2.502 & 540.9 & 4.890 & 5.012 & 1.6369 & 0.0971 & 0.19525 \\
\hline E 02513-04 & 2.468 & 541.6 & 4.928 & 5.046 & 1.5111 & 0.0893 & 0.18672 \\
\hline E 02513-05 & 2.485 & 540.8 & 4.880 & 5.003 & 1.4783 & 0.0868 & 0.19012 \\
\hline E 02514-01 & 2.657 & 545.2 & 4.979 & 5.028 & 1.6418 & 0.0948 & 0.22113 \\
\hline E 02514-02 & 2.530 & 542.5 & 4.938 & 5.008 & 1.5403 & 0.0894 & 0.19499 \\
\hline E 02514-03 & 2.512 & 541.1 & 4.921 & 4.991 & 1.6089 & 0.0931 & 0.19584 \\
\hline E 02514-04 & 2.507 & 541.0 & 4.951 & 4.999 & 1.5294 & 0.0876 & 0.19580 \\
\hline E 02514-05 & 2.542 & 541.0 & 4.982 & 5.038 & 1.5745 & 0.0898 & 0.19984 \\
\hline E 02514-06 & 2.538 & 540.5 & 4.935 & 4.997 & 1.5704 & 0.0865 & 0.19459 \\
\hline E 02517-01 & 2.588 & 536.9 & 4.940 & 4.997 & 1.6803 & 0.0964 & 0.19560 \\
\hline E 02517-02 & 2.577 & 540.9 & 4.944 & 5.046 & 1.6584 & 0.0953 & 0.19371 \\
\hline E 02517-03 & 2.622 & 541.6 & 4.930 & 5.035 & 1.6629 & 0.0984 & 0.19908 \\
\hline E 02517-04 & 2.584 & 541.0 & 4.920 & 5.023 & 1.5988 & 0.0952 & 0.19374 \\
\hline E 02517-05 & 2.576 & 539.3 & 4.941 & 5.029 & 1.6324 & 0.0974 & 0.19919 \\
\hline E 02518-01 & 2.676 & 544.5 & 4.969 & 5.000 & 1.7091 & 0.0957 & 0.20262 \\
\hline E 02518-02 & 2.586 & 540.2 & 4.956 & 5.010 & 1.6299 & 0.0917 & 0.19461 \\
\hline E 02518-03 & 2.537 & 540.5 & 4.996 & 5.041 & 1.5253 & 0.0854 & 0.19299 \\
\hline E 02518-04 & 2.544 & 538.7 & 4.967 & 4.992 & 1.5925 & 0.0923 & 0.19256 \\
\hline E 02518-05 & 2.570 & 538.5 & 4.953 & 4.996 & 1.6393 & 0.0954 & 0.19813 \\
\hline E 02518-06 & 2.563 & 538.0 & 4.950 & 4.982 & 1.5714 & 0.0887 & 0.19410 \\
\hline E 02520-01 & 2.614 & 536.7 & 4.960 & 4.999 & 1.6463 & 0.0968 & 0.19742 \\
\hline E 02520-02 & 2.592 & 537.8 & 4.969 & 5.021 & 1.6202 & 0.0955 & 0.19791 \\
\hline E 02520-03 & 2.607 & 537.9 & 4.943 & 5.021 & 1.6609 & 0.0980 & 0.20192 \\
\hline E 02520-04 & 2.586 & 538.6 & 4.953 & 4.992 & 1.5777 & 0.0937 & 0.20205 \\
\hline E 02520-05 & 2.559 & 539.3 & 4.971 & 4.994 & 1.5737 & 0.0916 & 0.19905 \\
\hline E 02521-01 & 2.685 & 543.9 & 5.015 & 5.042 & 1.6107 & 0.0889 & 0.20573 \\
\hline E 02521-02 & 2.622 & 541.4 & 4.969 & 5.012 & 1.6107 & 0.0899 & 0.19767 \\
\hline E 02521-03 & 2.554 & 540.8 & 4.952 & 5.002 & 1.6242 & 0.0924 & 0.19467 \\
\hline E 02521-04 & 2.543 & 541.1 & 4.970 & 5.031 & 1.6199 & 0.0921 & 0.19348 \\
\hline E 02521-05 & 2.514 & 539.3 & 4.943 & 5.003 & 1.5809 & 0.0893 & 0.19085 \\
\hline E 02522-01 & 2.203 & 538.7 & 4.950 & 4.980 & 1.4583 & 0.0809 & 0.15430 \\
\hline E 02522-02 & 2.188 & 539.1 & 4.942 & 5.018 & 1.4359 & 0.0829 & 0.14475 \\
\hline E 02522-03 & 2.174 & 540.9 & 4.942 & 5.014 & 1.5021 & 0.0860 & 0.14449 \\
\hline E 02522-04 & 2.217 & 540.5 & 4.946 & 5.005 & 1.5595 & 0.0889 & 0.14994 \\
\hline E 02522-05 & 2.184 & 539.9 & 4.949 & 5.006 & 1.5236 & 0.0885 & 0.14700 \\
\hline E 02523-01 & 2.508 & 539.9 & 4.957 & 5.023 & 1.5498 & 0.0922 & 0.18720 \\
\hline \begin{tabular}{|l|}
$E 02523-02$ \\
\end{tabular} & 2.486 & 539.8 & 4.986 & 5.032 & 1.5944 & 0.0939 & 0.18763 \\
\hline E 02523-03 & 2.490 & 538.3 & 4.968 & 5.029 & 1.5158 & 0.0895 & 0.18874 \\
\hline E 02523-04 & 2.445 & 539.3 & 4.959 & 5.017 & 1.5190 & 0.0882 & 0.18468 \\
\hline \begin{tabular}{|l|}
$E 02523-05$ \\
\end{tabular} & 2.475 & 540.0 & 4.940 & 4.994 & 1.5410 & 0.0889 & 0.19110 \\
\hline E 02526-01 & 2.829 & 540.8 & 5.054 & 4.998 & 0.0948 & 0.1052 & 0.21333 \\
\hline E 02526-02 & 2.694 & 543.4 & 4.920 & 4.936 & 0.0915 & 0.1042 & 0.20585 \\
\hline \begin{tabular}{|l|}
$E 02526-03$ \\
\end{tabular} & 2.654 & 542.8 & 4.862 & 4.908 & 0.0815 & 0.0929 & 0.20669 \\
\hline \begin{tabular}{|l|}
$E 02526-04$ \\
\end{tabular} & 2.605 & 542.6 & 4.909 & 4.931 & 0.0836 & 0.0933 & 0.19837 \\
\hline \begin{tabular}{|l|}
$E 02526-05$ \\
\end{tabular} & 2.625 & 542.0 & 4.922 & 4.928 & 0.0745 & 0.0932 & 0.20102 \\
\hline \begin{tabular}{|l|}
$E 02526-06$ \\
\end{tabular} & 2.504 & 533.3 & 4.908 & 4.954 & 0.0883 & 0.0997 & 0.19544 \\
\hline \begin{tabular}{|l|}
$E 02526-07$ \\
\end{tabular} & 2.617 & 541.8 & 4.918 & 4.262 & 0.0792 & 0.0896 & 0.19892 \\
\hline
\end{tabular}


Table A.3 : Emission from Second Set FTPs (g/bhp-hr).

\begin{tabular}{|c|c|c|c|c|c|c|c|}
\hline $\begin{array}{l}\text { Test } \\
\text { Sequence }\end{array}$ & $\mathrm{CO}$ & $\mathrm{CO} 2$ & $\mathrm{NOx}(\mathrm{I})$ & NOx(II) & $\mathrm{HC}$ & $\mathrm{SecHC}$ & PM \\
\hline E02531-01 & 2.715 & 542.5 & 4.903 & 4.938 & 0.0883 & 0.1010 & 0.20602 \\
\hline E 02531-02 & 2.646 & 540.2 & 4.893 & 4.939 & 0.0965 & 0.1108 & 0.20508 \\
\hline E 02531-03 & 2.614 & 539.5 & 4.866 & 4.926 & 0.0961 & 0.1117 & 0.20507 \\
\hline E 02531-04 & 2.623 & 538.6 & 4.906 & 4.982 & 0.0925 & 0.1079 & 0.20291 \\
\hline E 02532-01 & 2.787 & 547.7 & 5.063 & 5.093 & 0.0814 & 0.0948 & 0.20464 \\
\hline E 02533-01 & 2.681 & 547.7 & 4.971 & 5.059 & 0.0959 & 0.1071 & 0.19876 \\
\hline E 02533-02 & 2.539 & 540.1 & 4.946 & 5.008 & 0.0910 & 0.1020 & 0.19617 \\
\hline E 02533-03 & 2.537 & 539.4 & 4.916 & 4.961 & 0.0915 & 0.1025 & 0.20114 \\
\hline E 02533-04 & 2.531 & 538.0 & 4.952 & 4.963 & 0.0890 & 0.1016 & 0.20046 \\
\hline E 02533-05 & 2.517 & 538.7 & 4.934 & 4.961 & 0.0863 & 0.0988 & 0.19962 \\
\hline E 02534-01 & 2.628 & 547.4 & 4.938 & 5.032 & 0.0854 & 0.0980 & 0.19547 \\
\hline E 02534-02 & 2.532 & 541.0 & 4.922 & 4.942 & 0.0856 & 0.1000 & 0.19705 \\
\hline E 02534-03 & 2.522 & 541.7 & 4.916 & 4.945 & 0.0880 & 0.1040 & 0.21574 \\
\hline E 02534-04 & 2.520 & 540.4 & 4.927 & 4.943 & 0.0883 & 0.1026 & 0.20215 \\
\hline E 02534-05 & 2.486 & 539.9 & 4.904 & 4.931 & 0.0856 & 0.0987 & 0.19880 \\
\hline \begin{tabular}{|l|l|}
$E 02534-06$ \\
\end{tabular} & 2.505 & 539.8 & 4.910 & 4.941 & 0.0858 & 0.0986 & 0.19839 \\
\hline E 02535-01 & 2.681 & 544.4 & 4.879 & 4.964 & 0.0887 & 0.0970 & 0.20912 \\
\hline E 02535-02 & 2.546 & 542.2 & 4.915 & 4.926 & 0.0878 & 0.1009 & 0.20085 \\
\hline E 02535-03 & 2.498 & 540.7 & 4.954 & 4.967 & 0.0827 & 0.0949 & 0.19874 \\
\hline E 02535-04 & 2.510 & 540.7 & 4.904 & 4.933 & 0.0903 & 0.1047 & 0.20268 \\
\hline E02536-01 & 2.419 & 540.4 & 4.916 & 4.919 & 0.0827 & 0.0969 & 0.19887 \\
\hline E 02536-02 & 2.498 & 541.0 & 4.896 & 4.927 & 0.0816 & 0.0958 & 0.19634 \\
\hline E02536-03 & 2.495 & 539.4 & 4.883 & 4.907 & 0.0801 & 0.0942 & 0.19709 \\
\hline E 02536-04 & 2.507 & 540.5 & 4.903 & 4.936 & 0.0844 & 0.0979 & 0.20335 \\
\hline E 02538-01 & 2.249 & 538.8 & 4.884 & 4.887 & 0.0839 & 0.0947 & 0.15712 \\
\hline E02538-02 & 2.235 & 538.4 & 4.880 & 4.888 & 0.0780 & 0.0896 & 0.15502 \\
\hline E02538-03 & 2.245 & 540.1 & 4.881 & 4.909 & 0.0819 & 0.0932 & 0.16010 \\
\hline \begin{tabular}{|l|}
$E 02538-04$ \\
\end{tabular} & 2.211 & 539.6 & 4.890 & 4.917 & 0.0716 & 0.0829 & 0.15505 \\
\hline \begin{tabular}{|l|}
$E 02539-01$ \\
\end{tabular} & 2.504 & 541.7 & 4.921 & 4.975 & 0.0788 & 0.0921 & 0.20214 \\
\hline E 02539-02 & 2.478 & 538.5 & 4.935 & 4.962 & 0.0811 & 0.0930 & 0.19946 \\
\hline E 02539-03 & 2.476 & 538.7 & 4.936 & 4.924 & 0.0827 & 0.0944 & 0.19876 \\
\hline E02539-04 & 2.479 & 539.5 & 4.936 & 4.909 & 0.0796 & 0.0914 & 0.20136 \\
\hline \begin{tabular}{|l|}
$E 02540-01$ \\
\end{tabular} & 2.544 & 546.9 & 4.921 & 4.964 & 0.0844 & 0.0947 & 0.20030 \\
\hline E 02540-02 & 2.446 & 541.4 & 4.946 & 4.942 & 0.0803 & 0.0903 & 0.19737 \\
\hline E02540-03 & 2.415 & 541.5 & 4.876 & 4.936 & 0.0751 & 0.0849 & 0.19489 \\
\hline E 02540-04 & 2.405 & 539.8 & 4.871 & 4.898 & 0.0750 & 0.0881 & 0.19469 \\
\hline E 02540-05 & 2.431 & 541.2 & 4.883 & 4.946 & 0.0805 & 0.0923 & 0.19697 \\
\hline
\end{tabular}




\section{A.3. Emission from Steady State Test Sequences}

Table A.4 : Emission from Steady State Test Sequences (g/bhp-hr), Contd...

\begin{tabular}{|c|c|c|c|c|c|c|c|c|c|c|c|c|c|}
\hline \multirow{2}{*}{$\begin{array}{l}\text { Test } \\
\text { Sequences }\end{array}$} & Mode Sequence & 1 & 2 & 3 & 4 & 5 & 6 & 7 & 8 & 9 & 10 & 11 & 12 \\
\hline & ESC Modes & Idle & Mode 3 & Mode 2 & Mode 7 & Mode 10 & Mode 11 & Idle & Mode 3 & Mode 2 & Mode 7 & Mode 10 & Mode 11 \\
\hline \multirow[t]{6}{*}{ E02511 } & $\mathrm{HC}$ & - & -0.1188 & -0.0516 & -0.3320 & -0.0264 & -0.1991 & - & -0.1203 & -0.0538 & -0.3332 & -0.0266 & -0.2073 \\
\hline & $\mathrm{CO}$ & - & 0.4929 & 5.8342 & 0.4690 & 1.2671 & 0.6159 & - & 0.4658 & 5.8783 & 0.4450 & 1.2389 & 0.5950 \\
\hline & $\mathrm{CO} 2$ & - & 486.7690 & 72.0829 & 520.3264 & 60.6725 & 555.5110 & - & 481.7421 & 68.7433 & 514.9244 & 458.4941 & 549.9922 \\
\hline & NOx & - & 9.5923 & 5.2882 & 11.4924 & 4.1911 & 12.3062 & - & 9.5971 & 5.3095 & 11.5626 & 4.2156 & 12.3679 \\
\hline & NOx2 & - & 9.8172 & 6.1910 & 11.7882 & 7.2154 & 12.6127 & - & 9.6897 & 6.1276 & 11.6889 & 7.2065 & 12.5323 \\
\hline & $\mathrm{PM}$ & - & 0.0466 & 0.2275 & 0.0366 & 0.0957 & 0.0870 & - & 0.0509 & 0.2169 & 0.0420 & 0.1039 & 0.0763 \\
\hline \multirow[t]{6}{*}{$E 02512$} & $\mathrm{HC}$ & - & -0.2248 & -0.1012 & -0.5824 & -0.0661 & -0.4228 & - & -0.2318 & -0.1018 & -0.5842 & -0.0679 & -0.4185 \\
\hline & $\mathrm{CO}$ & - & 0.4581 & 5.6524 & 0.4439 & 1.2313 & 0.5783 & - & 0.4446 & 5.6429 & 0.4444 & 1.2332 & 0.5899 \\
\hline & $\mathrm{CO} 2$ & - & 85.1460 & 69.8489 & 515.5407 & 58.7388 & 551.2949 & - & 80.9623 & 69.4948 & 515.1203 & 459.4686 & 550.8028 \\
\hline & NOx & - & 9.6330 & 5.3103 & 11.4617 & 4.2343 & 12.3161 & - & 9.5564 & 5.3162 & 11.4771 & 4.2438 & 12.2510 \\
\hline & $\mathrm{NO} \times 2$ & - & 9.7718 & 6.1848 & 11.6534 & 7.2405 & 12.5271 & - & 9.7084 & 6.1440 & 11.6745 & 7.2165 & 12.4651 \\
\hline & PM & - & 0.0417 & 0.1992 & 0.0409 & 0.0969 & 0.0570 & - & 0.0418 & 0.2023 & 0.0512 & 0.0890 & 0.0668 \\
\hline \multirow[t]{6}{*}{$E 02515$} & $\mathrm{HC}$ & - & -0.0342 & -0.0109 & -0.1259 & 0.0003 & -0.0382 & - & -0.0316 & -0.0094 & -0.1228 & -0.0002 & -0.0417 \\
\hline & $\mathrm{CO}$ & - & 0.4933 & 6.1153 & 0.4331 & 1.2793 & 0.5833 & - & 0.4763 & 6.1764 & 0.4198 & 1.2890 & 0.5705 \\
\hline & $\mathrm{CO} 2$ & - & 485.1217 & 470.7538 & 517.9594 & 458.4768 & 552.3927 & - & 482.8702 & 470.4205 & 516.6974 & 459.4311 & 552.7880 \\
\hline & NOx & - & 9.7951 & 5.2847 & 11.5874 & 4.1985 & 12.4697 & - & 9.6183 & 5.3090 & 11.6280 & 4.1948 & 12.4511 \\
\hline & $\mathrm{NO} \times 2$ & - & 9.8712 & 6.1390 & 11.7751 & 7.2327 & 12.6852 & - & 9.7282 & 6.1317 & 11.7647 & 7.2206 & 12.6273 \\
\hline & $P M$ & - & 0.0410 & 0.2274 & 0.0316 & 0.0822 & 0.0649 & - & 0.0479 & 0.2177 & 0.0317 & 0.0812 & 0.0744 \\
\hline \multirow[t]{6}{*}{$E 02516$} & $\mathrm{HC}$ & - & -0.1643 & -0.0719 & -0.4368 & -0.0428 & -0.2841 & - & -0.1581 & -0.0706 & -0.4266 & -0.0432 & -0.2895 \\
\hline & $\mathrm{CO}$ & - & 0.4881 & 6.0644 & 0.4474 & 1.3204 & 0.6105 & - & 0.4799 & 6.0176 & 0.4459 & 1.2860 & 0.5899 \\
\hline & $\mathrm{CO} 2$ & - & 486.2957 & 470.3682 & 516.4855 & 458.3392 & 550.3558 & - & 480.3159 & 470.5129 & 515.2782 & 458.0567 & 549.9531 \\
\hline & NOx & - & 9.7001 & 5.3046 & 11.6830 & 4.1952 & 12.4261 & - & 9.6097 & 5.1804 & 11.6032 & 4.1431 & 12.4024 \\
\hline & $\mathrm{NO} \times 2$ & - & 9.8478 & 6.1922 & 11.8819 & 7.2041 & 12.6413 & - & 9.7401 & 6.1323 & 11.8085 & 7.2006 & 12.6193 \\
\hline & PM & - & 0.0388 & 0.2090 & 0.0281 & 0.0776 & 0.0716 & - & 0.0484 & 0.2107 & 0.0410 & 0.0798 & 0.0705 \\
\hline \multirow[t]{6}{*}{$E 02519$} & $\mathrm{HC}$ & - & -0.1929 & -0.0871 & -0.5124 & -0.0535 & -0.3556 & - & -0.1933 & -0.0884 & -0.5132 & -0.0557 & -0.3653 \\
\hline & $\mathrm{CO}$ & - & 0.5002 & 6.2600 & 0.4448 & 1.4023 & 0.5749 & - & 0.5009 & 6.1388 & 0.4526 & 1.3518 & 0.5731 \\
\hline & $\mathrm{CO} 2$ & - & 482.0290 & 468.1061 & 515.7355 & 457.6427 & 550.6870 & - & 480.2679 & 469.1365 & 514.3604 & 458.1896 & 548.9319 \\
\hline & $\mathrm{NOx}$ & - & 9.5903 & 5.2437 & 11.6626 & 4.1885 & 12.4127 & - & 9.4906 & 5.1803 & 11.5621 & 4.2079 & 12.4035 \\
\hline & $\mathrm{NO} \times 2$ & - & 9.7609 & 6.1271 & 11.8118 & 7.1905 & 12.5637 & - & 9.6945 & $\begin{array}{l}6.0627 \\
\end{array}$ & 11.8101 & 7.2136 & 12.6198 \\
\hline & $\mathrm{PM}$ & - & 0.0419 & 0.2275 & 0.0360 & 0.0859 & 0.0693 & - & 0.0486 & 0.2183 & 0.0455 & 0.0813 & 0.0578 \\
\hline
\end{tabular}


Table A.5 : Emission from Steady State Test Sequences (g/bhp-hr).

\begin{tabular}{|c|c|c|c|c|c|c|c|c|c|c|c|c|c|}
\hline \multirow{2}{*}{$\begin{array}{l}\text { Test } \\
\text { Sequences }\end{array}$} & Mode Sequence & 13 & 14 & 15 & 16 & 17 & 18 & 19 & 20 & 21 & 22 & 23 & 24 \\
\hline & ESC Modes & \begin{tabular}{|l|} 
Idle \\
\end{tabular} & Mode 3 & Mode 2 & Mode 7 & Mode10 & Idle & Mode 11 & Mode 3 & Mode 2 & Mode 7 & Mode10 & Mode 11 \\
\hline \multirow[t]{6}{*}{ E02511 } & $\mathrm{HC}$ & - & -0.1219 & -0.0533 & -0.3386 & -0.0288 & - & -0.2069 & -0.1219 & -0.0521 & -0.3371 & -0.0295 & -0.2145 \\
\hline & $\mathrm{CO}$ & - & 0.4497 & 5.7578 & 0.4303 & 1.2382 & - & 0.5873 & 0.4627 & 5.7083 & 0.4297 & 1.2063 & 0.5745 \\
\hline & $\mathrm{CO} 2$ & - & 481.5263 & 468.3202 & 514.2781 & 458.7965 & - & 550.8801 & 479.9140 & 468.1545 & 513.4991 & 458.3513 & 551.1971 \\
\hline & NOx & - & 9.5749 & 5.3215 & 11.4465 & 4.2367 & - & 12.2397 & 9.5692 & 5.2894 & 11.4979 & 4.2094 & 12.2578 \\
\hline & $\mathrm{NO} \times 2$ & - & 9.6981 & 6.1444 & 11.6343 & 7.2050 & - & 12.4358 & 9.6425 & 6.1168 & 11.6258 & 7.2059 & 12.4419 \\
\hline & $\overline{P M}$ & - & 0.0435 & 0.2056 & 0.0369 & 0.1250 & - & 0.0697 & 0.0477 & 0.2097 & 0.0359 & 0.1162 & 0.0663 \\
\hline \multirow[t]{6}{*}{ E02512 } & $\mathrm{HC}$ & - & -0.2263 & -0.1028 & -0.5868 & -0.0668 & - & -0.4192 & -0.2257 & -0.1001 & -0.5907 & -0.0661 & -0.4155 \\
\hline & $\mathrm{CO}$ & - & 0.4574 & 5.6586 & 0.4388 & 1.2261 & - & 0.5823 & 0.4356 & 5.5402 & 0.4219 & 1.2274 & 0.5901 \\
\hline & $\mathrm{CO} 2$ & - & 482.7704 & 470.6526 & 515.8332 & 459.0045 & - & 550.0050 & 480.2252 & 470.0434 & 514.7730 & 458.1996 & 549.8161 \\
\hline & NOx & - & 9.5150 & 5.3326 & 11.4405 & 4.2436 & - & 12.2680 & 9.5544 & 5.3263 & 11.4233 & 4.2541 & 12.2665 \\
\hline & NOx2 & - & 9.6402 & 6.1314 & 11.6148 & 7.2209 & - & 12.4538 & 9.7311 & 6.1640 & 11.6569 & 7.2549 & 12.5122 \\
\hline & $P M$ & - & 0.0428 & 0.2017 & 0.0303 & 0.0838 & - & 0.0496 & 0.0440 & 0.2009 & 0.0285 & 0.0852 & 0.0581 \\
\hline \multirow[t]{6}{*}{ E02515 } & $\mathrm{HC}$ & - & -0.0295 & -0.0096 & -0.1224 & 0.0021 & - & -0.0235 & -0.0303 & --- & -- & --- & --- \\
\hline & $\mathrm{CO}$ & - & 0.4901 & 6.0405 & 0.4172 & 1.2835 & - & 0.5995 & 0.4786 & --- & -- & --- & --- \\
\hline & CO2 & - & 483.2884 & 469.4402 & 516.3051 & 457.7395 & - & 549.4455 & \begin{tabular}{|l|}
480.7179 \\
\end{tabular} & --- & -- & --- & --- \\
\hline & NOx & - & 9.6182 & 5.2759 & 11.5961 & 4.1782 & - & 12.3946 & 9.5143 & --- & --- & --- & --- \\
\hline & $\mathrm{NO} \times 2$ & - & 9.7596 & 6.1567 & 11.7884 & 7.2290 & - & 12.5838 & 9.6759 & --- & -- & -- & --- \\
\hline & $P M$ & - & 0.0413 & 0.2080 & 0.0271 & 0.0766 & - & 0.0700 & 0.0430 & --- & --- & -- & --- \\
\hline \multirow[t]{6}{*}{\begin{tabular}{|l|}
$E 02516$ \\
\end{tabular}} & $\mathrm{HC}$ & - & -0.1625 & -0.0704 & -0.4339 & -0.0440 & - & -0.2784 & -0.1620 & -0.0706 & -0.4380 & -0.0455 & -0.2868 \\
\hline & $\mathrm{CO}$ & - & 0.4799 & 5.9939 & 0.4433 & 1.2989 & - & 0.6122 & 0.4723 & 6.0118 & 0.4295 & 1.2838 & 0.5974 \\
\hline & $\mathrm{CO} 2$ & - & 480.8449 & 469.0155 & 513.2647 & 458.5155 & - & 549.7844 & 480.9464 & 469.7113 & 513.5923 & 457.5237 & 549.1042 \\
\hline & NOx & - & 9.6222 & 5.2753 & 11.6077 & 4.2009 & - & 12.5389 & 9.6106 & 5.2726 & 11.5574 & 4.1986 & 12.3667 \\
\hline & $\mathrm{NO} \times 2$ & - & 9.7298 & 6.1345 & 11.7662 & 7.2344 & - & 12.6895 & 9.7406 & 6.1434 & 11.7628 & 7.1931 & 12.5658 \\
\hline & $P M$ & - & 0.0402 & 0.2089 & 0.0299 & 0.0797 & - & 0.0714 & 0.0450 & 0.2114 & 0.0300 & 0.0813 & 0.0692 \\
\hline \multirow[t]{6}{*}{$E 02519$} & $\mathrm{HC}$ & - & -0.1883 & -0.0907 & -0.5122 & -0.0532 & - & -0.3623 & -0.1928 & -0.0895 & -0.5209 & -0.0555 & -0.3571 \\
\hline & $\mathrm{CO}$ & - & 0.5156 & 6.3476 & 0.4493 & 1.4053 & - & 0.5721 & 0.4953 & 6.2547 & 0.4378 & 1.4125 & 0.5922 \\
\hline & CO2 & - & 481.6296 & 469.1269 & 514.4431 & 459.6582 & - & 547.2617 & 481.0590 & 469.6522 & 514.0463 & 460.1695 & 548.9420 \\
\hline & NOx & - & 9.6290 & 5.2812 & 11.6440 & 4.2134 & - & 12.4922 & 9.7097 & 5.2920 & 11.5686 & 4.2411 & 12.3883 \\
\hline & $\mathrm{NO} \times 2$ & - & 9.7174 & 6.1322 & 11.7561 & 7.2052 & - & 12.6416 & 9.8026 & 6.1349 & 11.7422 & 7.2133 & 12.5868 \\
\hline & $P M$ & - & 0.0461 & 0.2265 & 0.0462 & 0.0861 & - & 0.0598 & 0.0488 & 0.2185 & 0.0397 & 0.0860 & 0.0647 \\
\hline
\end{tabular}




\section{A.4. Humidity and Barometric Pressure from FTP Test Groups}

Table A.6 : Averaged Humidity and Barometric Pressure from First Set FTPs.

\begin{tabular}{|l|r|r|r|}
\hline Test Group & $\begin{array}{c}\text { Barometric } \\
\text { Pressure, (in } \\
\text { Hg) }\end{array}$ & $\begin{array}{c}\text { Intake Air } \\
\text { Humidity, } \\
\text { (grains/lb) }\end{array}$ & $\begin{array}{c}\text { Dilution Air } \\
\text { Humidity, } \\
\text { (grains/lb) }\end{array}$ \\
\hline E02510 & 29.10 & 77.879 & 61.874 \\
\hline E02513 & 29.20 & 74.473 & 60.402 \\
\hline E02514 & 29.16 & 76.107 & 47.907 \\
\hline E02517 & 28.87 & 77.638 & 50.385 \\
\hline E02518 & 28.86 & 75.208 & 53.576 \\
\hline E02520 & 28.87 & 75.904 & 51.533 \\
\hline E02521 & 29.01 & 73.442 & 54.005 \\
\hline E02522 & 29.10 & 74.738 & 51.813 \\
\hline E02523 & 29.18 & 73.945 & 51.439 \\
\hline E02526 & 28.90 & 78.838 & 67.054 \\
\hline
\end{tabular}

Table A.7 : Averaged Humidity and Barometric Pressure from Second Set FTPs.

\begin{tabular}{|l|r|r|r|}
\hline Test Group & $\begin{array}{c}\text { Barometric } \\
\text { Pressure, (in } \\
\mathrm{Hg} \text { ) }\end{array}$ & $\begin{array}{c}\text { Intake Air } \\
\text { Humidity, } \\
\text { (grains/lb) }\end{array}$ & $\begin{array}{c}\text { Dilution Air } \\
\text { Humidity, } \\
\text { (grains/lb) }\end{array}$ \\
\hline E02531 & 28.71 & 76.450 & 68.966 \\
\hline E02533 & 28.81 & 75.582 & 48.555 \\
\hline E02534 & 28.90 & 74.859 & 49.842 \\
\hline E02535 & 28.99 & 77.651 & 54.615 \\
\hline E02536 & 29.00 & 77.050 & 58.707 \\
\hline E02538 & 29.06 & 74.715 & 51.087 \\
\hline E02539 & 29.20 & 77.318 & 47.182 \\
\hline E02540 & 29.34 & 74.741 & 46.196 \\
\hline
\end{tabular}




\section{A.5. Biodiesel Mixing Information}

Table A.8 : Biodiesel Mixing Log Sheet-First Set Tests.

\begin{tabular}{|c|c|c|}
\hline Date & $11 / 21 / 2008$ & Units \\
\hline Base Fuel Name & Guttm an $500 \mathrm{gal}$ & \\
\hline Base Fuel Description & ULSD $500 \mathrm{gal}$ tank & \\
\hline Base Fuel API Gravity & 38.57 & \\
\hline Base Fuel Specific Gravity & 0.8320 & \\
\hline Base Fuel Weight & 87.40 & $\mathrm{Ibs}$ \\
\hline Base Fuel Volume & 12.600 & gal \\
\hline Biodiesel Name & B 100 (W VBR L01441) & \\
\hline Biodiesel Description & Bio-diesel (B 100) & \\
\hline Biodiesel API Gravity & 28.57 & \\
\hline Biodiesel Specific Gravity & 0.8840 & \\
\hline Biodiesel W eight & 23.25 & Ibs \\
\hline Biodiesel Volume & 3.155 & gal \\
\hline B20 Name & Guttm an B 20 & \\
\hline B20 Description & $20 \%$ Bio-diesel, $80 \%$ Fuel & \\
\hline B20 API Gravity & 36.47 & \\
\hline B20 Specific Gravity & 0.8424 & \\
\hline B20 W eight & 110.65 & $\mathrm{Ibs}$ \\
\hline B20 Volume & 15.75 & gal \\
\hline
\end{tabular}

Table A.9 : Biodiesel Mixing Log Sheet - Second Set Tests.

\begin{tabular}{|c|c|c|}
\hline Date & $12 / 15 / 2008$ & Units \\
\hline Base Fuel Name & Guttm an $500 \mathrm{gal}$ & \\
\hline Base Fuel Description & ULSD $500 \mathrm{gal}$ tank & \\
\hline Base Fuel API Gravity & 38.57 & \\
\hline Base Fuel Specific Gravity & 0.8320 & \\
\hline Base Fuel W eight & 72.50 & $\mathrm{Ibs}$ \\
\hline Base Fuel Volume & 10.452 & gal \\
\hline Biodiesel Name & B100 (W VBR L01441) & \\
\hline Biodiesel Description & Bio-diesel (B 100) & \\
\hline Biodiesel API Gravity & 28.57 & \\
\hline Biodiesel Specific Gravity & 0.8840 & \\
\hline Biodiesel W eight & 19.25 & Ibs \\
\hline Biodiesel Volume & 2.612 & gal \\
\hline B20 Name & Guttm an B 20 & \\
\hline B20 Description & $20 \%$ Bio-diesel, $80 \%$ Fuel & \\
\hline B20 API Gravity & 36.47 & \\
\hline B20 Specific Gravity & 0.8424 & \\
\hline B20 W eight & 91.75 & Ibs \\
\hline B20 Volume & 13.06 & gal \\
\hline
\end{tabular}




\section{A.6. SOF Filter Preparation Technique}

Table A.10 : Filter Preparation Technique for SOF Extraction.

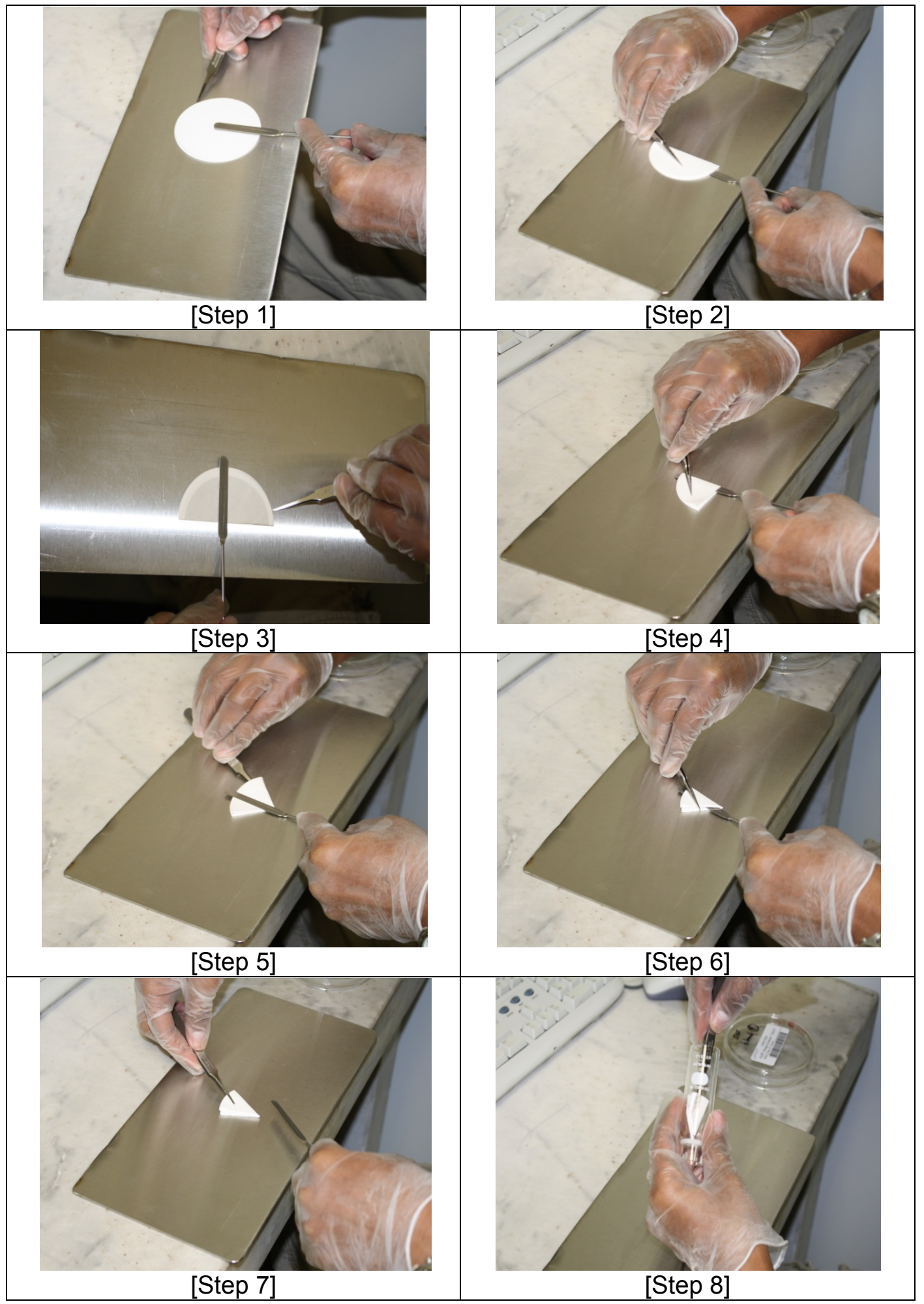




\section{A.7. Oil Sampling}

Table A.11 : Oil Sampling Log Sheet.

\begin{tabular}{|c|c|c|c|c|c|c|}
\hline Set & $\begin{array}{c}\text { Oil Sample } \\
\text { Number }\end{array}$ & $\begin{array}{l}\text { Sampling } \\
\text { Date }\end{array}$ & $\begin{array}{l}\text { Sampling } \\
\text { Time }\end{array}$ & $\begin{array}{c}\text { Sampling After } \\
\text { Test Seq. }\end{array}$ & $\begin{array}{c}\text { Aging } \\
\text { Minutes }\end{array}$ & $\begin{array}{c}\text { Cumulative } \\
\text { Minutes of } \\
\text { Aging }\end{array}$ \\
\hline \multirow{10}{*}{ 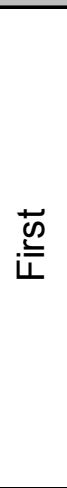 } & WVOil0343 & $11 / 17 / 2008$ & 6:26 PM & - & 120 & 120 \\
\hline & WVOil0344 & $11 / 18 / 2008$ & 3:53 PM & E02511-1d & 320 & 440 \\
\hline & WVOil0345 & $11 / 18 / 2008$ & 7:49 PM & E02512-1d & 200 & 640 \\
\hline & WVOil0346 & $11 / 19 / 2008$ & 10:07 AM & E02514-06 & 220 & 860 \\
\hline & WVOil0347 & $11 / 19 / 2008$ & $2: 35$ PM & E02515-1d & 177 & 1037 \\
\hline & WVOil0348 & 11/19/2008 & 6:30 PM & E02516-1d & 200 & 1237 \\
\hline & WVOil0349 & $11 / 20 / 2008$ & 10:30 AM & E02518-06 & 220 & 1457 \\
\hline & WVOil0350 & $11 / 20 / 2008$ & $2: 35 \mathrm{PM}$ & E025 & 200 & 1657 \\
\hline & WVOil0401 & $11 / 21 / 2008$ & 2:05 PM & E02522-05 & 300 & 1957 \\
\hline & WVOil0402 & $11 / 24 / 2008$ & $1: 42 \mathrm{PM}$ & E02526 & 460 & 2417 \\
\hline \multirow{6}{*}{$\begin{array}{l}\text { రृ } \\
\text { Oू } \\
\text { ஸ }\end{array}$} & WVOil0403 & $12 / 11 / 2008$ & $8: 25$ AM & E02532-02 & 110 & 110 \\
\hline & WVOil0404 & $12 / 12 / 2008$ & 2:45 PM & E02534-01 & 120 & 230 \\
\hline & WVOil0405 & $12 / 15 / 2008$ & $10: 38 \mathrm{AM}$ & E02535-04 & 80 & 310 \\
\hline & WVOil0406 & $12 / 15 / 2008$ & 1:53 PM & E02536-04 & 80 & 39 \\
\hline & WVOil0407 & $12 / 15 / 2008$ & 5:28 PM & E02538-04 & 80 & 470 \\
\hline & WVOil0408 & $12 / 16 / 2008$ & 10:46 AM & E02540-05 & 180 & 65 \\
\hline
\end{tabular}

\section{A.8. Zetasizer ${ }^{\circledR}$ Sample Preparation - Oil/Decane Mixing}

Table A.12 : Oil-Decane Mixing Ratio from $2^{\text {nd }}$ Trial Run.

\begin{tabular}{|c|c|c|c|c|c|c|c|}
\hline $\begin{array}{l}\text { Cuvette } \\
\text { Tag Nos. }\end{array}$ & $\begin{array}{l}\text { Oil Sample } \\
\text { Nos. }\end{array}$ & $\begin{array}{l}\text { Cuvette } \\
\text { (g) }\end{array}$ & $\begin{array}{c}\text { Cuvette+Decane } \\
\text { (g) }\end{array}$ & $\begin{array}{c}\text { Cuvette+Decane+Oil } \\
\text { sample (g) }\end{array}$ & $\begin{array}{c}\text { Mass of } \\
\text { Decane }(\mathrm{g})\end{array}$ & $\begin{array}{l}\text { Mass of Oil } \\
\text { Sample (g) }\end{array}$ & $\begin{array}{l}\text { Oil/Decane } \\
\text { Mass Ratio }\end{array}$ \\
\hline & Fresh Oil & 2.255 & 2.952 & 2.957 & 0.697 & 0.005 & 0.0072 \\
\hline & WVOil0343 & 2.287 & 2.967 & 3.163 & 0.680 & 0.196 & 0.2882 \\
\hline & WVOil0344 & 2.256 & 2.935 & 3.113 & 0.679 & 0.178 & 0.2622 \\
\hline & WVOil0345 & 2.257 & 2.947 & 2.985 & 0.690 & 0.038 & 0.0551 \\
\hline & WVOil0346 & 2.257 & 2.934 & 2.967 & 0.677 & 0.033 & 0.0487 \\
\hline & WVOil0347 & 2.256 & 2.999 & 2.996 & 0.743 & -0.003 & -0.0040 \\
\hline & WVOil0348 & 2.253 & 2.955 & 3.056 & 0.702 & 0.101 & 0.1439 \\
\hline & WVOil0349 & 2.253 & 2.938 & 2.952 & 0.685 & 0.014 & 0.0204 \\
\hline & WVOil0350 & 2.258 & 2.986 & 3.008 & 0.728 & 0.022 & 0.0302 \\
\hline & WVOil0401 & 2.252 & 2.948 & 2.956 & 0.696 & 0.008 & 0.0115 \\
\hline & WVOil0402 & 2.260 & 2.904 & 2.943 & 0.644 & 0.039 & 0.0606 \\
\hline & WVOil0403 & 2.260 & 2.931 & 3.040 & 0.671 & 0.109 & 0.1624 \\
\hline 13 & WVOil0404 & 2.257 & 2.989 & 3.059 & 0.732 & 0.070 & 0.0956 \\
\hline 14 & WVOil0405 & 2.259 & 2.908 & 3.017 & 0.649 & 0.109 & 0.1680 \\
\hline 15 & WVOil0406 & 2.257 & 2.855 & 2.953 & 0.598 & 0.098 & 0.1639 \\
\hline 16 & WVOil0407 & 2.257 & 2.830 & 2.914 & 0.573 & 0.084 & 0.1466 \\
\hline 17 & WVOil0408 & 2.257 & 2.859 & 2.987 & 0.602 & 0.128 & 0.2126 \\
\hline
\end{tabular}


Table A.13 : Oil-Decane Mixing Ratio from $3^{\text {rd }}$ Trial Run.

\begin{tabular}{|r|l|c|c|c|c|r|r|}
\hline $\begin{array}{r}\text { Cuvette } \\
\text { Tag Nos. }\end{array}$ & $\begin{array}{c}\text { Oil Sample } \\
\text { Nos. }\end{array}$ & $\begin{array}{c}\text { Cuvette } \\
(\mathrm{g})\end{array}$ & $\begin{array}{c}\text { Cuvette+Decane } \\
(\mathrm{g})\end{array}$ & $\begin{array}{c}\text { Cuvette+Decane+Oil } \\
\text { sample }(\mathrm{g})\end{array}$ & $\begin{array}{c}\text { Mass of } \\
\text { Decane }(\mathrm{g})\end{array}$ & $\begin{array}{c}\text { Mass of Oil } \\
\text { Sample }(\mathrm{g})\end{array}$ & $\begin{array}{c}\text { Oil/Decane } \\
\text { Mass Ratio }\end{array}$ \\
\hline 2 & WVOil0343 & 2.255 & 2.908 & 3.002 & 0.653 & 0.094 & 0.1440 \\
\hline 4 WVOil0345 & 2.255 & 2.817 & 2.912 & 0.562 & 0.095 & 0.1690 \\
\hline 6 & WVOil0347 & 2.255 & 2.878 & 2.970 & 0.623 & 0.092 & 0.1477 \\
\hline 7 & WVOil0348 & 2.257 & 2.876 & 2.970 & 0.619 & 0.094 & 0.1519 \\
\hline 9 WVOil0350 & 2.253 & 2.869 & 2.971 & 0.616 & 0.102 & 0.1656 \\
\hline 11 & WVOil0402 & 2.255 & 2.824 & 2.922 & 0.569 & 0.098 & 0.1722 \\
\hline
\end{tabular}

Table A.14 : Oil-Decane Mixing Ratio from $4^{\text {th }}$ Trial Run.

\begin{tabular}{|r|c|c|c|c|c|r|r|}
\hline $\begin{array}{c}\text { Cuvette } \\
\text { Tag Nos. }\end{array}$ & $\begin{array}{c}\text { Oil Sample } \\
\text { Nos. }\end{array}$ & $\begin{array}{c}\text { Cuvette } \\
(\mathrm{g})\end{array}$ & $\begin{array}{c}\text { Cuvette+Decane } \\
(\mathrm{g})\end{array}$ & $\begin{array}{c}\text { Cuvette+Decane+Oil } \\
\text { sample }(\mathrm{g})\end{array}$ & $\begin{array}{c}\text { Mass of } \\
\text { Decane }(\mathrm{g})\end{array}$ & $\begin{array}{c}\text { Mass of Oil } \\
\text { Sample }(\mathrm{g})\end{array}$ & $\begin{array}{c}\text { Oil/Decane } \\
\text { Mass Ratio }\end{array}$ \\
\hline 2 & WVOil0343 & 2.260 & 2.925 & 3.043 & 0.665 & 0.118 & 0.1774 \\
\hline 4 & WVOil0345 & 2.255 & 2.851 & 2.954 & 0.596 & 0.103 & 0.1728 \\
\hline 6 & WVOil0347 & 2.257 & 2.849 & 2.962 & 0.592 & 0.113 & 0.1909 \\
\hline 7 & WVOil0348 & 2.256 & 2.817 & 2.948 & 0.561 & 0.131 & 0.2335 \\
\hline 9 WVOil0350 & 2.255 & 2.947 & 3.067 & 0.692 & 0.120 & 0.1734 \\
\hline 11 & WVOil0402 & 2.253 & 2.853 & 2.971 & 0.600 & 0.118 & 0.1967 \\
\hline
\end{tabular}

Table A.15 : Oil-Decane Mixing Ratio from $5^{\text {th }}$ Trial Run.

\begin{tabular}{|c|c|c|c|c|c|c|c|}
\hline $\begin{array}{l}\text { Cuvette } \\
\text { Tag Nos. }\end{array}$ & $\begin{array}{l}\text { Oil Sample } \\
\text { Nos. }\end{array}$ & $\begin{array}{l}\text { Cuvette } \\
\text { (g) }\end{array}$ & $\begin{array}{c}\text { Cuvette+Decane } \\
\text { (g) }\end{array}$ & $\begin{array}{c}\text { Cuvette+Decane+Oil } \\
\text { sample }(\mathrm{g})\end{array}$ & $\begin{array}{c}\text { Mass of } \\
\text { Decane }(\mathrm{g})\end{array}$ & $\begin{array}{l}\text { Mass of Oil } \\
\text { Sample }(\mathrm{g})\end{array}$ & $\begin{array}{l}\text { Oil/Decane } \\
\text { Mass Ratio }\end{array}$ \\
\hline 2 & WVOil0343 & 2.258 & 2.882 & 3.014 & 0.624 & 0.132 & 0.2115 \\
\hline 3 & WVOil0344 & 2.253 & 2.842 & 2.979 & 0.589 & 0.137 & 0.2326 \\
\hline 4 & WVOil0345 & 2.256 & 2.863 & 2.989 & 0.607 & 0.126 & 0.2076 \\
\hline 5 & WVOil0346 & 2.257 & 2.860 & 2.974 & 0.603 & 0.114 & 0.1891 \\
\hline 6 & WVOil0347 & 2.253 & 2.919 & 3.051 & 0.666 & 0.132 & 0.1982 \\
\hline 7 & WVOil0348 & 2.259 & 2.776 & 2.895 & 0.517 & 0.119 & 0.2302 \\
\hline 8 & WVOil0349 & 2.256 & 2.917 & 3.053 & 0.661 & 0.136 & 0.2057 \\
\hline 9 & WVOil0350 & 2.255 & 2.892 & 3.024 & 0.637 & 0.132 & 0.2072 \\
\hline 10 & WVOil0401 & 2.259 & 2.932 & 3.085 & 0.673 & 0.153 & 0.2273 \\
\hline 11 & WVOil0402 & 2.254 & 2.917 & 3.029 & 0.663 & 0.112 & 0.1689 \\
\hline 12 & WVOil0403 & 2.253 & 2.889 & 3.044 & 0.636 & 0.155 & 0.2437 \\
\hline 13 & WVOil0404 & 2.251 & 2.910 & 3.061 & 0.659 & 0.151 & 0.2291 \\
\hline 14 & WVOil0405 & 2.253 & 2.865 & 3.038 & 0.612 & 0.173 & 0.2827 \\
\hline 15 & WVOil0406 & 2.259 & 2.922 & 3.080 & 0.663 & 0.158 & 0.2383 \\
\hline 16 & WVOil0407 & 2.256 & 2.817 & 3.026 & 0.561 & 0.209 & 0.3725 \\
\hline 17 & WVOil0408 & 2.259 & 2.930 & 3.116 & 0.671 & 0.186 & 0.2772 \\
\hline
\end{tabular}

Table A.16 : Oil-Decane Mixing Ratio from $6^{\text {th }}$ Trial Run.

\begin{tabular}{|r|l|c|c|c|c|r|r|}
\hline $\begin{array}{c}\text { Cuvette } \\
\text { Tag Nos. }\end{array}$ & $\begin{array}{c}\text { Oil Sample } \\
\text { Nos. }\end{array}$ & $\begin{array}{c}\text { Cuvette } \\
(\mathrm{g})\end{array}$ & $\begin{array}{c}\text { Cuvette+Decane } \\
(\mathrm{g})\end{array}$ & $\begin{array}{c}\text { Cuvette+Decane+Oil } \\
\text { sample }(\mathrm{g})\end{array}$ & $\begin{array}{c}\text { Mass of } \\
\text { Decane }(\mathrm{g})\end{array}$ & $\begin{array}{c}\text { Mass of Oil } \\
\text { Sample }(\mathrm{g})\end{array}$ & $\begin{array}{c}\text { Oil/Decane } \\
\text { Mass Ratio }\end{array}$ \\
\hline 12 & WVOil0403 & 2.256 & 2.936 & 3.073 & 0.680 & 0.137 & 0.2015 \\
\hline 13 & WVOil0404 & 2.256 & 2.896 & 3.005 & 0.640 & 0.109 & 0.1703 \\
\hline 14 & WVOil0405 & 2.255 & 2.908 & 3.019 & 0.653 & 0.111 & 0.1700 \\
\hline 15 & WVOil0406 & 2.256 & 2.882 & 3.077 & 0.626 & 0.195 & 0.3115 \\
\hline 16 & WVOil0407 & 2.253 & 2.896 & 3.007 & 0.643 & 0.111 & 0.1726 \\
\hline 17 & WVOil0408 & 2.258 & 2.921 & 2.998 & 0.663 & 0.077 & 0.1161 \\
\hline
\end{tabular}


Table A.17 : Oil-Decane Mixing Ratio from $7^{\text {th }}$ Trial Run.

\begin{tabular}{|c|c|c|c|c|c|c|c|}
\hline $\begin{array}{l}\text { Cuvette } \\
\text { Tag Nos. }\end{array}$ & $\begin{array}{l}\text { Oil Sample } \\
\text { Nos. }\end{array}$ & $\begin{array}{l}\text { Cuvette } \\
\text { (g) }\end{array}$ & $\begin{array}{c}\text { Cuvette+Decane } \\
\text { (g) }\end{array}$ & $\begin{array}{c}\text { Cuvette+Decane+Oil } \\
\text { sample }(\mathrm{g})\end{array}$ & $\begin{array}{c}\text { Mass of } \\
\text { Decane }(\mathrm{g})\end{array}$ & $\begin{array}{l}\text { Mass of Oil } \\
\text { Sample }(\mathrm{g})\end{array}$ & $\begin{array}{l}\text { Oil/Decane } \\
\text { Mass Ratio }\end{array}$ \\
\hline 1 & Fresh Oil & 2.253 & 2.969 & 3.120 & 0.716 & 0.151 & 0.2109 \\
\hline 2 & WVOil0343 & 2.251 & 2.977 & 3.052 & 0.726 & 0.075 & 0.1033 \\
\hline 3 & WVOil0344 & 2.256 & 2.980 & 3.091 & 0.724 & 0.111 & 0.1533 \\
\hline 4 & WVOil0345 & 2.261 & 2.976 & 3.126 & 0.715 & 0.150 & 0.2098 \\
\hline 5 & WVOil0346 & 2.252 & 2.947 & 3.094 & 0.695 & 0.147 & 0.2115 \\
\hline 6 & WVOil0347 & 2.253 & 2.955 & 3.112 & 0.702 & 0.157 & 0.2236 \\
\hline 7 & WVOil0348 & 2.256 & 2.856 & 2.994 & 0.600 & 0.138 & 0.2300 \\
\hline 8 & WVOil0349 & 2.256 & 2.916 & 3.027 & 0.660 & 0.111 & 0.1682 \\
\hline 9 & WVOil0350 & 2.251 & 2.948 & 3.066 & 0.697 & 0.118 & 0.1693 \\
\hline 10 & WVOil0401 & 2.258 & 3.013 & 3.138 & 0.755 & 0.125 & 0.1656 \\
\hline 11 & WVOil0402 & 2.255 & 2.928 & 3.088 & 0.673 & 0.160 & 0.2377 \\
\hline 12 & WVOil0403 & 2.304 & 3.016 & 3.153 & 0.712 & 0.137 & 0.1924 \\
\hline 13 & WVOil0404 & 2.294 & 2.980 & 3.098 & 0.686 & 0.118 & 0.1720 \\
\hline 14 & WVOil0405 & 2.283 & 2.941 & 3.064 & 0.658 & 0.123 & 0.1869 \\
\hline 15 & WVOil0406 & 2.287 & 3.052 & 3.148 & 0.765 & 0.096 & 0.1255 \\
\hline 16 & WVOil0407 & 2.257 & 2.929 & 3.088 & 0.672 & 0.159 & 0.2366 \\
\hline 17 & WVOil0408 & 2.304 & 3.018 & 3.176 & 0.714 & 0.158 & 0.2213 \\
\hline
\end{tabular}

Table A.18 : DP5820-Distilled Water Mixing Ratio for the Standard.

\begin{tabular}{|l|c|c|c|c|c|c|}
\hline Sample Nos. & Cuvette (g) & $\begin{array}{c}\text { Cuvette+Distilled } \\
\text { Water (g) }\end{array}$ & $\begin{array}{c}\text { Cuvette+Water+D } \\
\text { P5820 Sample (g) }\end{array}$ & $\begin{array}{c}\text { Mass of } \\
\text { Water (g) }\end{array}$ & $\begin{array}{c}\text { Mass of } \\
\text { DP5820 (g) }\end{array}$ & $\begin{array}{c}\text { DP5820/Water } \\
\text { mass ratio }\end{array}$ \\
\hline DP5820 (Std.) & 2.259 & 3.166 & 3.258 & 0.907 & 0.092 & 0.1014 \\
\hline DP5820 (Std.2) & 2.250 & 2.936 & 3.285 & 0.686 & 0.349 & 0.5087 \\
\hline
\end{tabular}




\section{APPENDIX B}

\section{B.1. Emissions versus Barometric Pressure}

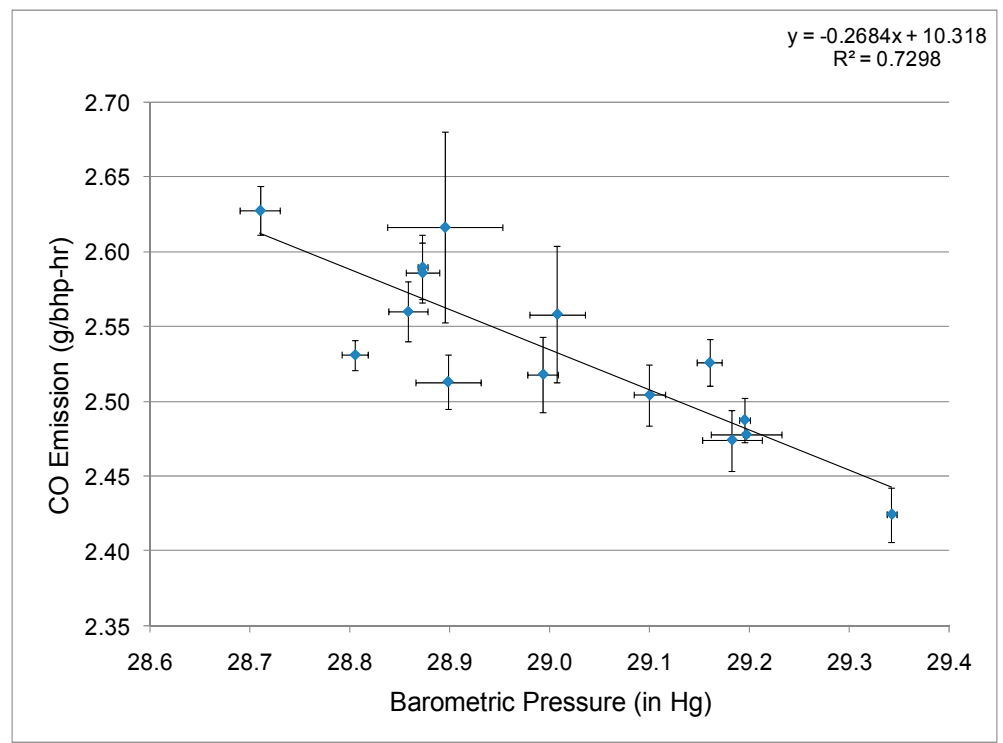

Figure B.1 : BsCO versus Barometric Pressure.

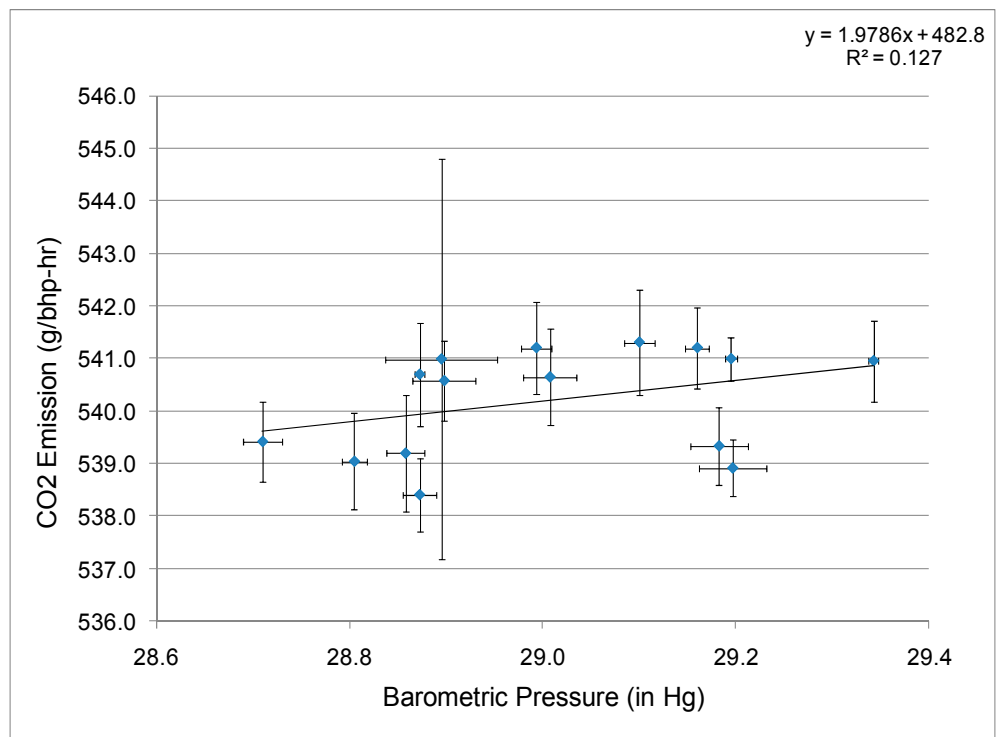

Figure B.2 : $\mathrm{BsCO}_{2}$ versus Barometric Pressure. 


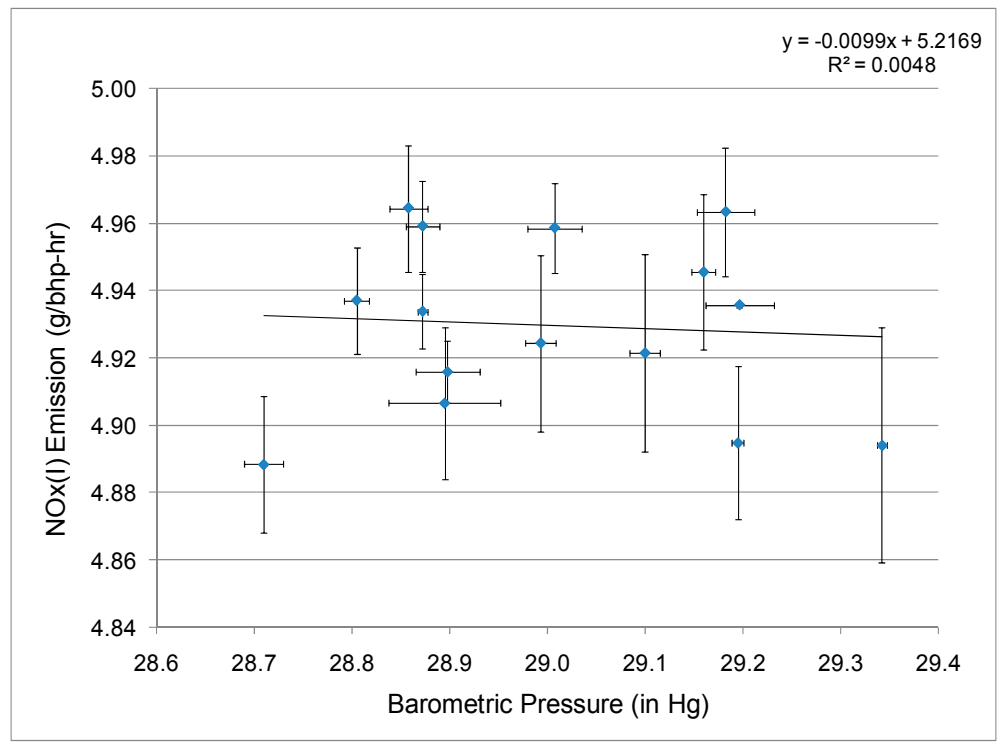

Figure B.3 : BsNOx (I) versus Barometric Pressure.

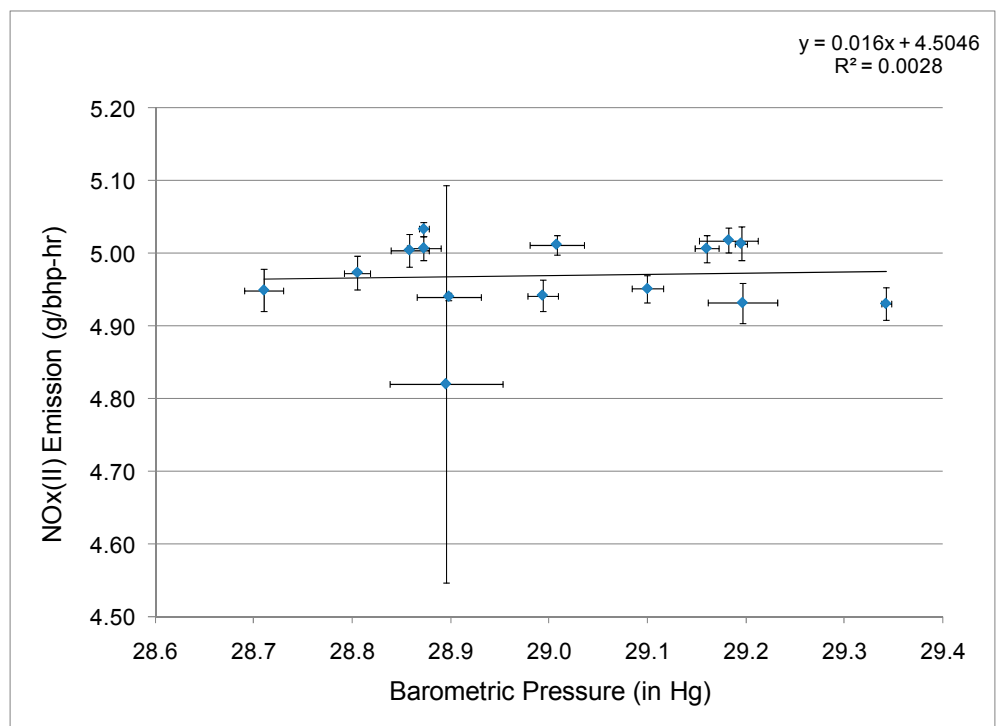

Figure B.4 : BsNOx (II) versus Barometric Pressure. 


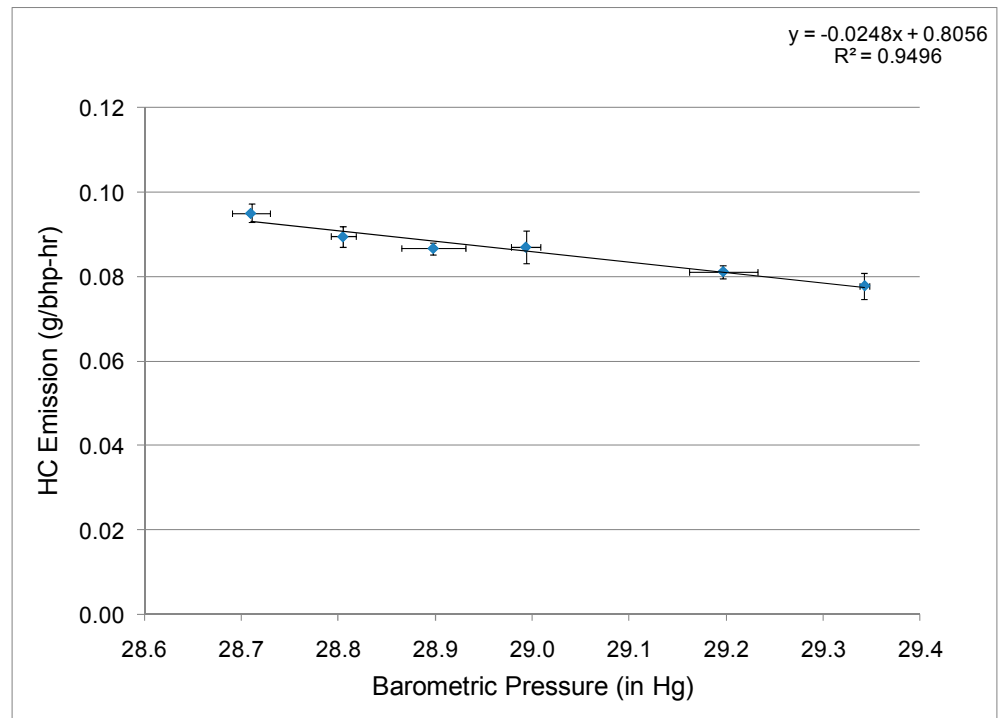

Figure B.5 : BsHC versus Barometric Pressure.

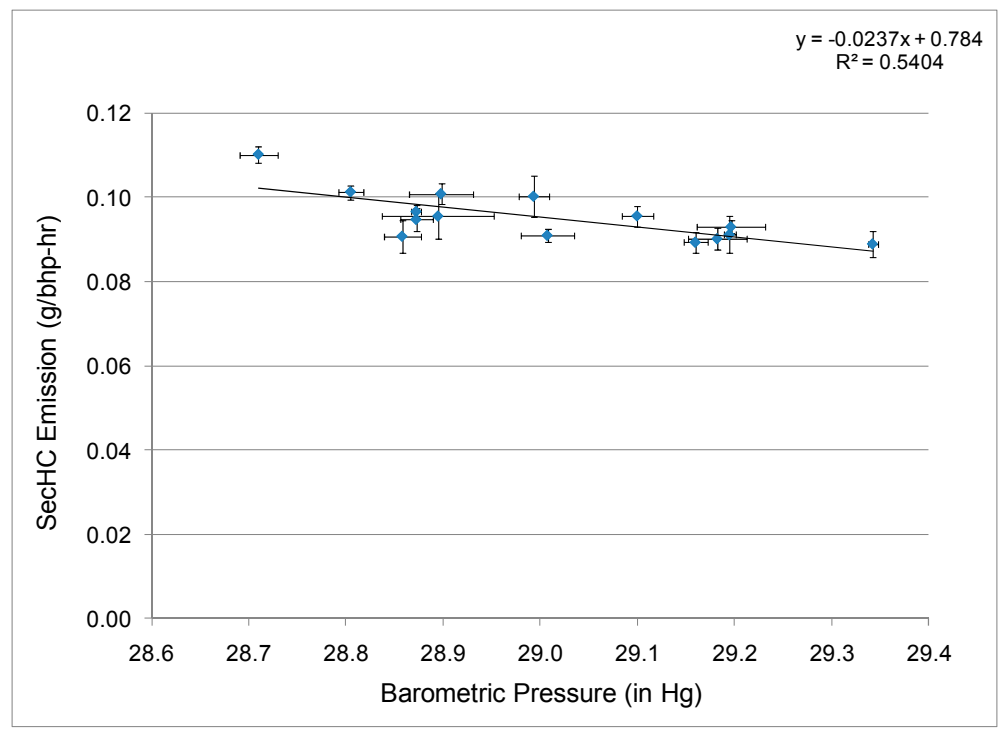

Figure B.6 : BsSecHC versus Barometric Pressure. 


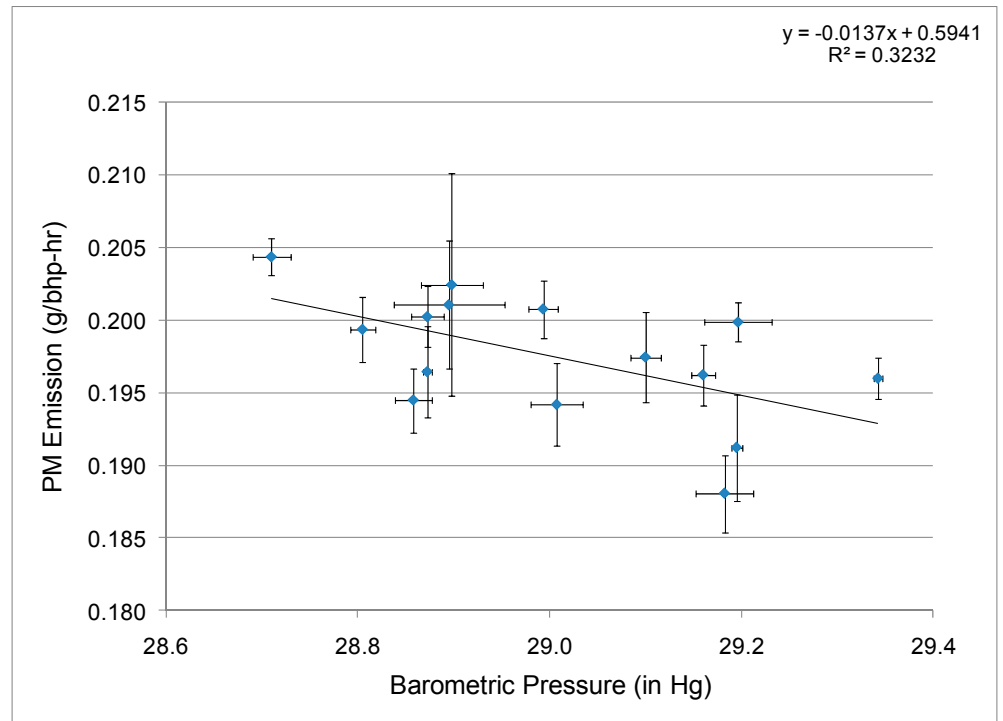

Figure B.7 : BsPM versus Barometric Pressure.

\section{B.2. Emissions versus Dilution Air Humidity}

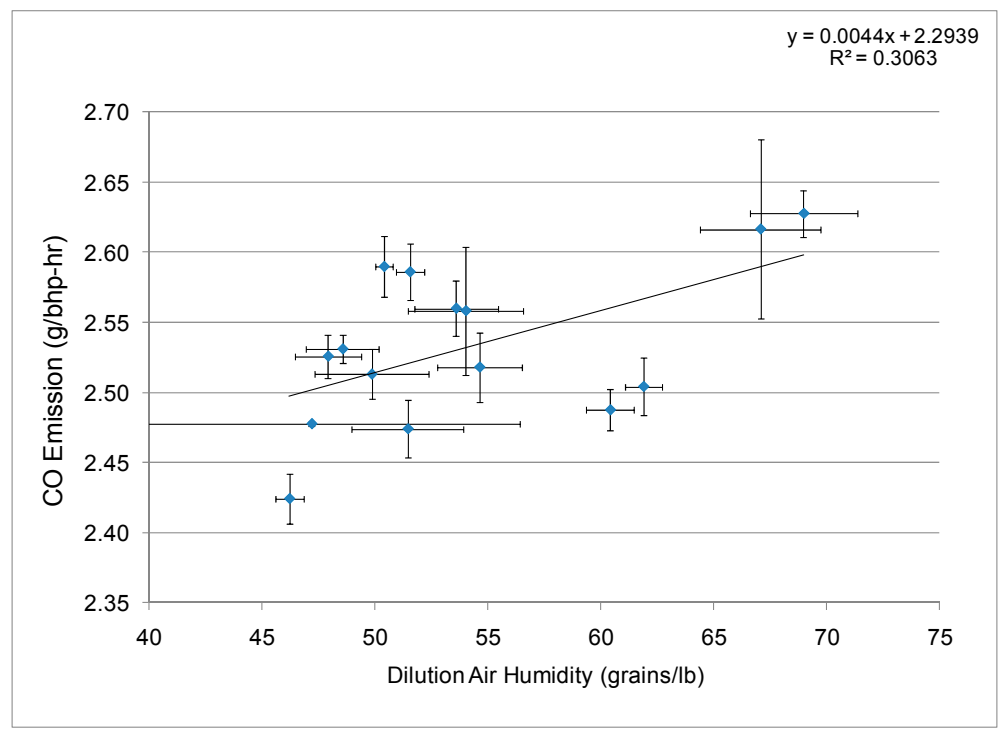

Figure B.8 : BsCO versus Dilution Air Humidity. 


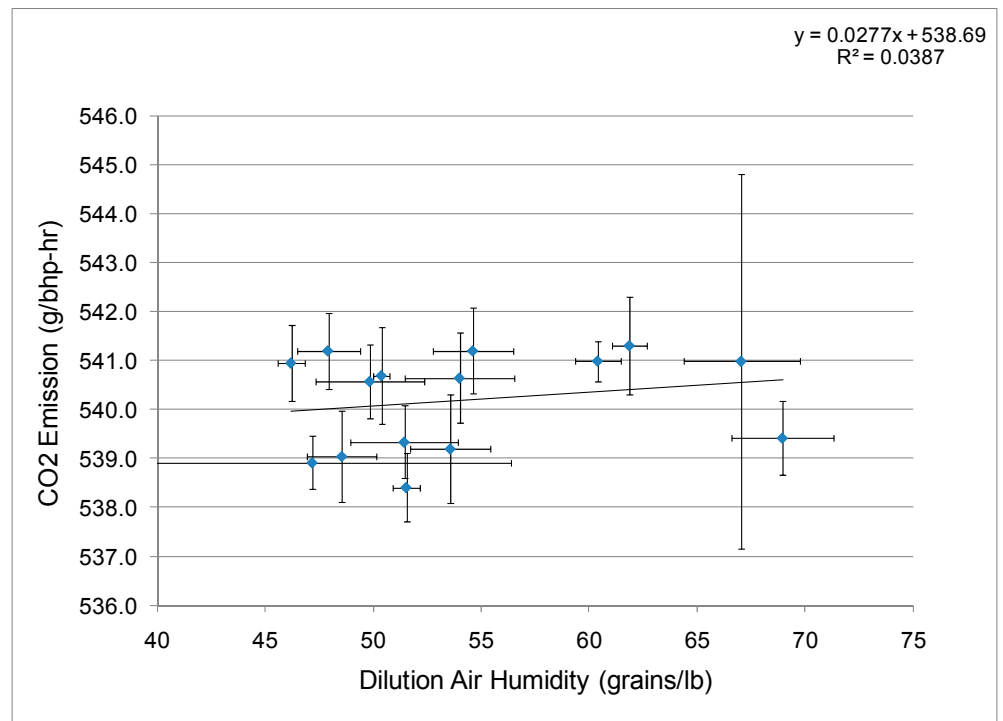

Figure B.9 : $\mathrm{BsCO}_{2}$ versus Dilution Air Humidity.

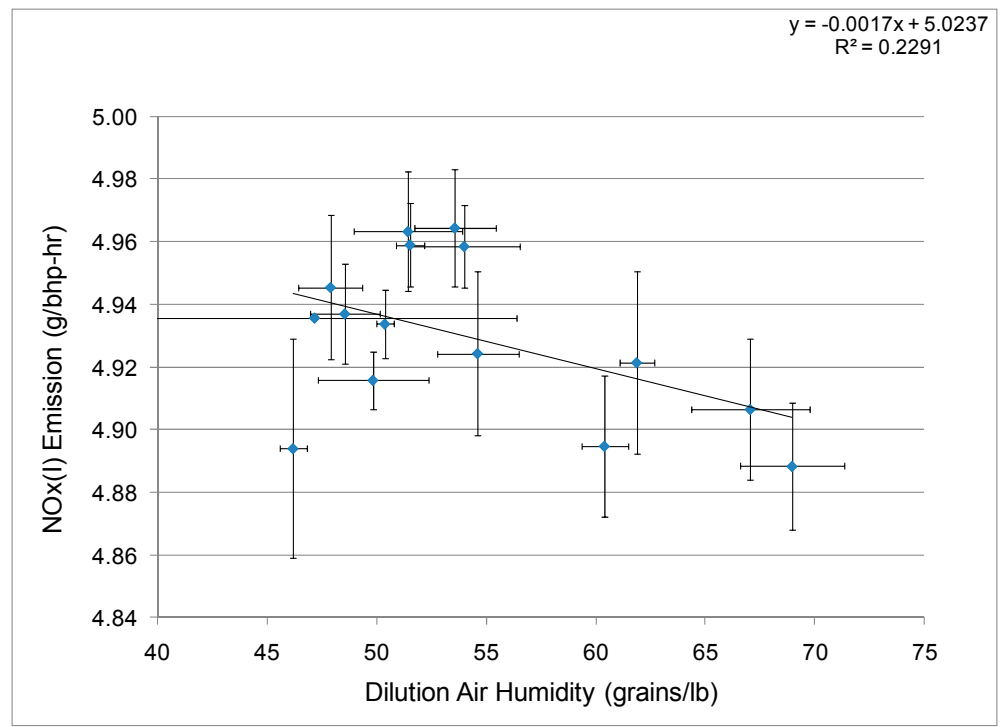

Figure B.10 : BsNOx (I) versus Dilution Air Humidity. 


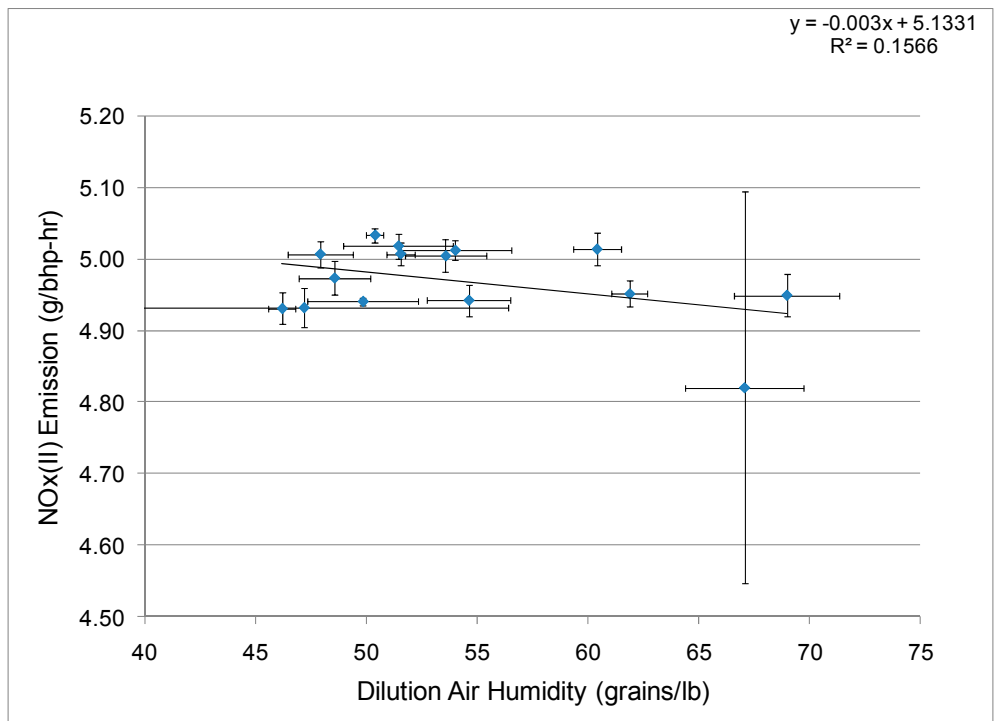

Figure B.11 : BsNOx (II) versus Dilution Air Humidity.

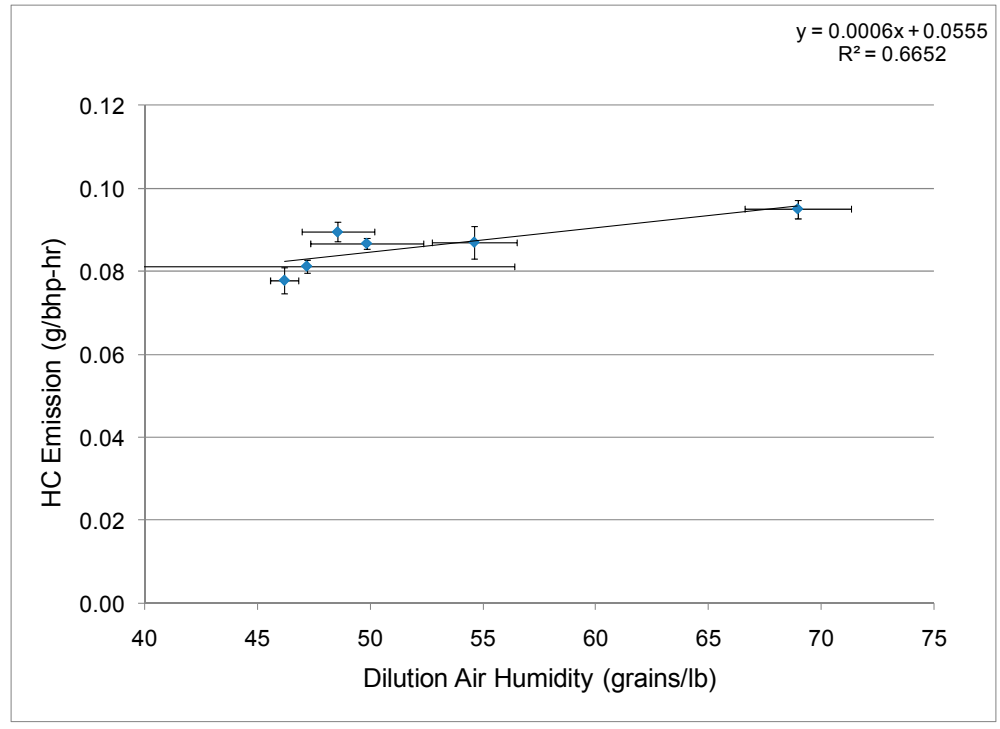

Figure B.12 : BsHC versus Dilution Air Humidity. 


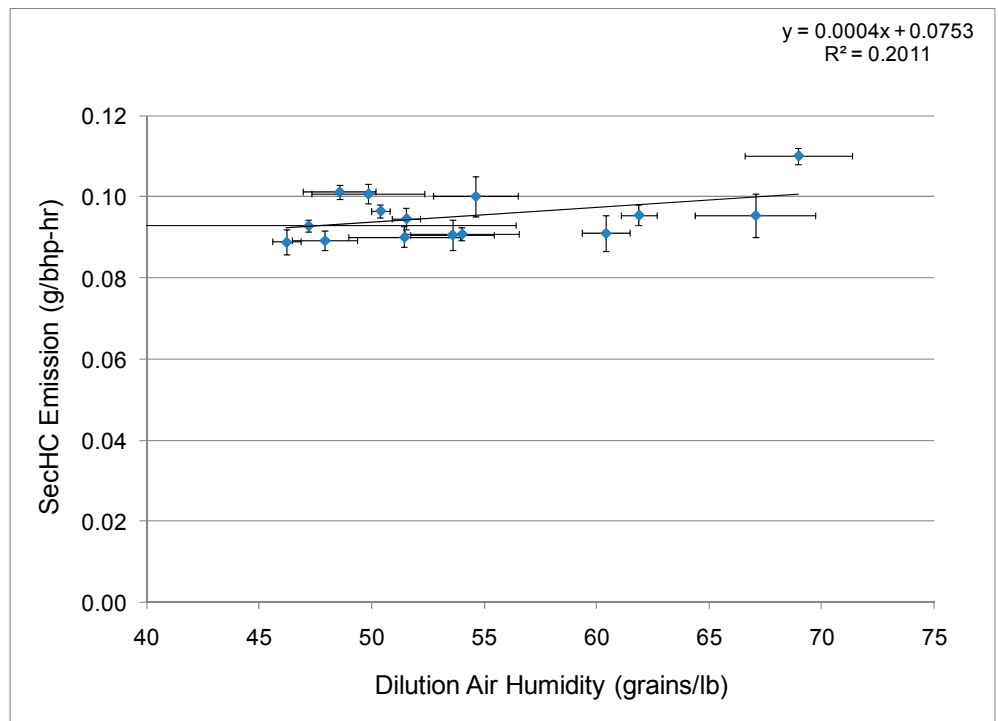

Figure B.13 : BsSecHC versus Dilution Air Humidity.

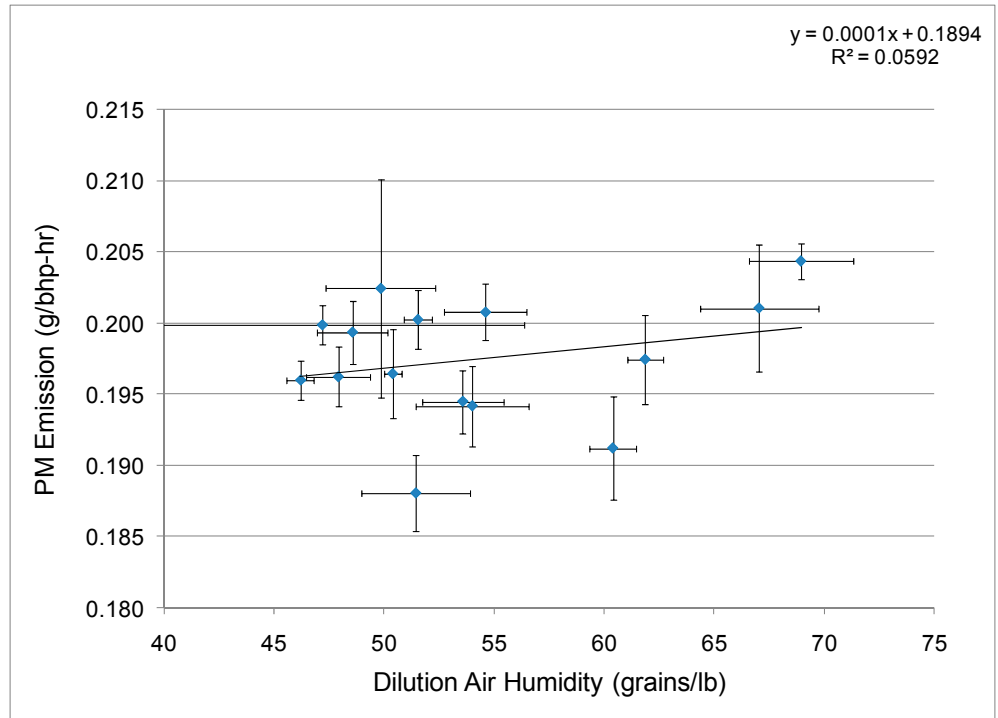

Figure B.14 : BsPM versus Dilution Air Humidity. 


\section{B.3. Emissions versus Intake Air Humidity}

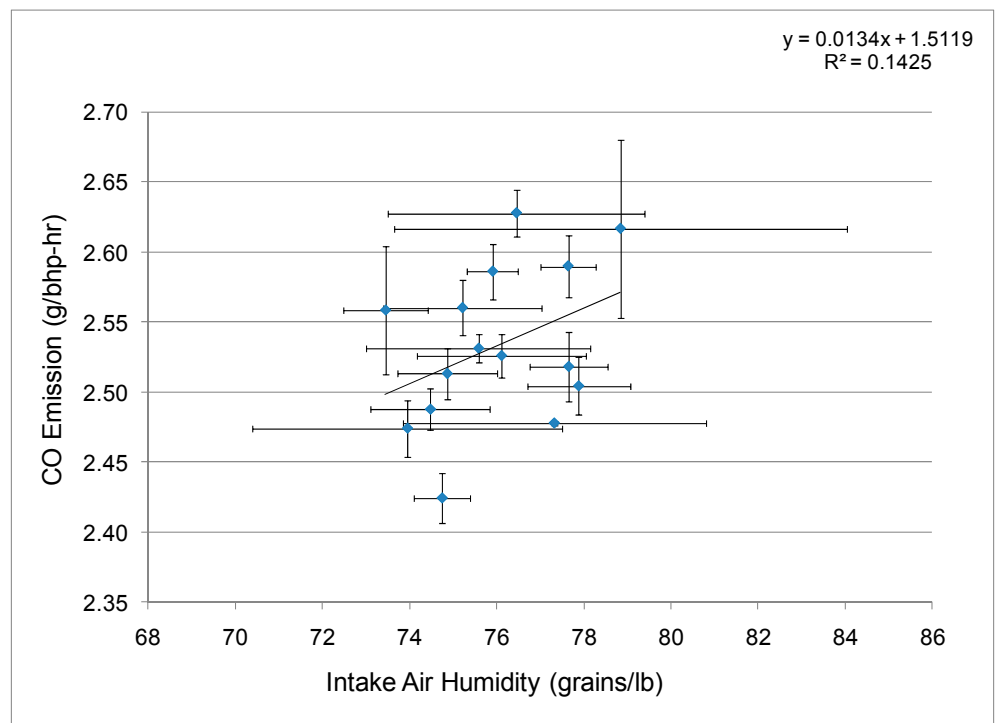

Figure B.15: BsCO versus Intake Air Humidity.

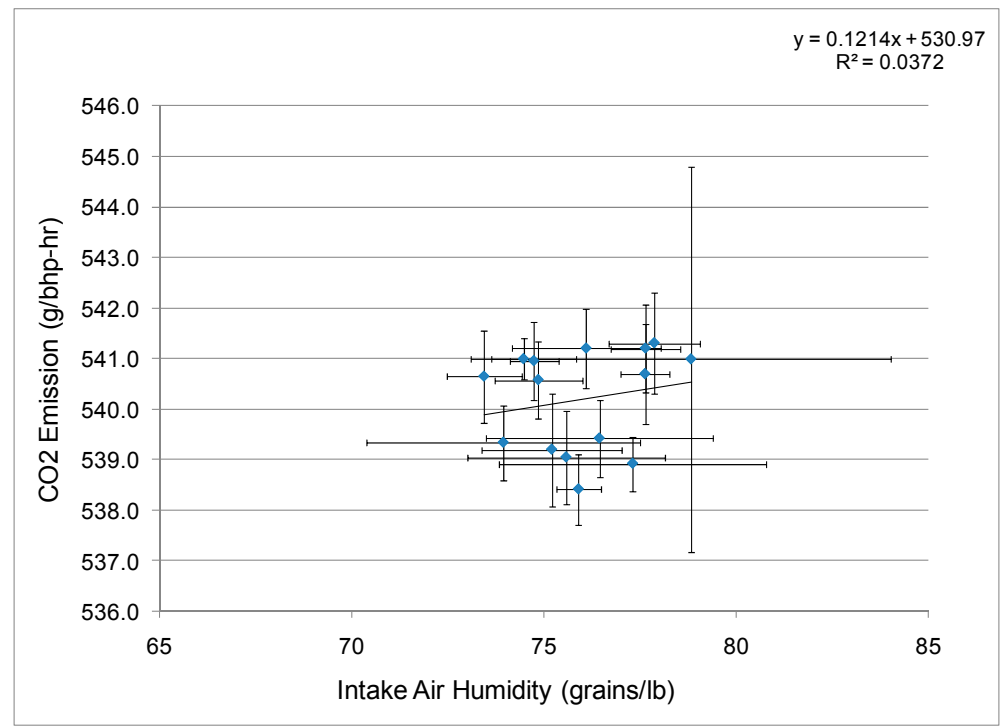

Figure B.16: $\mathrm{BsCO}_{2}$ versus Intake Air Humidity. 


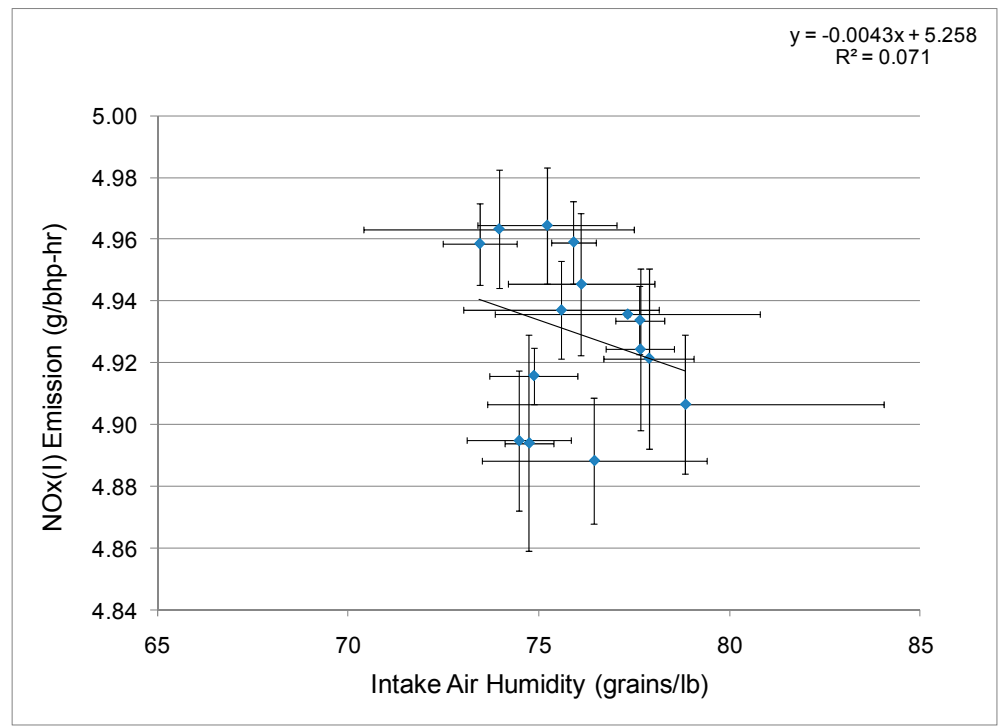

Figure B.17 : BsNOx (I) versus Intake Air Humidity.

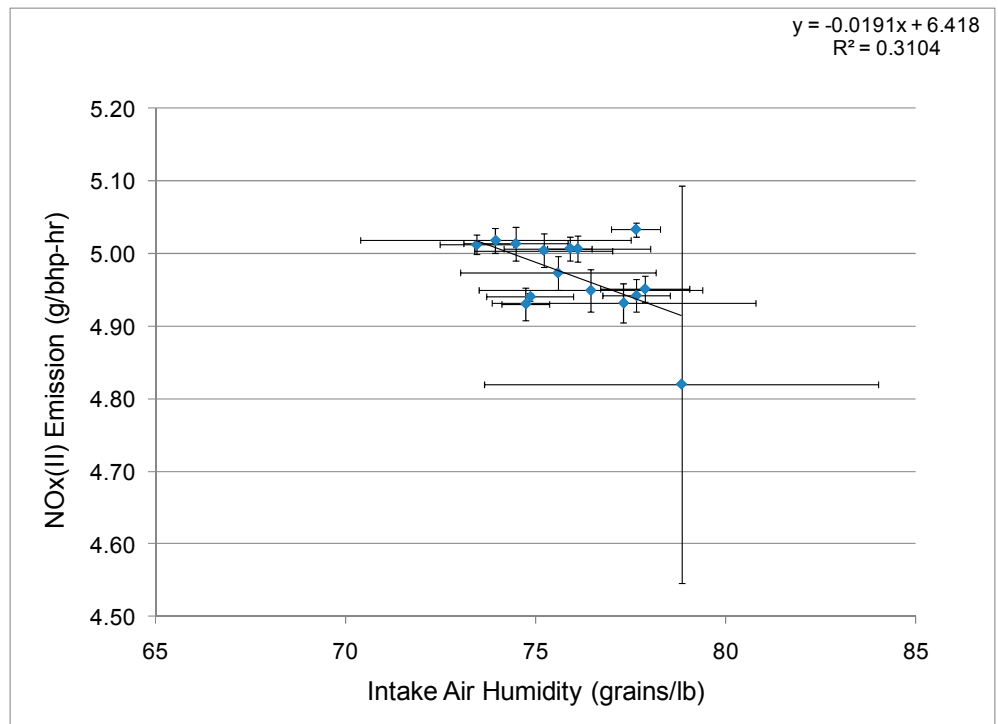

Figure B.18: BsNOx (II) versus Intake Air Humidity. 


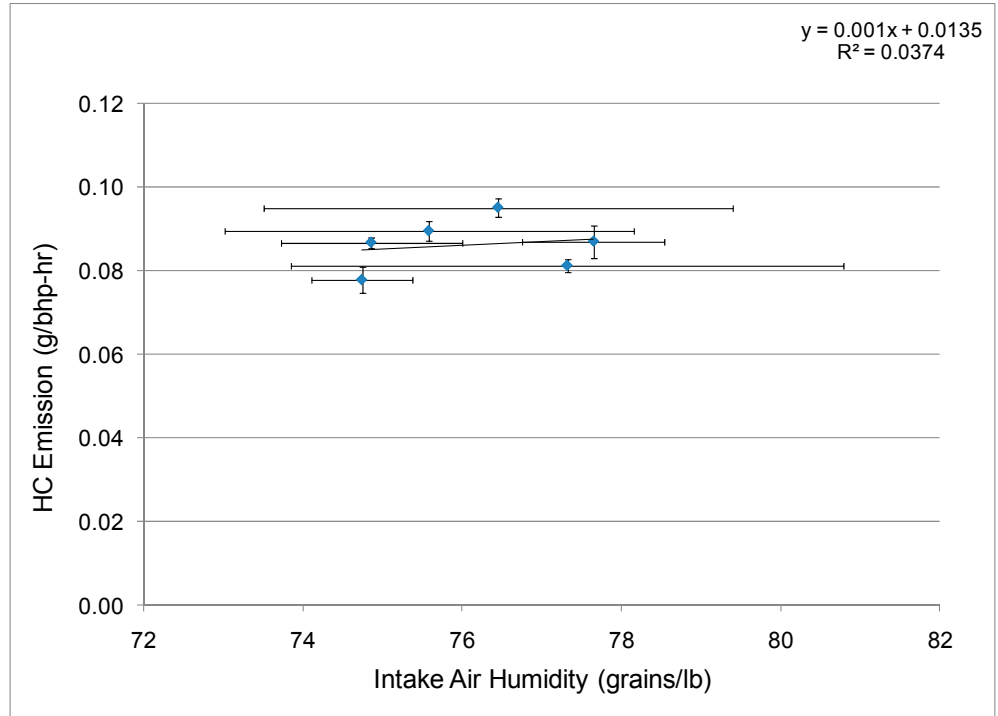

Figure B.19: BsHC versus Intake Air Humidity.

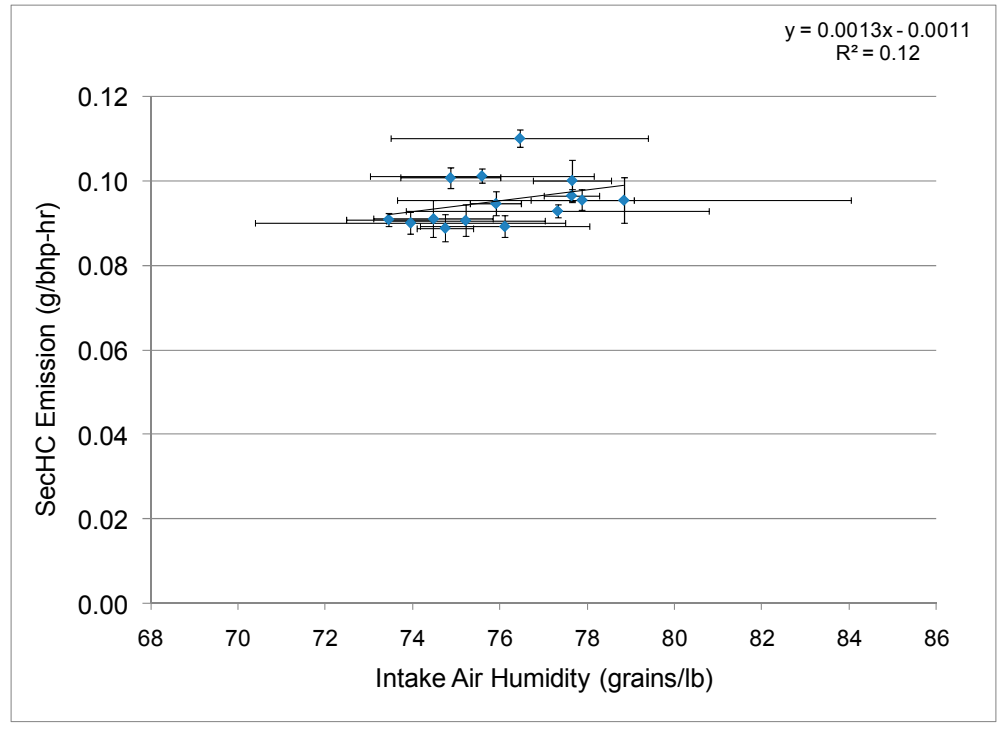

Figure B.20 : BsSecHC versus Intake Air Humidity. 


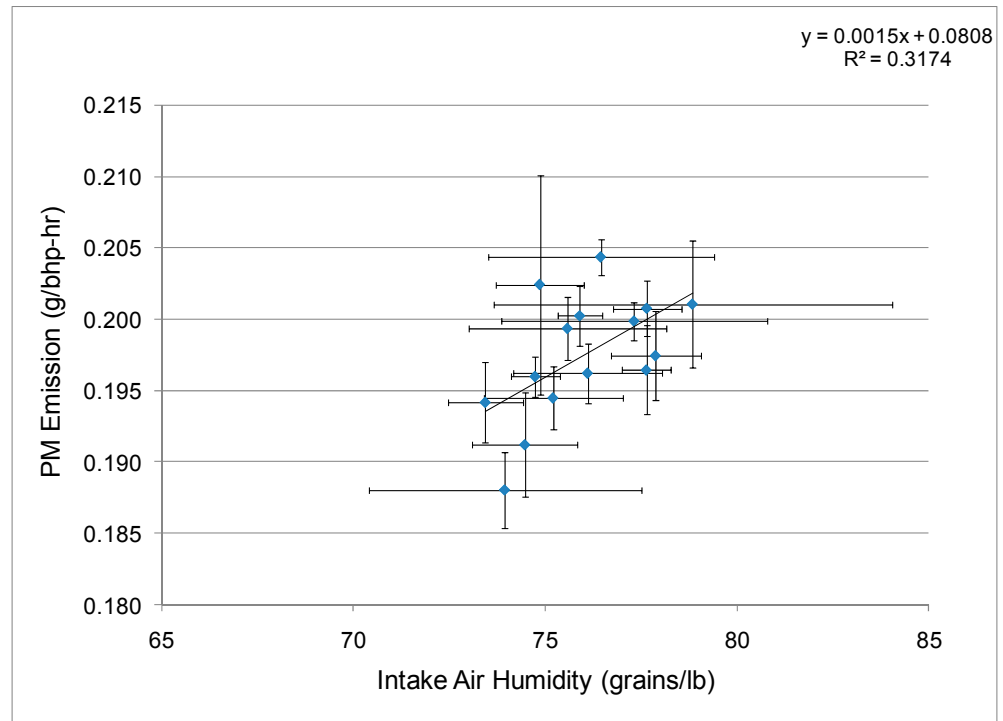

Figure B.21: BsPM versus Intake Air Humidity.

\section{B.4. Run-to-Run Variation in Emissions}

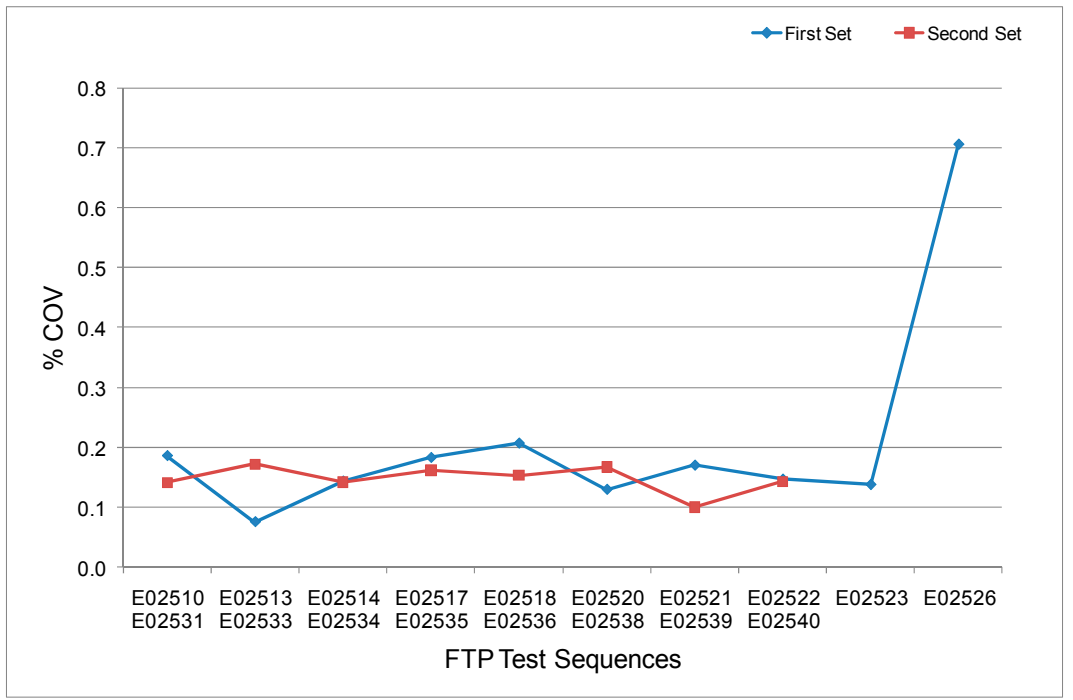

Figure B.22 : Run-to-Run Variation in $\mathrm{BsCO}_{2}$ Emission from FTPs. 


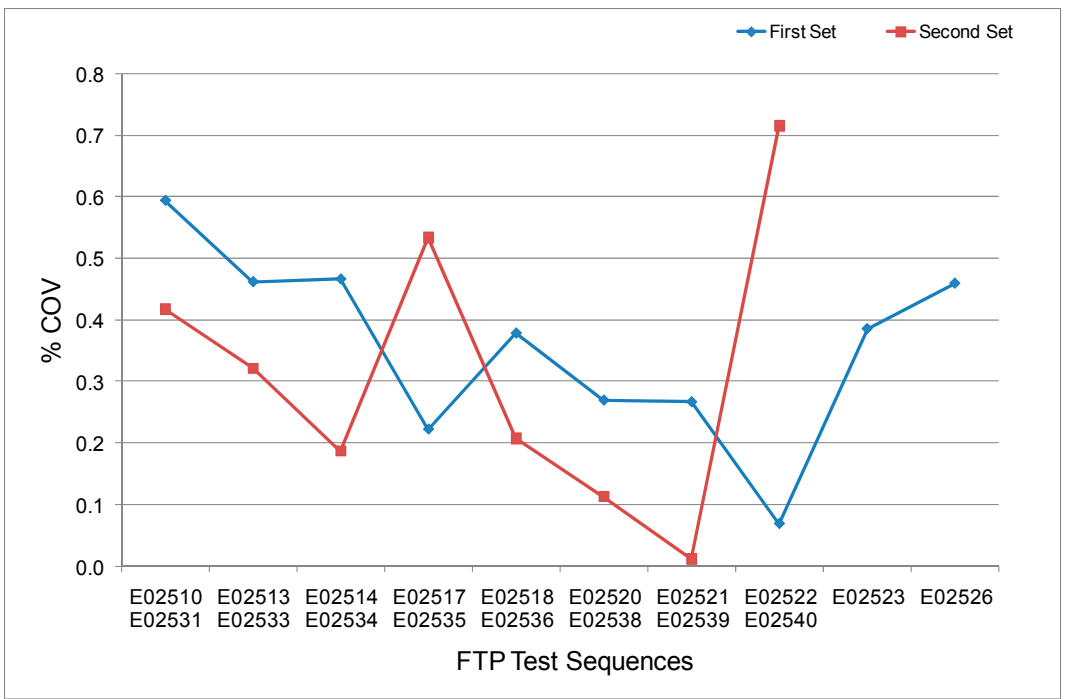

Figure B.23 : Run-to-Run Variation in BsNOx (I) Emission from FTPs.

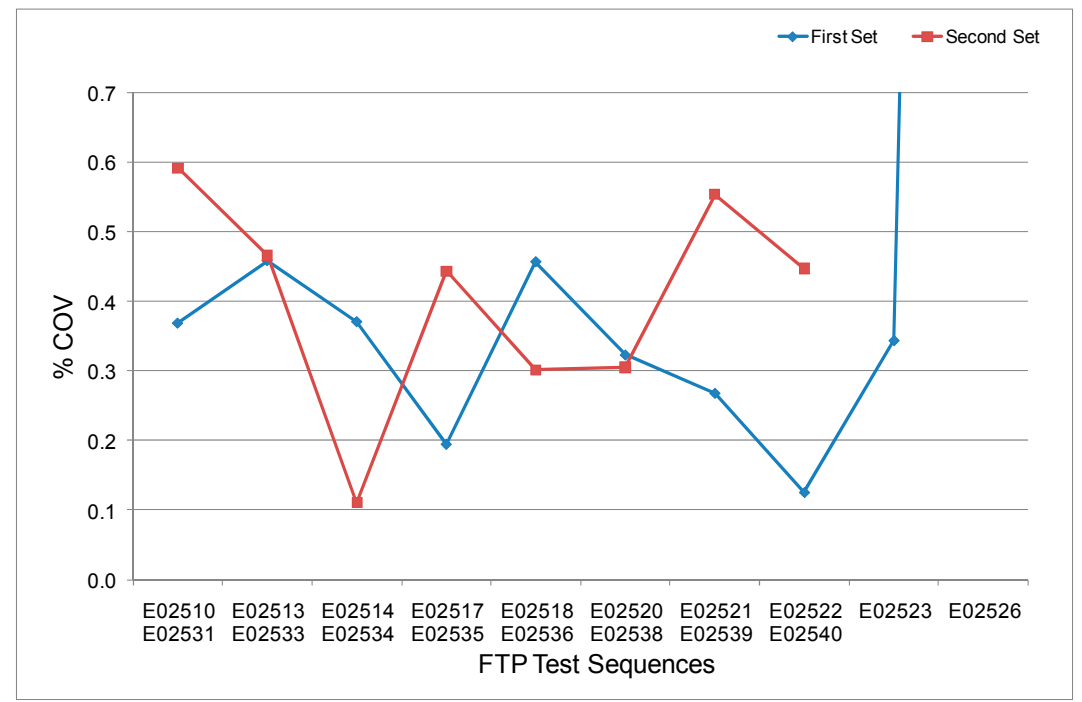

Figure B.24 : Run-to-Run Variation in BsNOx (II) Emission from FTPs. 


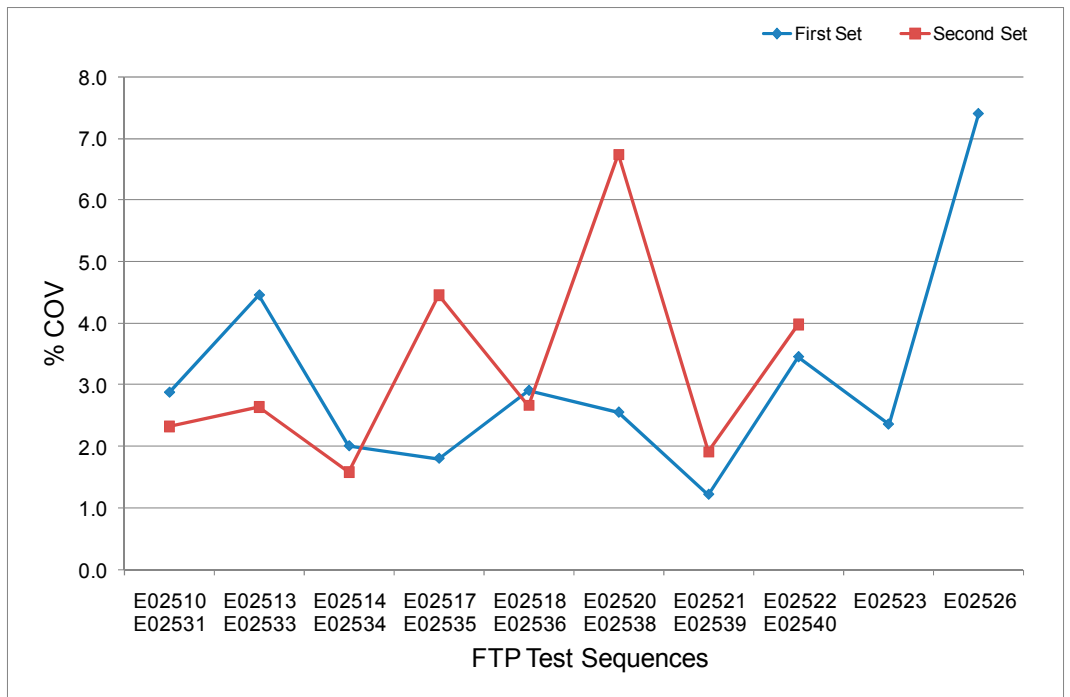

Figure B.25 : Run-to-Run Variation in BsHC Emission from FTPs.

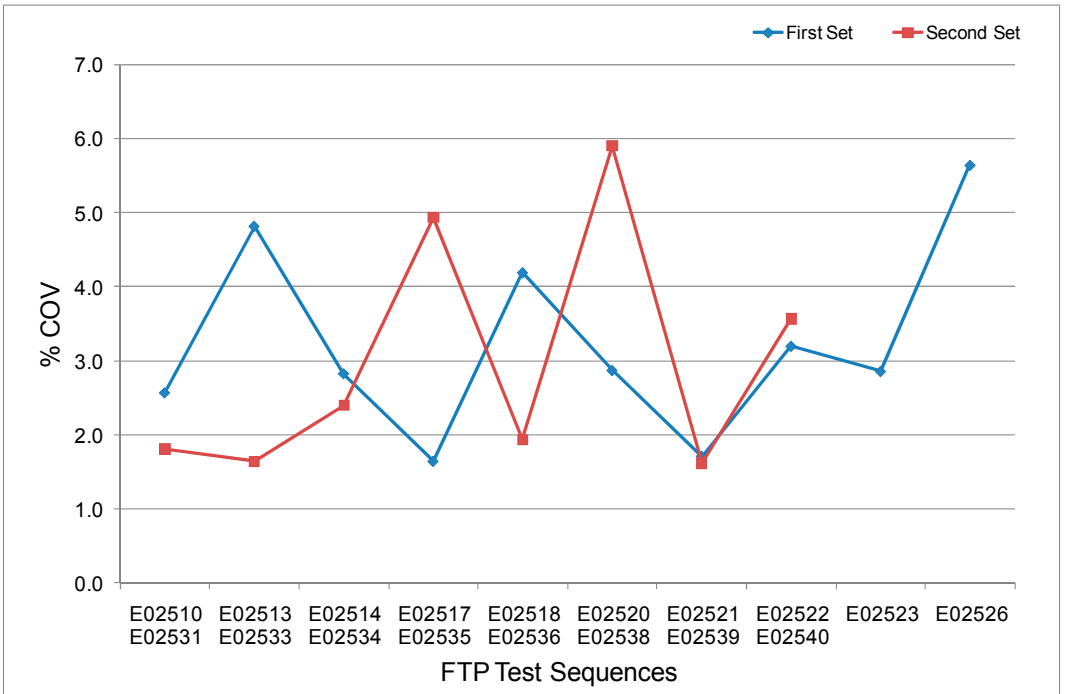

Figure B.26 : Run-to-Run Variation in BsSecHC Emission from FTPs. 


\section{B.5. Steady State Continuous Emissions}

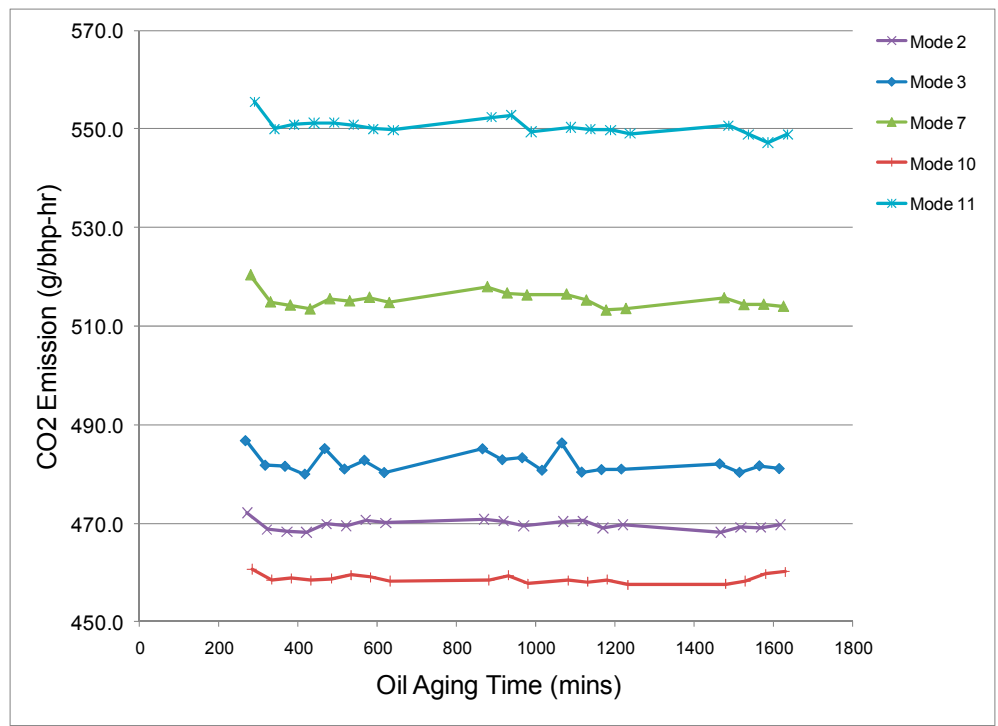

Figure B.27 : $\mathrm{BSCO}_{2}$ Emission at Steady State Modes.

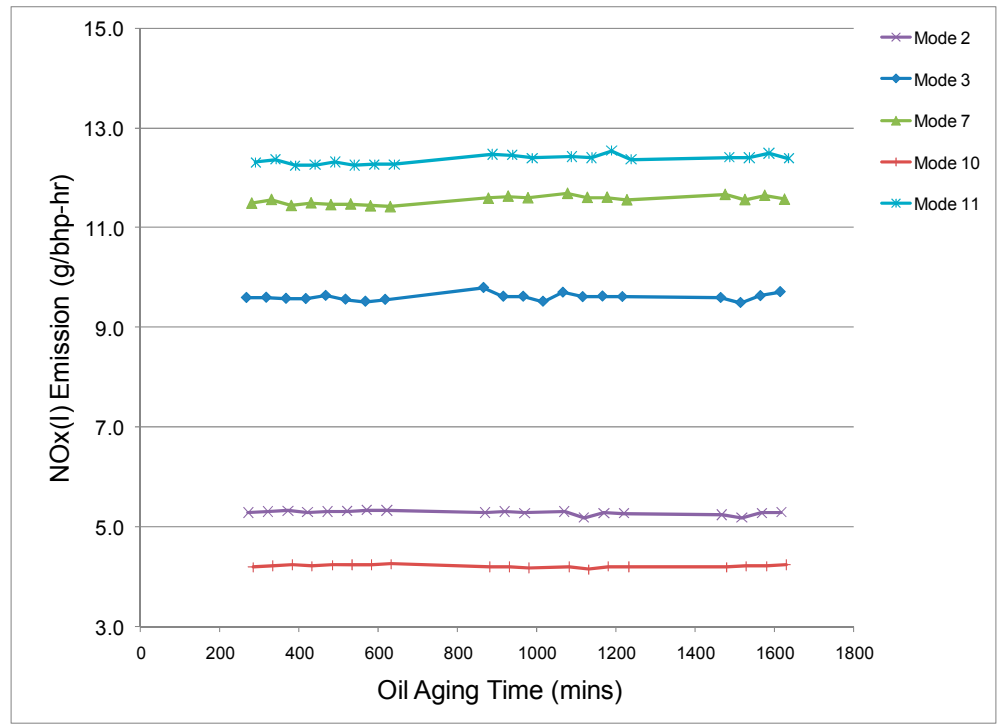

Figure B.28 : BsNOx (I) Emission at Steady State Modes. 


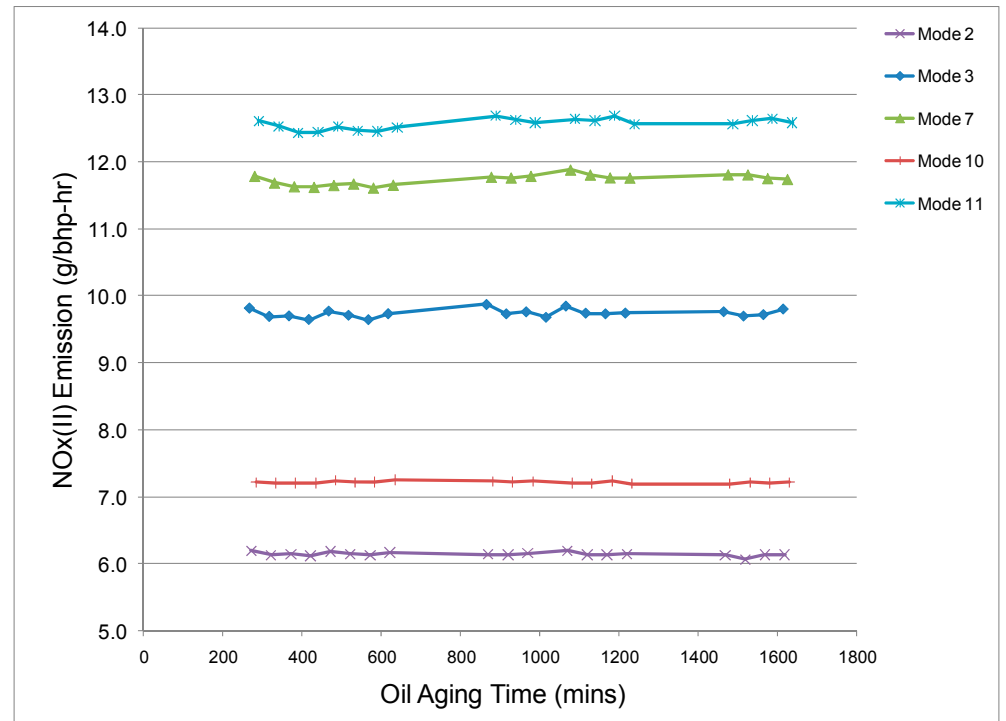

Figure B.29 : BsNOx (II) Emission at Steady State Modes.

\section{B.6. Statistical Analysis of Emission - Box Plots}

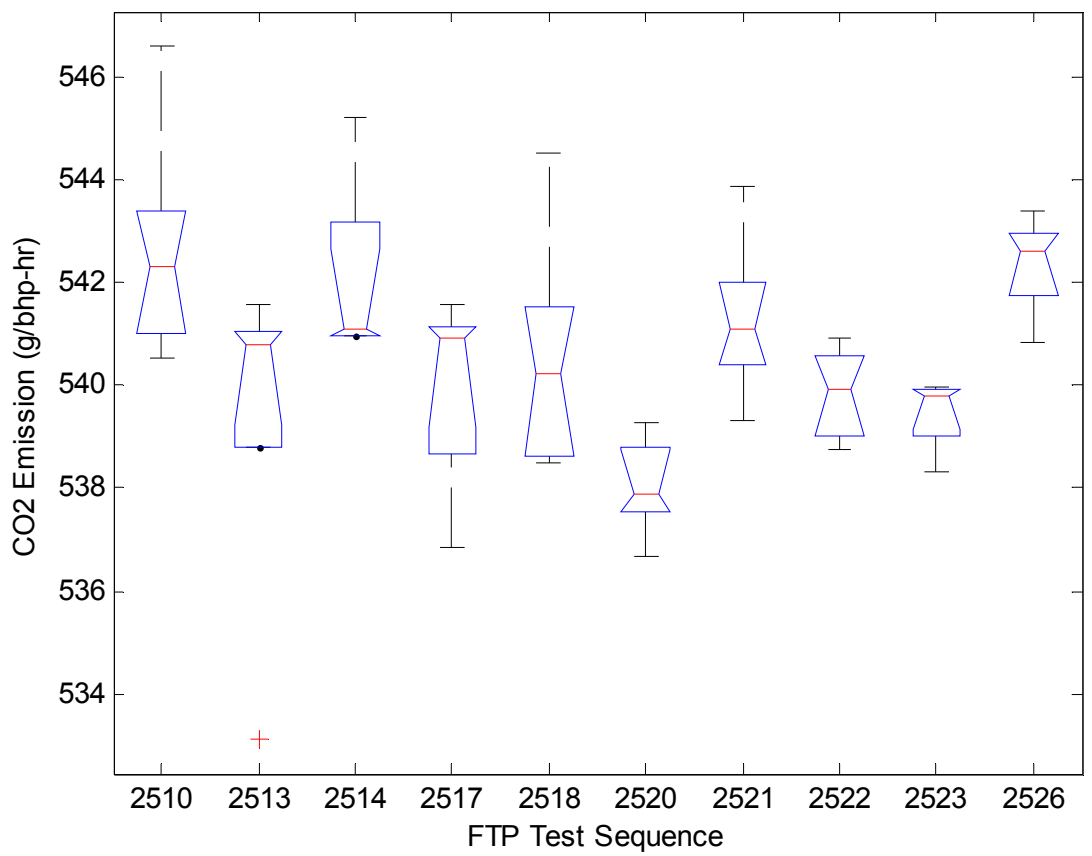

Figure B.30 : Box Plot of $\mathrm{CO}_{2}$ Emission from First Set FTP Test Groups. 


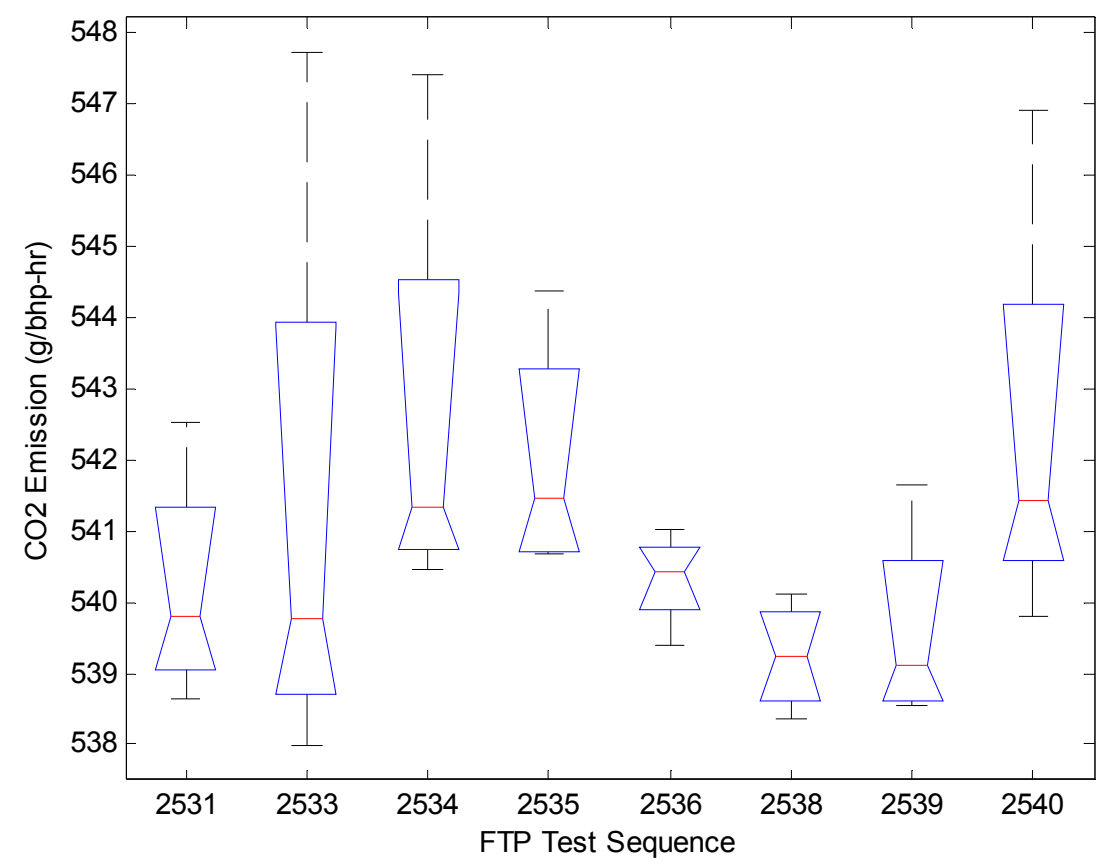

Figure B.31 : Box Plot of $\mathrm{CO}_{2}$ Emission from Second Set FTP Test Groups.

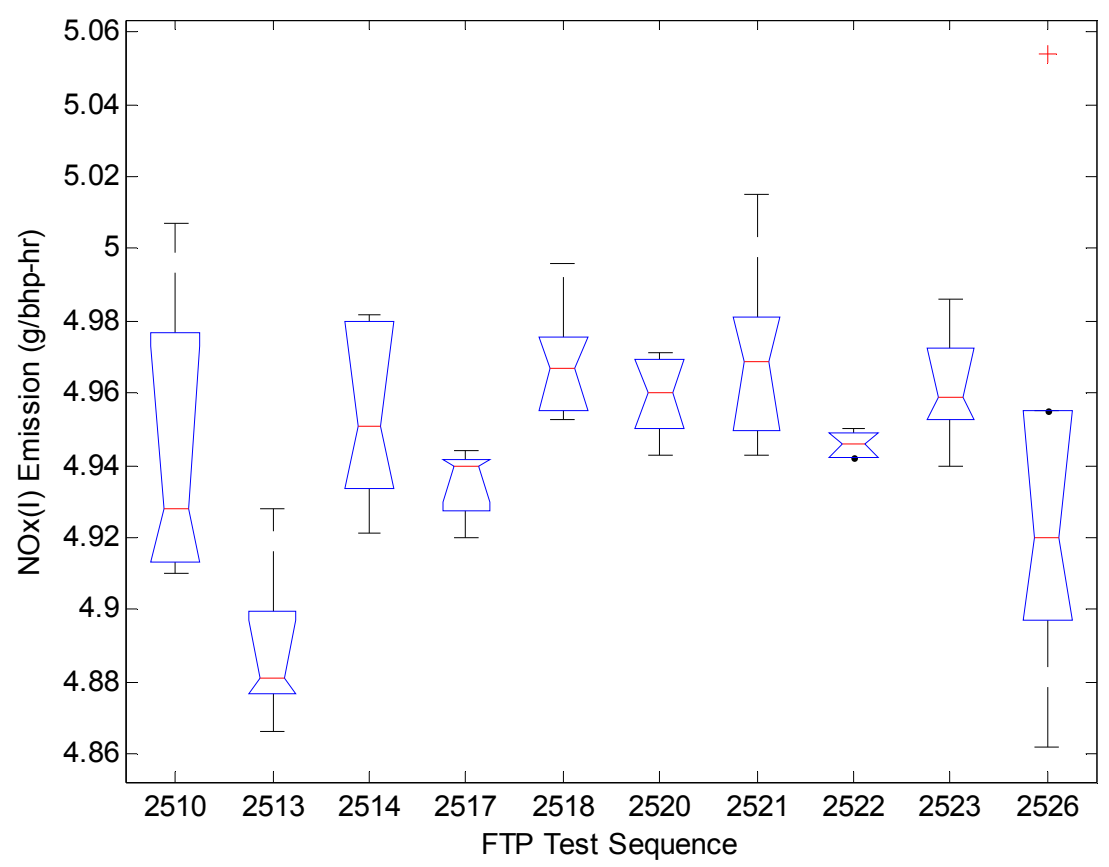

Figure B.32 : Box Plot of NOx (I) Emission from First Set FTP Test Groups. 


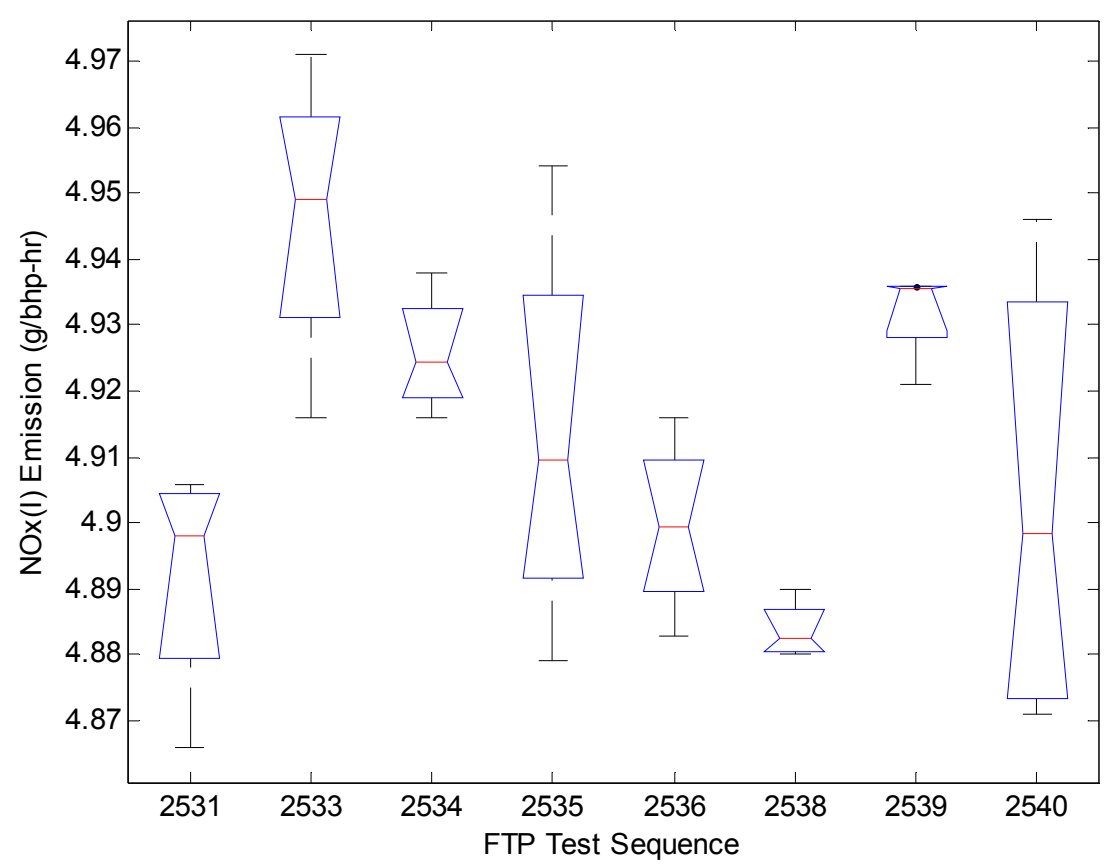

Figure B.33 : Box Plot of NOx (I) Emission from Second Set FTP Test Groups.

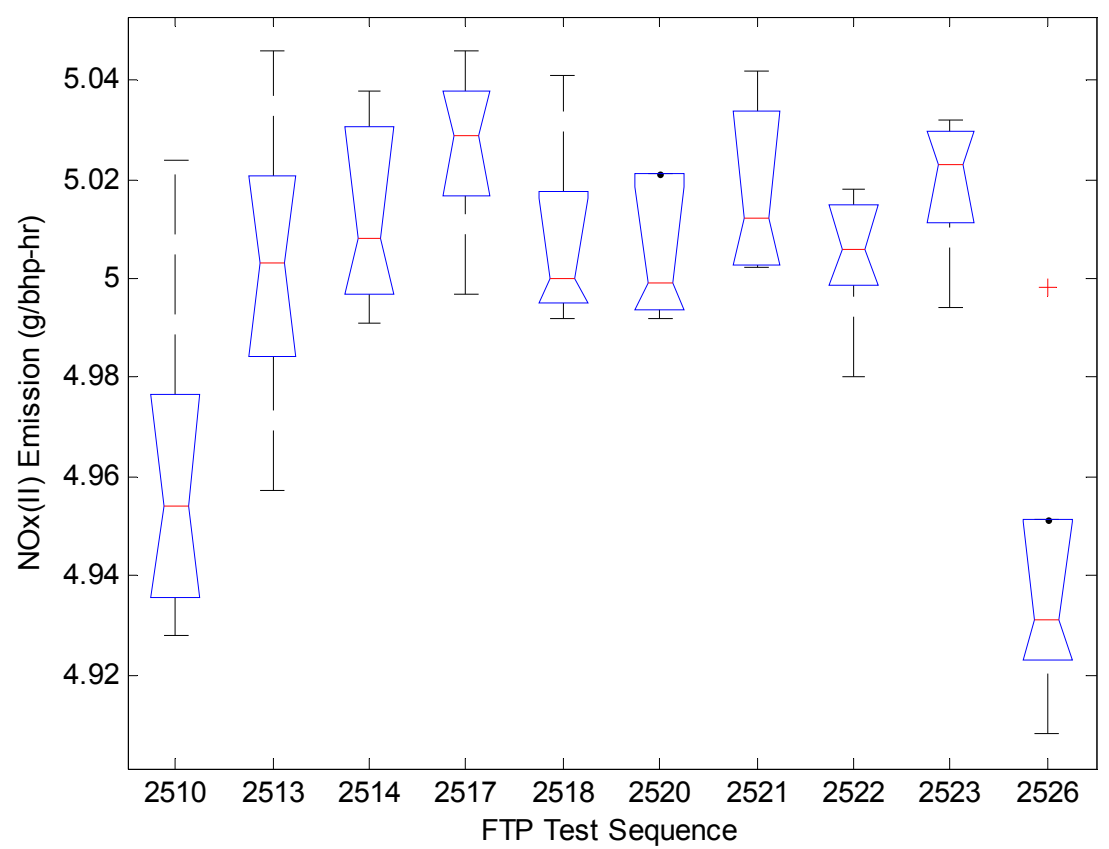

Figure B.34 : Box Plot of NOx (II) Emission from First Set FTP Test Groups. 


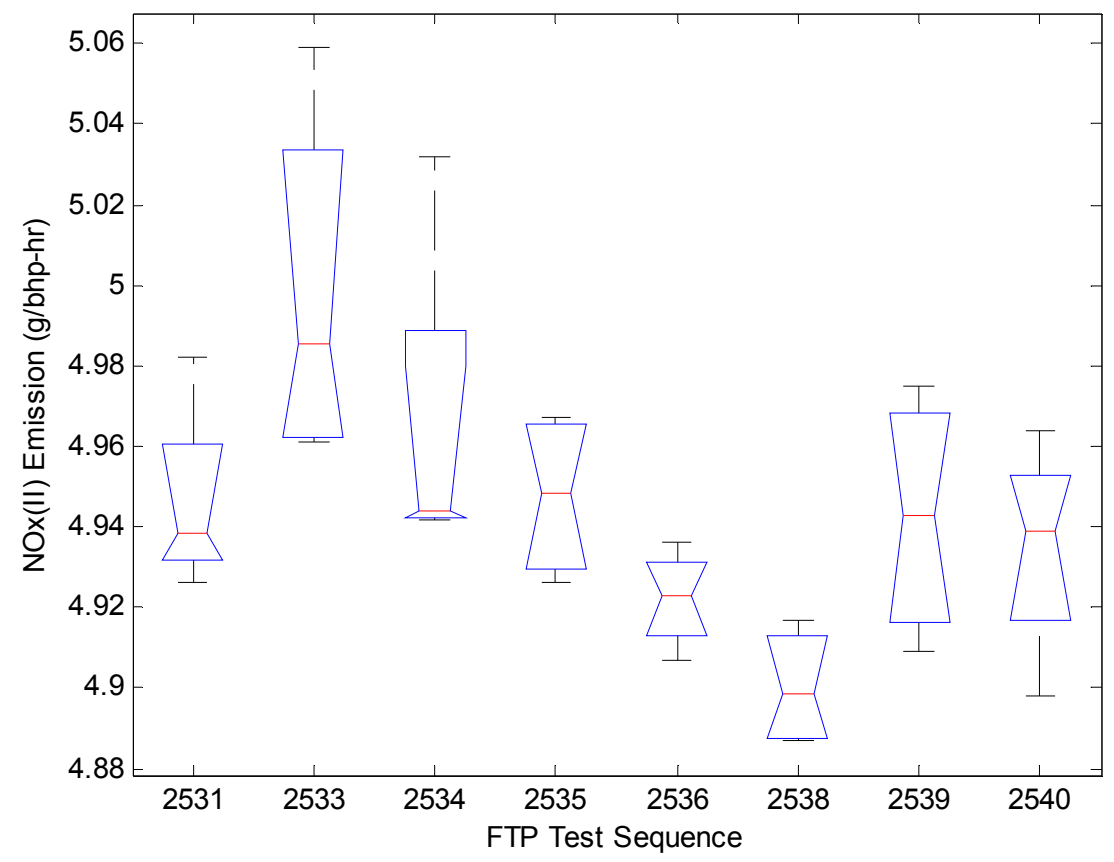

Figure B.35 : Box Plot of NOx (II) Emission from Second Set FTP Test Groups.

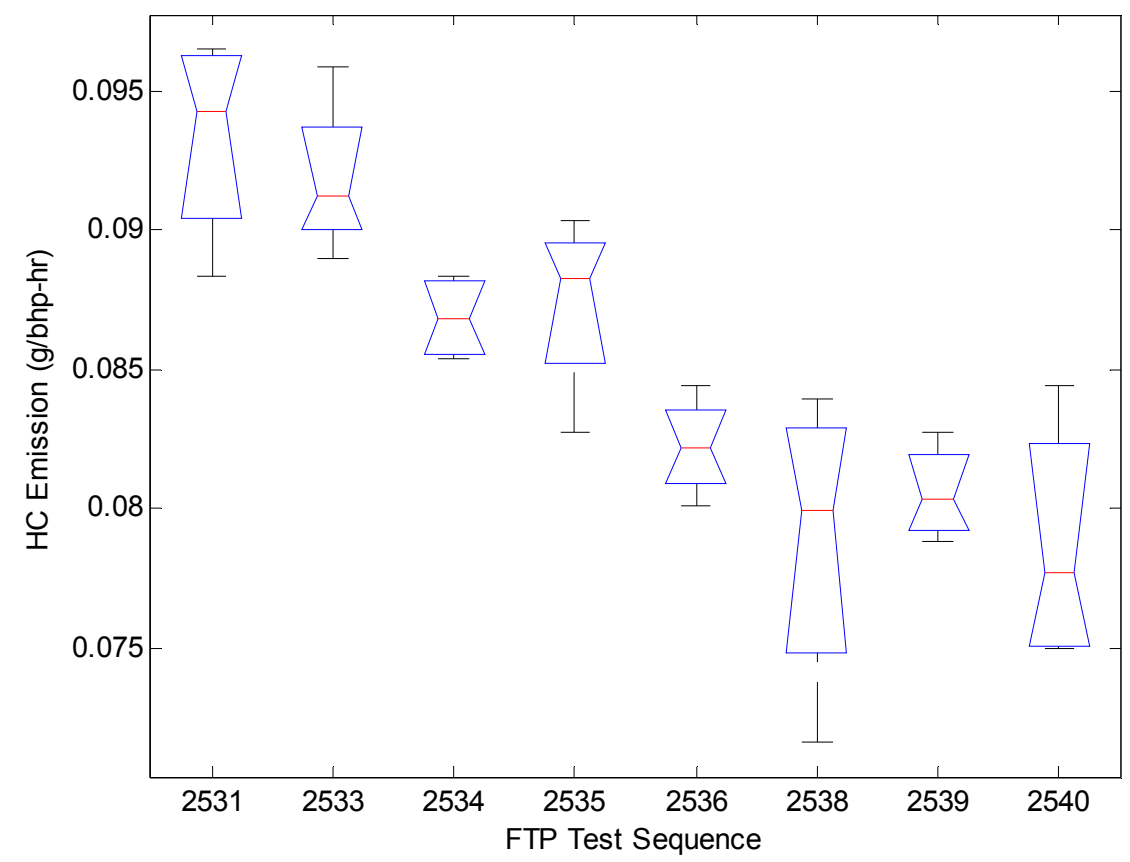

Figure B.36 : Box Plot of HC Emission from Second Set FTP Test Groups. 


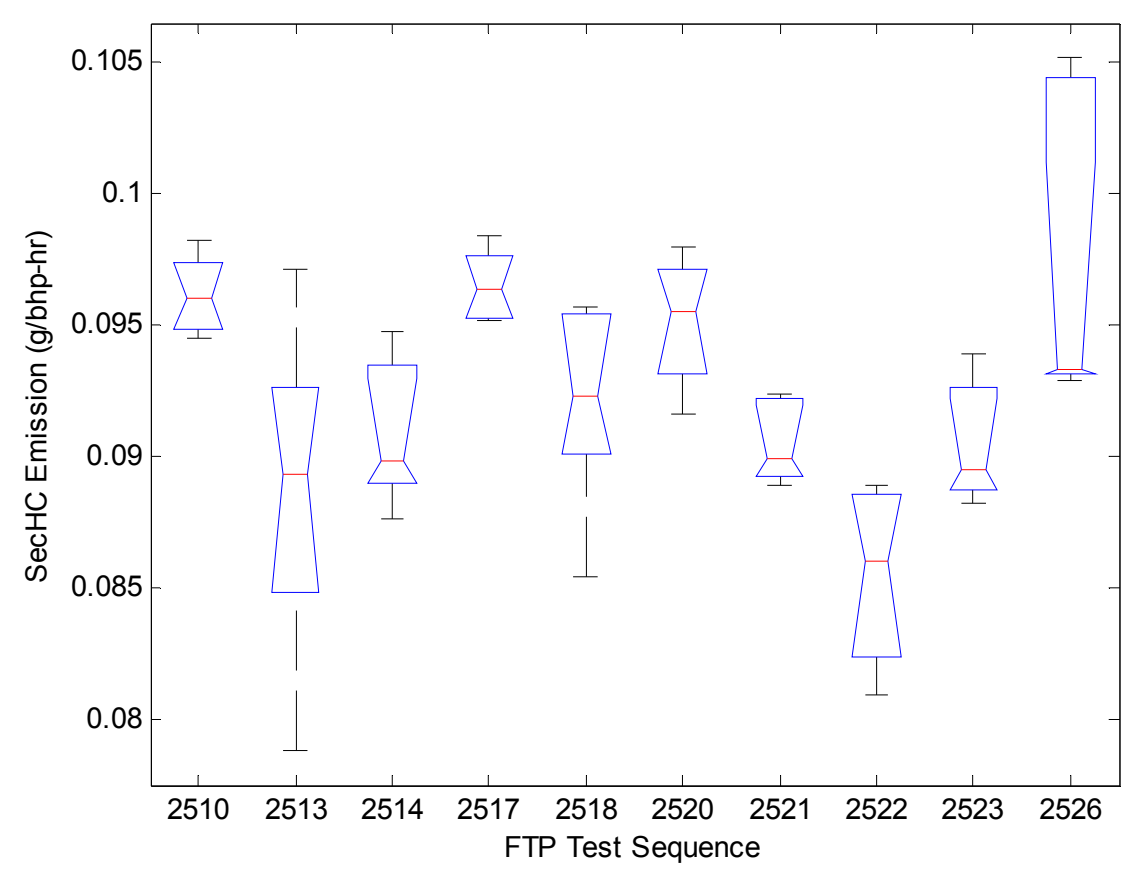

Figure B.37 : Box Plot of SecHC Emission from First Set FTP Test Groups.

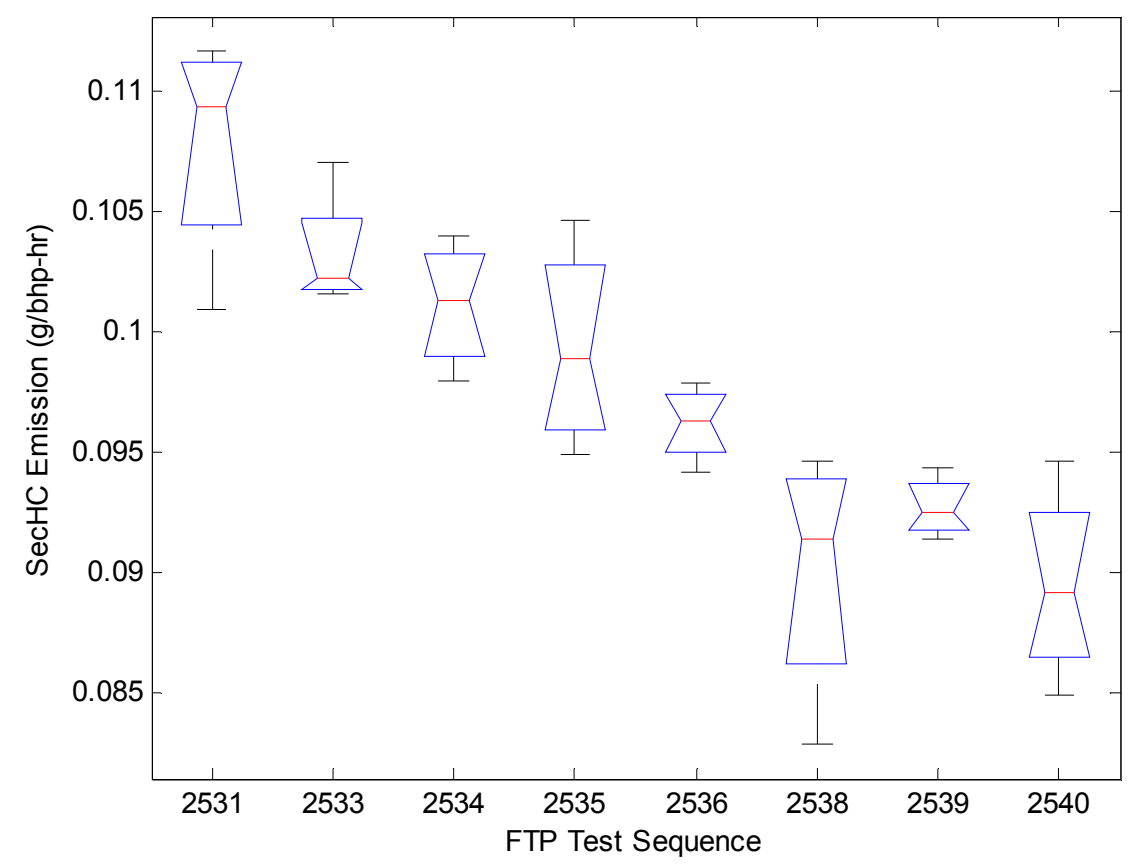

Figure B.38 : Box Plot of SecHC Emission from Second Set FTP Test Groups. 


\section{B.7. Statistical Analysis of Emission - Multiple-Comparison Plots}

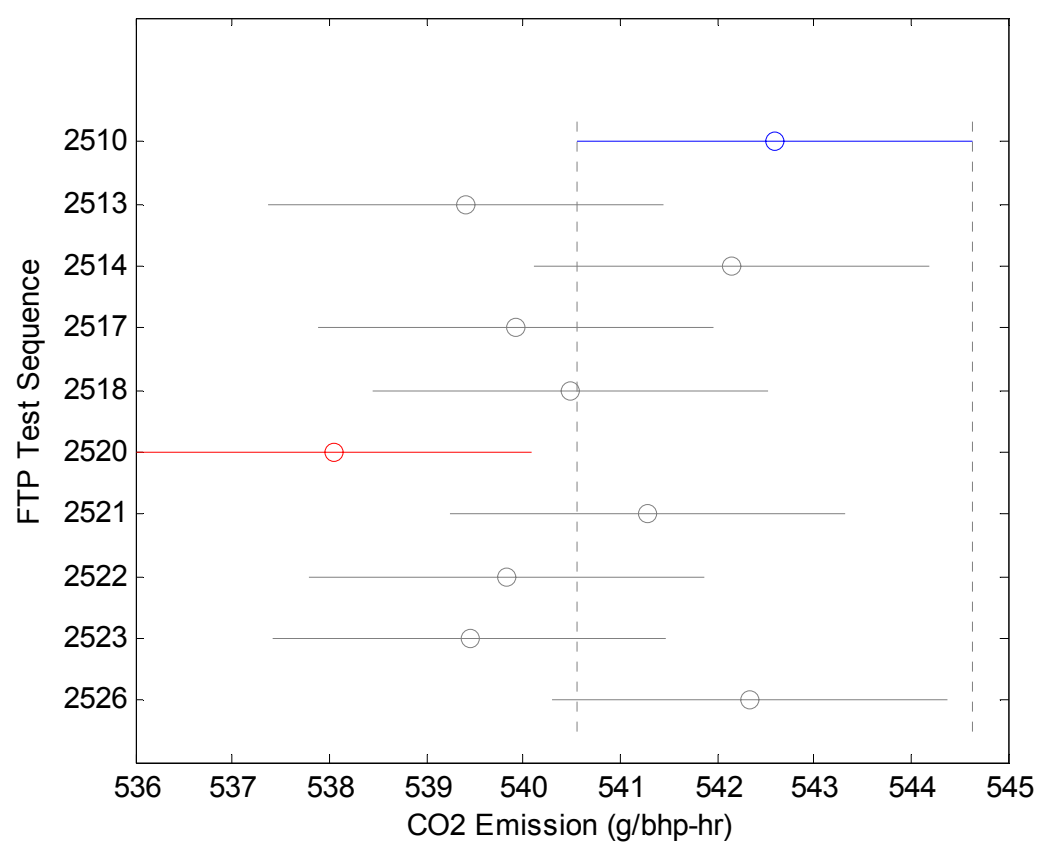

Figure B.39 : Multiple-Comparison Plot of $\mathrm{CO}_{2}$ Emission from First Set FTP Test Groups.

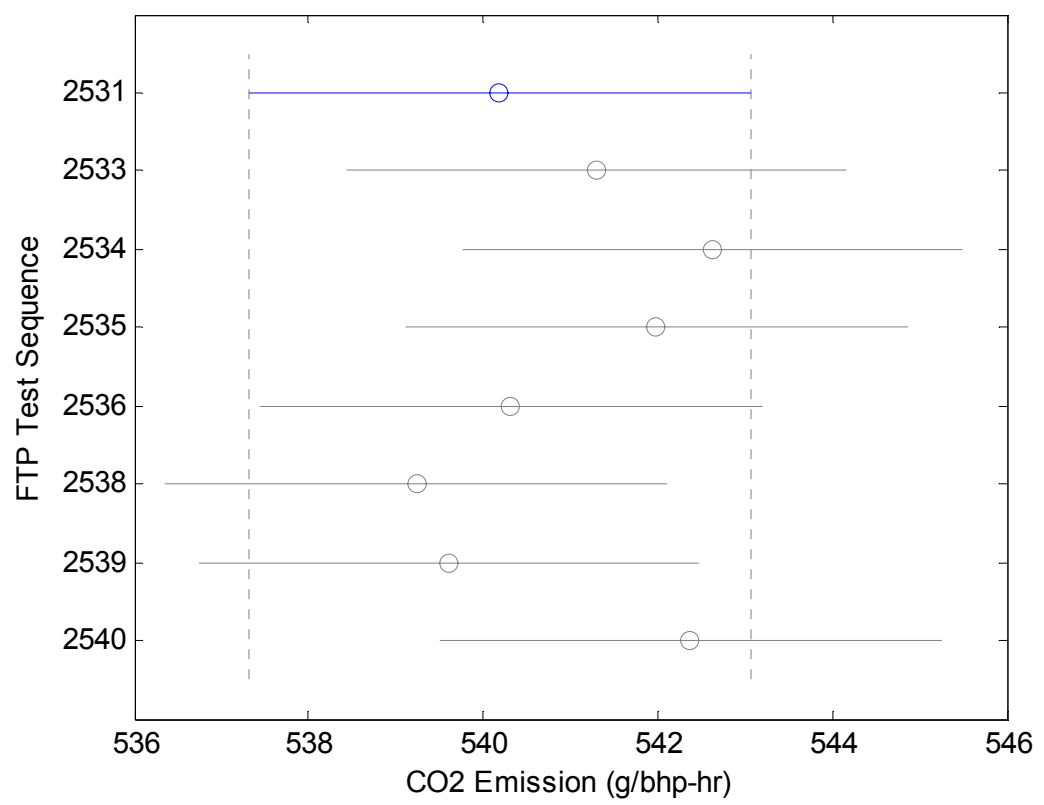

Figure B.40 : Multiple-Comparison Plot of $\mathrm{CO}_{2}$ Emission from Second Set FTP Test Groups. 


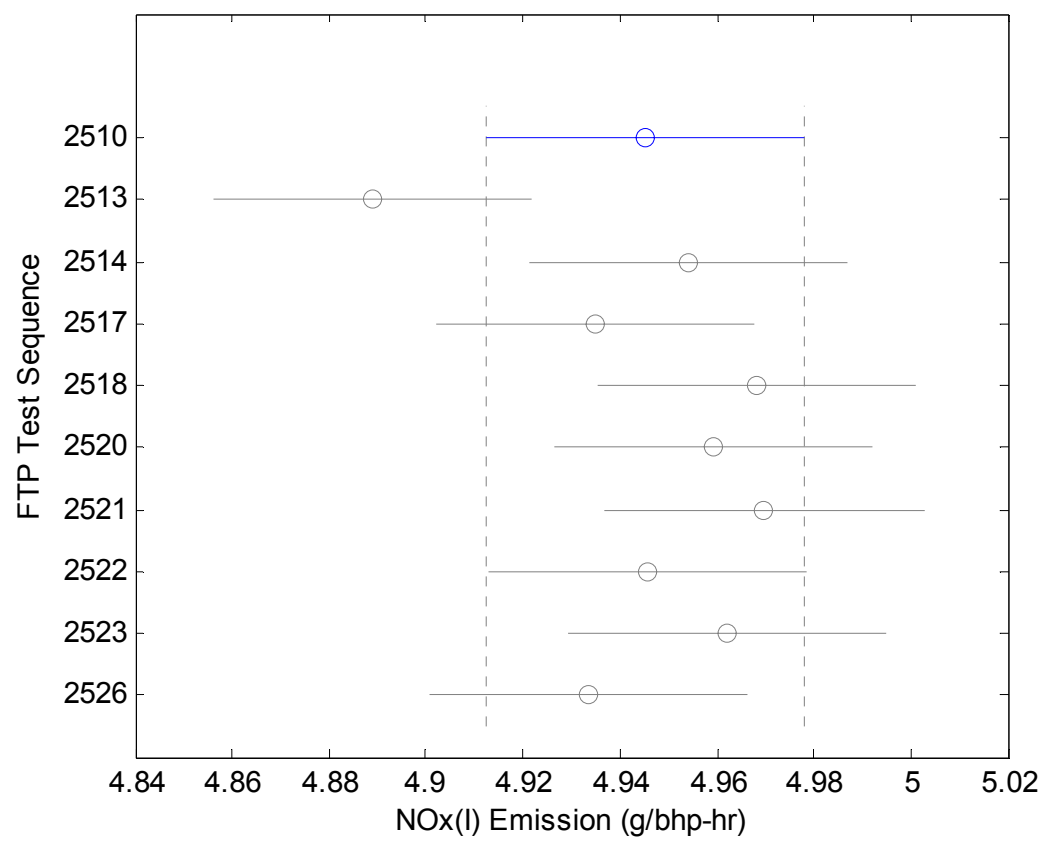

Figure B.41 : Multiple-Comparison Plot of NOx (I) Emission from First Set FTP Test Groups.

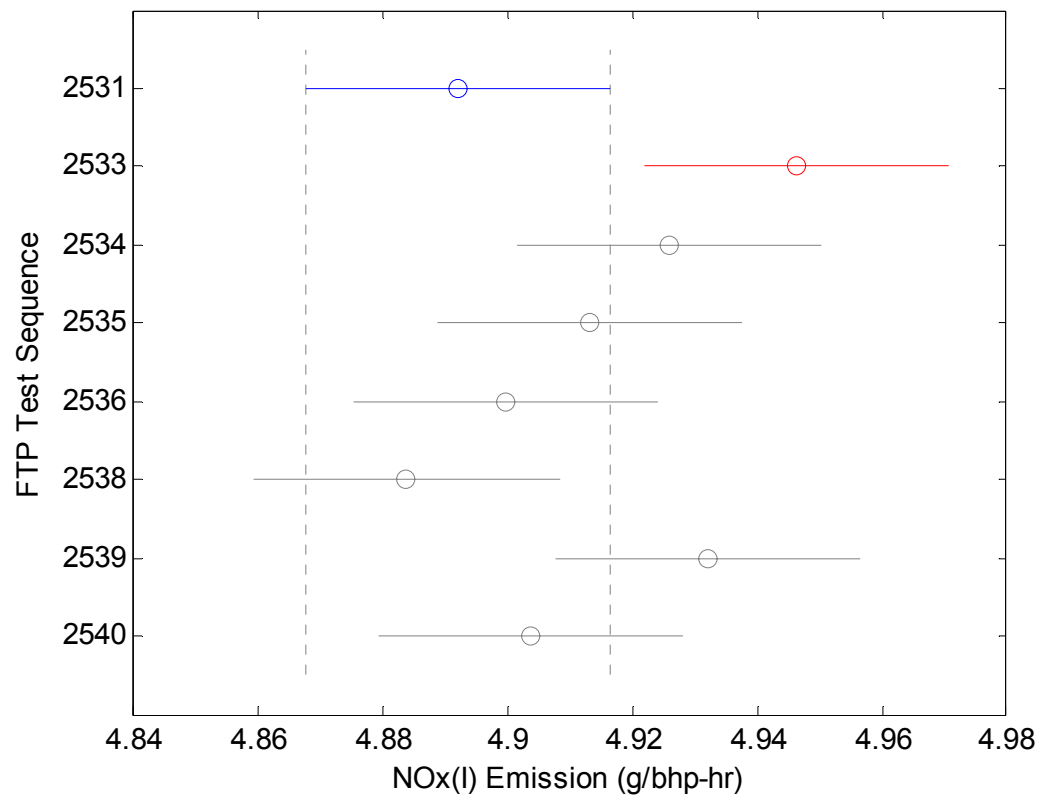

Figure B.42 : Multiple-Comparison Plot of NOx (I) Emission from Second Set FTP Test Groups. 


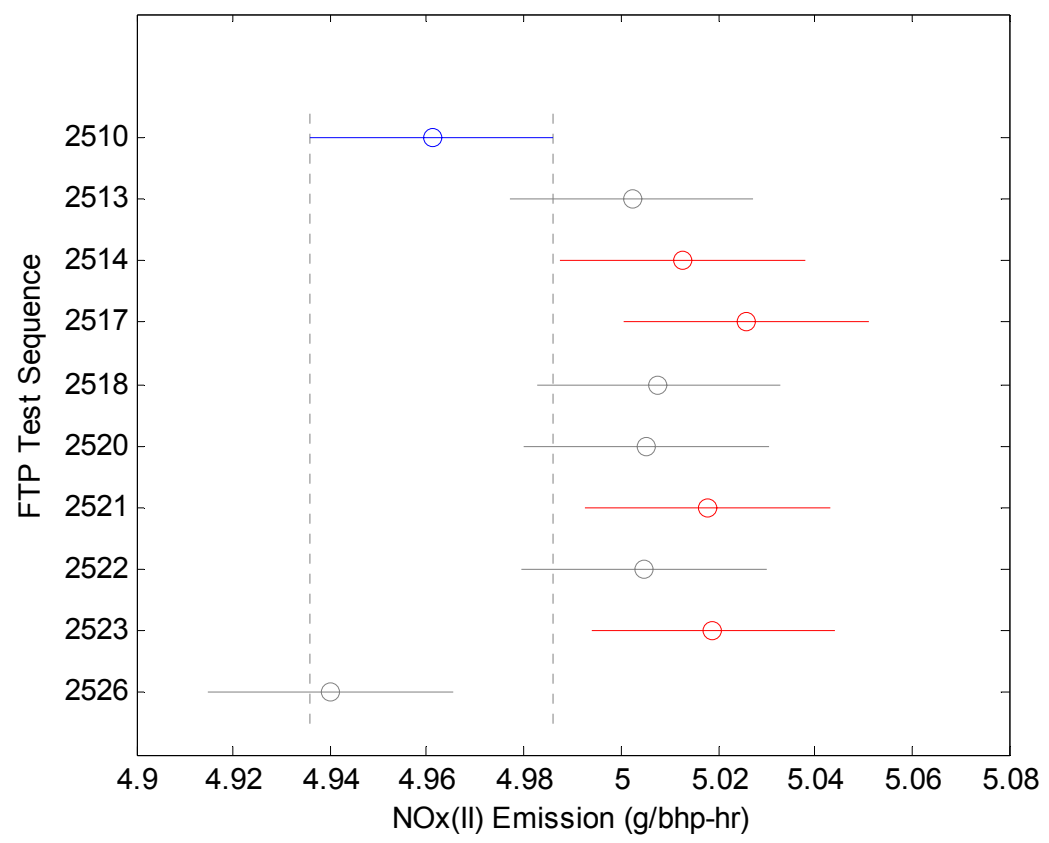

Figure B.43 : Multiple-Comparison Plot of NOx (II) Emission from First Set FTP Test Groups.

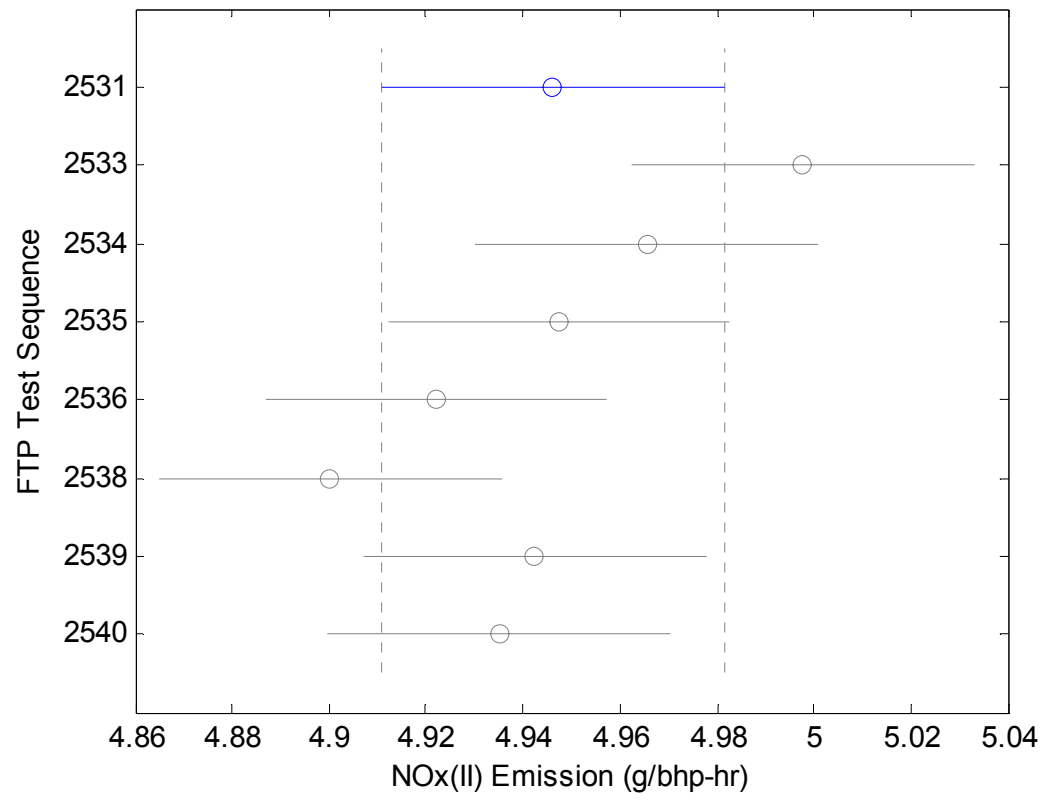

Figure B.44 : Multiple-Comparison Plot of NOx (II) Emission from Second Set FTP Test Groups. 


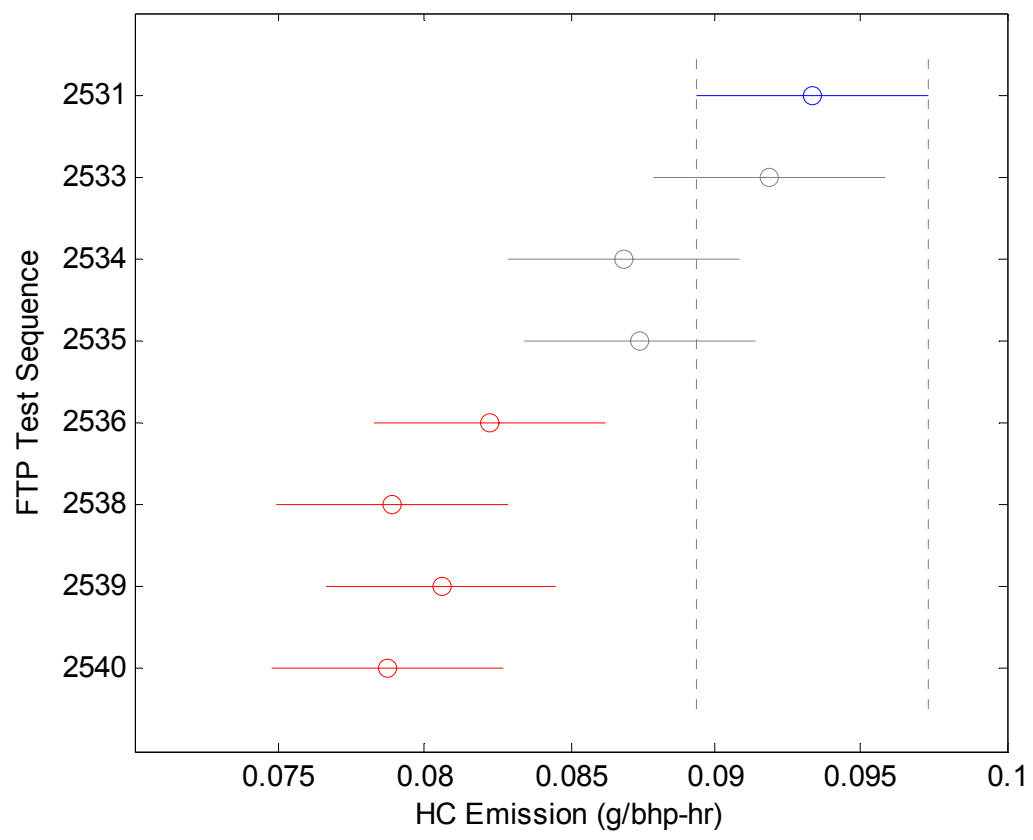

Figure B.45 : Multiple-Comparison Plot of HC Emission from Second Set FTP Test Groups.

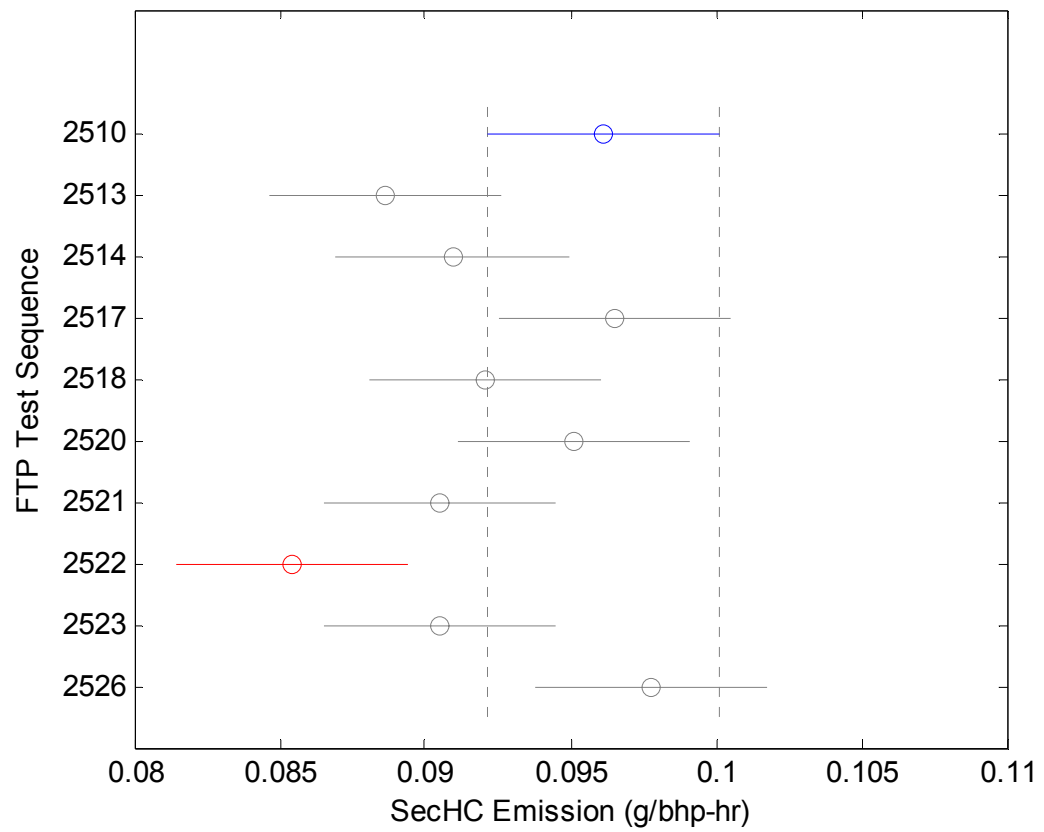

Figure B.46 : Multiple-Comparison Plot of SecHC Emission from First Set FTP Test Groups. 


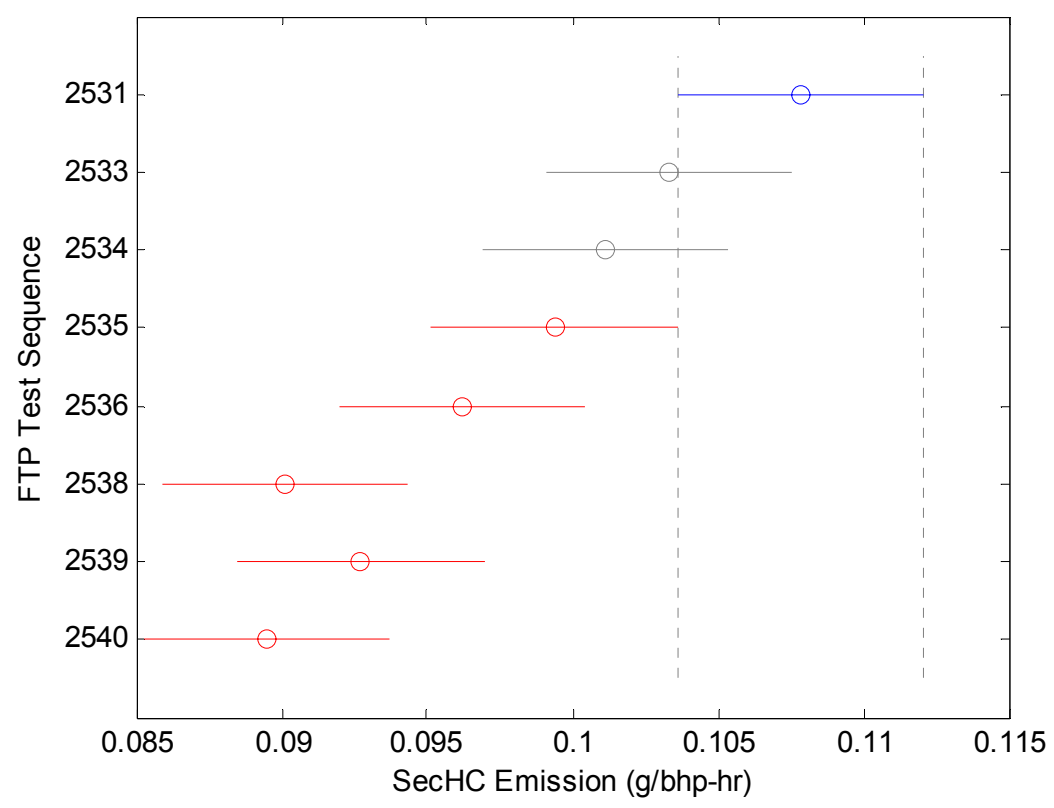

Figure B.47 : Multiple-Comparison Plot of SecHC Emission from Second Set FTP Test Groups.

\section{B.8. Statistical Analysis of Emission - ANOVA Results}

\begin{tabular}{|c|c|c|c|c|c|}
\hline \multicolumn{6}{|c|}{ CO2 Emission-First Set } \\
\hline Source & Sum of Squares & df & Mean Square & $\mathbf{F}$ & Prob $>$ F \\
\hline Columns & 100.5122476 & 9 & 11.16802751 & 3.019780169 & 0.007592919 \\
\hline Error & 147.9316624 & 40 & 3.69829156 & & \\
\hline Total & 248.443914 & 49 & & & \\
\hline
\end{tabular}

\begin{tabular}{|c|c|c|c|c|c|}
\hline \multicolumn{6}{|c|}{ CO2 Emission-Second Set } \\
\hline \multicolumn{6}{|c|}{ Analysis of Variance } \\
\hline Source & Sum of Squares & df & Mean Square & $\mathbf{F}$ & Prob $>F$ \\
\hline Columns & 47.23251847 & 7 & 6.747502638 & 1.124192384 & 0.380831156 \\
\hline Error & 144.0501338 & 24 & 6.002088906 & & \\
\hline Total & 191.2826522 & 31 & & & \\
\hline
\end{tabular}

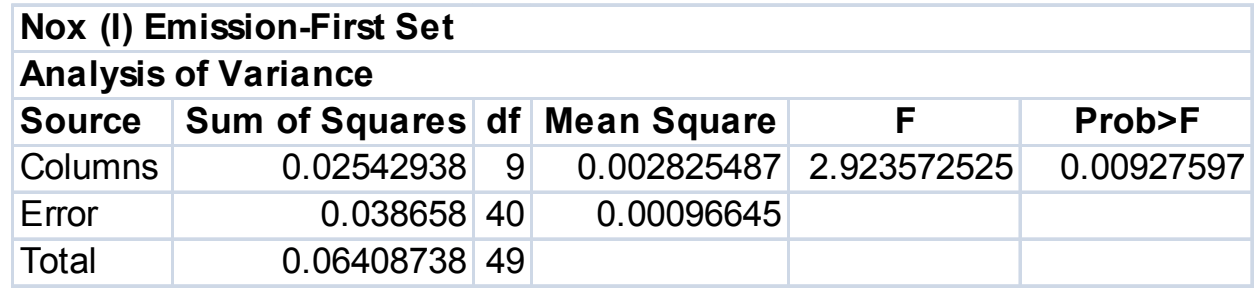


Nox (I) Emission-Second Set

Analysis of Variance

\begin{tabular}{|l|r|r|r|c|c|}
\hline Source & Sum of Squares & df & Mean Square & F & Prob >F \\
\hline Columns & 0.012758719 & 7 & 0.001822674 & 4.18434403 & 0.003843298 \\
\hline Error & 0.01045425 & 24 & 0.000435594 & & \\
\hline Total & 0.023212969 & 31 & & & \\
\hline
\end{tabular}

NOx (II) Emission-First Set

Analysis of Variance

\begin{tabular}{|l|r|r|r|r|r|}
\hline Source & Sum of Squares & df & Mean Square & F & Prob>F \\
\hline Columns & 0.0336849 & 9 & 0.003742767 & 6.581382944 & $1.05 \mathrm{E}-05$ \\
\hline Error & 0.0227476 & 40 & 0.00056869 & & \\
\hline Total & 0.0564325 & 49 & & & \\
\hline
\end{tabular}

NOx (II) Emission-Second Set

Analysis of Variance

\begin{tabular}{|l|r|r|r|c|c|}
\hline Source & Sum of Squares & df & Mean Square & F & Prob>F \\
\hline Columns & 0.0233435 & 7 & 0.003334786 & 3.680101947 & 0.007696686 \\
\hline Error & 0.021748 & 24 & 0.000906167 & & \\
\hline Total & 0.0450915 & 31 & & & \\
\hline
\end{tabular}

HC Emission-Second Set

Analysis of Variance

\begin{tabular}{|l|r|r|r|r|r|r|}
\hline Source & Sum of Squares & df & Mean Square & F & Prob $>$ F \\
\hline Columns & 0.00092304 & 7 & 0.000131863 & 11.42267265 & $2.65 E-06$ \\
\hline Error & 0.000277055 & 24 & $1.15 \mathrm{E}-05$ & & \\
\hline Total & 0.001200095 & 31 & & & \\
\hline
\end{tabular}

SecHC Emission-First Set

Analysis of Variance

\begin{tabular}{|l|r|r|r|r|r|}
\hline Source & Sum of Squares & df & Mean Square & F & Prob>F \\
\hline Columns & 0.00069672 & 9 & $7.74 \mathrm{E}-05$ & 5.454948459 & $7.03 \mathrm{E}-05$ \\
\hline Error & 0.000567656 & 40 & $1.42 \mathrm{E}-05$ & & \\
\hline Total & 0.001264376 & 49 & & & \\
\hline
\end{tabular}

SecHC Emission-Second Set

Analysis of Variance

\begin{tabular}{|l|r|r|r|r|r|}
\hline Source & Sum of Squares & df & Mean Square & F & \multicolumn{1}{|c|}{ Prob>F } \\
\hline Columns & 0.001203385 & 7 & 0.000171912 & 13.13329862 & $7.67 \mathrm{E}-07$ \\
\hline Error & 0.000314155 & 24 & $1.31 \mathrm{E}-05$ & & \\
\hline Total & 0.00151754 & 31 & & & \\
\hline
\end{tabular}


TPM Emission-First Set

Analysis of Variance

\begin{tabular}{|l|l|l|l|l|}
\hline Source & Sum of Squares df & Mean Square & F & Prob>F
\end{tabular}

\begin{tabular}{|l|l|l|l|l|l|}
\hline Columns & 0.011931673 & 9 & 0.001325741 & 46.65542404 & 0
\end{tabular}

\begin{tabular}{|l|l|l|l|l|}
\hline Error & 0.00113662440 & $2.84 \mathrm{E}-05$ \\
\hline
\end{tabular}

Total $\quad 0.01306829649$

TPM Emission-Second Set

Analysis of Variance

Source Sum of Squares df Mean Square

$\mathbf{F}$

Prob>F

\begin{tabular}{|l|l|l|l|l|l|l|}
\hline Columns & 0.006947329 & 7 & 0.000992476 & 58.13895073 & $1.64 \mathrm{E}-13$ \\
\hline
\end{tabular}

\begin{tabular}{|l|l|l|l|}
\hline Error & 0.000409698 & 24 & $1.71 \mathrm{E}-05$ \\
\hline
\end{tabular}

\begin{tabular}{l|lll} 
Total & 0.007357027 & 31
\end{tabular} 


\section{B.9. Oil Analysis Results}

Table B.1 : Oil Sample Analysis Results.

\begin{tabular}{|c|c|c|c|c|c|c|c|c|c|c|c|c|c|c|c|}
\hline Property & \begin{tabular}{|l|} 
Test \\
Method
\end{tabular} & Units & Fresh oil & WVOil0343 & WVOil0344 & WVOil0345 & WVOil0346 & WVOil0348 & WVOil0350 & WVOil0401 & WVOil0402 & WVOil0405 & WVOil0406 & WVOil0407 & WVOil0408 \\
\hline $\begin{array}{l}\text { Fuel } \\
\text { Dilution }\end{array}$ & OEM & & 1.9 & 1.7 & 1.7 & 1.7 & 1.7 & 1.8 & 1.8 & 1.9 & 1.9 & - & 1.7 & 1.7 & \\
\hline Soot & LEM & $\%$ weight & 0.01 & 0.01 & 0.01 & 0.05 & 0.06 & 2.33 & 0.14 & 0.25 & 0.05 & 0.09 & 0.15 & 0.11 & 0.12 \\
\hline \begin{tabular}{|l} 
Viscosity \\
$@$ \\
100DegC
\end{tabular} & D445 & cSt & 15.4 & 15.1 & 15.2 & 15.2 & 15 & 15 & 15 & 15 & 15.1 & 15.2 & 15.1 & 15.1 & \\
\hline Acid No. & D664m & $\mathrm{mg} / \mathrm{g} \mathrm{KOH}$ & 1.34 & 1.46 & 1.18 & 1.57 & 1.62 & 1.4 & 1.62 & 1.62 & 1.57 & 1.4 & 1.34 & 1.34 & \\
\hline Base No. & D664m & $\mathrm{mg} \mathrm{KOH} / \mathrm{g}$ & 8.51 & 7.73 & 7.5 & 8.85 & 7.95 & 8.06 & 6.5 & 7.17 & 7.28 & 8.74 & 8.06 & 7.39 & \\
\hline \begin{tabular}{|l} 
Sulfated \\
Ash
\end{tabular} & \begin{tabular}{|l|} 
D482/D \\
874
\end{tabular} & $\%$ wt & 0.94 & 0.809 & 0.8 & 0.795 & 0.771 & 0.807 & 0.812 & 0.783 & 0.809 & 0.749 & 0.737 & 0.778 & 0.787 \\
\hline $\begin{array}{l}\text { Density @ } \\
15 \text { DegC }\end{array}$ & D1298 & $\mathrm{Kg} / \mathrm{L}$ & 0.8707 & 0.8707 & 0.8707 & 0.8707 & 0.8707 & 0.8707 & 0.8707 & 0.8707 & 0.8707 & 0.8707 & 0.8707 & 0.8707 & . \\
\hline \multirow{21}{*}{ Metals } & \multirow{21}{*}{ D5185 } & $\mathrm{Fe}, \mathrm{ppm}$ & 2.0 & 2.0 & 2.0 & 2.0 & 3.0 & 3.0 & 3.0 & 3.0 & 4.0 & 2.0 & 2.0 & 2.0 & 2.0 \\
\hline & & $\mathrm{Cr}, \mathrm{ppm}$ & $<1$ & $<1$ & $<1$ & $<1$ & $<1$ & $<1$ & $<1$ & $<1$ & $<1$ & $<1$ & $<1$ & $<1$ & $<1$ \\
\hline & & Ni, ppm & $<1$ & $<1$ & $<1$ & $<1$ & $<1$ & $<1$ & $<1$ & $<1$ & $<1$ & $<1$ & $<1$ & $<1$ & $<1$ \\
\hline & & $\mathrm{Al}, \mathrm{ppm}$ & $<1$ & $<1$ & $<1$ & $<1$ & $<1$ & $<1$ & $<1$ & $<1$ & 1.0 & $<1$ & $<1$ & $<1$ & $<1$ \\
\hline & & $\mathrm{Pb}, \mathrm{ppm}$ & $<1$ & $<1$ & $<1$ & $<1$ & $<1$ & $<1$ & $<1$ & $<1$ & $<1$ & 1.0 & $<1$ & 1.0 & 1.0 \\
\hline & & $\mathrm{Cu}, \mathrm{ppm}$ & $<1$ & $<1$ & $<1$ & $<1$ & $<1$ & $<1$ & $<1$ & $<1$ & $<1$ & $<1$ & $<1$ & $<1$ & $<1$ \\
\hline & & Sn, ppm & 1.0 & 2.0 & 1.0 & 1.0 & 2.0 & 2.0 & 1.0 & 2.0 & 1.0 & 1.0 & 1.0 & 1.0 & 1.0 \\
\hline & & $\mathrm{Ag}, \mathrm{ppm}$ & $<0.1$ & $<0.1$ & $<0.1$ & $<0.1$ & $<0.1$ & $<0.1$ & $<0.1$ & $<0.1$ & $<0.1$ & $<0.1$ & $<0.1$ & $<0.1$ & $<0.1$ \\
\hline & & $\mathrm{Ti}, \mathrm{ppm}$ & $<1$ & $<1$ & $<1$ & $<1$ & $<1$ & $<1$ & $<1$ & $<1$ & $<1$ & $<1$ & $<1$ & $<1$ & $<1$ \\
\hline & & Si, ppm & 2.0 & 4.0 & 5.0 & 5.0 & 6.0 & 6.0 & 8.0 & 8.0 & 9.0 & 3.0 & 4.0 & 4.0 & 4.0 \\
\hline & & $\mathrm{B}, \mathrm{ppm}$ & 36.0 & 42.0 & 39.0 & 38.0 & 37.0 & 36.0 & 35.0 & 35.0 & 35.0 & 37.0 & 37.0 & 37.0 & 36.0 \\
\hline & & $\mathrm{Na}, \mathrm{ppm}$ & 1.0 & 2.0 & 1.0 & 2.0 & 3.0 & 1.0 & 1.0 & 2.0 & 2.0 & 2.0 & 3.0 & 2.0 & 2.0 \\
\hline & & $\mathrm{K}, \mathrm{ppm}$ & $<10$ & $<10$ & $<10$ & $<10$ & $<10$ & $<10$ & $<10$ & $<10$ & $<10$ & $<10$ & $<10$ & $<10$ & $<10$ \\
\hline & & $\mathrm{Mo}, \mathrm{ppm}$ & $<5$ & $<5$ & $<5$ & $<5$ & $<5$ & $<5$ & $<5$ & $<5$ & $<5$ & $<5$ & $<5$ & $<5$ & $<5$ \\
\hline & & $\mathrm{P}, \mathrm{ppm}$ & 985.0 & 1218.0 & 1134.0 & 1115.0 & 1053.0 & 1087.0 & 1073.0 & 1073.0 & 1055.0 & 1096.0 & 1066.0 & 1082.0 & 1046.0 \\
\hline & & $\mathrm{Zn}, \mathrm{ppm}$ & 1153.0 & 1409.0 & 1329.0 & 1299.0 & 1239.0 & 1258.0 & 1256.0 & 1262.0 & 1252.0 & 1279.0 & 1255.0 & 1260.0 & 1233.0 \\
\hline & & $\mathrm{Ca}, \mathrm{ppm}$ & 2094.0 & 2582.0 & 2428.0 & 2390.0 & 2275.0 & 2302.0 & 2310.0 & 2320.0 & 2307.0 & 2342.0 & 2304.0 & 2306.0 & 2267.0 \\
\hline & & $\mathrm{Ba}, \mathrm{ppm}$ & $<10$ & $<10$ & $<10$ & $<10$ & $<10$ & $<10$ & $<10$ & $<10$ & $<10$ & $<10$ & $<10$ & $<10$ & $<10$ \\
\hline & & $\mathrm{Mg}, \mathrm{ppm}$ & 7.0 & 8.0 & 8.0 & 7.0 & 7.0 & 7.0 & 7.0 & 7.0 & 7.0 & 6.0 & 7.0 & 7.0 & 7.0 \\
\hline & & Sb, ppm & $<30$ & $<30$ & $<30$ & $<30$ & $<30$ & $<30$ & $<30$ & $<30$ & $<30$ & $<30$ & $<30$ & $<30$ & $<30$ \\
\hline & & $\mathrm{V}, \mathrm{ppm}$ & $<1$ & $<1$ & $<1$ & $<1$ & $<1$ & $<1$ & $<1$ & $<1$ & $<1$ & $<1$ & $<1$ & $<1$ & $<1$ \\
\hline
\end{tabular}




\section{B.10. Metal Concentration in Oil Samples}

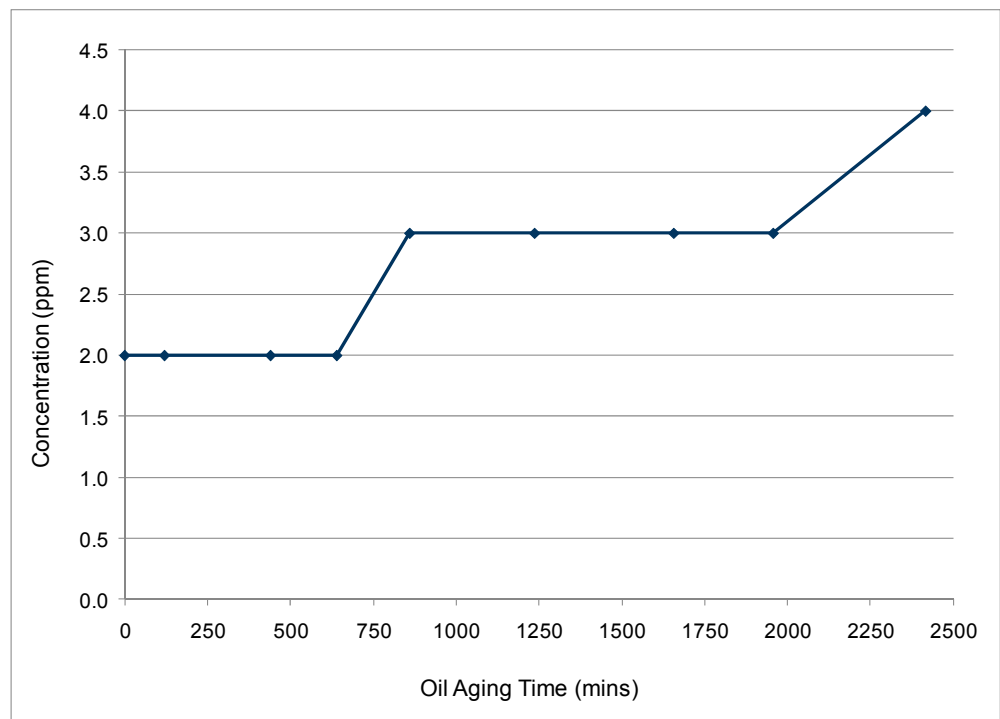

Figure B.48 : Iron Content in Oil Samples.

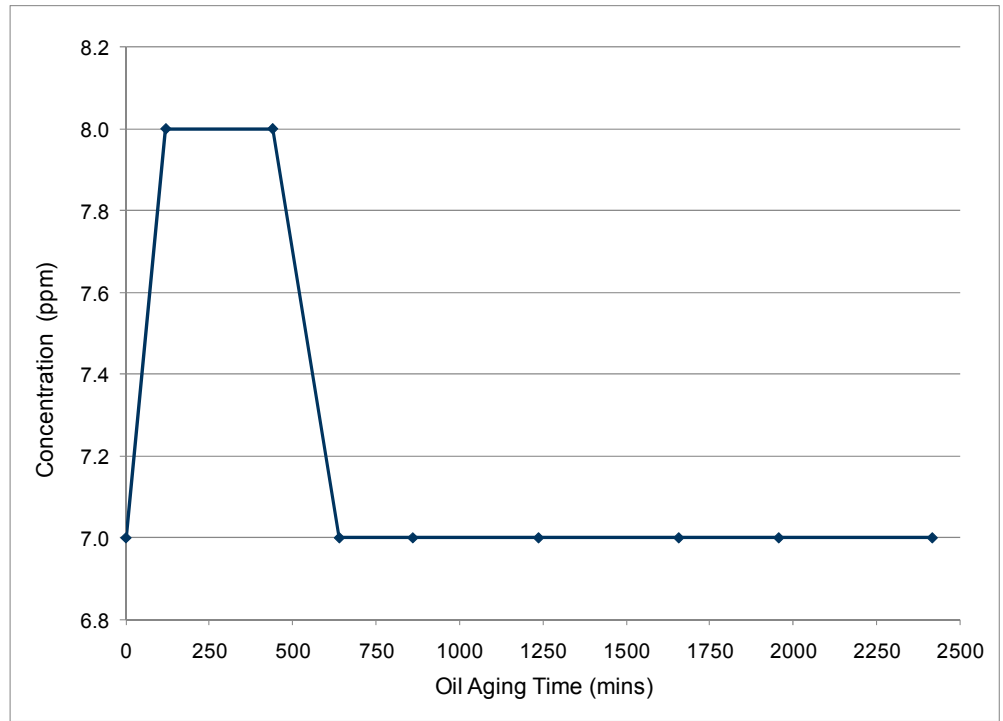

Figure B.49 : Magnesium Content in Oil Samples. 


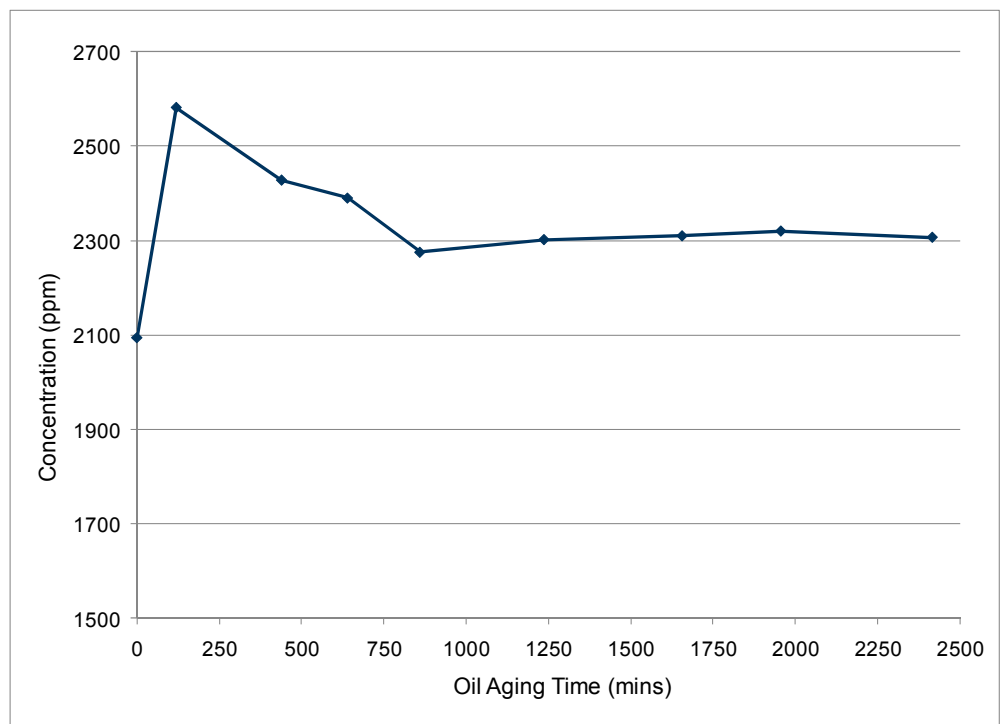

Figure B.50 : Calcium Content in Oil Samples.

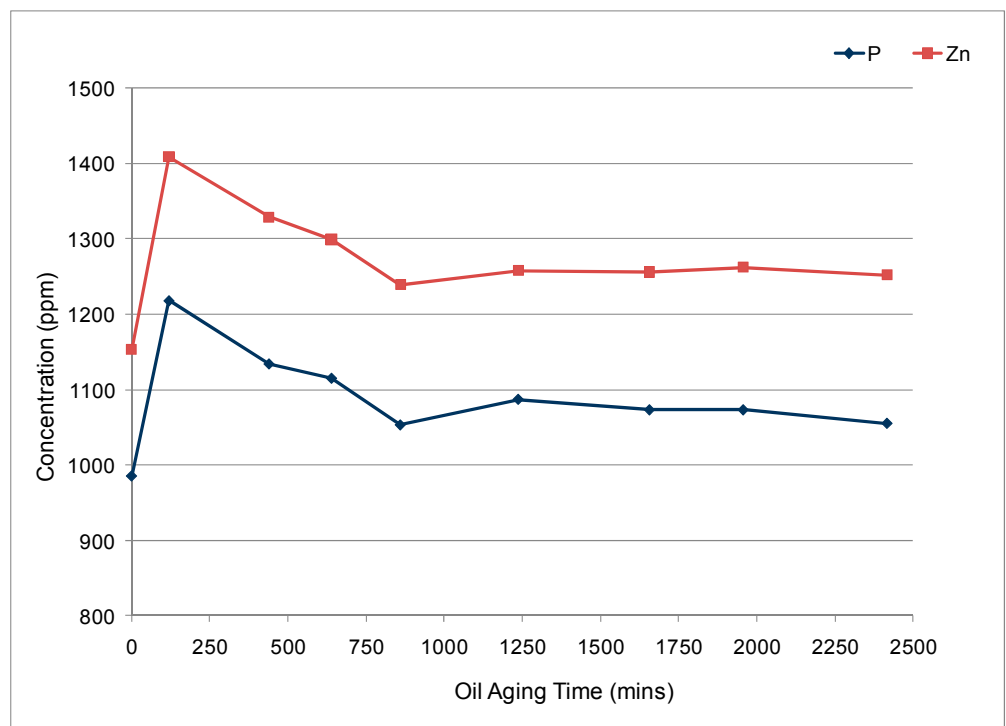

Figure B.51 : Phosphorus and Zinc Content in Oil Samples. 


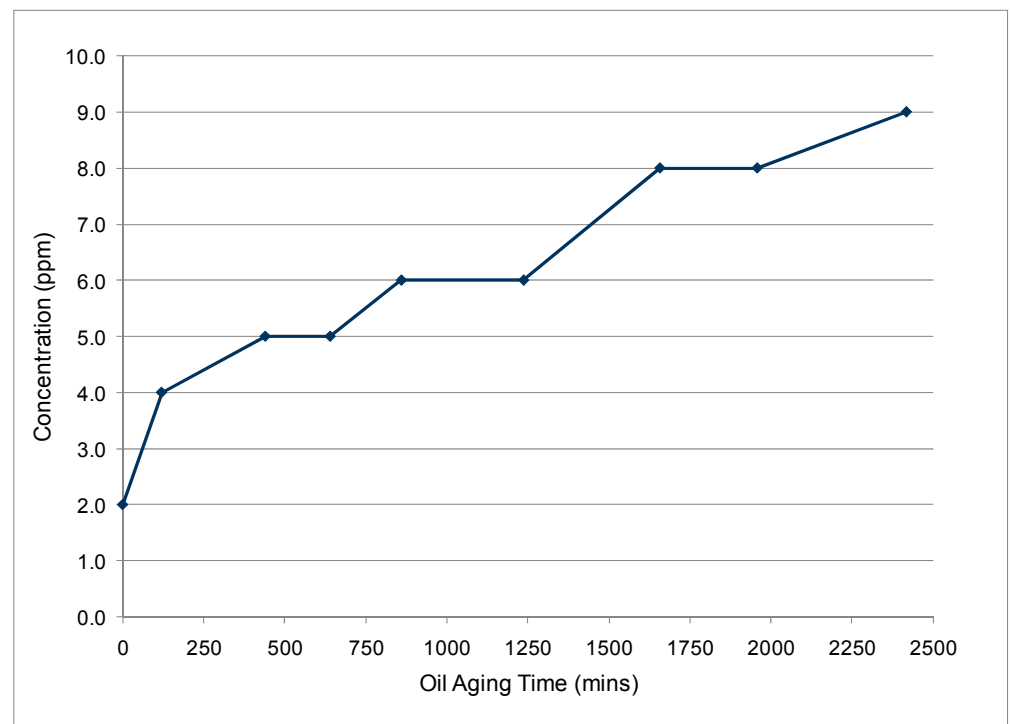

Figure B.52 : Silicon Content in Oil Samples.

\section{B.11. Normalized Particle Size Distribution Plots}

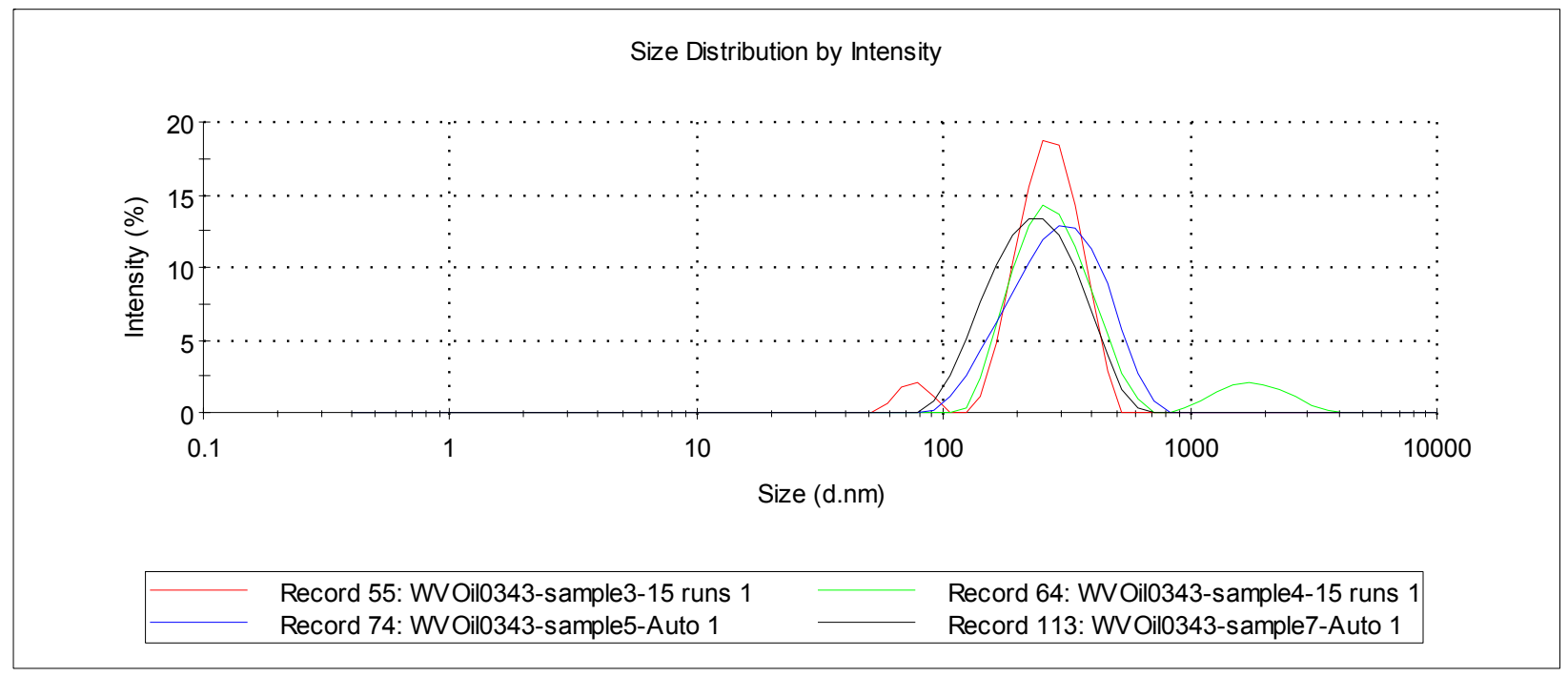

Figure B.53 : Normalized Particle Size Distribution in WVOil0343 Oil Sample. 
Size Distribution by Intensity

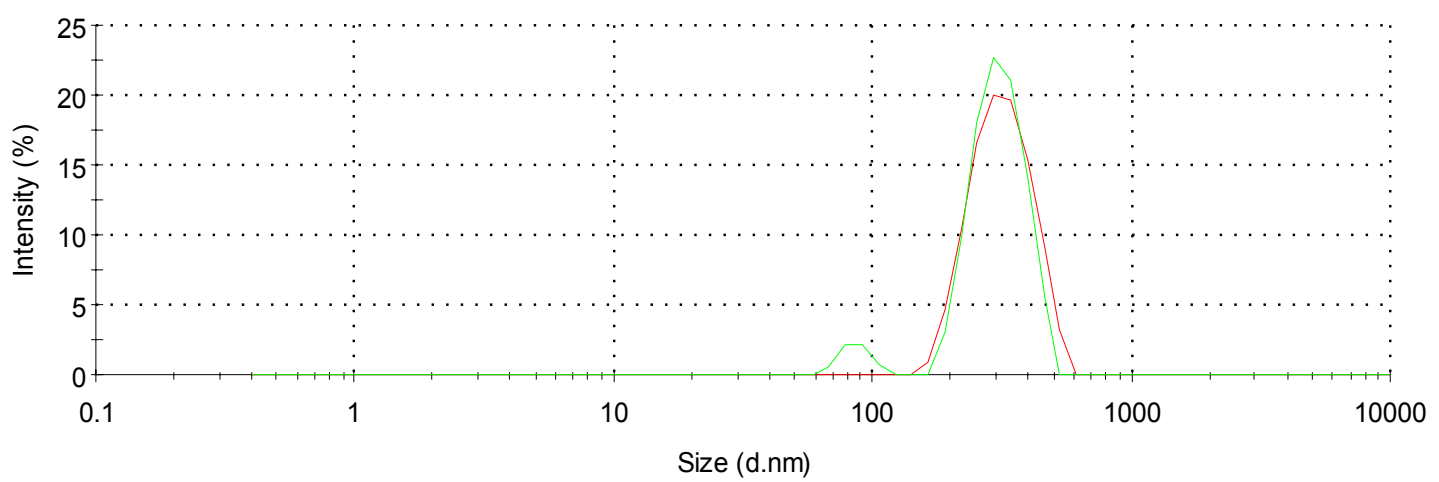

Record 75: WV Oil0344-sample5-Auto $1 \_$Record 114: WVOil0344-sample7-Auto 1

Figure B.54 : Normalized Particle Size Distribution in WVOil0344 Oil Sample.

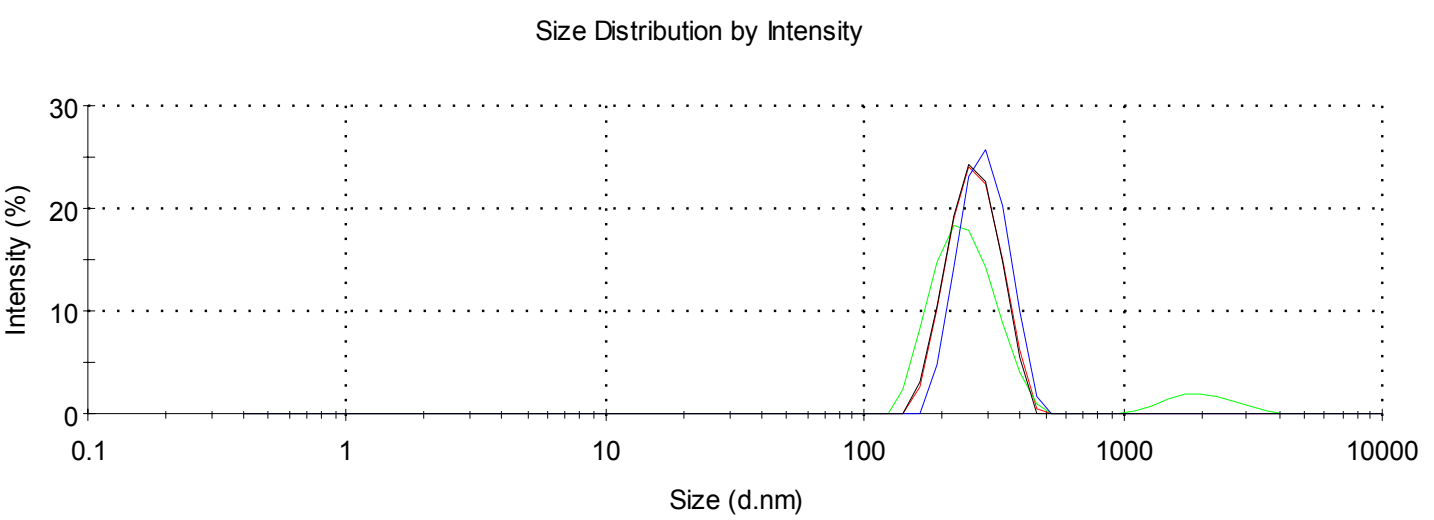

Record 56: WVOil0345-sample3-15 runs 1

Record 65: WVOil0345-sample4-15 runs 1

Record 76: WVOil0345-sample5-Auto 1 Record 117: WVOil0346-sample7-Auto 1

Figure B.55 : Normalized Particle Size Distribution in WVOil0345 Oil Sample. 
Size Distribution by Intensity

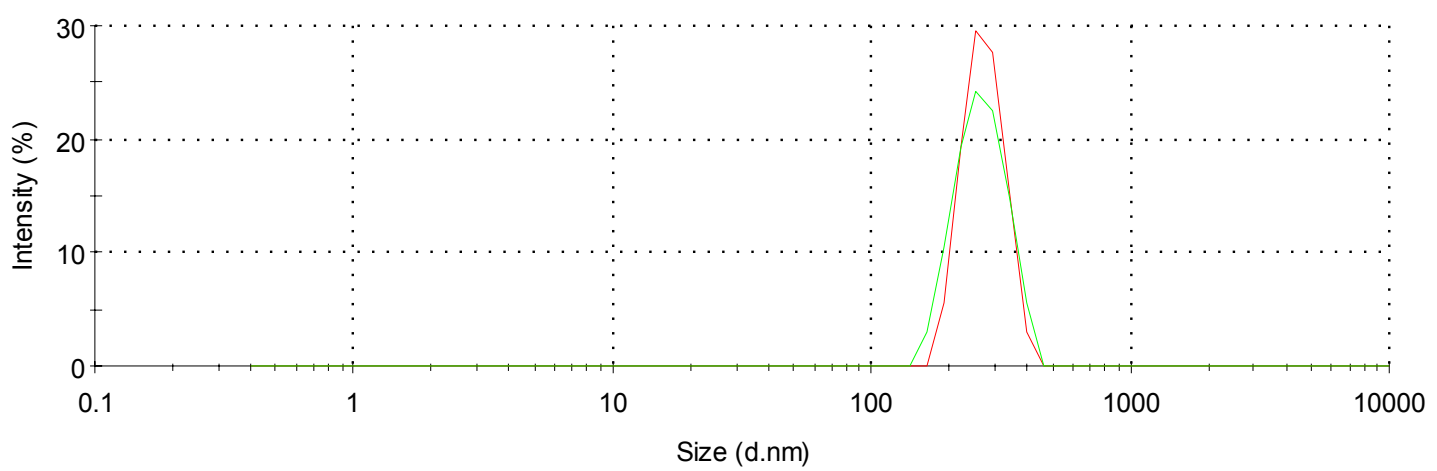

Record 77: WVOil0346-sample5-Auto 1

Record 117: WVOil0346-sample7-Auto 1

Figure B.56 : Normalized Particle Size Distribution in WVOil0346 Oil Sample.

Size Distribution by Intensity

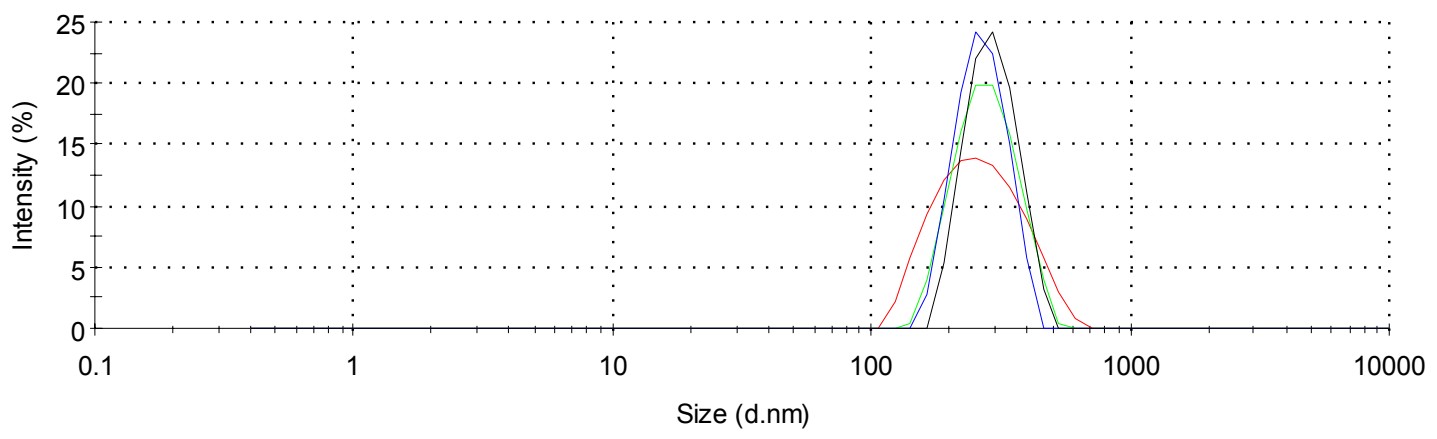

Record 57: WVOil0347-sample3-15 runs 1

Record 66: WVOil0347-sample4-15 runs 1 Record 78: WVOil0347-sample5-Auto 1 Record 118: WVOil0347-sample7-Auto 1

Figure B.57 : Normalized Particle Size Distribution in WVOil0347 Oil Sample. 
Size Distribution by Intensity

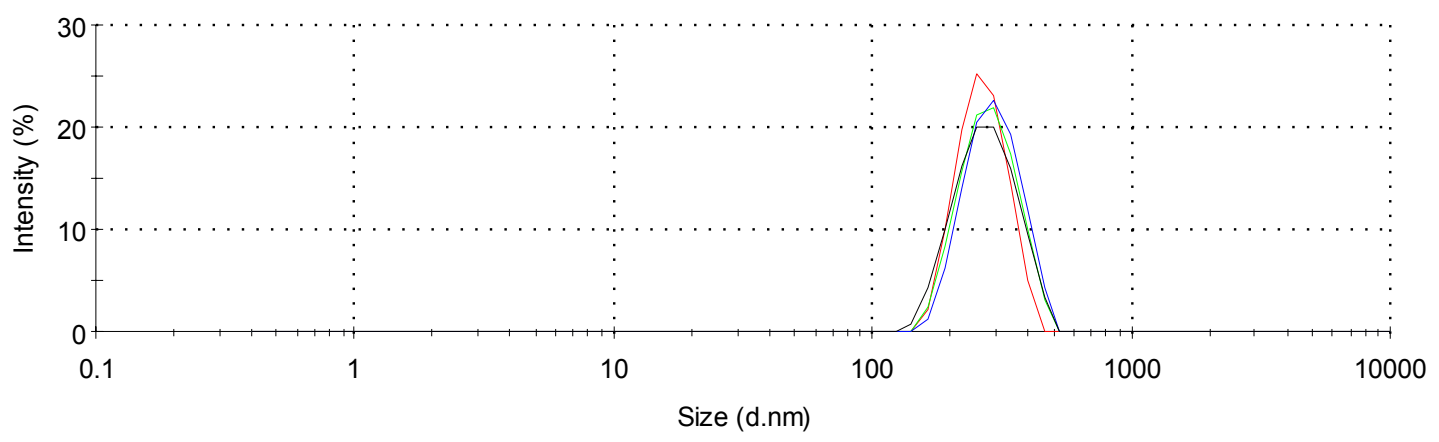

Record 58: WVOil0348-sample3-15 runs 1

Record 67: WVOil0348-sample4-15 runs 1

Record 80: WVOil0348-sample5-Auto 1

Record 120: WVOil0348-sample7-Auto 1

Figure B.58: Normalized Particle Size Distribution in WVOil0348 Oil Sample.

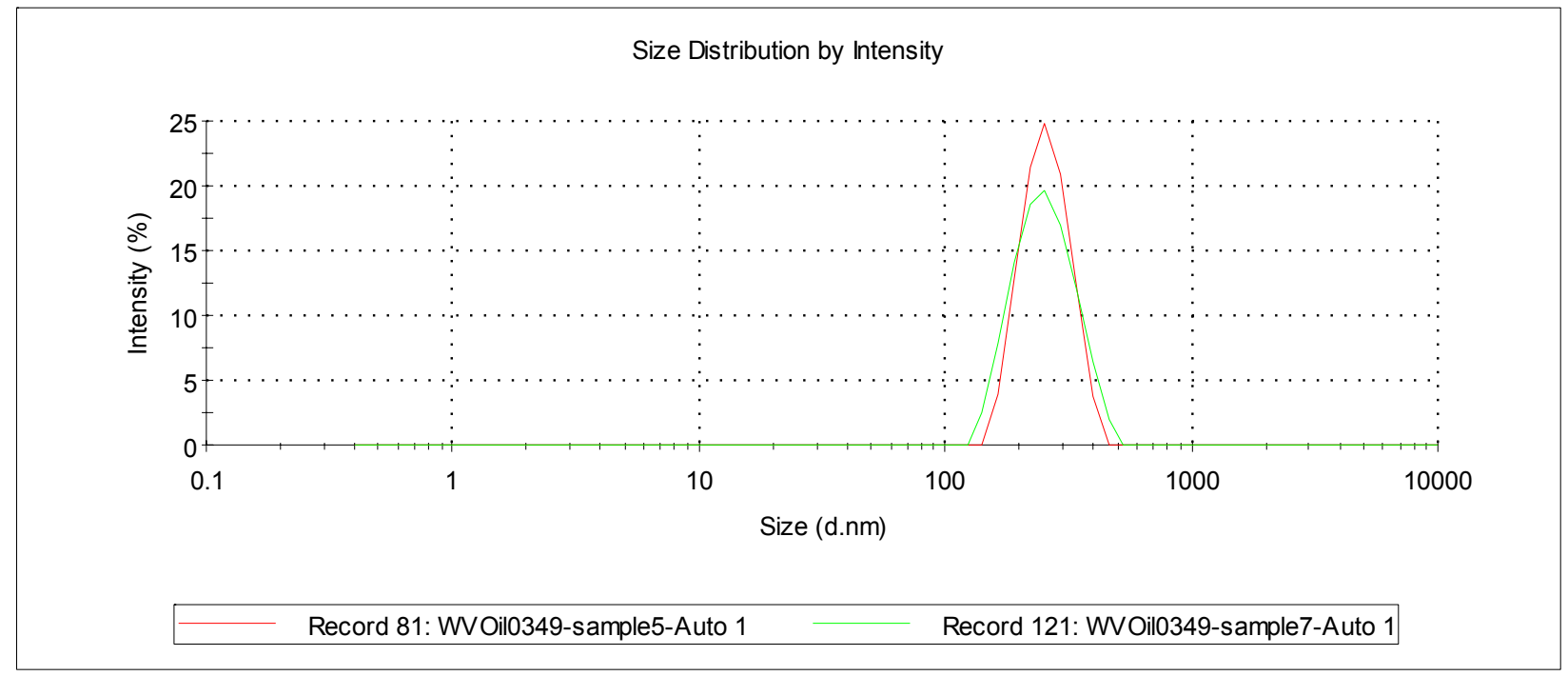

Figure B.59 : Normalized Particle Size Distribution in WVOil0349 Oil Sample. 


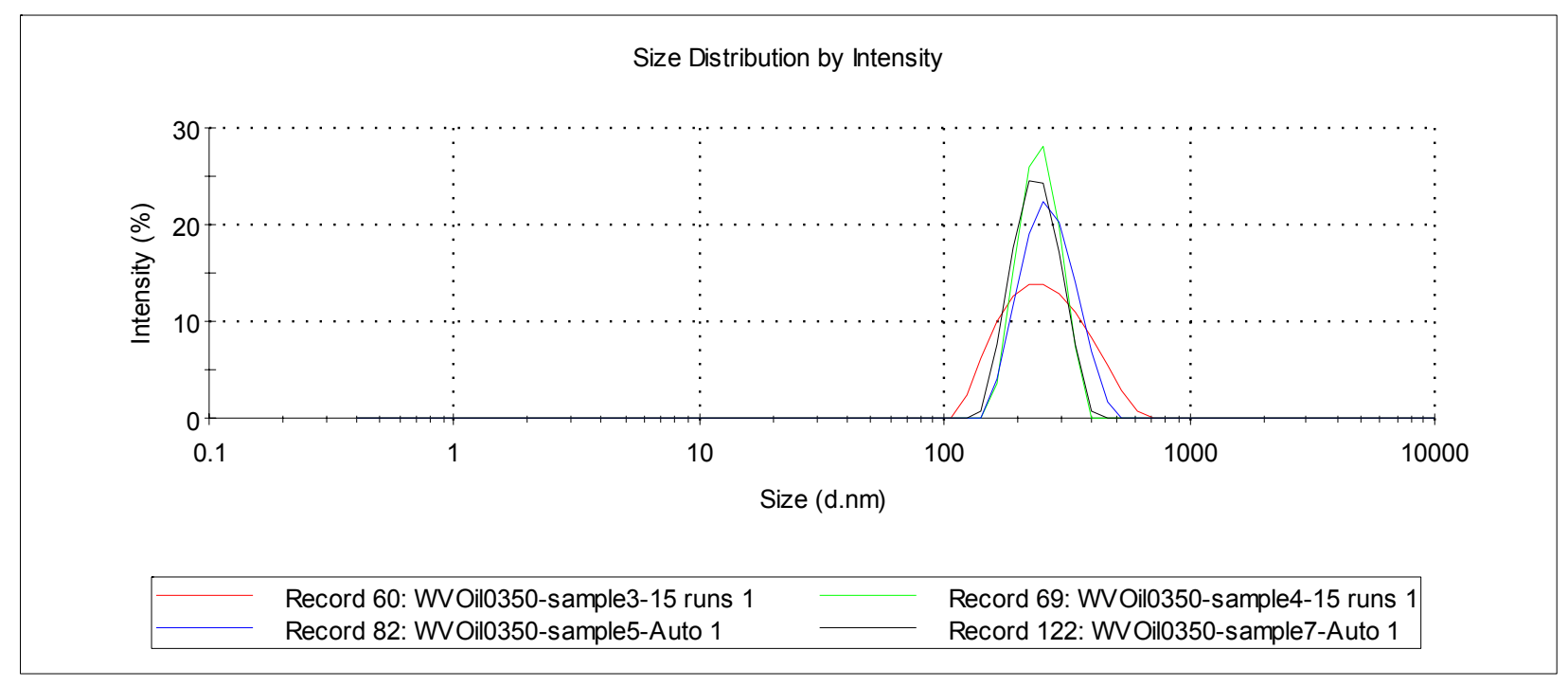

Figure B.60 : Normalized Particle Size Distribution in WVOil0350 Oil Sample.

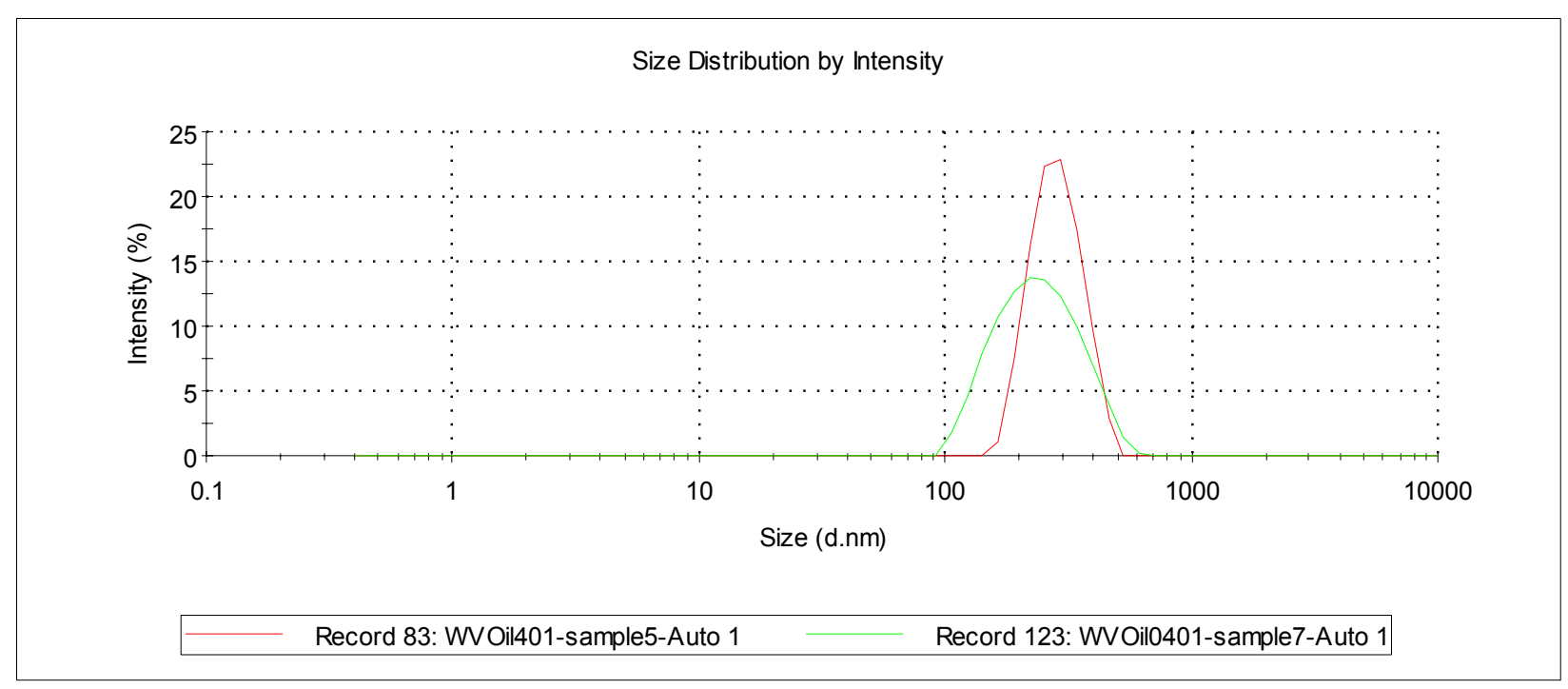

Figure B.61 : Normalized Particle Size Distribution in WVOil0401 Oil Sample. 
Size Distribution by Intensity

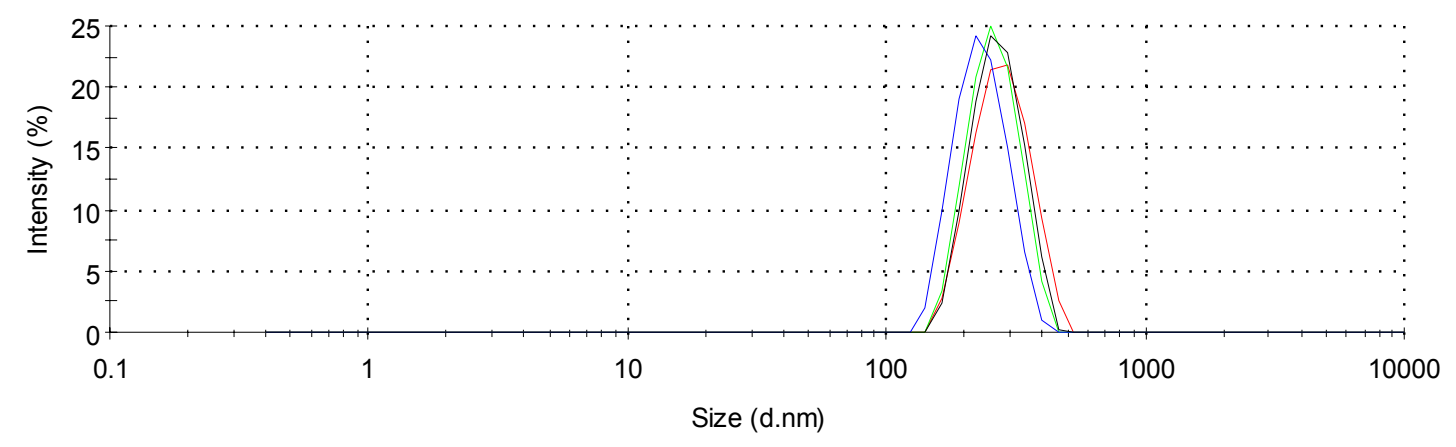

Record 61: WVOil0402-sample3-15 runs 1

Record 84: WVOil0402-sample5-Auto 1

Record 70: WVOil0402-sample4-15 runs 1 Record 126: WVOil0402-sample7-Auto-rep 1

Figure B.62 : Normalized Particle Size Distribution in WVOil0402 Oil Sample.

Size Distribution by Intensity

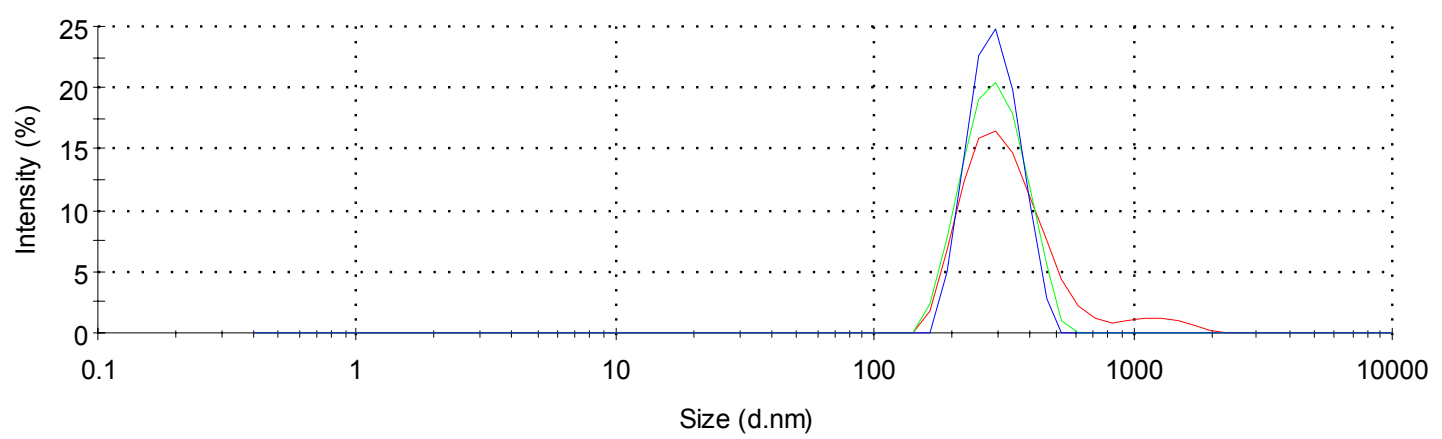

Record 86: WVOil0403-sample5-Auto 1

Record 128: WVOil0403-sample7-Auto 1

Record 106: WVOil0403-sample6-Auto 1

Figure B.63 : Normalized Particle Size Distribution in WVOil0403 Oil Sample. 


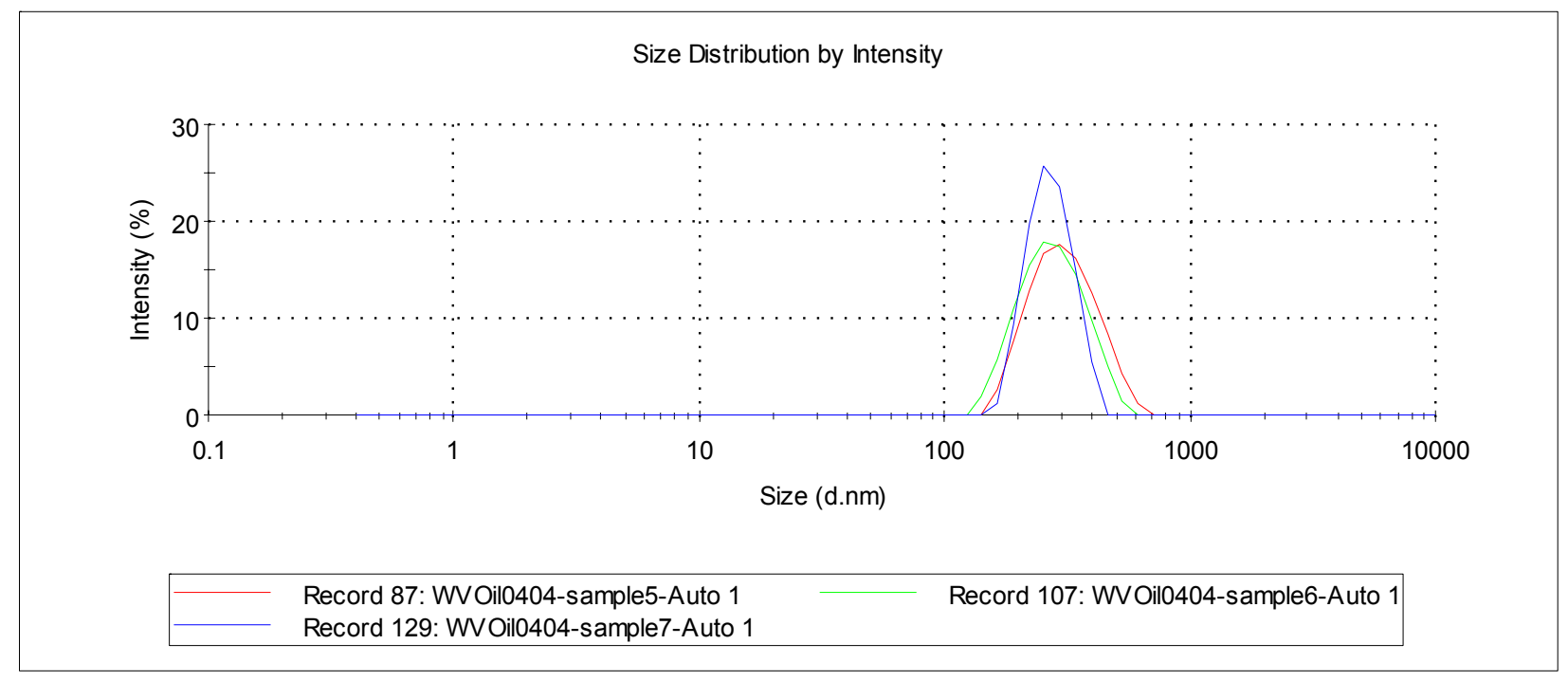

Figure B.64 : Normalized Particle Size Distribution in WVOil0404 Oil Sample.

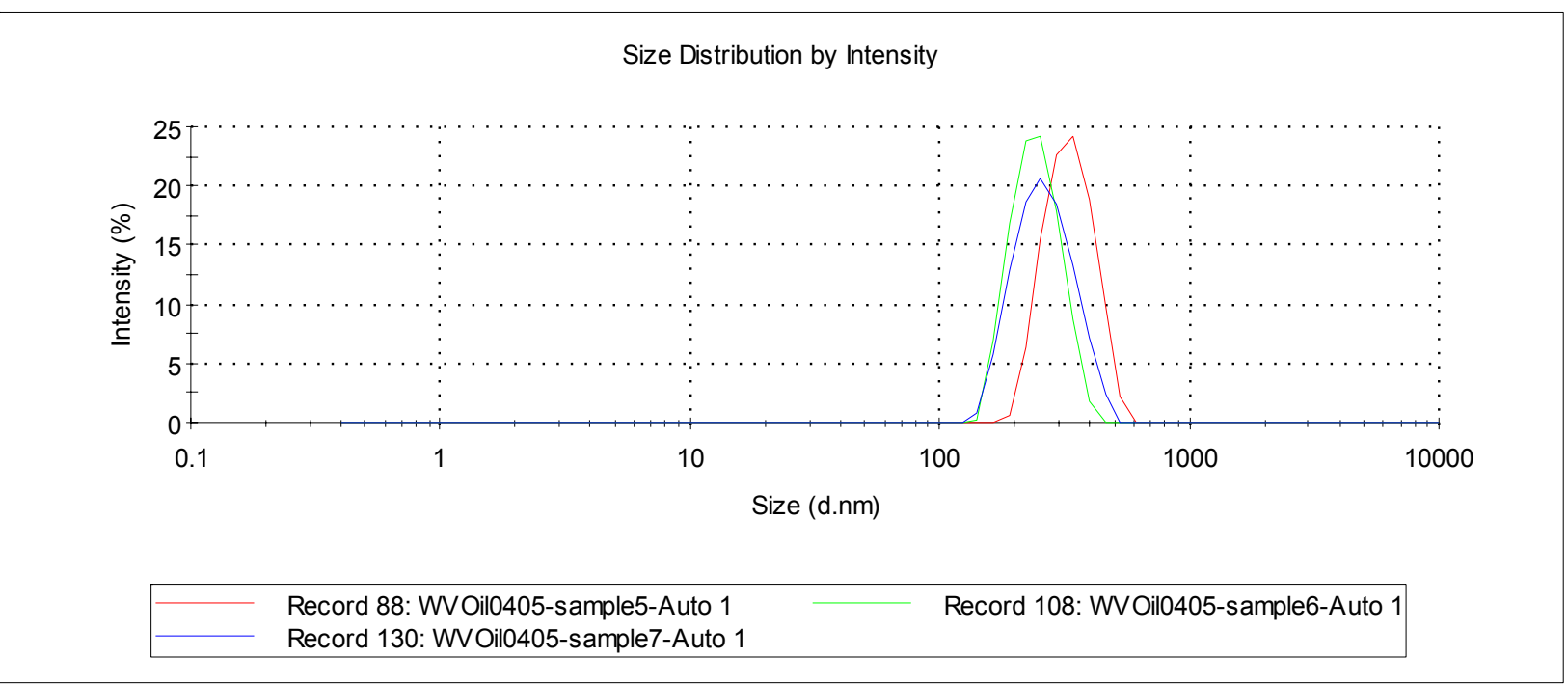

Figure B.65 : Normalized Particle Size Distribution in WVOil0405 Oil Sample. 
Size Distribution by Intensity

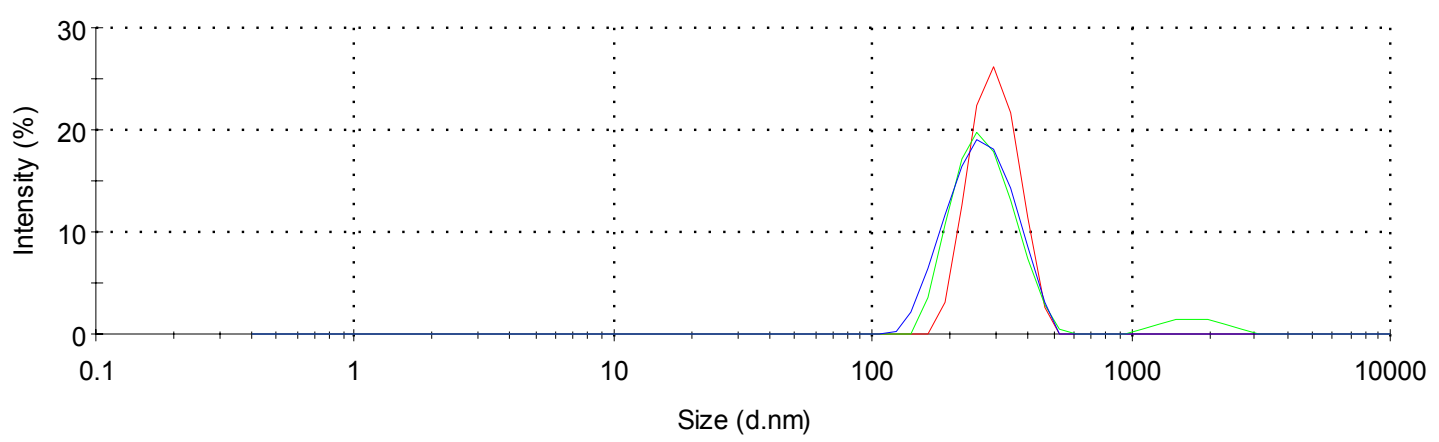

Record 89: WVOil0406-sample5-Auto 1

Record 109: WVOil0406-sample6-Auto 1

Record 131: WVOil0406-sample7-Auto 1

Figure B.66 : Normalized Particle Size Distribution in WVOil0406 Oil Sample.

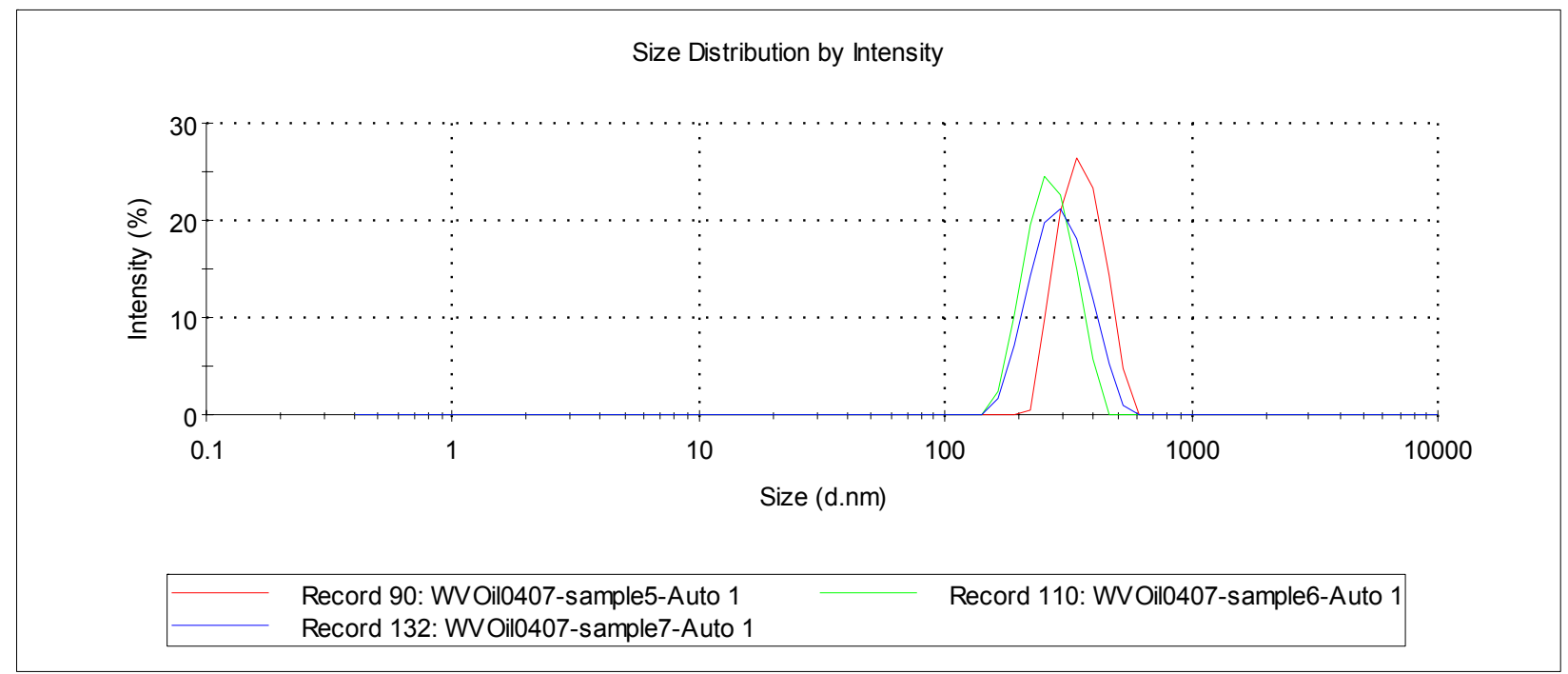

Figure B.67 : Normalized Particle Size Distribution in WVOil0407 Oil Sample. 


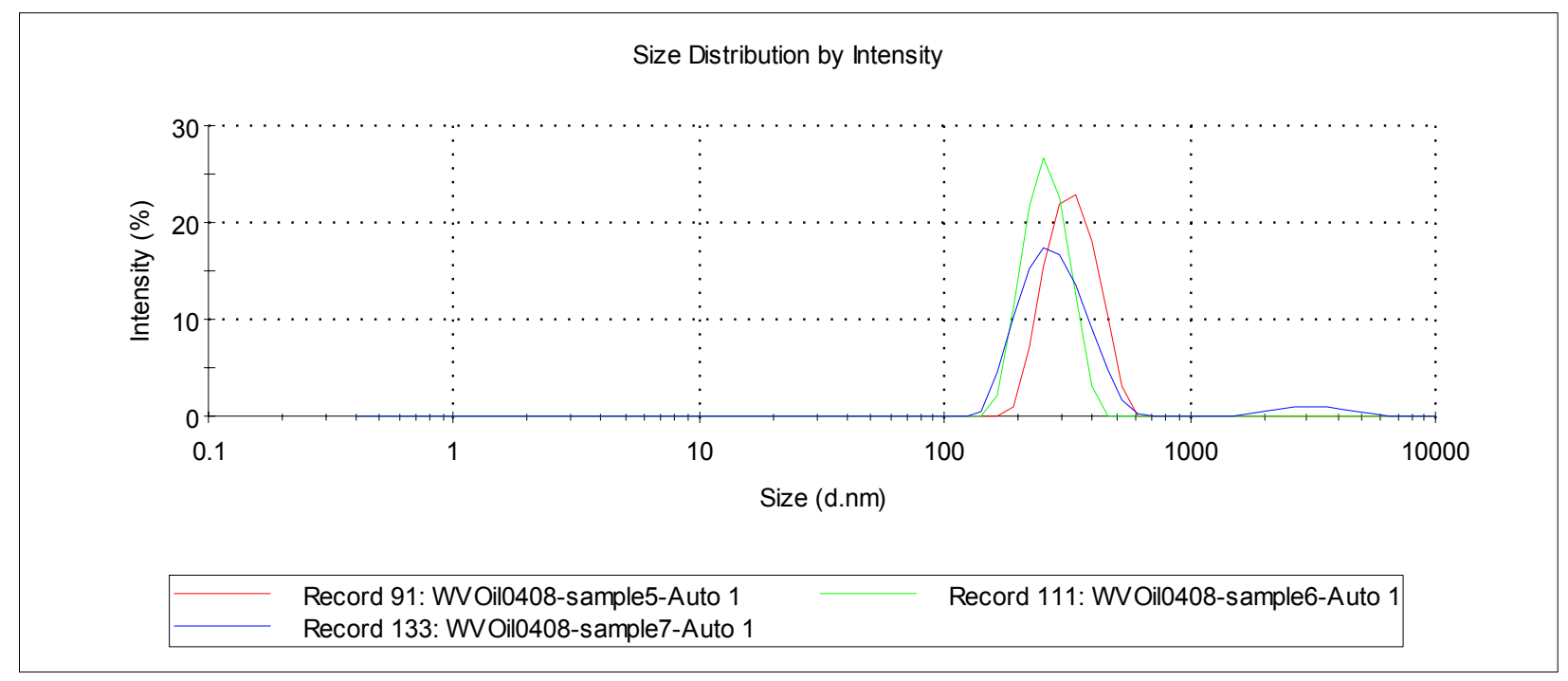

Figure B.68 : Normalized Particle Size Distribution in WVOil0408 Oil Sample. 